\title{
Untersuchungen zu \\ Nitrat-induzierbaren Proteinen der Plasmamembran von Chlorella saccharophila (Krüger) Nadson
}

\author{
Dissertation \\ zur Erlangung des Doktorgrades \\ der Mathematisch-Naturwissenschaftlichen Fakultäten \\ der Georg-August-Universität zu Göttingen
}

vorgelegt von
Peter Brechlin
aus Hannover

Göttingen 2002 
D 7

Referent: Prof. Dr. Rudolf Tischner

Korreferent: Prof. Dr. Dietrich Gradmann

Tag der mündlichen Prüfung: 30. 10. 2002 


\section{INHALTSVERZEICHNIS}

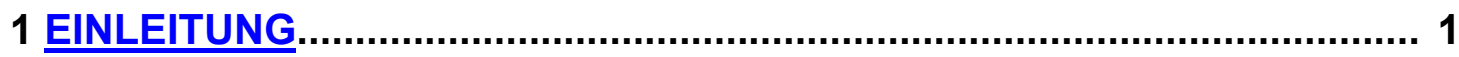

2 MATERIAL UND METHODEN............................................................. 5

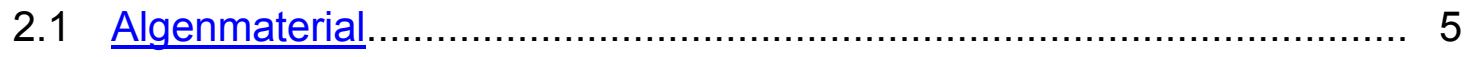

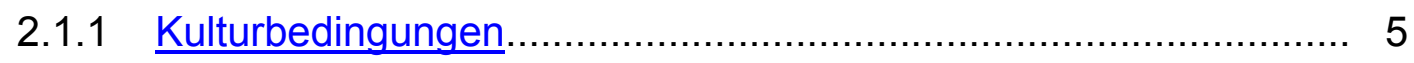

2.1.2 Stammkulturen................................................................ 5

2.2. Präparation der Mikrosomalen Fraktion............................................. 5

2.2.1 Protoplasten-Präparation und -Aufbruch................................... 5

2.2.2 Präparation des zellfreien Extraktes.......................................... 7

2.3 Plasmamembran-Präparation....................................................... 7

2.4 right side out Vesikel-Päparation................................................... 8

2.5 Temperatur-induzierte Phasenverteilung mit Triton X 114 ................... 9

2.6 Hydrophobe Interaktionschromatographie der PM-Proteine.................. 9

2.7 Markierung von NO3--induzierten PM-Proteinen mit 35S-Methionin...... 10

2.8 Photoaffinitätsmarkierung von PM-Proteinen mit 14C-2,6-DNPA............11

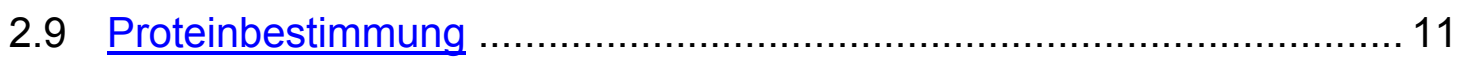

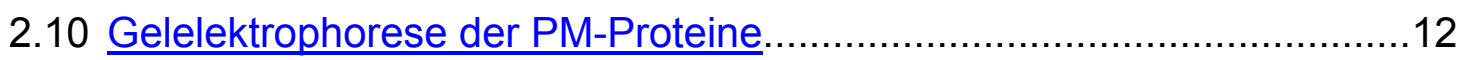

2.10.1 SDS-Polyacrylamid-Gel-Elektrophorese (SDS-PAGE)................ 12

2.10.1.1 Probenvorbereitung......................................................12

2.10.1.2 Diskontinuierliche SDS-PAGE........................................ 12

2.10.2 Isoelektrische Fokussierung (IEF) mit Träger-Ampholyten............ 12

2.10.2.1 Probenvorbereitung ……..............................................12

2.10.2.2 „small scale"-IEF für Minigele.............................................13

2.10.2.3 „large scale“-IEF zur Proteinisolierung..................................13

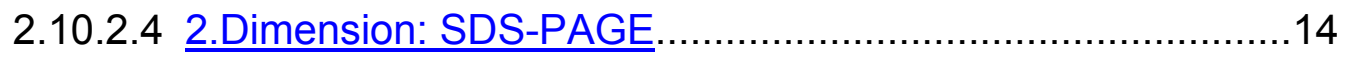

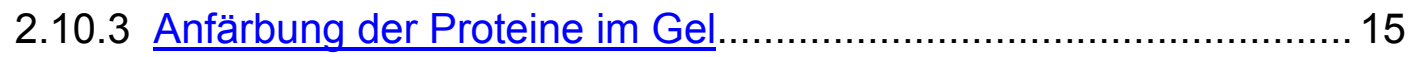

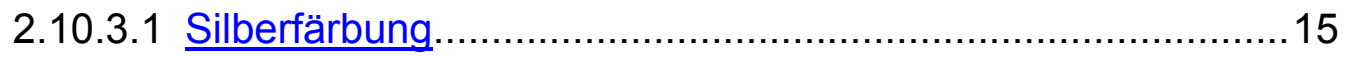

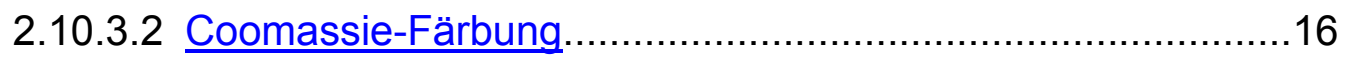

2.10.4 Geltrocknung und Autoradiographie..........................................16

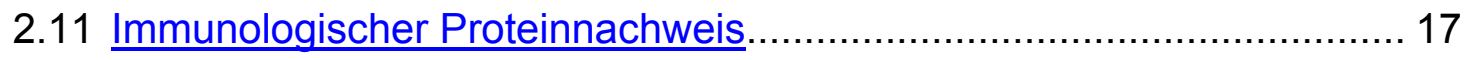

2.11.1 Western Blotting der PM-Proteine............................................... 17

2.11.2 Anfärbung der PM-Proteine auf NC-Folie und PVDF-Membran.....17

2.11.3 Immunologische Nachweise...................................................... 17

2.11.3.1 Nachweis mit alkalischer Phosphatase...............................18

2.11.3.2 Peroxidase/Enhanced Chemiluminescence...........................19 
2.11.4 Molekulargewichtsbestimmung................................................ 19

2.12 Erstellung einer 2D-Proteinverteilungskarte......................................19

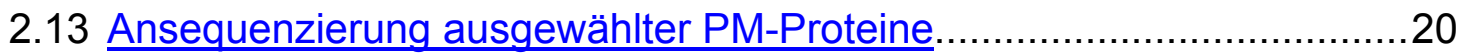

2.14 Herstellen von polyklonalen Antikörpern...........................................20

2.14.1 Datenbankrecherche zu Nitrat-Transporter-

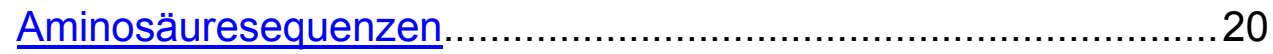

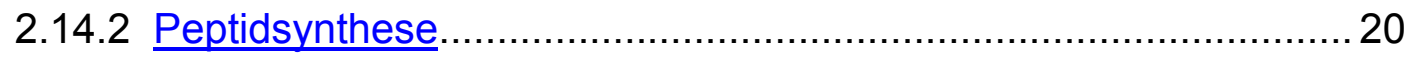

2.14.3 Immunisierung und Antikörpergewinnung.................................... 21

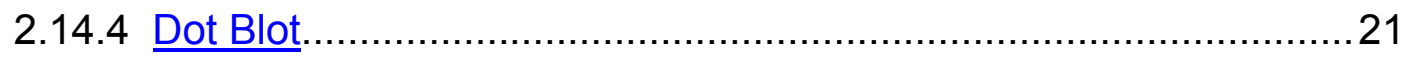

2.15 PCR

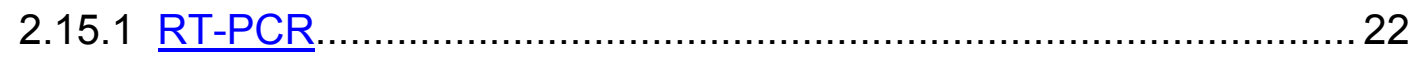

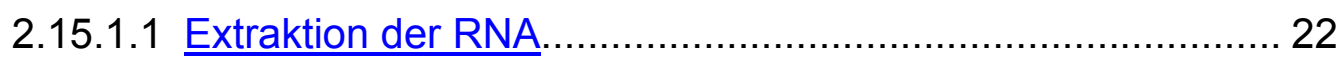

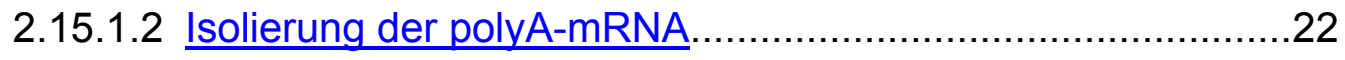

2.15.2 PCR: Primer und PCR-Bedingungen .......................................... 23

2.15.2.1 Agarose-Gelelektrophorese ............................................ 25

2.15.2.2 Isolierung und Klonierung von PCR-generierten DNA-

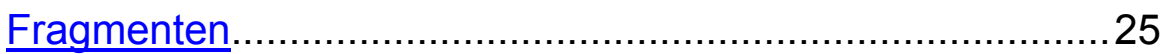

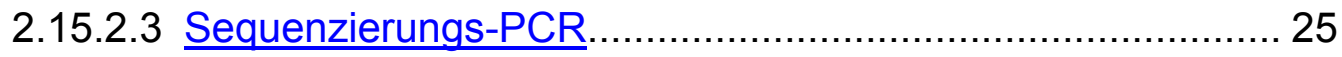

2.16 Konzentrationsbestimmung von Nukleinsäuren..................................26

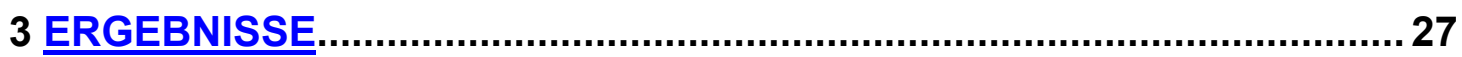

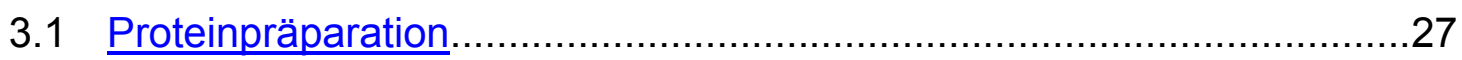

3.1.1 Algenkultur in $300 \mathrm{ml}$-Glasröhren......................................... 27

3.1.2 Massenkultur in 4,5 I-Penicillium-Glaskolben.............................. 27

3.2 Plasmamembran-Proteine in der 2D-SDS-PAGE...............................28

3.2.1 Optimierung der Detergenz- und Ampholytkonzentration.............. 28

3.2.2. Hochauflösende 2D-Gelelektrophorese der Plasmamembran-

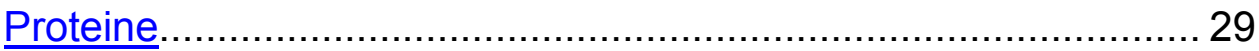

3.2.3 Hydrophobizität der PM-Proteine: TritonX114-Phasen.................. 31

3.2.4 Schema der Proteinverteilung der TritonX114-Phasen in der 2D-

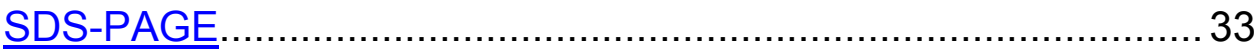

3.3 Einfluß der Stickstoff-Quelle: 35S-Methionin in vivo markierte PMProteine

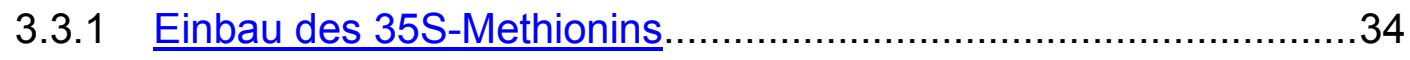

3.3.2 PM-Proteine der wässrigen Phase des TX114-Systems..................35

3.3.2.1 Lokalisation der 35S-markierten Proteine der WP in der 2D-SDS-PAGE. 
3.3.2.2 Stickstoff-Quellen-spezifisch 35S-markierte Proteine der WP 37

3.3.3 PM-Proteine der Detergenz-Phase des TX114-Systems. 40

3.3.3.1 Lokalisation der 35S-markierten Proteine der DP in der 2D-SDS-PAGE.

3.3.3.2 Stickstoff-Quellen-spezifisch 35S-markierte Proteine der DP 42

3.3.4 35S-markierte Proteine in der Übersicht..................................... 44

3.4 Photoaffinitätsmarkierung durch 14C-2,6-Dinitrophenylazid (DNPA)....... 46

3.4.1 Zerfallskinetik und Spaltung von DNPA durch UV-Licht................... 46

3.4.2 14C-DNPA-Konzentration und 14C-Markierung von PM-Proteinen 46

3.4.3 14C-DNPA-Markierung nach HIC der PM-Proteine. .48

3.4.4 14C-DNPA in der 2D-SDS-PAGE: markierte Proteine und Einfluß auf das IEF 49

3.4.5 PM-Vesikel-Orientierung und Kompetition durch NO3-. 51

3.4.6 Triton X114-Phasenverteilung der 14C-DNPA markierten Proteine 52 3.5 Nitrat-Reduktase der PM in der 2D-SDS-PAGE..................................... 54

3.6 Herstellen von Antikörpern gegen Nitrat-Transporter-Proteine...................56

3.6.1 Zur Peptidsynthese ausgewählte Aminosäure-Sequenzen...............56

3.6.2 Peptidspezifität: Dot-Blot der Seren und PM-Proteine im

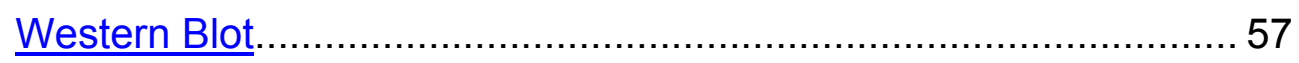

3.6.3 Nitrat-Transporter-Antikörper (Antigen aus Hordeum vulgare).........60

3.7 Proteinisolierung aus 2D-SDS-PAGE-Gelen........................................ 62

3.7.1 Quantitätsabschätzung der durch 2D-SDS-PAGE getrennten

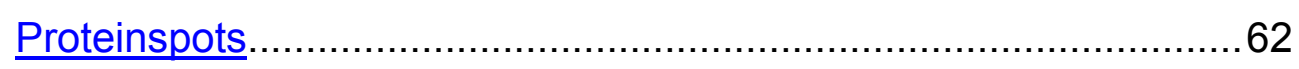

3.7.2 "large scale"-2D-SDS-PAGE: Präparatives IEF............................... 63

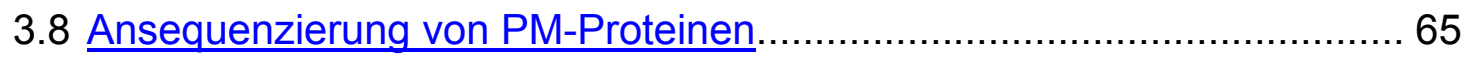

3.8.1 Zur Ansequenzierung ausgewählte Proteine ..................................65

3.8.2 Protein-Sequenzen: Ein Porin in Chlorella..................................... 66

3.9 Molekularbiologische Untersuchungen zum Nitrat-Transporter.................70

3.9.1 Primerauswahl und Primer-Paarungen..........................................

3.9.2 RT-PCR und PCR-Produkte..................................................... 71

3.9.3 Sequenzierung und Alignments.................................................. 74

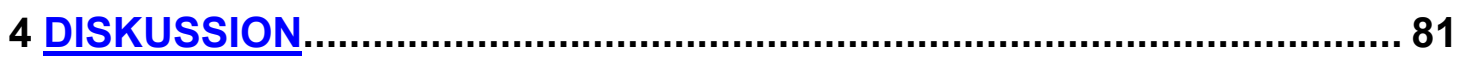

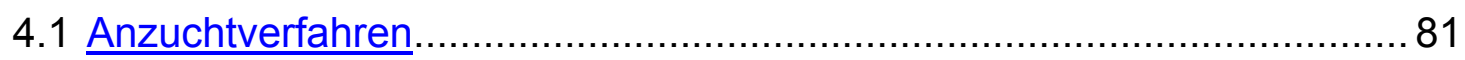

4.2 2D-SDS-PAGE mit Trägerampholyten................................................ 81

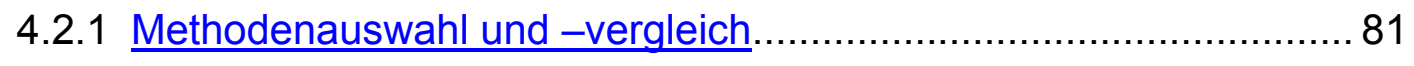

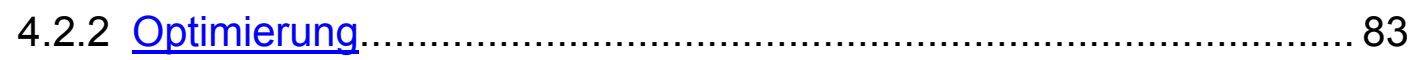

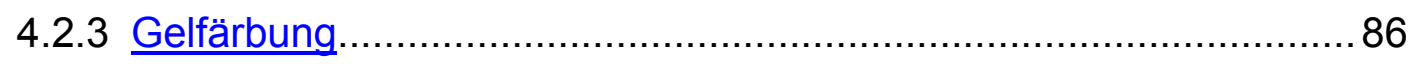


4.2.4 Triton X114-Phasen und 2D-SDS-PAGE-Auswertung................... 86

4.3. In vivo 35S-Methionin markierte Plasmamembran Proteine.................... 88

4.3.1 Induktionsbedingungen und Einbau des 35S-Methionins.................89

4.3.2 Auswertung der Radiographien der 35S-markierten Proteine...........90

4.3.3 Trennleistung und „low-abundant“-Proteine................................. 91

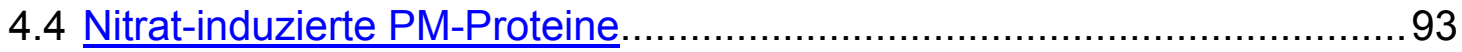

4.4.1 PM-Proteine der wässrigen Phase des TX114-Systems.................93

4.4.2 PM-Proteine der Detergenz-Phase des TX114-Systems.................96 96

4.4.2.1 De novo $\mathrm{NO}_{3}{ }^{-}$-induzierte PM-Proteine: Nitrat-Transporter? ....96 96

4.4.2.2 Proteine mit $\mathrm{NO}_{3}{ }^{-}$-induzierter Konzentrationszunahme ${ }^{-}$...........98

4.5 Photoaffinitätsmarkierung mit 14C-DNPA............................................ 99

4.6 Plasmamembran-gebundene Nitrat-Reduktase................................... 103

4.7 Immunologischer Nachweis eines Nitrat-Transporters......................... 105

4.8 Präparative 2D-SDS-PAGE und ansequenzierte PlasmamembranProteine................................................................................... 109

4.9 Molekularbiologische Untersuchungen......................................... 114

5 ZUSAMMENFASSUNG UND AUSBLICK...........................................118

6 LITERATURVERZEICHNIS .............................................................. 121 


\section{ABKÜRZUNGSVERZEICHNIS}

\begin{tabular}{|c|c|}
\hline${ }^{14} \mathrm{C}$ & Radioaktives Kohlenstoff-Isotop14 \\
\hline $2 \mathrm{D}$ & zweidimensional \\
\hline${ }^{32} \mathrm{P}$ & Radioaktives Phosphor-Isotop 32 \\
\hline${ }^{35} \mathrm{~S}$ & Radioaktives Schwefel-Isotop 35 \\
\hline AA & Acrylamid \\
\hline Abb. & Abbildung \\
\hline AK & Antikörper \\
\hline AS & Aminosäure \\
\hline ATP & Adenosin-triphosphat \\
\hline BAC & Benzyl-dimethyl-hexadecyl-ammoniumchlorid \\
\hline $\mathrm{BCIP}$ & 5-Brom-4-chlor-3-indolylphosphat \\
\hline Bidest. & Bidestilliert \\
\hline $\mathrm{Bq}$ & Bequerel \\
\hline cDNA & copyDNA \\
\hline CHAPS & 3-[(3-Cholamidopropyl) dimethylammonio]-1-propansulfat \\
\hline $\mathrm{Ci}$ & Curie \\
\hline$d$ & Tag \\
\hline $\mathrm{Da}$ & Dalton \\
\hline DNA & desoxyribonucleic acid \\
\hline DNPA & 2,6-Dinitrophenylazid \\
\hline DP & Detergenz-Phase (des Triton X114-Phasensystems) \\
\hline DTT & Dithiothreitol \\
\hline $\mathrm{E}$ & Extinktion \\
\hline ECL & Enhanced Chemiluminescence \\
\hline EDTA & Ethylendiamintetraacetat \\
\hline FAD & Flavinadenindinukleotid \\
\hline FPLC & Fast Protein Liquid Chromatography \\
\hline$g$ & Erdbeschleunigung $\left(9,81 \mathrm{~m} \mathrm{x} \mathrm{s}^{-2}\right)$ \\
\hline $\mathrm{h}$ & Stunde \\
\hline $\mathrm{HIC}$ & Hydrophobe Interaktions-Chromatographie \\
\hline IEF & Isoelektrisches Fokussieren \\
\hline IEP & Isoelektrischer Punkt (pl) \\
\hline $\lg G$ & Immunglobulin G \\
\hline IPG & Immobilisierter pH-Gradient \\
\hline $\mathrm{KB}$ & Kilobasenpaar \\
\hline
\end{tabular}




$\begin{array}{ll}\text { kDa } & \text { kilo Dalton } \\ \text { KM }_{M} & \text { Michaelis-Menten-Konstante } \\ \text { M } & \text { Molarität } \\ \text { MALDI-ToF } & \text { Matrix-Assisted Laser-Desorption lonization-Time of Flight MS } \\ \text { ME } & \text { Mercaptoethanol } \\ \text { MES } & \text { 4-Morpholinoethansulfonsäure } \\ \text { min } & \text { Minute } \\ \text { MOPS } & \text { 3(N-morpholino)propansulfonsäure } \\ \text { mRNA } & \text { messenger ribonucleic acid } \\ \text { MS } & \text { Mass Spectrometry } \\ \text { MS/MS } & \text { nanoelectrospray ionization tandem MS } \\ \text { NBT } & \text { Nitroblau-Tetrazoliumchlorid } \\ \text { NC } & \text { Nitrocellulose } \\ \text { NL } & \text { Nährlösung } \\ \text { NP40 } & \text { Nonidet P40 (Igepal C630) } \\ \text { NR } & \text { Nitrat-Reduktase } \\ \text { OD } & \text { optische Dichte } \\ \text { PAGE } & \text { Polyacrylamid-Gelelektrophorese } \\ \text { PCR } & \text { Polymerase Chain Reaction } \\ \text { PEG } & \text { Polyethylenglykol } \\ \text { PM } & \text { Plasmamembran } \\ \text { PVDF } & \text { Polyvinyldifluorid } \\ \text { RNA } & \text { ribonucleic acid } \\ \text { RPM } & \text { Revolutions per minute } \\ \text { RT } & \text { Raumtemperatur } \\ \text { SDS } & \text { Natriumdodecylsulfat } \\ \text { TBS } & \text { TRIS-buffered saline } \\ \text { TEMED } & \text { N,N,N,N-Tetramethylethylendiamin } \\ \text { TRIS } & \text { Tris (hydroxymethyl) aminomethan } \\ \text { TX114 } & \text { Triton X 114 (Detergenz) } \\ \text { V } & \text { Volt } \\ V_{\text {max }} & \text { Maximalgeschwindigkeit } \\ \text { V/v w/w } & \text { Volumen pro Volumen, Gewicht pro Gewicht } \\ \text { WP } & \text { Wässrige Phase (des Triton X114-Phasensystems) } \\ & \end{array}$




\section{EINLEITUNG}

\section{Stickstoff-Aufnahme und -Assimilation}

Stickstoff gehört zu den Schlüsselelementen der Biosphäre. Proteine und Nukleinsäuren als informationstragende Makromoleküle enthalten Stickstoff als wesentlichen Baustein. Neben Kohlenstoff ist daher Stickstoff das quantitativ wichtigste Nährelement. Pflanzen nehmen Stickstoff in anorganischer Form als Ammonium und Nitrat auf. Eine Distickstoff-Nutzung durch symbiontische Bakterien ist nur für einige wenige Pflanzenfamilien, z. B. Leguminosen wichtig. Dem hohen Stickstoff-Bedarf der Pflanzen steht die begrenzte Verfügbarkeit gegenüber. Auslaugung und Verbrauch durch Mikroorganismen bedingen eine geringe Stickstoff-Konzentration im Boden. Das Wachstum der Pflanze ist daher an erster Stelle durch eine unzureichende Verfügbarkeit von Stickstoff limitiert. Abgesehen von sauren Böden liegt in gemäßigten Zonen hauptsächlich der durch nitrifizierende Bakterien gebildete Nitrat-Stickstoff vor. Nitrat stellt so auch für die meisten Pflanzen die wichtigste Stickstoff-Quelle dar. Um die Stickstoffversorgung sicherzustellen, haben Pflanzen leistungsfähige Systeme zur Aufnahme von Nitrat entwickelt. Diese Aufnahmesysteme sind aktiv, reguliert und multiphasisch. Sie ermöglichen der Pflanze die Reaktion auf variierende Nitrat-Konzentrationen des Bodens. Die Aufnahme des Nitrates erfolgt im Cotransport mit Protonen durch den Nitrat-Transporter, ein Plasmamembran-integrales Protein. Der dazu nötige $\mathrm{pH}-\mathrm{Gradient}$ wird durch membranständige $\mathrm{H}^{+}$-ATPasen an der Plasmamembran aufgebaut (Mistrik und Ullrich, 1996). Einmal aufgenommen, wird das Nitrat entweder in der Vakuole gespeichert und kann so auch osmoregulatorische Funktion ausüben, oder wird durch die cytosolische Nitrat-Reduktase (NR) zu Nitrit reduziert. Das Nitrit wird in Plastiden, im Sproß in Chloroplasten eintransportiert und dort zu Ammonium reduziert. Dieser Schritt wird von der Nitrit-Reduktase (NiR) katalysiert. Das Ammonium wird schließlich durch das Glutaminsynthetase/Glutamin-2Oxoglutarat-Aminotransferase-System (GS/GOGAT-System) in Aminosäuren fixiert. Damit erreicht der aufgenommene Stickstoff die Schnittstelle zwischen Kohlenstoff- und Stickstoffmetabolismus (Joy, 1988). Glutamin und Glutamat stehen als Substrate für Transaminierungsreaktionen bereit, mit denen die proteinogenen Aminosäuren aufgebaut werden. Nitrat-Aufnahme und -Reduktion stellen die limitierenden Schritte der Nitratassimilation dar. (Tischner, 2000; Forde und Clarkson, 1999; Daniel-Vedele et al., 1998; Crawford, 1995; Lam et al., 1996; Marschner, 1995; Glass et al., 1990; Goyal und Huffaker, 1986; Campbell und Smarelli, 1986).

\section{Stickstoff-Metabolismus und Plasmamembran-Proteine}

Im Vordergrund dieser Untersuchung stand der erste Schritt der NitratAssimilation: die Nitrat-Aufnahme über die Plasmamembran und daran beteiligte oder vom N-Metabolismus rückgekoppelt beeinflußte Plasmamembran-Proteine. An der Plasmamembran sind vielfältige Prozesse lokalisiert. Sie bildet die äußere Barriere zum Cytoplasma und verhindert die Permeation hydrophiler Moleküle. Metabolite und anorganische Ionen müssen selektiv durch die Plasmamembran hindurch transportiert werden. Extrazelluläre 
Signale wie z. B. Licht, Nährstoffe, Hormone, Elicitoren etc. müssen wahrgenommen und in spezifische intrazelluläre Signale umgewandelt werden. Die dazu notwendigen Rezeptoren sind an der Plasmamembran lokalisiert und können eine intrinsische enzymatische Aktivität auslösen oder die Modulation eines signalübertragenden Proteins (Elzenga et al., 2000; Schenk und Snaar, 1999; Chrispeels et al., 1999; Ebel, 1998). An der Plasmamembran finden auch der bereits genannte Aufbau eines ATP-abhängigen Potential-Gradienten sowie die Aufnahme des Nitrates durch Transporterproteine statt. Durch Inhibition der $\mathrm{H}^{+}$-ATPasen kommt auch die Nitrat-Aufnahme zum Erliegen, damit wurde die Beteiligung von $\mathrm{H}^{+}$-ATPasen an der Nitrat-Aufnahme durch ProtonenCotransport nachgewiesen (McClure et al., 1990). Weitere Faktoren beeinflussen die Nitrat-Aufnahme in Algen: erhöhte $\mathrm{CO}_{2}$-Konzentrationen reprimieren die Aufnahme (Magnusson et al., 1996), eingestrahltes blaues Licht wirkt stimulierend (Aparicio et al., 1994). Eine Plasmamembran-gebundene Nitrat-Reduktase (PM-NR) scheint an diesem Effekt beteiligt (Stöhr et al., 1995) und Bestandteil einer Signaltransduktionskette zu sein, in der verschiedene PMProteine phosphoryliert werden (Mätschke et al., 1997). Auch für den PMintegralen Nitrattransporter selbst wird eine Regulation durch Phosphorylierung vermutet (Orsel et al., 2002). Ebenfalls an der PM lokalisiert sind stressbedingte $\mathrm{N}$-Effluxreaktionen unter Beteiligung von $\mathrm{Ca}^{2+}$-sensitiven Ionenkanälen, wie dies von Ter Steege et al. (1998) an höheren Pflanzen nachgewiesen wurde. Hinweise auf ein Nitrat-Rezeptor-Protein an der Plasmamembran-Außenseite liegen für Bakterien (Caviacchioli et al., 1996), wie auch für höhere Pflanzen vor (Tischner et al., 1993). Die PM-NR ist ein solcher möglicher Nitrat-Rezeptor. Bei niederen Pflanzen wie z. B. Chlamydomas reinhardtii scheint demgegenüber die Konzentration des Nitrates im Cytoplasma eine regulative Funktion auf transkriptioneller Ebene auszuüben (Navarro et al., 1996).

\section{Molekulare Genetik und Kinetik der Nitrat-Aufnahme}

Die Aufnahme des Nitrates über die Plasmamembran ist eingehend untersucht. Zum einen durch Studien zu den Kinetiken der Aufnahme, zum anderen durch molekularbiologische Untersuchungen von Nitrat-Transporter codierenden Genen (Übersicht der Nitrat-Transporter in: Galvan und Fernandez, 2001). Kinetische Daten der Nitrat-Aufnahme zeigen ein Vorliegen von mindestens drei Nitrat-Aufnahmesystemen in höheren Pflanzen. Unterschieden wird zwischen einem Low-Affinity Transport-System (LATS) mit niedriger Substrat- (Nitrat-) Affinität und zwei High-Affinity Transport-Systemen (HATS). Eines davon ist induzierbar ("inducible“ = iHATS), eines konstitutiv ("constitutive“ = cHATS) (Aslam et al., 1992; Glass und Siddiqi, 1995). Die Systeme sind anhand der Plots ihrer Kinetiken durch unterschiedliche $\mathrm{K}_{\mathrm{M}}$ und $\mathrm{V}_{\max } \mathrm{zu}$ unterscheiden (Peuke und Kaiser, 1996). Bei hohen externen Nitrat-Konzentrationen von mehr als $1 \mathrm{mM} \mathrm{NO}_{3}{ }^{-}$überwiegt die Nitrat-Aufnahme durch das nicht-sättigbare LATS; bei niedrigeren $\mathrm{NO}_{3}^{-}$-Konzentrationen durch die beiden HATS. Das iHATSSystem unterliegt einer negativen feed-back-Regulation durch Ammonium und den Amino-N-Pool der Zelle (Krapp et al., 1998). Galvan und Fernandez (2001) differenzieren auch das LATS und unterscheiden zwischen einem induzierbaren und einem konstitutiven Low-Affinity Nitrat-Transport (iLANT bzw. cLANT) aufgrund der Beziehungen zwischen Transporter-codierenden Genen und resultierenden Aufnahme-Kinetiken. 
Hinweise auf ein Nitrat-Aufnahmesystem in Algen gehen auf kinetische Untersuchungen der Nitrat-Aufnahme in Chlorella vulgaris bzw. Chlamydomonas reinhardtii durch Pistorius et al. (1978) und Florencio und Vega (1982) zurück. Die Autoren zeigten Nitrat-Induzierbarkeit und eine Inhibition des Nitrat-Aufnahmesystem durch Ammonium. Mit molekularbiologischen Methoden wurden vor rund zehn Jahren Einblicke in die molekulare Genetik der Nitrattransporter möglich. Erstmals wurde von Unkles et al. (1991) die Klonierung und Sequenzierung eines Nitrat-Transporter codierenden Gens crnA des Pilzes Aspergillus nidulans berichtet. Quesada et al. (1994) wiesen Nitrat-Transporter-codierende Gene in Chlamydomonas reinhardtii nach. Bei dieser Grünalge sind auf einem Gen-Cluster zwei verschiedene Nitrat- und Nitrat-/Nitrit-bispezifische Transporter codiert. Sie werden als NRT 2;1 und NRT 2;2 bezeichnet (Quesada et al., 1998) und werden in der Gruppe der Nitrat-Nitrit-Porter zusammengefaßt (Poa et al., 1998). In höheren Pflanzen treten zu den NRT2-Nitrat-Transportern homologe Gene auf. Zusätzlich existieren die ebenfalls Nitrat-Transporter codierenden, als NRT 1 (PTR) bezeichneten Gene. Aufgrund phylogenetischer Beziehungen erfolgte die Zuordnung der klonierten Nitrat-Transporter-Gene aus Bakterien, Pilzen, niederen und höheren Pflanzen zur Gruppe der Major Facilitator Superfamily (MFS) durch Trueman et al. (1996). Die MFS ist gekennzeichnet durch passiv getriebene, funktionell aus einem einzelnen Protein bestehende Transporter. Diese transportieren ausschließlich niedrigmolekulare Substanzen („small solutes“) innerhalb eines chemo-osmotischen Gradienten. Allen integralen Plasmamembran-Proteinen der MFS gemeinsam sind zwölf Membran-durchspannende, hydrophobe Domänen und konservierte Sequenzmotive im Umfeld der Transmembran-Domänen 2 bis 4 (Poa et al., 1998). Aus der Basensequenz von Nitrat-Transportern niederer Eukaryoten (Asp. nidulans; Chlam. reinhardtii) sind Proteine mit Molekulargewichten zwischen 56, 59 sowie 67 kDa für Chlorella sorokiniana abzuleiten. Funktionelle Expressionsstudien der für verschiedene Transporter codierenden Gene durch mRNA-Mikroinjektion in Xenopus-Oocyten führten zu deren kinetischer Charakterisierung (Lin et al., 2000; Liu et al., 1999; Huang et al., 1996; Tsay et al., 1993).

\section{Nitrat-induzierte Proteine: Molekulare Genetik versus Proteinbiochemie}

Den umfangreichen Kenntnissen der Nitrat-Transport-Proteine aus AufnahmeKinetiken und molekularer Genetik steht ein Mangel an biochemischen Untersuchungen gegenüber. Weder aus niederen noch aus höheren Pflanzen konnte bislang ein Nitrat-Transporter-Protein auf biochemischem Weg isoliert und durch Ansequenzierung identifiziert werden. Wiederum durch einen molekularbiologischen Ansatz, das Screening von cDNA-libraries in Form von Micro-Arrays Hunderter bis Tausender von Genen, wird gegenwärtig die Vielzahl der Nitrat-induzierten Prozesse im Metabolismus der Pflanzenzelle deutlich. Nach Screening von 5524 Arabidopsis-Genen wurden die 40 am stärksten Nitrat-induzierten Gene sequenziert. Diese codieren für bekanntermaßen Nitrat-induzierte Proteine (z.B. Nitrat-Transporter, NitratReduktase, Glutamat-Synthase), daneben für Proteine, deren NitratInduzierbarkeit bislang nicht bekannt war, z.B. verschiedene Transkriptionsfaktoren, Proteinkinasen, Calcium-Antiporter (Wang et al., 2000). 
Auch Plasmamembran-Proteine wurden identifiziert, wie z.B. WasserkanalProteine oder Kalium- und Phosphat-Transporter, für die eine Nitrat-Induktion bislang nicht bekannt war (Wang et al., 2001a), weitere sind zu erwarten.

Nur wenige Untersuchungen von Nitrat-induzierten Proteinen der PM mit biochemischem und gelelektrophoretischen Methoden liegen vor (McClure et al., 1987; Dhugga et al, 1988; Ni und Beevers, 1994). Aufgetrennt wurden ausschließlich Proteine aus der PM von Maiswurzel und -keimlingen. Ageorges et al. (1996) haben am gleichen Objekt erstmals die zweidimensionale SDS-Polyacrylamid-Gelektrophorese (2D-SDS-PAGE) zur Auftrennung der PM-Proteine herangezogen. In diesem Verfahren werden die Proteine zunächst durch Isoelektrisches Fokussieren (IEF) nach Nettoladung ihrer Aminosäuren aufgetrennt (1. Dimension). Anschließend erfolgt eine Auftrennung nach Molekulargewicht im SDS-Gel (2. Dimension). Sowohl das Isoelektrisches Fokussieren (IEF) der Proteine mit Trägerampholyten, als auch das IEF mit immobilisierten pH-Gradienten ermöglichen, mehrere hundert bis Tausende von Proteinen auf einem einzigen Gel aufzutrennen (Görg et al., 2001). Die 2D-SDS-PAGE steht in der Leistungsfähigkeit der Proteinauftrennung dem cDNA-Micro-Array als Äquivalent auf genomischer Ebene kaum nach. Darüberhinaus gewährleistet die 2D-SDS-PAGE auch posttranslationale Modifikationen von Proteinen zu erfassen (Santoni et al., 2000). Allerdings kann das IEF von Plasmamembran-Proteinen erhebliche Schwierigkeiten bereiten: Insbesondere integrale (intrinsische) PM-Proteine wie z.B. Kanalproteine mit hohem Anteil hydrophober Aminosäuren können unter den Bedingungen des IEF nur schwierig in Lösung zu bringen oder zu halten sein. Durch geeignete Detergenzien und Lysisbedingungen können aber auch solche stark hydrophoben PM-Proteine isoelektrisch aufgetrennt werden; eine Reihe von Protokollen wurden dazu in den vergangenen Jahren entwickelt (Görg et al. 2001).

\section{Ziele}

Mit der vorliegenden Untersuchung sollte zunächst ein geeignetes Verfahren zur zweidimensionalen Gelelektrophorese (2D-SDS-PAGE) von Plasmamembran-Proteinen erarbeitet werden. Im nächsten Schritt sollten die Plasmamembran-Proteine nach ihren Hydrophobizitätseigenschaften aufgetrennt und durch 2D-SDS-PAGE reproduzierbar dargestellt werden. Nitratinduzierte sowie durch Nitrat in ihrer Konzentration beeinflußte Plasmamembran-Proteine sollten erfaßt werden und nach Konstruktion einer zweidimensionalen Karte der Protein-Verteilung im 2D-SDS-Gel eindeutig zugeordnet werden können.

Auf dieser Grundlage sollten sich weitere Untersuchungen zu den an der NitratAufnahme beteiligten, oder durch Nitrat quantitativ beeinflußten Proteine der Plasmamembran anschließen. An erster Stelle stand dabei die Identifikation eines Nitrat-Transporters in Chlorella saccharophila. Verschiedene Strategien sollten dazu verfolgt werden: Photoaffinitätsmarkierung von PM-Proteinen mit einem Hemmstoff der Nitrat-Aufnahme; immunologische Nachweisverfahren; Anreicherung und Ansequenzierung von Proteinen. Molekularbiologische Untersuchungen durch PCR mit heterologen Primern sollten zur Klonierung des Nitrat-Transporters auf genetischer Ebene durchgeführt werden. 


\section{MATERIAL UND METHODEN}

\subsection{Algenmaterial}

Alle Versuche wurden mit der einzelligen Chlorophyceae Chlorella saccharophila (Krüger) Nadson Stamm 211-1a durchgeführt. Die Kulturen wurden aus der Algensammlung des Albrecht-von-Haller-Institutes für Pflanzenwissenschaften der Universität Göttingen bezogen.

\subsubsection{Kulturbedingungen}

Aus Stammkulturen wurden je nach Bedarf entweder 300 ml-Sterilröhren oder 4,5 I Penicillium-Flaschen angeimpft. Als Nährmedium wurde

1.) $\mathrm{NO}_{3}{ }^{-}-\mathrm{NL}$ nach Kuhl (1962)

2.) $\mathrm{NH}_{4}{ }^{+} \mathrm{NL}$ nach Galling (1963)

3.) -N-NL (N-freie NL) nach Galling (1963) eingesetzt. Alle Nährlösungen waren zusätzlich mit $1 \%$ Saccharose versetzt und wurden $30 \mathrm{~min}$ bei $121^{\circ} \mathrm{C}$ autoklaviert. Eisen wurde als Fe-EDTA-Komplex getrennt autoklaviert (zur Vermeidung von Präzipitatbildung) und vor Animpfen der NL separat zugegeben. Die Kulturen wurden in Lichtthermostaten eingehängt und bei $28^{\circ}$ C, 6000 Lux und einem Licht-Dunkel-Wechsel von 12:12 h geführt, zusätzlich wurde mit $\mathrm{CO}_{2}$ in einer Konzentration von $2 \mathrm{Vol}-\%$ in Luft begast.

\subsubsection{Stammkulturen}

Ein Teil der aus der Algensammlung bezogenen Algen wurden zur Anlage von Stammkulturen auf Schrägagarröhrchen überimpft. Dazu wurden Reagenzgläser mit ca. $10 \mathrm{ml}$ einer $2 \%$ Agar enthaltenen $\mathrm{NO}_{3}{ }^{-}-\mathrm{NL}$ nach Kuhl (1962) befüllt und mit Kapsenbergverschlüssen versehen, autoklaviert. Die Reagenzgläser wurden bis zur Aushärtung des Agars schräg gelagert. Die mit Chlorella saccharophila inokulierten Röhrchen wurden in Lichtthermostaten bei ca. $25^{\circ} \mathrm{C}$ und 5000 Lux und einem Licht-Dunkel-Wechsel von 12:12 h gelagert.

\subsection{Präparation der Mikrosomalen Fraktion}

\subsubsection{Protoplasten-Präparation und -Aufbruch}

Zur Protoplastierung wurden die Algen bei einer durchschnittlichen Zelldichte von $10^{7}$ Zellen $/ \mathrm{ml}$ zwischen der achten und neunten Lichtstunde des fünften Lichtzyklus' durch Zentrifugation bei $3000 \times \mathrm{g}$ in der Heraeus Christ Makrofuge (Heraeus Christ, Osterode/Harz, Deutschland) geerntet. Bei der Aufarbeitung der Penicillium-Flaschen wurden die Algen mit einem Durchflußrotor (HeraeusChrist CR 20, $15.000 \mathrm{U} / \mathrm{min}$ ) bei $12000 \mathrm{U} / \mathrm{min}$ sedimentiert. Die Algen wurden zum Verdau der Zellwand in eine modifizierte Enzymlösung nach Stöhr (1993) überführt. 
Enzymlösung

$\begin{array}{lrl}\text { Mannit } & 0,6 \mathrm{M} \\ \mathrm{KCl} & 0,1 \mathrm{M} \\ \mathrm{CaCl}_{2} & 0,02 \mathrm{M} \\ \mathrm{Na}-\text { Ascorbat } & 0,01 \mathrm{M} \\ \mathrm{BSA} & 0,05 \% \\ \mathrm{KNO}_{3} \text { (Induktion) } & 1 \mathrm{mM} \\ \text { Pectinase Asp. } & 1,5 \% \\ \text { niger (Serva) } & \\ \text { Cellulase TC } & 3,0 \% \\ \text { (Serva) } & & \end{array}$

Die Zellsuspension wurde in eine Kulturröhre überführt und unter o.g. Kulturbedingungen für 3-4 $\mathrm{h}$ inkubiert; die Ernte der Protoplasten erfolgte, sobald bei entnommener Probe mindestens $50 \%$ der Protoplasten nach Wasserzugabe platzten. Die Protoplasten wurden durch Zentrifugation bei 3000 $x \mathrm{~g}$ von der Enzymlösung abgetrennt und zweimal mit Osmotikum (=Enzymlösung ohne Enzyme) gewaschen.

Das Zellpellet wurde zum Aufbruch der Protoplasten in einem hypo-osmolaren Aufbruchmedium nach Stöhr (1993) resuspendiert und anschließend 30 min auf Eis inkubiert. Zur Vervollständigung des Aufbruchs wurde die Suspension in flüssigem Stickstoff schockgefroren und bis zur Abtrennung der mikrosomalen Fraktion bei $-70^{\circ} \mathrm{C}$ tiefgefroren gelagert.

Alternativ zur Protoplastierung wurde ein Zellaufbruch mit einer Zellmühle (Vibrogen Vi4; Bühler, Tübingen) durchgeführt. Dazu wurden die Algen abzentrifugiert und das Pellet in $4 \times$ Volumen eiskaltem Aufbruchmedium aufgenommen. Die resuspendierten Algen wurden mit dem halben Volumen Glasperlen (0,8 $\mathrm{mm}$ Durchmesser) versetzt, $15 \mathrm{~min}$ auf Eis gelagert und in den vorgekühlten Einsatzbecher der Zellmühle eingebracht und unter Wasserkühlung (ca. $\left.8{ }^{\circ} \mathrm{C}\right) 5 \times 20 \mathrm{~s}$ aufgebrochen $(20 \mathrm{~s}$-Intervall). Die gewonnene Suspension wurde abgegossen; zwischen den Glasperlen verbliebene Suspension wurde durch Spülen der Glasperlen mit eiskaltem Aufbruchmedium von unten nach oben gewonnen. Die Suspension wurde bei $70^{\circ} \mathrm{C}$ tiefgefroren gelagert.

Aufbruchmedium

$\begin{array}{lrlr}\text { KPP } \mathrm{pH} 7,5 & 100 \mathrm{mM} & \text { FAD } & 1 \mu \mathrm{M} \\ \text { DTT } & 1 \mathrm{mM} & \text { Leupeptin } & 10 \mu \mathrm{M} \\ \text { EDTA } & 1 \mathrm{mM} & \text { Pepstatin } & 10 \mu \mathrm{M} \\ \mathrm{Na}_{2} \mathrm{MoO}_{4} & 1 \mu \mathrm{M} & \text { Chymostatin } & 10 \mu \mathrm{M}\end{array}$




\subsubsection{Präparation des zellfreien Extraktes}

Zur Gewinnung der mikrosomalen Fraktion wurde die gefrorene Suspension in einem auf einem Magnetrührer aufgestellten Becherglas mit Wassermantel (RT) unter Rühren aufgetaut und in ein Eisbad überführt, sobald die letzten Eisstücke aufgetaut waren. Alle folgenden Schritte wurden auf Eis, bzw. bei $4^{\circ}$ C durchgeführt. Nicht-protoplastierte Algen und Zelltrümmer wurden durch Zentrifugation bei $1000 \times \mathrm{g}$ abgetrennt, der Überstand wurde in $32 \mathrm{ml}-$ Ultrazentrifugationsröhrchen überführt und die mikrosomalen Bestandteile bei 100000 x g (Kontron TL 36.28 swing-out Rotor, Kontron Ultrazentrifuge TA 1170, Kontron Instruments, USA) für $1 \mathrm{~h}$ pelletiert. Das erhaltene Pellet bildete das Ausgangsmaterial für die Abtrennung der Plasmamembran-Fraktion.

\subsection{Plasmamembran-Präparation}

Zur Extraktion der Plasmamembranen aus dem mikrosomalen Pellet wurden die Plasmamembranen in einem Dextran/PEG-Zweiphasensystem (Larsson, $1985)$ in die für die PM affinere PEG-Phase ausgeschüttelt. Dazu wurde das mikrosomale Pellet zunächst im Resuspensionspuffer I aufgenommen und darin homogenisiert. Das Homogenat wurde nach Bestimmung seines Proteingehaltes auf vorbereitete 8g-Phasensysteme bzw. zur Aufarbeitung großer Mengen auch 32g-Systeme ("Trennröhrchen") aufgeladen.

\section{$\underline{\text { Resuspensionspuffer I }}$}

TRIS-MES pH 7,2

$$
1 \mathrm{mM}
$$

Saccharose $250 \mathrm{mM}$

Leupeptin $10 \mu \mathrm{M}$

Pepstatin

$10 \mu \mathrm{M}$

Chymostatin

$10 \mu \mathrm{M}$

\section{Zweiphasen-System}

$20 \%$ Dextran

40 \% PEG 3350

$1 \mathrm{M}$ Saccharose in

20 mM KPP pH 7,8

$117 \mathrm{mM} \mathrm{KCl}$
$8 \mathrm{~g}$-System $32 \mathrm{~g}$-System Endkonzentration
$2,6 \mathrm{~g}$
$10,4 \mathrm{~g}$
$6,5 \%$
$1,3 \mathrm{~g}$
$5,2 \mathrm{~g}$
$6,5 \%$
$1,5 \mathrm{ml}$
$6 \mathrm{ml}$
$187 \mathrm{mM}$
$3,74 \mathrm{mM}$
$0,2 \mathrm{ml}$
$0,8 \mathrm{ml}$
$3 \mathrm{mM}$ 
Die $8 \mathrm{~g}$-Systeme wurden mit maximal $3 \mathrm{mg}$ Homogenat-Protein beladen, die $32 \mathrm{~g}$-Systeme mit maximal $10 \mathrm{mg}$. Die beladenen Phasensysteme wurden nach gründlichem Schütteln von Hand für mindestens $15 \mathrm{~s}$ durch eine Zentrifugation bei $1000 \times \mathrm{g}$ für $5 \mathrm{~min}$ wieder entmischt. Die Plasmamembranen wandern dabei in die PEG-Phase, diese wurde noch zweimal auf eine frische (untere) Dextranphase ("Waschröhrchen") überführt und mit dieser erneut ausgewaschen. Die erhaltenen PEG-Phasen wurden zur Abtrennung der PM mit Protease-Inhibitorfreiem Aufbruchmedium im Verhältnis $1: 3$ verdünnt und für $1 \mathrm{~h}$ bei $150000 \times \mathrm{g}$ (Kontron TFT 45.94) zentrifugiert. Die sedimentierten PM-Pellets wurden zur Abtrennung noch anhaftener Zucker- und PEG-Reste in Resuspensionspuffer II (= Aufbruchmedium mit $200 \mathrm{mM} \mathrm{NaCl}$ ) aufgenommen, der Proteingehalt bestimmt, und die PM durch erneute Zentrifugation bei 100000 x g für 20 min (Beckman TL 100.3, Beckman Instruments, USA) in Mikro-Reagiergefäßen wieder pelletiert und bis zur weiteren Verwendung bei $80^{\circ} \mathrm{C}$ gelagert.

\section{4 right side out Vesikel-Päparation}

Die Gewinnung der right side out-Vesikel wurde nach Palmgren et al. (1990) durchgeführt. Das PM-Pellet wurde dazu in Resuspensionspuffer IV aufgenommen und einem viermaligen Gefrier-Auftau-Zyklus mit flüssigem N2 und Auftauen bei RT unterworfen. Die Vesikel wurden bei 100000 xg für 15 min abzentrifugiert und in $5 \mathrm{mM}$ Tris- $\mathrm{HCl} \mathrm{pH} 7,8$ resuspendiert. $800 \mu \mathrm{l}$ der Suspension wurden mit $200 \mu$ Resuspensionspuffer $V$ versetzt und auf das vorbereitete 8g-Phasensystem II aufgeladen.

Das Gewicht der Phasensysteme wurde mit in $5 \mathrm{mM}$ Tris- $\mathrm{HCl} \mathrm{pH} 7,8$ auf $8 \mathrm{~g}$ eingestellt, die Phasentrennung wurde wie für die PM oben beschrieben durchgeführt. Die obere (PEG-) Phase reicherte die gewünschten right side outVesikel an, diese wurden nach Verdünnung in Resuspensionspuffer III durch Zentrifugation bei 100000 x g für 2,5 h abgetrennt und pelletiert.

Resuspensionspuffer III

TRIS-HCl pH 7,8

$$
5 \mathrm{mM}
$$

Saccharose

$\mathrm{KCl}$

$330 \mathrm{mM}$

DTT

$50 \mathrm{mM}$

EDTA

$$
1 \mathrm{mM}
$$

$0,1 \mathrm{mM}$

Resuspensionspuffer IV

TRIS-HCl pH 7,8

$26 \mathrm{mM}$

Saccharose

$330 \mathrm{mM}$

$\mathrm{KCl}$

$26 \mathrm{mM}$ 
Phasensystem II

8 g-System Endkonzentration

$20 \%$ Dextran

$2,6 \mathrm{~g}$

$6,5 \%$

40 \% PEG 3350

$1,3 \mathrm{~g}$

$6,5 \%$

1,3 $\mathrm{M}$ Saccharose in

$1,5 \mathrm{ml}$

$330 \mathrm{mM}$

26 mM TRIS-HCl pH 7,8

$5,5 \mathrm{mM}$

$26 \mathrm{mM} \mathrm{KCl}$

$0,2 \mathrm{ml}$

$5,5 \mathrm{mM}$

\subsection{Temperatur-induzierte Phasenverteilung mit Triton X114}

Zur Abtrennung transmembranärer Proteine der PM-Proteinfraktion kann ihr ausgeprägt hydrophober Charakter zur Separation genutzt werden (Pryde, 1986). Dazu wurden die PM-Proteine in in $2 \%$ Triton X114 in Aufbruchmedium für $1 \mathrm{~h}$ bei $0{ }^{\circ} \mathrm{C}$ gerührt. Dabei nicht solubilisierte Proteine wurden abzentrifugiert (100 $000 \mathrm{x} \mathrm{g,} 15$ min, Beckman TL 100.3) und der Überstand für 6-8 min bei $30^{\circ} \mathrm{C}$ inkubiert. Dabei aggregierten Detergenzmicellen, die durch Zentrifugation bei $1000 \times \mathrm{g}$ für $5 \mathrm{~min}$ von der oberen, wässrigen Phase abgetrennt wurden. Die untere Detergenzphase wurde erneut mit einem, der entfernten wässrigen Phase entsprechenden Volumen Aufbruchmedium versetzt und die Zweiphasenverteilung wiederholt. Nach zweimaligem Auswaschen wurden die untere Detergenz- und die oberen wässrigen Phasen nach deren Vereinigung mit Methanol/Chloroform gefällt und das Proteinpellet für $15 \mathrm{~min}$ im Luftstrom getrocknet und bei $-20^{\circ} \mathrm{C}$ gelagert.

\subsection{Hydrophobe Interaktionschromatographie der PM-Proteine}

1,5 mg Plasmamembran-Protein wurde in HIC-Laufpuffer aufgenommen und mit $1 \mathrm{M}$ Ammoniumsulfat versetzt, bei $\mathrm{RT}$ für 20 min gerührt und nicht solubilisierte Bestandteile abzentrifugiert (100 000 x g, 15 min, Beckman TL 100.3). Der Überstand wurde auf eine mit HIC-Laufpuffer äquilibrierte Phenylsuperose-Säule aufgeladen (HR 5/5, Pharmacia) aufgeladen, die an ein FPLC-System (Pharmacia) gekoppelt war.

HIC-Laufpuffer

$\begin{array}{lr}\text { MOPS, pH 7,5 } & 50 \mathrm{mM} \\ \text { DTT } & 2 \mathrm{mM} \\ \text { Octylglucosid } & 2 \mathrm{mM} \\ \text { FAD } & 5 \mathrm{mM} \\ \left(\mathrm{NH}_{4}\right)_{2} \mathrm{SO}_{4} & 1 \mathrm{M}\end{array}$


Die PM-Proteine wurden in einem abnehmenden $\left(\mathrm{NH}_{4}\right)_{2} \mathrm{SO}_{4}$-Gradienten $(1 \mathrm{M}$ $0 \mathrm{M})$ und einem parallel ansteigenden Harnstoff-Gradienten (0-1M, Harnstoff gelöst in HIC-Laufpuffer ohne $\left(\mathrm{NH}_{4}\right)_{2} \mathrm{SO}_{4}$ von der Säule eluiert. Besonders hydrophobe Proteine wurden im Anschluß durch $50 \mathrm{mM} \mathrm{NaOH}$ (mit $2 \mathrm{mM}$ Octylglucosid versetzt) eluiert. Die Flußrate betrug $0,8 \mathrm{ml} / \mathrm{min}$, die gesammelte Fraktionensgröße betrug $1,0 \mathrm{ml}$. Aus den gesammelten Fraktionen wurden entsprechend der zunehmenden Hydrophobizität der eluierten Proteine sechs Gruppen gebildet und diese durch Zentrifugation über CentriconFiltrationseinheiten mit 10 kDa-Ausschlußgrenze (Centricon 10; Amicon Inc., USA) für $50 \mathrm{~min}$ bei $4^{\circ} \mathrm{C}$ mit $2500 \mathrm{Upm}(1000 \times \mathrm{g}$; Sorvall RC 5B; Rotor SA 600) entsalzt. Die Retentate der Filtrationseinheiten wurden in Resuspensionpuffer I aufgenommen und zur DNPA-Markierung eingesetzt.

\subsection{Markierung von $\mathrm{NO}_{3}$-induzierten PM-Proteinen mit ${ }^{35} \mathrm{~S}$-Methionin}

Zur Identifizierung von de novo synthetisierten Proteinen der Plasmamembran wurden die Algen mit ${ }^{35} \mathrm{~S}$-markiertem Methionin in der Nährlösung inkubiert und mit $\mathrm{NO}_{3}$ induziert. Dabei synthetisierte Proteine enthalten radioaktives Methionin und können nach ihrer gelelektrophoretischen Auftrennung durch Autoradiographie detektiert werden. Die Markierungsexperimente und die anschließend durchgeführte PM-Präparation wurde im Zentralen Isotopenlabor der Universität Göttingen durchgeführt.

In 4,5 I Penicillin-Flaschen wurden drei Massenkulturen angelegt und diese mit $\mathrm{NH}_{4}{ }^{+}$als $\mathrm{N}$-Quelle versorgt. Nach $\mathrm{N}$-Verarmung für $12 \mathrm{~h}$ durch Umsetzen in $-\mathrm{N}$ $\mathrm{NL}$ wurden die Algen aus den drei Flaschen abzentrifugiert, die Pellets in 300 $\mathrm{ml}$-N-NL resuspendiert, vereinigt und in Aliquots aufgeteilt, in drei Kulturröhren eingefüllt. Die Zelldichte betrug dabei $3,2 \times 10^{9}$ Zellen/ml. Die Kulturröhren wurden in einen Lichtthermostaten eingehängt und mit $2 \% \mathrm{CO}_{2}$ begast.

Induziert wurde durch Zugabe von $\mathrm{NO}_{3}{ }^{-}$(Endkonzentration $10 \mathrm{mM}$ ), parallel dazu wurden Kontrollen mit $5 \mathrm{mM} \mathrm{NH}_{4}{ }^{+}$versetzt bzW. verblieben in N-freier NL. Das zur Markierung der drei Ansätze zugesetzte ${ }^{35}$ S-Methionin (Amersham) hatte eine spezifische Aktivität von $1215 \mathrm{Ci} / \mathrm{mmol}$; pro Kulturröhre wurden 250 $\mu \mathrm{Ci}$ eingesetzt, die Endkonzentration Methionin (nicht markiert $+{ }^{35} \mathrm{~S}$-markiert) betrug 0,1 mM. Das nichtmarkierte Methionin wurde den Kulturröhren zum Induktionsbeginn bereits in dieser Konzentration zugesetzt, da die Konzentration des markierten Methionins im Gesamtansatz aufgrund der hohen spez. Aktivität vernachlässigbar gering war. Entstehende flüchtige radioaktive Schwefelverbindungen wurden über Entlüftungsschläuche abgeführt. Die Kulturröhren wurden für $3 \mathrm{~h}$ belichtet. Nach Abzentrifugieren wurden die Algenpellets in Protoplastierungs-Enzymlösung aufgenommen und für weitere 3 $h$ in den Lichtthermostaten eingehängt. Die Algen wurden erneut abzentrifugiert, in eiskaltem Aufschlußpuffer aufgenommen, für 30 min auf Eis inkubiert, bis die Protoplasten osmotisch aufgebrochen waren und in flüssigem $\mathrm{N}_{2}$ schockgefroren. Die Lagerung erfolgte bis zur PM-Präparation bei $-70{ }^{\circ} \mathrm{C}$. Aufnahme und Einbau des ${ }^{35}$ S-Methionins wurden durch Szintillationszählung von Aliquots des sedimentierten Algenpellets, des Algenfreien Überstandes sowie im Verlauf der PM-Präpation, von Mikrosomalem Pellet als auch der PM überprüft. 


\subsection{Photoaffinitätsmarkierung von PM-Proteinen mit ${ }^{14} \mathrm{C}-2,6-\mathrm{DNPA}$}

Glogau (1994) zeigte, daß das Arylazid 2,6-di-Nitro-Phenylazid (DNPA) ein kompetitiver Hemmstoff der Nitrataufnahme in Chlorella ist. Der $\mathrm{K}_{\mathrm{i}}$ wurde mit $16 \mu \mathrm{M}$ DNPA bestimmt. Durch Belichtung mit kurzwelligem Licht kann die AzidGruppe des DNPA gespalten werden. Das dann sehr reaktive DNPA kann dadurch zu einer Photoaffinitätsmarkierung genutzt werden. Für die Markierungsversuche mit DNPA wurden ein nicht markierter Ansatz und ein Ansatz mit ${ }^{14} \mathrm{C}$-Markierung synthetisiert. Das unter Einbau des KohlenstoffIsotopes ${ }^{14} \mathrm{C}$ synthetisierte Dinitrophenylazid hatte eine spezifische Aktivität von ca. $6 \mathrm{mCi}\left(2,2 \times 10^{11} \mathrm{~Bq}\right) / \mathrm{mMol}$. Das zur Markierung eingesetzte, radioaktive DNPA wurde, wie in Vorversuchen als geeignetstes Lösungsmittel bestimmt, in Ethanol gelöst. Die Zeit- und Lichtwellenlängen-abhängige Zerfallsgeschwindigkeit der instabilen Azid-Gruppe wurde photometrisch und durch ein kontinuierliches Spektrum bestimmt. Das DNPA wurde bei einer Wellenlänge von $364 \mathrm{~nm}$ in den zur Versuchsdurchführung benutzten Mikroreagiergefäßen mit einem Hand-UV-Belichter gespalten, die Belichtungszeit betrug $10 \mathrm{~min}$. Die gesättigte Lösung von DNPA in Ethanol hatte eine Konzentration von 93,4 $\mu \mathrm{mol} / \mathrm{ml}$ (Daten nicht gezeigt). Zur Photoaffinitätsmarkierung der PM wurden dem Reaktionsansatz maximal 7,5 Volumenprozent einer ethanolischen ${ }^{14} \mathrm{C}$-DNPA-Stammlösung zugesetzt. Die im Reaktionsansatz eingesetzten DNPA-Endkonzentrationen wurden durch Zugabe eines Aliquots aus einer entsprechenden höher konzentrierten ${ }^{14} \mathrm{C}-$ DNPA-Stammlösung hergestellt, die Endkonzentrationen waren 0,5; 5; 50 und $500 \mu \mathrm{M}$.

Die Markierungsexperimente wurden mit gereinigter Plasmamembran sowie right-side-out-Vesikeln durchgeführt, eingesetzt wurden je Ansatz $200 \mu \mathrm{g}$ Gesamtprotein bei $150 \mu$ l Reaktionsvolumen. Bei der spezifischen Aktivität des ${ }^{14} \mathrm{C}$-DNPA von $6 \mathrm{mCi} / \mathrm{mmol}$ wurde je nach Reaktionsansatz eine GesamtRadioaktivität von 16,5; 165; 1654 bzw. 16540 Bq eingesetzt. Aufgrund der geringen Löslichkeit des DNPA mußte zum Erreichen der $500 \mu \mathrm{M}$ Konzentration 15 Volumenprozent der gesättigten ethanolischen Stammlösung eingesetzt werden. Als Puffersystem für die Experimente diente der Tris/MESResuspensionspuffer I. Zur elektrophoretischen Trennung der markierten Proteine wurden die Proben entweder mit $1 / 4$ Vol SDS-Beladungspuffer 5 min bei $100^{\circ} \mathrm{C}$ gekocht und in die Taschen des vorbereiteten Gels geladen (SDSPAGGE) oder mit gleichem Volumen 2X Harnstoffbeladungspuffer versetzt und unter Zugabe von festem Harnstoff bis zur Sättigung (ca. 9M) für $10 \mathrm{~min}$ gevortext und auf die vorbereiteten IEF-Kapillarröhrchen aufgebracht.

\subsection{Proteinbestimmung}

Die Quantifizierung des löslichen Proteins erfolgte nach Bradford (1976). Als Standard diente Rinderserumalbumin (Boehringer, Mannheim). 


\subsection{Gelelektrophorese der PM-Proteine}

\subsubsection{SDS-Polyacrylamid-Gel-Elektrophorese (SDS-PAGE)}

\subsubsection{Probenvorbereitung}

Zur SDS-Gelelektrophorese vorgesehene Proben wurden mit 1/8 Vol SDSBeladungspuffer versetzt, dem ca. 0,01\% Bromphenolblau zugesetzt war, für 5 min gekocht und entweder sofort eingesetzt oder bei $-20^{\circ} \mathrm{C}$ eingefroren.

\section{X SDS-Probenpuffer}

$\begin{array}{lcc}\text { Tris/HCl } \mathrm{pH} 6,8 & 0,250 & \mathrm{M} \\ \text { SDS } & 8 & \%(\mathrm{w} / \mathrm{v}) \\ \text { Glycerin } & 40 & \%(\mathrm{v} / \mathrm{v}) \\ \beta \text {-Mercaptoethanol } & 20 & \%(\mathrm{v} / \mathrm{v})\end{array}$

\subsubsection{Diskontinuierliche SDS-PAGE}

Modifiziert nach Lämmli (1970) wurden Polyacrylamid-Gele mit einem diskontinuierlichen Tris/HCl-Puffersystem zur elektrophoretischen Proteintrennung benutzt. Es wurden sowohl homogene- als auch GradientenGele eingesetzt. Die Acrylamid-Konzentration der Trenngele betrug 12,5\% in homogenen Gelen, die der Gradienten-Gele umfaßte 7,5-20 \%. Das Sammelgel besaß jeweils eine Acrylamid-Konzentration von $3 \%$.

Die Elektrophorese erfolgte bei Raumtemperatur in vertikalen, $1,5 \mathrm{~mm}$ messenden Gelstäben bei konstanter Spannung von zunächst $70 \mathrm{~V}$ bis zum Eintritt der Bromphenolblau-Front in das Trenngel, dann $170 \mathrm{~V}(210 \mathrm{~V}$ im Kühlraum) bzw. $120 \mathrm{~V}$ bei Mini-Gelen. Der Polymerisationsgrad war in allen Gelen gleich (Verhältnis bis-Acrylamid : Acrylamid $1: 36$ ).

\subsubsection{Isoelektrische Fokussierung (IEF) mit Träger-Ampholyten}

\subsubsection{Probenvorbereitung}

Zur isoelektrischen Fokussierung in denaturierenden Harnstoffgelen wurden die Proben mit Harnstoff-Probenpuffer denaturiert, auch hier erfolgte die Zugabe von etwas Bromphenolblau. Wenn die Proteine bereits in wässriger Lösung vorlagen, wurde ein 2X Harnstoff-Probenpuffer mit ebenfalls 9M Harnstoff zugesetzt und zusätzlich fester Harnstoff bis zur Sättigung eingerührt. 
Harnstoff-Probenpuffer

$\begin{array}{ll}\text { Harnstoff (reinst) } & 9 \mathrm{M} \\ \text { Nonidet-P40 } & 4 \% \\ \beta \text {-Mercaptoethanol } & 2 \% \\ \text { Träger-Ampholyte } & 4 \%\end{array}$

Die Träger-Ampholyte (Servalyt pH 3,0-10; Fa. Serva, Heidelberg) wurden erst unmittelbar vor Beginn der Elektrophorese zugesetzt.

\subsubsection{2 „small scale“-IEF für Minigele}

Die isoelektrische Fokussierung in Harnstoffgelen wurde in Gelstäben (Kapillargelen) in $6 \%$ Polyacrylamid und 9M Harnstoff, in Anlehnung an Dunbar et al. (1990) durchgeführt. Der pH-Gradient wurde mit pH 3-10 sehr weit gewählt, um keine Proteine mit IEPs in den pH-Extrema zu verlieren.

In ein Reagenzglas wurden 1,77 g Harnstoff (reinst) eingewogen, $1200 \mu \mathrm{l}$ bidest. Wasser und $400 \mu \mathrm{l}$ Acrylamid-Lösung (30\% Acrylamid; 1,8 \% bisAcrylamid) zugegeben und auf einem Magnetrührer bei ca. $30^{\circ} \mathrm{C}$ im Wasserbad (Becherglas) gelöst. Nach vollständiger Auflösung des Harnstoffes wurden $60 \mu$ Nonidet P-40 einpipettiert und $15 \mathrm{~min}$. (bis zum Verschwinden der entstandenen Schlieren) gelöst. Ein Aliquot von $1000 \mu \mathrm{l}$ dieser Lösung wurde in ein Mikroreagier-Gefäß überführt und mit Ampholytmix $\mathrm{pH} 3-10$ auf $8 \%$ eingestellt. Zur Polymerisation wurde mit $12 \mu \mathrm{l}$ APS (10 \% w/v) versetzt, kurz durchmischt, mit 5,6 $\mu$ l TEMED $(10 \% \mathrm{v} / \mathrm{v})$ versetzt und erneut kurz durchmischt. Die entstandenen Luftblasen wurden mit einer Pipette entfernt und aus der luftblasenfreien Lösung Aliquots von $92 \mu \mathrm{l}$ in Glaskapillaren $(1,5 \mathrm{~mm}$ Innendurchmesser, $100 \mathrm{~mm}$ Länge; Fa. Biometra, Göttingen) aufgezogen und 5-10 min in horizontaler Lagerung auspolymerisiert. Der an den Kapillarenden auskristallisierte Harnstoff wurde entfernt und die Gele in die ElekrophoreseApparatur eingespannt. Die mit Harnstoff-Beladungspuffer und ggfs. festem Harnstoff versetzten Proben wurden mit einer Hamilton-Mikropipette auf die Kapillargele aufgebracht und mit einem $3 \mathrm{X}$ in $\mathrm{H}_{2} \mathrm{O}$ verdünnten HarnstoffProbenpuffer luftblasenfrei überschichtet. Als Elektroden-Lösungen diente eine $50 \mathrm{mM} \mathrm{NaOH}$-Lösung (Kathode) sowie eine $50 \mathrm{mM} \mathrm{H} \mathrm{PO}_{4}$ (Anode). Die Elektrophorese der Kapillargele erfolgte ohne Vorfokussieren bei Raumtemperatur mit $260 \mathrm{~V}$ über $16 \mathrm{~h}$.

\subsubsection{3 „Iarge scale“-IEF zur Proteinisolierung}

Zur Proteinisolierung und direkter Ansequenzierung der aufgetrennten Proteine wurde ein „upscaling“ der IEF-Minigele durchgeführt, um zur Ansequenzierung ausreichende Proteinmengen hoher Reinheit zu gewinnen.

In einem Erlenmeyerkolben wurden 14,2 g Harnstoff in 9,6 ml bidest. Wasser und 3,2 ml Acrylamid-Lösung $(30 / 1,8)$ gelöst und nach Lösen des Harnstoffes $480 \mu \mathrm{l}$ Nonidet P-40 zugesetzt und bis zur Klärung bei ca. $30{ }^{\circ} \mathrm{C}$ gelöst. Nach Zugabe von 1,6 ml Ampholyten pH 3-10 wurde durch Einpipettieren von $250 \mu \mathrm{l}$ 
APS (10\% w/v) und $110 \mu$ TEMED (10 \% v/v) die Polymerisierung gestartet. Nach gründlichem Durchmischen wurde jeweils 6,5 ml Lösung in Glasröhren mit einem Innendurchmesser von ca. $6 \mathrm{~mm}$ mit einer arretierbaren Pipettierhilfe aufgezogen und mit Parafilm gegen ein Austrocknen verschlossen. Die Glasröhren waren aus 10 ml-Pipetten durch Entfernen des verjüngten Endes hergestellt. Die Polymerisation in vertikaler Stellung war nach 15 min abgeschlossen, der Parafilm wurde entfernt und die Röhren wurden in eine Rotophor-Kammer eingespannt. Maximal 1,5 mg PM-Protein wurde, gelöst in 3 $\mathrm{ml}$ Harnstoffbeladungspuffer mit $8 \%$ Ampholyten $\mathrm{pH}$ 3-10 auf das Gel aufgeladen, mit 0,5 X Harnstoffbeladungspuffer bis zum Pipettenrand aufgefüllt und die Kammern der Rotophor mit dem o.g. Kathoden- bzw. Anodenpuffer (50 $\mathrm{mM} \mathrm{NaOH} / 50 \mathrm{mM} \mathrm{H}_{3} \mathrm{PO}_{4}$ ) gefüllt. Die Elektrophorese wurde bei RT zunächst mit $150 \mathrm{~V}$ für $30 \mathrm{~min}$, dann mit $250 \mathrm{~V}$ für $14 \mathrm{~h}$ durchgeführt. Zum Fokussierungsabschluß wurde die Spannung auf $400 \mathrm{~V}$ (30 min) und schließlich $600 \mathrm{~V}$ für $1 \mathrm{~h}$ angehoben.

\subsubsection{2.Dimension: SDS-PAGE}

Nach Abschluß der Fokussierung (Phenolrot-Ring im sauren Kapillarende) der small scale Harnstoff-Kapillargele wurden die Gele aus den Glaskapillaren mithilfe einer Einwegspritze aus den Kapillaren getrieben und bei RT für 10 min mit SDS-Beladungspuffer inkubiert. Es folgte die Übertragung auf SDSGradienten-Gele (7,5-20 \%) ohne Sammelgel und Elektrophorese über 2,5 h bei $120 \mathrm{~V}$ unter Raumtemperatur. Zur Molekulargewichtsbestimmung dienten LMW-Markerproteine der Fa. Pharmacia.

Nach Fokussierungsabschluß der large scale Harnstoffgele wurden die Gelstäbe ebenfalls durch vorsichtiges Austreiben mit einer Einwegspritze aus den Glasröhren in SDS-Beladungspuffer LS (= SDS-Beladungspuffer, $\mathrm{pH}$ aber auf 6,8 eingestellt) überführt. Aufgrund des großen Durchmessers wurden die Gelstäbe auf einer Laborwippe bei RT für 30 min inkubiert. Zur Auftrennung der Proteine in der zweiten Dimension wurden die Gelstäbe auf ein $16 \times 20 \times 0,3$ $\mathrm{cm}$ SDS-Gradientengel (7,5 - $20 \%$, mit $3 \%$ Sammelgel) überführt und durch vorsichtiges, gleichmäßiges Quetschen in den $3 \mathrm{~mm}$-Zwischenraum eingebracht, die Elektrophorese erfolgte für 45 min bei $70 \mathrm{~V}$ (Einwandern der Proteine in das Sammelgel) und die Auftrennung der Proteine im Trenngel über Nacht bei 100 V. Die Gel-Elektrophorese wurde ca. 30 min nach "Herauslaufen" der Bromphenolblau-Lauffront beendet.

\section{SDS-Beladungspuffer}

Tris / HCl; pH 7,8

$125 \mathrm{mM}$

SDS

$2 \%$

Glycerin

$10 \%$

$\beta$-Mercaptoethanol

$0,5 \%$ 


\subsubsection{Anfärbung der Proteine im Gel}

\subsubsection{Silberfärbung}

Die Silberfärbung der Proteine im 2D-IEF-Gel wurde nach Blum et al. (1987) durchgeführt, die untere Nachweisgrenze liegt bei diesem Verfahren bei 2DGelen bei ca. 0,2 - 5 ng Protein pro Spot, bei einfachen SDS-Gelen bei ca. 1 30 ng/Proteinbande. Molekulargewichtsmarker-Proteine wurden entsprechend stark herunterverdünnt, um eine Überfärbung des Geles im Bereich dieser Proteinbanden zu vermeiden.

\section{Fixieren $1 \mathrm{~h}$}

$50 \%(\mathrm{v} / \mathrm{v})$ Methanol

$12 \%(v / v)$ Essigsäure

$0,019 \%(v / v)$ Formaldehyd

Waschen $3 \times 20 \mathrm{~min}$

$50 \%(\mathrm{v} / \mathrm{v})$ Ethanol

Imprägnieren $1 \mathrm{~min}$

$0,022 \%(w / v) \mathrm{Na}_{2} \mathrm{~S}_{2} \mathrm{O}_{5} \times 5 \mathrm{H}_{2} \mathrm{O}$

Waschen $3 \times 20 \mathrm{sec}$

$\mathrm{H}_{2} \mathrm{O}$ bid

Färben 20 min

$0,2 \%(\mathrm{w} / \mathrm{v}) \mathrm{AgNO}_{3}$

$0,019 \%$ (v/v) Formaldehyd

Waschen $2 \times 20 \mathrm{sec}$

$\mathrm{H}_{2} \mathrm{O}$ bid.

Reduzieren (Sichtkontrolle; ca. 2-10 min)

$6 \%(\mathrm{w} / \mathrm{v}) \mathrm{Na}_{2} \mathrm{CO}_{3}$

$0,019 \%(\mathrm{v} / \mathrm{v})$ Formaldehyd

$0,004 \%(w / v) \mathrm{Na}_{2} \mathrm{~S}_{2} \mathrm{O}_{5} \times 5 \mathrm{H}_{2} \mathrm{O}$

Waschen $10 \mathrm{sec}$.

$\mathrm{H}_{2} \mathrm{O}$ bid.

Stoppen $10 \mathrm{~min}$

$50 \%(\mathrm{v} / \mathrm{v})$ Methanol

$12 \%(v / v)$ Essigsäure

Waschen $>10 \mathrm{~min}$

$50 \%(\mathrm{v} / \mathrm{v})$ Methanol

Die Gele wurden nach dem Waschen fotografiert oder mit einem digitalen Bildauswertungssystem von BioTech-Fischer, Deutschland aufgenommen, da die Gele zu Nachfärbung neigten. Konserviert wurden die Gele durch 
Einschweißen in Gefrierbeutel und anschließender Lagerung bei $4{ }^{\circ} \mathrm{C}$; die Färbung ist stabil, zeigte langfristig (Monate) aber Kontrastverlust.

\subsubsection{Coomassie-Färbung}

Bei höheren Proteinkonzentrationen im Gel, wie z.B. den Kontrollgelen zur Proteinisolierung, wurden die Gele mit einer schnelleren, aber unempfindlicheren Coomassie-Färbung (Neuhoff et al., 1985) angefärbt.

\section{Färben $1 \mathrm{~h}$ auf der Laborwippe}

$2 \%(\mathrm{w} / \mathrm{v})$ Coomassie Brilliant Blue R250

$0,5 \%(w / v)$ Coomassie Brilliant Blue G250

$42,5 \%(v / v)$ Ethanol

$5 \%(\mathrm{v} / \mathrm{v})$ Methanol

$10 \%(v / v)$ Essigsäure

\section{Entfärben I $5 \mathrm{~min}$}

Entfärbelsg. I

$45 \%(\mathrm{v} / \mathrm{v})$ Ethanol

$10 \%(v / v)$ Essigsäure

Entfärben II $3 \times 20$ min, bis zur Entfärbung des Hintergrundes

Entfärbelsg. II

$7 \%(v / v)$ Essigsäure

\subsubsection{Geltrocknung und Autoradiographie}

Radioaktiv markierte Proteine wurden nach ihrer Elektrophorese und Silberfärbung zur Anfertigung einer Autoradiographie mit einem beheizten Geltrockner (Pharmacia, Schweden) auf Whatman 3MM Papier für 3-4 h bei 0,7 bar Vakuum (Vakuumpumpe) getrocknet. Die trockenen Gele wurden noch heiß und restfeucht in lichtundurchlässige Kassetten eingelegt; zur Autoradiographie wurde ein ß-max Film (Amersham, England) verwendet. Die Expositionsdauer variierte in Abhängigkeit der mit dem Handzählgerät bestimmten Aktivität zwischen 10-45 d. Alternativ wurde ein Phospho-Imager mit entsprechenden Imager-Platten $\left({ }^{14} \mathrm{C}-\right.$ bzw. ${ }^{35} \mathrm{~S}$-sensitiv) benutzt, um vorab eine Auswertung mit entsprechend geringerer Auflösung (max. 100 $\mu \mathrm{m} /$ Bildpunkt) vornehmen zu können; die Datenauslesung und Aufarbeitung erfolgte durch den BASReader 2,9 und die Auswertungssoftware TINA 2,0. 


\subsection{Immunologischer Proteinnachweis}

\subsubsection{Western Blotting der PM-Proteine}

Der elektrophoretische Transfer der Proteine aus den Polyacrylamid-Gelen auf Nitrocellulose (NC)-Folie bzw. PVDF (polyvinyldifluorid)-Membranen erfolgte nach Towbin et al. (1979). Verwendet wurde für Western Blots eine Nitrocellulose-Folie mit 0,2 $\mu \mathrm{m}$ Porengröße (NC-40; Fa. Sartorius, bezogen über Fa. Bio-filtronic, Nörten-Hardenberg); für die Ansequenzierung ausgewählter Proteine wurde PVDF-Folie (PVDF sequencing membrane Westran von Schleicher \& Schuell Deutschland) eingesetzt.

Der Protein-Transfer erfolgte in einem Naßkammer-Blotting-System (TransblotCell; Fa. Bio-Rad).

\section{Blotting-Puffer}

Tris $25 \mathrm{mM}$

Glycin $200 \mathrm{mM}$

Methanol (v/v) $20 \%$

Die Elektrophorese wurde bei $4^{\circ} \mathrm{C}$ mit konstanter Stromstärke von $150 \mathrm{~mA}$ über Nacht oder $650 \mathrm{~mA}$ für 2,5 h durchgeführt. Dem Blottingpuffer wurde für den Transfer von Proteinen auf PVDF-Membran zusätzlich 0,2 \% SDS (w/v) zugesetzt.

\subsubsection{Anfärbung der PM-Proteine auf NC-Folie und PVDF-Membran}

Zur reversibelen Anfärbung der Markerproteine (Bestimmung des Molekulargewichts) wurde die NC-Folie für $3 \mathrm{~min}$ in 0,5\% (w/v) Ponceau S (Fa. Serva, Heidelberg) in $1 \%(\mathrm{v} / \mathrm{v}) \mathrm{HAc}$ inkubiert; nach Kennzeichnung der Markerproteine wurde durch Waschen mit großem Überschuß $\mathrm{H}_{2} \mathrm{O}$ demin. wieder entfärbt.

Die zur Ansequenzierung von Proteinen benutzte PVDF-Membran wurde 10-15 min mit 0,1\% (w/v) Coomassie Brilliant Blue R 250 in $10 \%$ (v/v) Essigsäure und $50 \%$ (v/v) Methanol angefärbt; entfärbt wurde durch 1-3 min Waschen mit $80 \%(\mathrm{v} / \mathrm{v})$ Methanol und $10 \%(\mathrm{v} / \mathrm{v})$ Essigsäure und $3 \times 20$ min Waschen mit 50 $\%(\mathrm{v} / \mathrm{v})$ Methanol und $10 \%(\mathrm{v} / \mathrm{v})$ Essigsäure.

Zur Amidoblackfärbung wurden die Membranen für 10-15 min in 0,1 \% (w/v) Amidoblack in $45 \%(\mathrm{v} / \mathrm{v})$ Methanol und $2 \%(\mathrm{v} / \mathrm{v})$ Essigsäure inkubiert. Entfärbt wurde mit $90 \%$ (v/v) Methanol und $2 \%(v / v)$ Essigsäure.

\subsubsection{Immunologische Nachweise}

I.) Blockierung der NC-Folie

Nach der Ponceau-Färbung wurde die NC-Folie mit demin. Wasser gespült und zur Absättigung ("blocking") der freigebliebenen Protein-Bindungsstellen der Folie mit überschüssigem Protein für mindestens $3 \mathrm{~h}$ oder über Nacht in einer 
Protein- (= Casein; Blocking-Reagenz der Fa. Boehringer, Mannheim) Lösung inkubiert.

blocking-Lösung

Tris/ $\mathrm{HCl} \quad \mathrm{pH} 7,5 \quad 20 \mathrm{mM}$

$\mathrm{NaCl} \quad 500 \mathrm{mM}$

Blocking-Reagenz $\quad 0,25 \%$

II.) Inkubation mit Primär-Antikörper (Antiserum)

Nach Sättigung der Folie mit Protein wurde mit einem polyklonalen Antikörper aus Kaninchen (Rabbit IgG) gegen NR sowie gegen den Nitrat-Transporter in Hordeum vulgare (freundlicherweise zur Verfügung gestellt von Brian Forde PhD., Rothamsted Exp. Station, Harpenden, England) inkubiert. Die AntikörperLösung wurde $1: 2000$ bis 1:5000 in blocking-Lösung verdünnt. Die Inkubation mit dem primären Antikörper erfolgte bei Raumtemperatur über mindestens 2,5 h oder über Nacht auf einer Wippe. Die durch Immunsierung von Kaninchen gewonnenen Seren \# 29, 58 (119) wurden unterschiedlich verdünnt (siehe Kapitel 3.6.3).

Ungebundener Antikörper wurde im Anschluß durch $5 \times 10$ min Waschen mit TBS ("Tris buffered saline" $=500 \mathrm{mM} \mathrm{NaCl} ; 20 \mathrm{mM}$ Tris/HCl pH 7,5) entfernt

III.) Inkubation mit Sekundär-Antikörper

Zur Sichtbarmachung der Antigen/Antikörper-Reaktion wurde für $2,5 \mathrm{~h}$ mit einem Sekundär-Antikörper inkubiert, abhängig von der zu erwartenden Proteinmenge wurde mit AP- oder bei sehr geringen Proteinmengen mit dem für das empfindlichere ECL-System benötigten Peroxidase-Konjugat inkubiert:

A.) Alkalische-Phosphatase-gekoppeltes Anti-Kaninchen IgG (goat anti rabbit IgG; Fa. Bio Rad) in einer 1: 1500 Verdünnung in TBS. -oder-

B.) Meerrettich-Peroxidase-gekoppeltes Anti-Kaninchen IgG (goat-anti-rabbit IgG; Fa. Amersham) in einer 1:2000 Verdünnung in TBS.

Ungebundener Antikörper wurde durch $5 \times 10$ min Waschen mit TBS entfernt.

\subsubsection{Nachweis mit alkalischer Phosphatase}

Die an den Sekundär-Antikörper konjugierte Phosphatase setzt BCIP (Bromchlor-indolyl-phosphat) mit NBT (Nitroblau-Tetrazolium) zu einem unlöslichen Farblack um, der sich auf der NC-Folie niederschlägt und das Antigen damit sichtbar macht. Die Reaktion erfolgte in einem alkalischen Puffer $(100 \mathrm{mM}$ $\mathrm{NaHCO}_{3} ; 1 \mathrm{mM} \mathrm{MgCl} ; \mathrm{pH} 9,8$ mit $\mathrm{NaOH}$ ), dem auf $100 \mathrm{ml}$ zugesetzt waren:

$-1 \mathrm{ml} 3 \% \mathrm{NBT}$ (Fa. Biomol) in $70 \%$ DMF

$-1 \mathrm{ml} 1,5 \%$ BCIP (Fa. Biomol) in $100 \%$ DMF

Die Entwicklungszeit erfolgte entsprechend der eingesetzten Proteinmenge und betrug 1-6 h (0,5-64 h min/max). 


\subsubsection{Peroxidase/Enhanced Chemiluminescence}

Der Nachweis beruht auf Umsetzung eines bei Zerfall Licht emittierenden Substrates durch die an den Sekundär-Antikörper gekoppelte Peroxidase. Die Lokalisation des Antigens entspricht der Schwärzung eines an der dieser Stelle entsprechend belichteten Films. Die Durchführung des Nachweises durch Chemolumineszens erfolgte gemäß der Arbeitsvorschrift des Herstellers (Enhanced ChemiLuminescence (ECL)-Kit; Film: Hyperfilm-ECL; Fa. Amersham-Buchler, Braunschweig).

\subsubsection{Molekulargewichtsbestimmung}

Die Bestimmung der Molekulargewichte der elektrophoretisch aufgetrennten Proteine erfolgte in Gradienten-Gelen durch gleichzeitige Elektrophorese von Proteinen bekannten Molekulargewichts. Als Proteingewichtsmarker dienten low molecular weight Proteinstandards mit einem Molekulargewicht von 14,4; 20,1; 30; 43; 67; 94 kDa (LMW Calibration Kit, Pharmacia Biotech, Schweden). Die Festlegung der Rf-Werte und Bestimmung der Molekulargewichte der Proteine folgten einer Anweisung der Fa. Pharmacia.

\subsection{Erstellung einer 2D-Proteinverteilungskarte}

Zur Erstellung einer zweidimensionalen Verteilungskarte (horizontal: Verteilung nach isoelektrischem Punkt; vertikal: Verteilung nach Molekulargewicht der Proteine) wurden folgende 2D-Gele ausgewertet:

-Plasmamembran nach Ernte (100.000 x g Zentrifugation); 1x gewaschen mit $200 \mathrm{mM} \mathrm{NaCl}$

-PM durch Triton X114 zweiphasenverteilt: Detergenzphase (=hydrophobe Proteine)

-PM durch Triton X114 zweiphasenverteilt: Wäss. Phase

(=hydrophile Proteine + cytosol. Verunreinigungen)

Die Gele wurden mit Silber gefärbt und unmittelbar nach Fixierung digital aufgenommen und mit dem 2D-Analysis Programm BASys (BioTec-Fischer, Reiskirchen, Deutschland) sowie Corel Photo Paint (Graphische Entzerrung und Erzeugung von Falschfarbenbildern der Scans) ausgewertet. Bei den radioktiv markierten Proteinen wurde sowohl der Silverstain des getrockneten Geles als auch dessen Autoradiographie eingescannt. Zur Erhöhung der Auswertungssicherheit wurden nicht spezifizierte Referenzproteine festgelegt, die aufgrund ihrer distinkten Lage (z.B. Extrema im $\mathrm{pH}$, oder spezifischen Farbabweichung (gelb, schwarz) der silbergefärbten Proteine, oder mithilfe eines Antikörpers sicher zu identifizieren waren. Zur Immunodetektion herangezogen wurde die Plasmamambran-gebundene NR oder die als cytosolische Verunreinigung auftretende cytosolische NR. Diese Proteine dienten in der Konstruktion der 2D-Protein-Verteilungskarten als Ankerpunkte. Quantitative und qualitative Unterschiede im Auftreten der Proteine wurden durch subtraktive Überlagerung der einzelnen Images sichtbar gemacht. 


\subsection{Ansequenzierung ausgewählter PM-Proteine}

Die zur Peptid-Sequenzierung ausgewählten Proteine wurden zur quantitativen Gewinnung in "large scale"-IEF-Gelstäben in der ersten Dimension und in „großen“ 7,5-20 \% SDS-PAGE-Gradientengelen in der zweiten Dimension aufgetrennt. Die Proteine wurden anschließend auf PVDF-Membran geblottet und mit Coomassie angefärbt (s.o.). Die entsprechenden Proteinspots wurden mit einem Skalpell aus dem 2D-Blot ausgeschnitten und an die Gesellschaft für Biologische Forschung in Braunschweig gesandt. Dort erfolgte ein schrittweiser Abbau der jeweils C-terminalen Aminosäure des fraglichen Proteins („EdmanDegradation") und anschließende HPLC-Auftrennung der mit jedem Degradationsschritt freigesetzten Aminosäure(n) und deren Identifikation über die Retentionszeit auf der Säule. Über Datenbankvergleich (Swiss-Prot) wurden die ermittelten Peptidsequenzen auf Homologien zu bekannten Proteinen überprüft.

\subsection{Herstellen von polyklonalen Antikörpern}

\subsubsection{Datenbankrecherche zu Nitrat-Transporter-Aminosäuresequenzen}

Auf der Basis der Aminosäuresequenzen von allen bekannten putativen $\mathrm{NO}_{3}$ Transportern in höheren und niederen Pflanzen wurden mit dem multiple alignment Programm „multalign“ (Network Proteinsequenz-Analysis des Pòle Bio-Informatique, Lyon) die zwischen allen Transportern am höchsten konservierten Aminosäure-Sequenzen ermittelt. Mit dem Program „TopPred2“ (Theoretical Chemistry Protein Prediction Server der Universität Stockholm) wurde eine topologische Vorhersage der wahrscheinlichsten räumlichen Konfiguration der aus den verschiedenen Transportern zusammengestellten Aminosäuresequenz erstellt. Für diese Aminosäuresequenz wurden die jeweils zwischen allen Transportern häufigsten Aminosäuren je Position ausgewählt. Der erhaltene Plot zeigte die wahrscheinliche Lage und Orientierung (transmembranär/innen/außen) gemäß beta-Faltblatt- oder alpha-helikaler Struktur der Aminosäuresequenz einschließlich der höchstkonservierten Regionen. Darauf basierend wurden drei Bereiche der höchstkonservierten Regionen zur Peptidsynthese ausgewählt, diese lagen in ihrer Orientierung extracytosolisch und transmembranär sowie intracytosolisch.

\subsubsection{Peptidsynthese}

Die zur Peptidsynthese als hochkonservierte Motive ausgewählten Aminosäuresequenzen (gemäß Einbuchstaben-Code) waren

Sequenz $1\left(\mathrm{NH}_{2}\right)$ WGNMGGGATQLIMPL $(\mathrm{COOH})$

Sequenz $2\left(\mathrm{NH}_{2}\right)$ RPTGGMISDL $(\mathrm{COOH})$

Sequenz $3\left(\mathrm{NH}_{2}\right)$ RAYGIISGLVGAGGN $(\mathrm{COOH})$

Die ausgewählten Peptid-Sequenzen wurden von Dr. M. Benli bei der Fa. BioScience Göttingen synthetisiert, der garantierte Reinheitsgrad betrug mindestens 70 \%. Es wurde eine Kopplungsreaktion (KLH) der Peptide mit 
Cystein durchgeführt, eine Länge von 15 AS wurde nicht überschritten (Empfehlung Dr. Benli).

\subsubsection{Immunisierung und Antikörpergewinnung}

Mit einem Peptidgemisch der drei verschiedenen Peptide wurden 2 Kaninchen \# 29 und \# 58 immunisiert, vor Erstinjektion wurde Prä-Immunserum abgenommen. Nach 4 Wochen wurde Immunserum („first bleeding“) abgenommen, es wurde eine weitere („boost“-) Injektion durchgeführt und nach 12 Wochen nach Erstinjektion erneut Immunserum („second bleeding“) abgenommen; geliefert wurde das Blutserum. Kaninchen \# 29 starb vor dem Zeitpunkt des $2^{\text {nd }}$ Bleeding. Ein 8 Wochen nach Erstimmunisierung von \# 29 und 58 immunisiertes, drittes Kaninchen \# 119 (als Ersatz für \# 29) starb ebenfalls vor dem $2^{\text {nd }}$ Bleeding. Insgesamt wurden gewonnen: Drei PräImmunseren sowie drei Seren \# 29; \# 58; \# 119; nur von \# 58 wurde $2^{\text {nd }}$ Bleeding gewonnen.

Die Immunseren wurden in einer Verdünnung von 1:2000 bis 1:5000 Serum/Blocking-Lsg. eingesetzt, detektiert wurde mit alk. Phospatase konjugierten Goat-anti-Rabbit IgG.

\subsubsection{Dot Blot}

Zur Überprüfung der Seren hinsichtlich Peptid-Spezifität und einzusetzendem Serum-Titer wurden Verdünnungsreihen der o.g. Peptide angelegt. Dazu wurde eine NC-Folie (NC-40, Fa. Sartorius) trocken in eine 96-Loch Dot BlotApparatur von Schleicher und Schuell eingespannt. Von den Peptiden wurden Verdünnungsreihen angelegt: $10 \mu \mathrm{g} ; 1 \mu \mathrm{g} ; 0,1 \mu \mathrm{g} ; 0,01 \mu \mathrm{g}$ pro $\mathrm{ml}$ in 1:500 verdünntem SDS-Beladungspuffer. Aliquots von 100 $\mu$ l wurden in die Löcher der Apparatur eingebracht und mit einer Wasserstrahlpumpe hindurchgesaugt. Die Proben wurden nachgespült mit 2 × $500 \mu$ 1:500 verdünntem SDSBeladungspuffer. Beladen wurden acht Zeilen, aufgeladen wurden in der Horizontalen (je Zeile): 1; 0,1;0,01, 0,001 $\mu$ g Peptid I; 1; 0,1; 0,01, 0,001 $\mu \mathrm{g}$ Peptid II; 1; 0,1;0,01, 0,001 $\mu \mathrm{g}$ Peptid III. Die mit den insgesamt 96 Dots beladene NC-Folie wurde in 1:500 verdünntem SDS-Beladungspuffer äquilibriert und die freien Bindungsstellen mit Protein-Lösung (Blocking) abgesättigt. Der Blot wurde in vier Streifen je zwei Zeilen zerschnitten. Die Streifen (zwei Zeilen Peptide I-III) wurden mit unterschiedlichen ImmunserumKonzentrationen in Blockinglösung inkubiert: a.) 1:500; b.) 1:2500; c.) 1:5000; d.) 1:10000. Die Streifen wurden $4 \mathrm{~h}$ inkubiert, $5 \mathrm{x}$ mit TBS in großem Überschuß gewaschen und für $3 \mathrm{~h}$ in 1:3000 verdünntem sekundärem, alk. Phosphatase-konjugiertem Antikörper Goat-anti-Rabbit-IgG inkubiert. Nach $5 \mathrm{x}$ Waschen mit TBS erfolgte die Visualisierung durch NBT/BCIP-Umsetzung in Phosphatase-Puffer (s.o.). 


\subsection{PCR}

\subsubsection{RT-PCR}

Zur Gewinnung der Gesamt-RNA wurden N-veramte Algen wie unter 2.7 beschrieben $\mathrm{NO}_{3}^{-}$-induziert und die 20 min und 45 min-induzierten Ansätze wieder vereinigt. Dies sollte sicherzustellen, ausreichende Mengen von $\mathrm{NO}_{3}^{-}-$ induzierten Transkripten aufzuarbeiten. Die RNA wurde mit sowohl mit TRIZOLReagenz (GibcoBRL) gemäß Herstellerangaben isoliert, als auch mit Z6-Puffer. Die Intaktheit der RNA wurde durch Elektrophorese von Aliquots der RNA kontrolliert.

\subsubsection{Extraktion der RNA}

Zur RNA-Isolierung wurden Algen für 10 Tage in $\mathrm{NH}_{4}-\mathrm{NL}$ herangezogen und 18 $\mathrm{h}$ vor der Ernte in -N-NL überführt. Die Algen wurden für 20 bzw. $45 \mathrm{~min}$ mit $\mathrm{NO}_{3}$ im Lichtthermostaten induziert, abzentrifugiert und in eiskaltem Z6-Puffer mit $1 \%$ ß-Mercaptoethanol im Verhältnis 1:2 FG:Vol Z6 aufgenommen. Zum Aufbrechen der Algen wurde die Suspension in sterilisierte, mit flüssigem $\mathrm{N}_{2}$ gefüllte Mörser eingetropft und die gefrorenen Tropfen zermahlen. Das erhaltenen Pulver wurde in Mikroreagiergefäße überführt, diese zu dreiviertel gefüllt und mit $1 \mathrm{ml}$ Phenol/Chloroform/lsoamylalkohol (25/24/1; pH 7,5) versetzt und auf Eis aufgetaut, 1 min gevortext, 10 min auf Eis inkubiert und die wässrige, RNA-haltige Phase durch Zentrifugation bei 13000 Upm und RT in einer Tischzentrifuge abgetrennt. Die wässrige Phase wurde in neue Mikroreagiergefäße überführt, erneut mit Phenol/Chloroform/lsoamylalkohol im Verhältnis 1:1 versetzt, 10 min inkubiert und nach Zentrifugation wieder die obere Phase abgenommen. Nach Zusatz von 1/20 Vol 1M Essigsäure und dem 0,7 fachen Vol Ethanol wurde die RNA ü.N. bei $-20^{\circ} \mathrm{C}$ gefällt.

\subsubsection{Isolierung der polyA-mRNA}

Die gefällte RNA wurde für 20 min mit 13000 Upm bei RT abzentrifugiert, der Überstand verworfen und das Pellet zur Entfernung von Kohlenhydraten mit jeweils $150 \mu \mathrm{l} 3 \mathrm{M} \mathrm{NaAc}$ gewaschen, erneut für $10 \mathrm{~min}$ bei RT abzentrifugiert und verbliebenes Salz durch Waschen mit $150 \mu \mathrm{l} 70$ \%igem Ethanol entfernt. Nach Ablaufenlassen des überschüssigen Ethanols und vorsichtiger Trocknung wurden die Pellets mit $150 \mu$ l sterilem Wasser aufgenommen, vorsichtig geschüttelt und nach Erhitzen auf $65^{\circ} \mathrm{C}$ mehrfach langsam in einer sterilen Einmalspritze aufgezogen. Die Konzentration und Reinheit der gelösten RNA wurde photometrisch bei den Wellenlängen 260 und $280 \mathrm{~nm}$ bestimmt und die Intaktheit durch ein Formaldehyd-Agarose-Gel überprüft. Dazu wurden jeweils $10 \mu \mathrm{g}$ der RNA mit $15 \mu \mathrm{l}$ RNA-Farbmix versetzt, für $10 \mathrm{~min}$ bei $65^{\circ} \mathrm{C}$ denaturiert, 2 min auf Eis gestellt und gegen ein Molekulargewichtsmarkergemisch der Fa. Invitrogen mit $90 \mathrm{~V}$ über 2,5 h elektrophoretisch aufgetrennt. 
Formaldehyd-Agarose-Gelelektrophorese (nach Sambrook et al.,1989)

\begin{tabular}{|c|c|c|}
\hline & $50 \mathrm{ml}$ & $100 \mathrm{ml}$ \\
\hline $1 \%$ Agarose & $0,5 \mathrm{~g}$ & $1 \mathrm{~g}$ \\
\hline aldehyd, $37 \%$ & $9 \mathrm{ml}$ & $18 \mathrm{ml}$ \\
\hline $10 \times$ Running buffer & $5 \mathrm{ml}$ & $10 \mathrm{ml}$ \\
\hline
\end{tabular}

$10 \times$ Running buffer

$\begin{array}{lrr}\text { MOPS } & 200 & \mathrm{mM} \\ \text { NaAc } & 80 & \mathrm{mM} \\ \text { EDTA pH 8 } & 10 & \mathrm{mM}\end{array}$

Zur Isolierung der mRNA wurden spun columns aus einem mRNA purification kit (Pharmacia) verwendet, die Isolation erfolgte entsprechend den Herstellerangaben, statt der im Kit empfohlenen 0,25 ml Waschpuffer wurde mit $0,5 \mathrm{ml}$ gewaschen. Die $\mathrm{NO}_{3}{ }^{-}$-induzierten Ansätze wurde vor der Isolierung der mRNA vereinigt. Die erhaltene mRNA wurde mit $70 \%$ igem Ethanol bei $-20^{\circ} \mathrm{C}$ ü.N. gefällt, bei 13000 Upm und RT abzentrifugiert, getrocknet und die beiden Pellets (Kontrolle und Induziert) in $30 \mu \mathrm{l}$ sterilem $\mathrm{H}_{2} \mathrm{O}$ bid. aufgenommen. Die optische Dichte der mRNA wurde photometrisch bei 260 und $280 \mathrm{~nm}$ bestimmt, eine Gelelektrophorese wurde nicht durchgeführt.

Zur RT-PCR wurde zunächst total-RNA benutzt, führte dies nicht zu einem Ergebnis bzw. zu einer großen Zahl von Produkten in der PCR, wurde mRNA zur RT-PCR eingesetzt.

\subsubsection{PCR: Primer und PCR-Bedingungen}

Die mit PTN beginnend bezeichneten Primer (s.u.) wurden nach Quesada et al. (1997) synthetisiert, die PNR-Primer wurden ebenfalls nach konservierten Regionen der Carrierproteine ausgewählt. Die PENRT-Primer wurden zusätzlich mithilfe des Primersynthese-Programms Oligo 2.0 hinsichtlich ihrer günstigsten Eigenschaften (zur Primerpaarung passender melting point, keine hairpin-loops, kein self-priming etc.) ausgewählt. Alle Primer sind in $5^{\prime}-3^{\prime}$ Richtung aufgeführt. forward primer

$\mathrm{P} 1$ :

P2:

AAC ATG GGT GGC GGC GCA ACG CAG CTC

PNTA: GCC WCC NRI AGG ACG

PNTB: GCI CCI ACI GTI TTY TGY ATG GC

PNTC: CCI CCI CCC ATR TTI CCC CAN CC

PNTD: GCH GCH GGM TGG GGN AAY ATG

PENRTF 2: $\quad$ GBT GYG CNT ACT TYG TNC C

PENRTF 3: $\quad$ GCN CCV GCN GTB TTY TGY ATG 
reverse primer

P3:

PNTE:

AGT CAA ACC GGA HAT HAT GCC

PNTF:

TAC TCD GCD ATN ACR TTR TC

PNTG:

CCD GCR GTT TGN ARD ATC C

PENRTR 10:

CCM ACG TTK CCN CCN GCN CC

PENRTR 20:

CCV ACG TTB CCN CCN GCB CC

PENRTR-M21:

CAT NSR NCC CCA YTG BGG RAA

$(\mathrm{N}=\mathrm{G}, \mathrm{A}, \mathrm{T}, \mathrm{C} ; \mathrm{V}=\mathrm{G}, \mathrm{A}, \mathrm{C} ; \mathrm{B}=\mathrm{G}, \mathrm{T}, \mathrm{C} ; \mathrm{H}=\mathrm{A}, \mathrm{T}, \mathrm{C} ; \mathrm{D}=\mathrm{G}, \mathrm{A}, \mathrm{T} ; \mathrm{K}=\mathrm{G}, \mathrm{T} ; \mathrm{S}=\mathrm{G}, \mathrm{C} ;$ $\mathrm{W}=\mathrm{A}, \mathrm{T} ; \mathrm{M}=\mathrm{A}, \mathrm{C} ; \mathrm{Y}=\mathrm{C}, \mathrm{T} ; \mathrm{R}=\mathrm{A}, \mathrm{G} ; \mathrm{I}=$ Inosin)

Die PCR wurde, abhängig von den eingesetzten primer-Paarungen, unter variierenden Bedingungen hinsichtlich Temperatur und Dauer von annealing (Gradient) und extension sowie der Anzahl der Zyklen und der Primerkonzentrationen durchgeführt. Gemäß PCR-Protokoll von GibcoBRL bzw. Quiagen wurde allgemein folgende Reaktionsansätze eingesetzt:

Qiagen $(\mu \mathrm{l}) \quad$ GibcoBRL $(\mu \mathrm{l})$

\begin{tabular}{|lcc|}
\hline DEPC-treated $\mathrm{H}_{2} \mathrm{O}$ & 30 & 37,5 \\
10x PCR Buffer & - & 5 \\
Q-Solution & 10 & - \\
$25 \mathrm{mM} \mathrm{MgCl} 2$ & - & 3 \\
$10 \mathrm{mM} \mathrm{dNTP} \mathrm{mix}^{*}(0,1-1-5 \mu \mathrm{M})$ & 0,4 & 1 \\
Primer I* & 1,4 & 1 \\
Primer II* $(0,1-1-5 \mu \mathrm{M})$ & 1,4 & 1 \\
cDNA-Template $(\approx 10 \mathrm{ng} / \mu \mathrm{l})$ & 1 & 1 \\
\hline Taq-Polymerase $(5 \mathrm{U} / \mu \mathrm{l})$ & 0,7 & 0,5 \\
\hline Endvolumen & 50 & 50 \\
\hline
\end{tabular}

${ }^{*}$ Primerpaarungen variierend

Die Taq-Polymerase wurde nach Erreichen der Denaturierungstemperatur (94 ${ }^{\circ} \mathrm{C}$ ) separat zugegeben ("hot start"). Die Zyklenzahl betrug abhängig von der Menge des eingesetzten Templates 28-34 Zyklen. Die PCR (Mastercycler gradient, Eppendorf) wurde anfangs grundsätzlich als gradient-PCR durchgeführt zur Ermittlung der idealen annealing-Temperaturen, der Gradient umfasste zunächst in $2^{\circ} \mathrm{C}$-Schritten $56-66^{\circ} \mathrm{C}$ und die PCR anschließend auf die der entsprechenden Paarung optimalen Temperatur eingestellt. Die Parameter Annealing und Elongation wurden wie auch ein increasement der Elongation variiert, bis hinsichtlich Menge und Anzahl der erhaltenen PCR-Produkte möglichst wenig und distinkte DNA-Banden auftraten. Grundsätzlich folgte das Protokoll folgenden Bedingungen: 


\begin{tabular}{|l|l|l|l|}
\hline \multicolumn{3}{|c|}{ PCR-Protokoll } \\
\hline $1 \mathrm{x}$ & $2 \mathrm{~min}$ & Denaturieren & $94^{\circ} \mathrm{C}$ \\
\hline \multirow{3}{*}{$32 \mathrm{x}$} & $1 \mathrm{~min}$ & Denaturieren & $94^{\circ} \mathrm{C}$ \\
\cline { 2 - 4 } & $1 \mathrm{~min}$ & annealing & $56 / 58 / 60 / 62 / 64^{\circ} \mathrm{C}$ (Gradient) \\
\cline { 2 - 4 } & $1 \mathrm{~min}$ & elongation & $72^{\circ} \mathrm{C} ; 3 \mathrm{sec}$ increasemt. \\
\hline \multirow{2}{*}{$1 \mathrm{x}$} & $10 \mathrm{~min}$ & elongation & $72^{\circ} \mathrm{C}$ \\
\hline
\end{tabular}

\subsubsection{Agarose-Gelelektrophorese}

(modifiziert nach Sambrook et al. 1989)

Die DNA wurde in Agarosegelen in einem elektrischen Feld nach der Länge ihrer Fragmente aufgetrennt. Die Konzentration der Agarose wurde je nach der zu erwartenden Größe der Fragmente zwischen 0,7 und 1,5 \% Agarose gewählt, Puffersystem war stets 1 x TAE. Der noch flüssigen Agaroselösung wurde 0,005 \% EtBr zugesetzt; die Detektion der mit dem EtBr interkalierenden DNA erfolgte bei $254 \mathrm{~nm}$ unter UV-Licht. Zur Elektrophorese der erhaltenen PCR-Produkte wurde je ein Aliquot von $10 \mu$ des PCR-Ansatzes mit 1,7 $\mu$ l 6x loading buffer (MBI Fermentas) versetzt, mit $\mathrm{H}_{2} \mathrm{O}$ auf das entsprechende Volumen 1 x Puffer-Konzentration eingestellt und die entsprechende Tasche des Gels eingebracht. Die Elektrophorese wurde mit einer Spannung von ca. 5 V / cm Gel über 2,5 h durchgeführt.

\section{$50 \times$ TAE-Puffer}

Tris/ $\mathrm{HCl} \mathrm{pH} \mathrm{8,0} 40 \mathrm{mM}$

Eisessig $\quad 20 \mathrm{mM}$

EDTA $\quad 1 \mathrm{mM}$

EtBr-Stammlösung: 0,5 \% (w/v) Ethidiumbromid

\subsubsection{Isolierung und Klonierung von PCR-generierten DNA-Fragmenten}

PCR-Produkte, die das zur jeweiligen Primer-Paarung berechnete richtige Molekulargewicht besaßen wurden aus dem Gel unter UV-Licht mit einem Skalpell ausgeschnitten und die DNA durch Glasmilch-Extraktion (Qiagen DNA purification Kit) isoliert. Ein Aliquot davon wurde hinsichtlich Intaktheit und Reinheit erneut durch Elektrophorese in einem Agarosegel wie beschrieben überprüft. Das gereinigte PCR-Produkt wurde in kompetente $\mathrm{E}$. coli Bakterienzellen einkloniert gemäß Herstellerangaben (TOPO Cloning Kit mit "One Shot Cells" von Invitrogen).

\subsubsection{Sequenzierungs-PCR}

Von den auf Kanamycin-Agar gewachsenen und demzufolge mit dem einzubauenden Insert transfizierten TOPO-Cloning One Shot Cells wurde gemäß Herstellerangaben die DNA isoliert. Zur Sequenzierung wurde die DNA entweder zur Fa. Seqlab, Göttingen gesandt, oder im Institut für Humangenetik 
bzw. Institut für Pflanzengenetik sequenziert. Zur Probenvorbereitung wurde 1 $\mu \mathrm{g}$ DNA mit $4 \mu \mathrm{l}$ Reaktionsgemisch (Polymerase; PCR-Puffer, dNTP-Mix und ddNTP-Mix "Big Dye-Terminatoren") versetzt, je $1 \mu \mathrm{l}$ T3 bzw. T7-Primer (10 pmolar) zugegeben und mit DEPC- $\mathrm{H}_{2} \mathrm{O}$ auf $10 \mu \mathrm{l}$ aufgefüllt. Mit Mineralöl überschichtet wurden 30 Zyklen der PCR-Reaktion durchgeführt

\begin{tabular}{|l|l|l|l|}
\hline \multicolumn{3}{|c|}{ PCR-Protokoll } & zur Sequenzierung \\
\hline \multirow{3}{*}{$30 \mathrm{x}$} & $1 \mathrm{~min}$ & Denaturieren & $90^{\circ} \mathrm{C}$ \\
\cline { 2 - 4 } & $1 \mathrm{~min}$ & annealing & $50^{\circ} \mathrm{C}$ \\
\cline { 2 - 4 } & $1 \mathrm{~min}$ & elongation & $60^{\circ} \mathrm{C}$ \\
\hline & $\infty$ & & $4{ }^{\circ} \mathrm{C}$ \\
\hline
\end{tabular}

nach Abschluß der Sequenzierungsreaktion wurde mit $10 \mu \mathrm{LEPC}-\mathrm{H}_{2} \mathrm{O}$ aufgefüllt, die $20 \mu \mathrm{l}$ Endvolumen vollständig in ein $1,5 \mathrm{ml}$ Mikroreagiergefäß überführt, in das $100 \mu \mathrm{l} 95 \% \mathrm{EtOH}$ und $2 \mu \mathrm{l} 3 \mathrm{M}$ Natriumacetat vorgelegt war. Die Fällung wurde durch 15 min Lagerung bei $-20^{\circ} \mathrm{C}$ vervollständigt und die DNA für 15 min bei $13000 \mathrm{Upm}$ (Tischzentrifuge) und $4^{\circ} \mathrm{C}$ abzentrifugiert. Der Überstand wurde verworfen und das Pellet mit $100 \mu \mathrm{l} 70 \% \mathrm{EtOH}$ gewaschen, erneut bei13000 Upm für 5 min bei RT abzentrifugiert und das Pellet bei $65^{\circ} \mathrm{C}$ für 10-15 min getrocknet. Unmittelbar vor Auftrag der Probe auf das Sequenziergel bzw. die -Kapillare wurde die DNA mit $\mathrm{H}_{2} \mathrm{O}$ resuspendiert.

\subsection{Konzentrationsbestimmung von Nukleinsäuren}

Konzentration und Reinheit der DNA in einer Probe wurde durch Messung der Extinktion in einem Spektralphotometer bei den Wellenlängen 230, 260 und 280 nm errechnet.

Die Konzentration doppelsträngiger DNA wird errechnet nach

cDNA $[\mu \mathrm{g} / \mu \mathrm{l}]=(50 \times$ OD260 $\times$ Verdünnungsfaktor $) / 1000$

Die Konzentration von RNA wird errechnet nach

cRNA $[\mu \mathrm{g} / \mu \mathrm{l}]=(42 \times$ OD260 $\times$ Verdünnungsfaktor $) / 1000$

Ein OD260/OD280 -Quotient von < 1,8 zeigt eine Verunreinigung der DNA/RNA mit Proteinen oder Phenolresten; ein OD260/OD230 -Quotient von < 2,0 zeigt eine Verunreinigung der DNA/RNA mit Polysacchariden. OD=optische Dichte. 


\section{ERGEBNISSE}

\subsection{Proteinpräparation und Ausbeute}

\subsubsection{Algenkultur in 300 ml-Glasröhren}

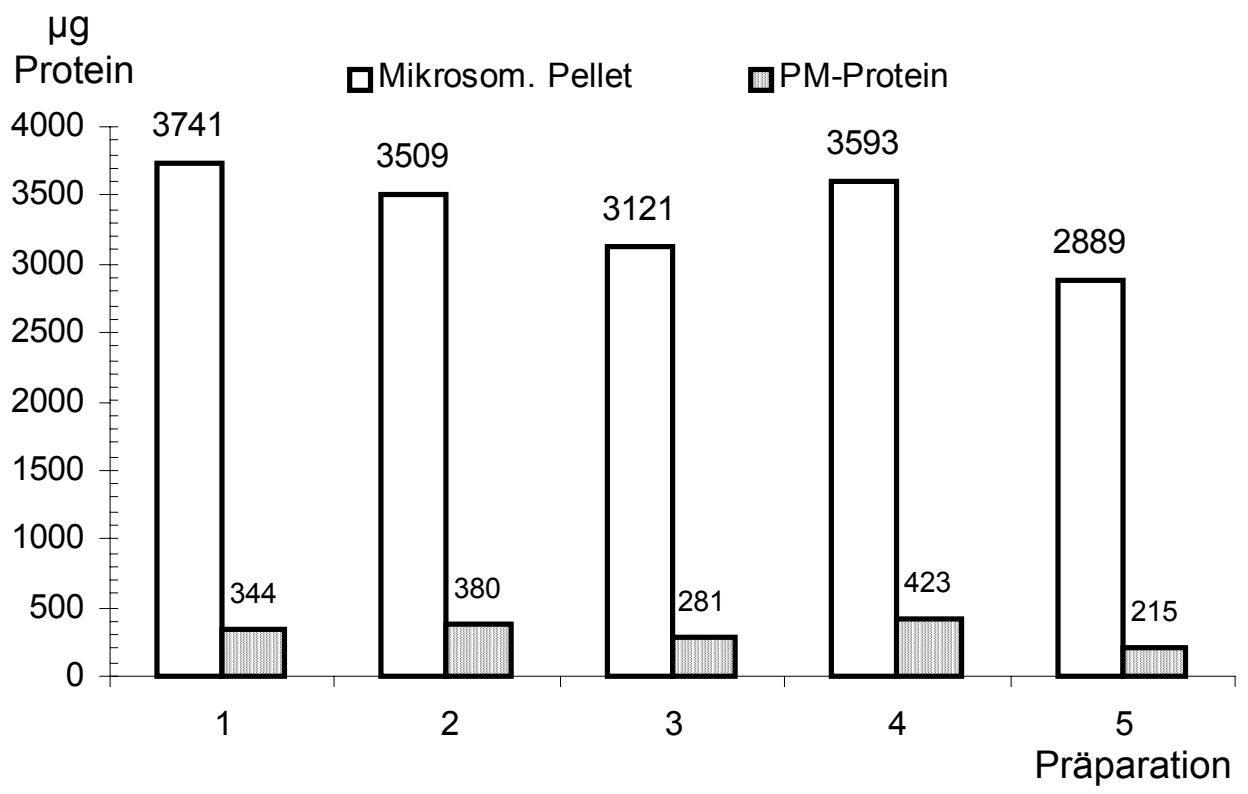

Abb. 1: Ausbeute von Protein im Mikrosomalem Pellet und der Plasmamembran je Liter Zellsuspension ( $10^{10}$ Zellen). Angegeben sind die Proteinmengen von fünf verschiedenen Präparationen unter Verwendung von 8g-PEG/Dextran-Trennsystemen. Beladung je 8g-System: $1000 \mu \mathrm{g}$ Mikrosomales Pellet.

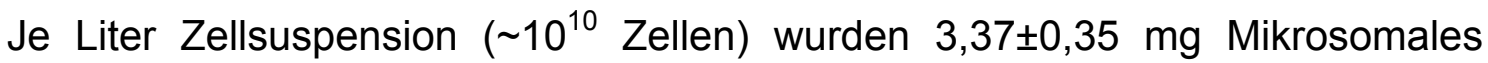
Pellet (MP) gewonnen. Daraus wurden durch PEG/DextranZweiphasenverteilung in $8 \mathrm{~g}$-Systemen $0,328 \pm 0,08 \mathrm{mg}$ Plasmamembran-Protein extrahiert; die Ausbeute an Plasmamembran-Protein aus dem MP betrug $9,65 \pm 1,69 \%$. In einer durchschnittlichen Präparation von 18 Röhren $(5,4$ I) wurden somit 18,201 mg Mikrosomales Pellet (MP) und daraus 1,775 mg Plasmamembran-Protein gewonnen.

\subsubsection{Massenkultur in 4,5 I-Penicillium-Glaskolben}

Zur Gewinnung größerer Mengen Plasmamembran-Proteins wurden die Algen in 4,5 I fassenden Penicillium-Glaskolben (entsprechend 15 Kulturröhren á 300 $\mathrm{ml})$ kultiviert. Entsprechend der größeren Menge Mikrosomalen Pellets wurden 32g-PEG/Dextran-Systeme mit einer 4x höheren Beladungskapazität eingesetzt. Sowohl die Ausbeuten an Mikrosomalem Pellet mit 3,12 $\pm 0,33 \mathrm{mg}$ je Liter, als auch die Menge des daraus gewonnenen Plasmamembran-Proteins sanken geringfügig ab: Es wurden 0,289 $\pm 0,07 \mathrm{mg}$ Plasmamembran-Protein je Liter gewonnen. Dies entsprach 88,1 \% der Ausbeute von PM-Protein durch 8gSysteme. Trotz der geringeren Ausbeute von PM-Protein wurde durch diese Anzucht bei geringerem präparativem Aufwand eine größere PM-Menge je Präparation gewonnen: Bei 13,5 I Algensuspension (Inhalt dreier PenicilliumFlaschen) wurden 42,12 mg Mikrosomales Pellet und daraus 3,902 mg 
Plasmamembran-Protein gewonnen. Das gewonnene Plasmamembran-Protein wurde mit $200 \mathrm{mM} \mathrm{NaCl}$ resuspendiert (,gewaschen“), erneut bei $10^{5} \times \mathrm{g}$ abzentrifugiert und bis zur Verwendung bei $-80{ }^{\circ} \mathrm{C}$ tiefgefroren.

\subsection{Plasmamembran-Proteine in der 2D-SDS-PAGE}

\subsubsection{Optimierung der Detergenz- und Ampholytkonzentration}

Voraussetzung für eine hochauflösende 2D-SDS-PAGE ist eine gute Solubilisierung der Proteine unter reduzierenden Bedingungen und eine trennscharfe Fokussierung über den gesamten, jeweils gewählten $\mathrm{pH}$ Gradienten. In Anlehnung an Dunbar et al. (1990) wurde als nicht-ionisches Detergenz Nonidet P40 eingesetzt und mit dem breitgefächerten pH-Bereich 310 gearbeitet. Zur Optimierung der 2D-Trennleistung wurden sowohl die Konzentration des Detergenzes, wie auch die der Trägerampholyte variiert.

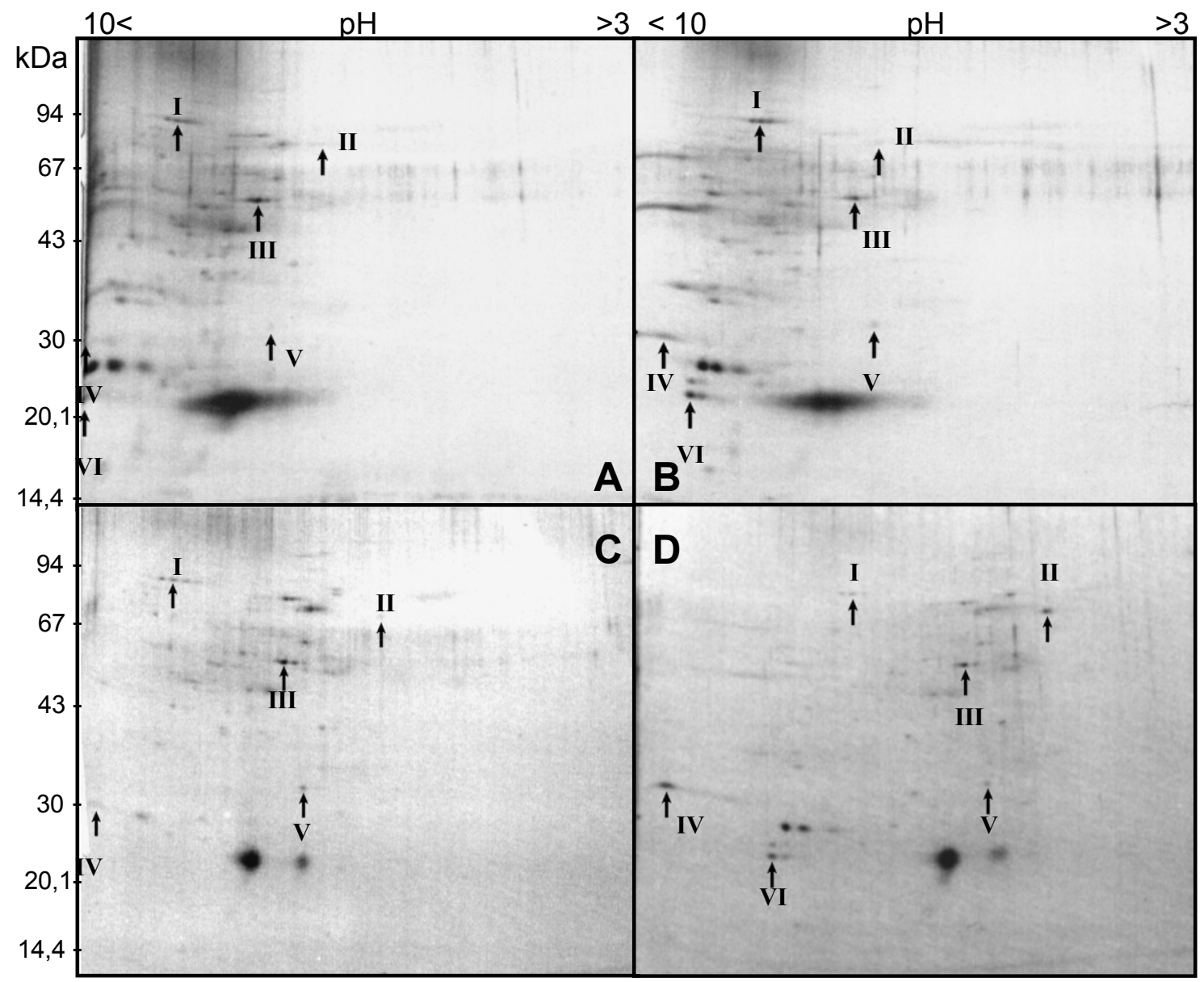

Abb. 2: 2-Dimensionale Gelelektrophorese (2D-SDS-PAGE) von PlasmamembranProteinen bei unterschiedlichen Detergenz- (NP40-) und Ampholytkonzentrationen. Obere Reihe: 4\% NP40; $2 \%$ Ampholyte (A) bzw. $4 \%$ Ampholyte (B).

Untere Reihe: $2 \%$ NP40; $2 \%$ Ampholyte (C) bzw. 4\% Ampholyte (D). Pfeile kennzeichnen die nicht spezifizierten Proteine I-VI und dienen als Referenzpunkte zur Darstellung der Stauchung oder Streckung des $\mathrm{pH}$-Gradienten. Fokussiert wurden jeweils $10 \mu \mathrm{g}$ Plasmamembran-Protein; 2. Dimension: 7,5-20\% SDS-Gradientengel. 
Bei einer Detergenz-Konzentration von 4\% NP40 war das Verteilungsmuster der fokussierten Proteine im basischen Bereich stark gestaucht; die Referenzproteine IV und VI mit betont basischem IEP traten nicht in das Kapillargel ein (A). Bei höherer Ampholytkonzentration fokussierten alle Proteine in das Kapillargel; das Verteilungsmuster blieb im basischen Bereich gestaucht (B).

Bei einer Detergenz-Konzentration von 2\% NP40 war das Verteilungsmuster deutlich weiter über den $\mathrm{pH}$-Gradienten gestreckt, einzelne Proteine fokussierten bei der Ampholytkonzentration von 2\% nicht (siehe Protein $\mathrm{VI}$ in Abb. C). Bei 4\% Ampholyten fokussierten alle Proteine im Gel; ihre Trennung erfolgte in einem über die gesamte Länge des Kapillargels gestreckten $\mathrm{pH}$ Gradienten (D). Die 2D-Gelelektrophorese unter diesen Bedingungen (D) zeigte die beste Trennleistung von Plasmamembran-Proteinen von Chlorella im IEF; die nachfolgenden 2D-Experimente wurden gemäß $D$ durchgeführt.

\subsubsection{Hochauflösende 2D-Gelelektrophorese der Plasmamembran-Proteine}

Ziel bei der Etablierung einer hochauflösenden 2D-Gelelektrophorese der Plasmamembran-Proteine war es, eine eindeutige Zuordnung von am $\mathrm{NO}_{3}{ }^{-}$$/ \mathrm{NH}_{4}{ }^{+}$-Metabolismus beteiligten Proteinen der PM zu gewährleisten. Die 2DSDS-PAGE ermöglichte die Trennung von mehr als 600 Proteinen in einem Gel; nach der Ermittlung der optimalen Detergenz- und Ampholytkonzentration wurde ein 2D-Referenzgel angelegt. Da die 2D-Gelelektropherogramme der PM-Proteine der einzelnen Präparationen untereinander qualitative und quantitative Unterschiede in der Proteinverteilung aufwiesen (nicht gezeigt), wurde ein Gemisch von PM-Proteinen aus sechs verschiedenen Plasmamembran-Präparationen zur Anlage des Referenz-Gels aufgetrennt. Die aufgetrennten Proteine wurden mit Silber gefärbt und zeigten, je nach ihrer Konzentration unterschiedliches Anfärbeverhalten. Einzelne, durch Quantität oder abweichende Färbung (gelb; rötlich) auffällige Proteine wie z.B. ein basisches, in der TX114-Detergenz-Phase angereichertes $30 \mathrm{kDa}$-Protein ermöglichten eine schnelle Auffindung und Orientierung im Elektropherogramm und wurden als Referenzproteine benutzt. Dazu dienten auch in charakteristischer Verteilung auftretende Proteingruppierungen wie bei der Identifizierung der Nitratreduktase gezeigt (siehe 3.5). Bei der Silberfärbung beeinträchtigten die in hoher Konzentration vorliegenden Proteine (,high abundance protein") durch beginnende Überfärbung die Detektion der Proteine geringerer Konzentration, da diese überdeckt wurden oder die Färbung bereits vor inrer Anfärbung abgebrochen werden mußte. Die Trennschärfe des IEFs sank mit steigender Proteinmenge (vergl. Abb. 3 und Abb. 34). Je 1,5 mmKapillargel wurden 50-70 $\mu \mathrm{g}$ PM-Protein aufgeladen. Allerdings trennte das IEF Proteine höherer Konzentration mit nahe beieinander liegendem IEP und Mol.Gewicht nicht mehr in distinkte Proteinspots. Diese Proteine wurden in Vergleichsgelen mit $10 \mu \mathrm{g}$ Protein erfaßt. 


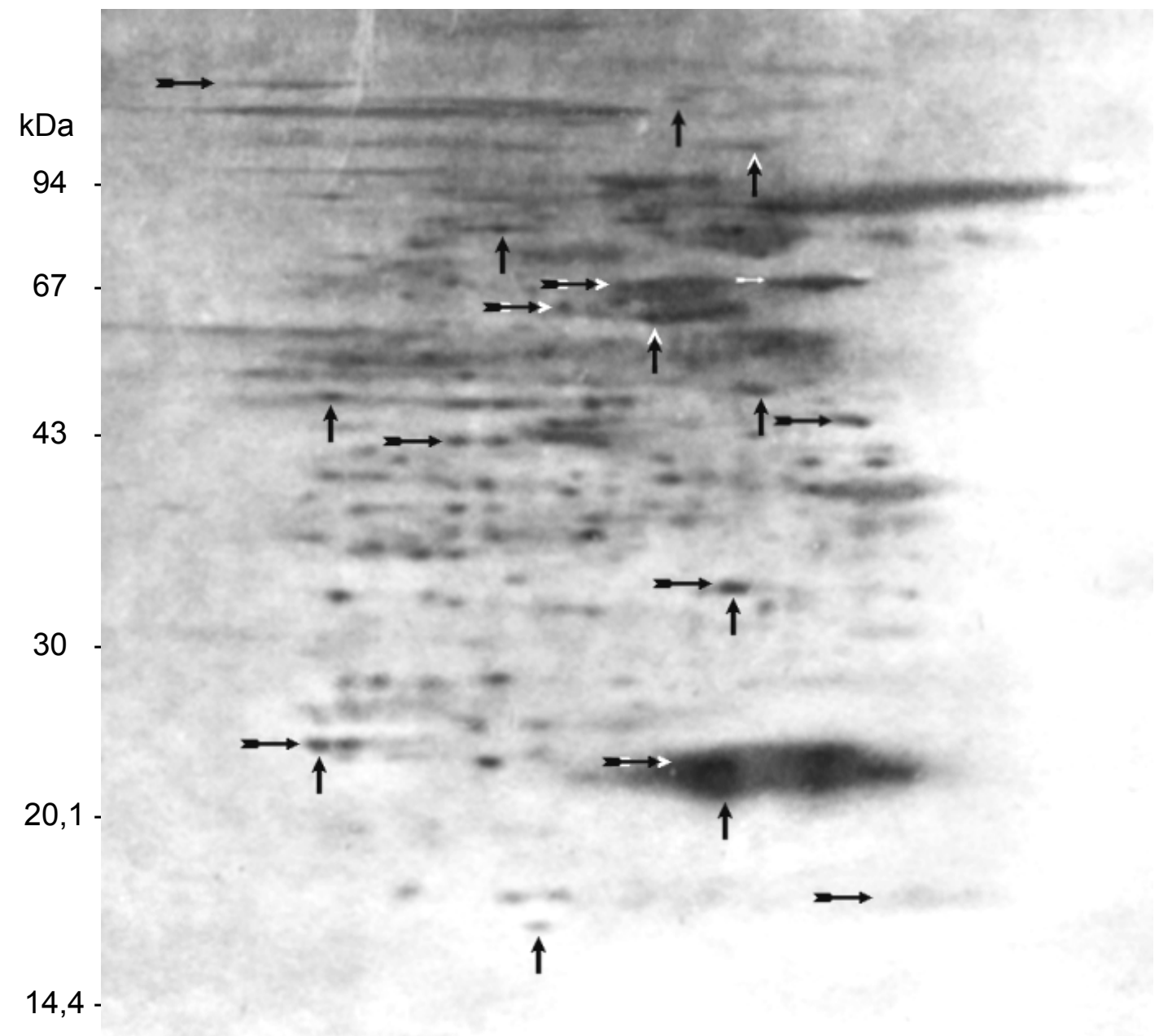

Abb. 3: $70 \mu g$ Plasmamembran-Protein von Chlorella saccharophila nach 2D-SDSPAGE und Silberfärbung. Pfeile markieren als Referenzproteine im Elektropherogramm herangezogene Proteine. Vertikale Pfeile: Referenzprotein in der wässrigen TX114Phase; horizontal: Referenzprotein in der TX114-Detergenz-Phase. Einige Pfeile sind zur Erhöhung des Kontrastes weiß unterlegt

Die 2D-SDS-PAGE von 70ug Plasmamembran-Protein trennte ca. 150 Proteine auf; eng benachbarte Proteine ähnlicher IEPe und Molekulargewichte wurden nicht getrennt (z.B. Anhäufung eng benachbarter Proteine zwischen 60 und 68 $\mathrm{kDa})$. Die Proteine am basischen und sauren Rand des Verteilungsfeldes zeigten eine Tendenz zum Verschmieren, insbesondere bei höheren Molekulargewichten. Mit abnehmender Proteinkonzentration bzw. niedrigerem Molekulargewicht zeigten die Proteine zunehmend eine punktförmige Fokussierung. Die quantitativ häufigsten Proteine waren zwei ineinanderlaufende Proteinspots von $\sim 23 \mathrm{kDa}$ Molekulargewicht.

Das gezeigte Gel bildet das Referenzgel zur Orientierung und Zuordnung der durch TX114-Zweiphasen-Verteilung nach ihren HydrophobizitätsEigenschaften weiter differenzierten PM-Proteine. 


\subsubsection{Hydrophobizität der PM-Proteine: Triton X114-Phasen}

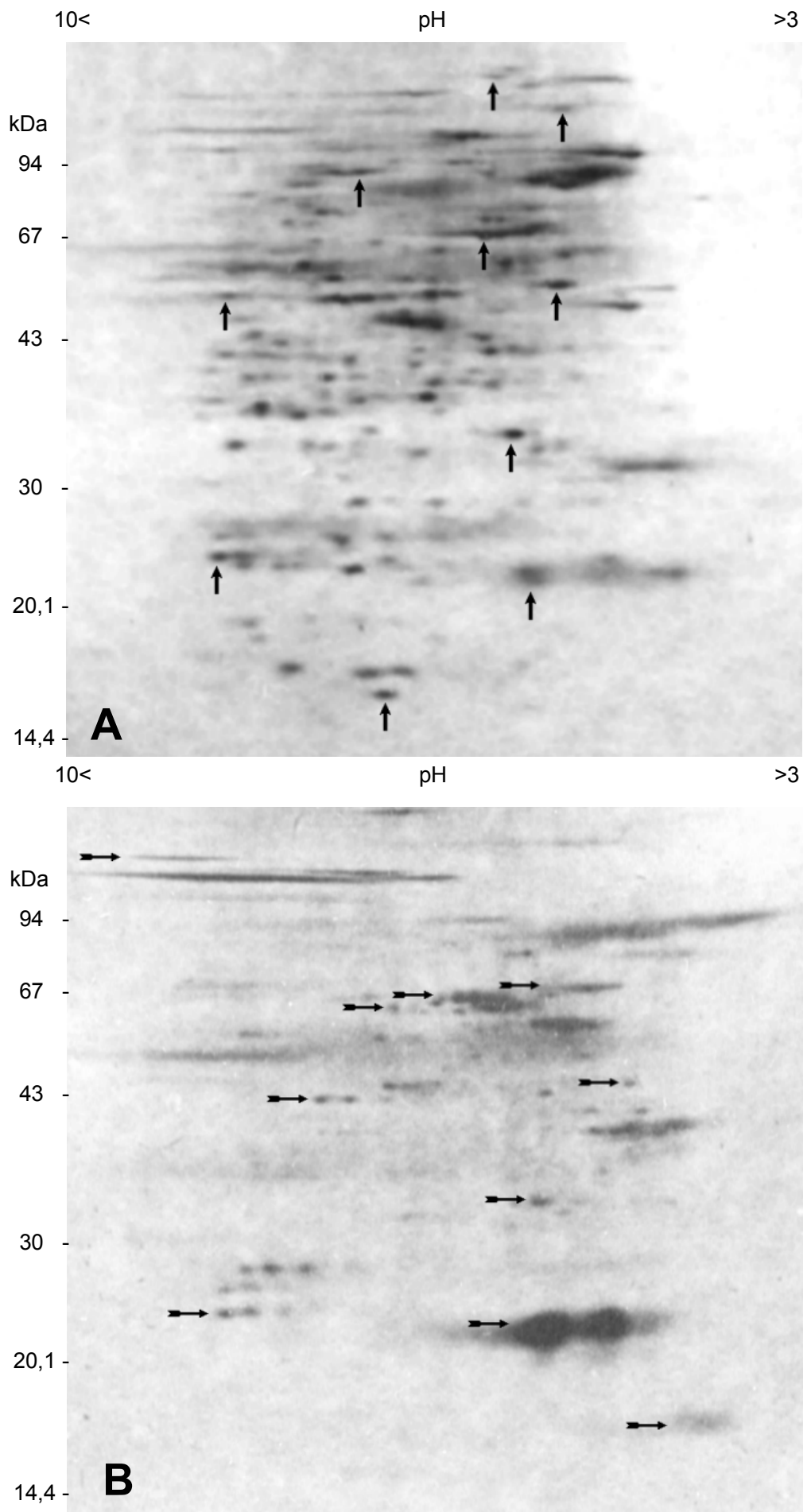

Abb.4: 2D-SDS-PAGE der PlasmamembranProteine nach TX114Zweiphasen-Verteilung. Pfeile bezeichnen die in Abb. 3 gekennzeichneten Proteine und zeigen deren Verteilung in Wässriger- und Detergenz-Phase

A: Hydrophile Proteine der wässrigen Phase des TX-114-Systems

B: Hydrophobe Proteine der Detergenz-Phase des TX-114-Systems

Durch die 2D-SDS-PAGE konnten die Plasmamembran-Proteine beider TritonX114-Phasen, entsprechend ihrer unterschiedlichen Hydrophobizität, aufgetrennt werden. Auch die hydrophoben Proteine der Detergenz-Phase zeigten, abgesehen von Proteinen in den $\mathrm{pH}$-Extrema und hoher Molekulargewichte eine fast punktförmige Fokussierung. Die Referenzproteine aus Abb. 3 konnten gemäß ihrer Verteilung in die entsprechende Phase 
eindeutig identifiziert werden und erlaubten eine Lokalisation der in ihrer Umgebung auftretenden Proteine. Einzelne Proteine zeigten dabei eine Verteilung auf beide Triton-Phasen. Durch Überlagerung von je sechs Elektropherogrammen der einzelnen Phasen konnte ein Verteilungsschema der in innen aufgetrennten Proteine in Form einer zweidimensionalen Verteilungskarte der Proteine erstellt werden.

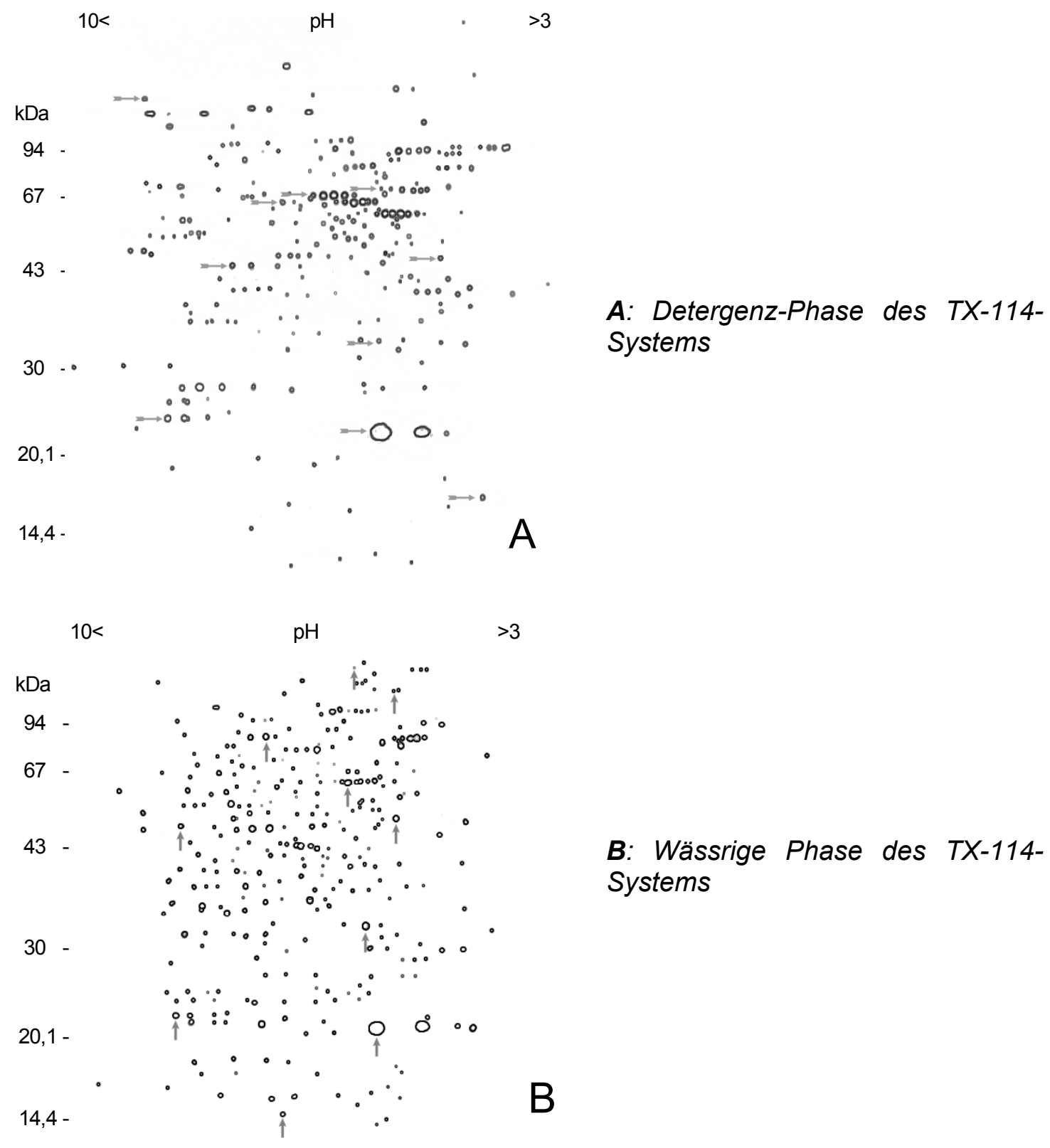

Abb. 5: 2D-SDS-PAGE-Verteilungsschemata der Plasmamembran-Proteine von Chlorella saccharophila nach TritonX114-Verteilung. Pfeile wie in Abb. 3.

Abb. 5 zeigt die schematisierte Verteilung der in den Phasen des TX114Systems enthaltenen Proteine nach 2D-SDS-PAGE. Die Schemata der Proteinverteilung wurden durch die Überlagerung der 2D-Verteilungskarten von sechs unabhängigen 2D-SDS-PAGE der TritonX114-Phasen erstellt. 


\subsubsection{Schema der Proteinverteilung der TritonX114-Phasen in der 2D-SDS- PAGE}

$10<$

$\circ \mathrm{pH}$

$>3$

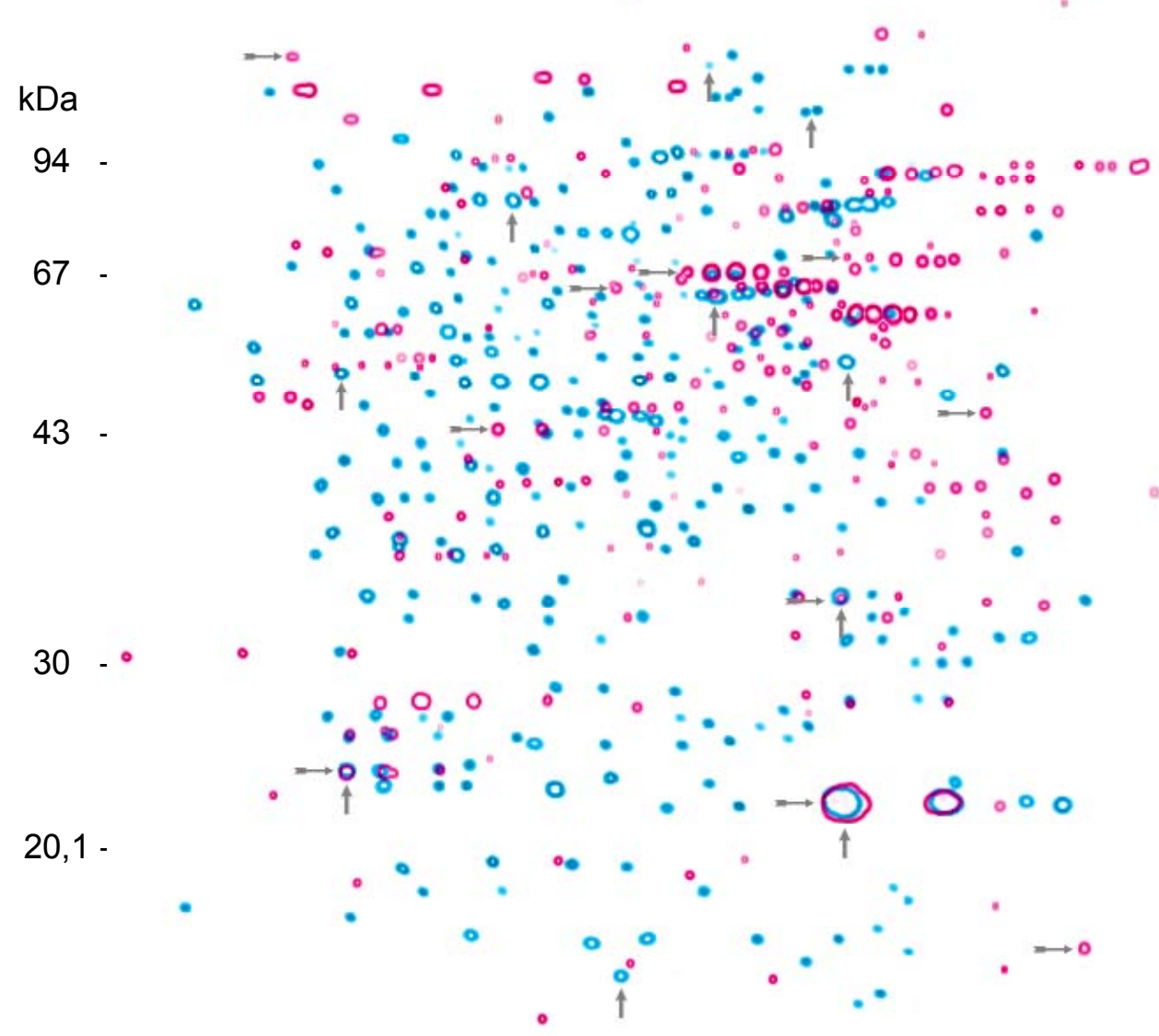

14,4

Abb. 6: 2D-Verteilungsschema (2D-Karte) der Plasmamembran-Proteine, aufgetrennt nach Hydrophobizitäteigenschaften im TritonX114-Phasensystem. Magenta: Proteine der TX114-Detergenz-Phase; Blau: Proteine der wässrigen Phase. Pfeile markieren die in Abb. 3 gekennzeichneten Proteine.

Die in Abb. 3 gezeigte 2D-SDS-PAGE der silbergefärbten Proteine wurde in einem Schema mit hoher Trennschärfe rekonstruiert. Alle häufigen Proteine der Plasmamembran von Chlorella saccharophila konnten, nach dem TritonX114System verteilt, in der 2D-Karte wiedergefunden und zugeordnet werden. Dies bildete die Voraussetzung für die nachfolgenden Experimente. In beiden TritonX114-Phasen auftretende (amphiphile) Proteine wurden zweifarbig überlagernde Proteinspots sichtbar. 


\subsection{Einfluß der Stickstoff-Quelle: ${ }^{35}$ S-Methionin in vivo markierte PM- Proteine}

Ziel der $\mathrm{NO}_{3}$-Induktionsexperimente war die Auffindung von spezifisch $\mathrm{NO}_{3}$ induzierbaren Proteinen in der Plasmamembran. Dazu wurden in Gegenwart von $\mathrm{NO}_{3}$ sowie ${ }^{35} \mathrm{~S}$-Methionin neu gebildete und radioaktiv markierte Proteine durch TX114 nach Hydrophobizitäts-Eigenschaften getrennt und nach 2D-SDSPAGE in der 2D-Karte zugeordnet.

\subsubsection{Einbau des ${ }^{35}$ S-Methionins}

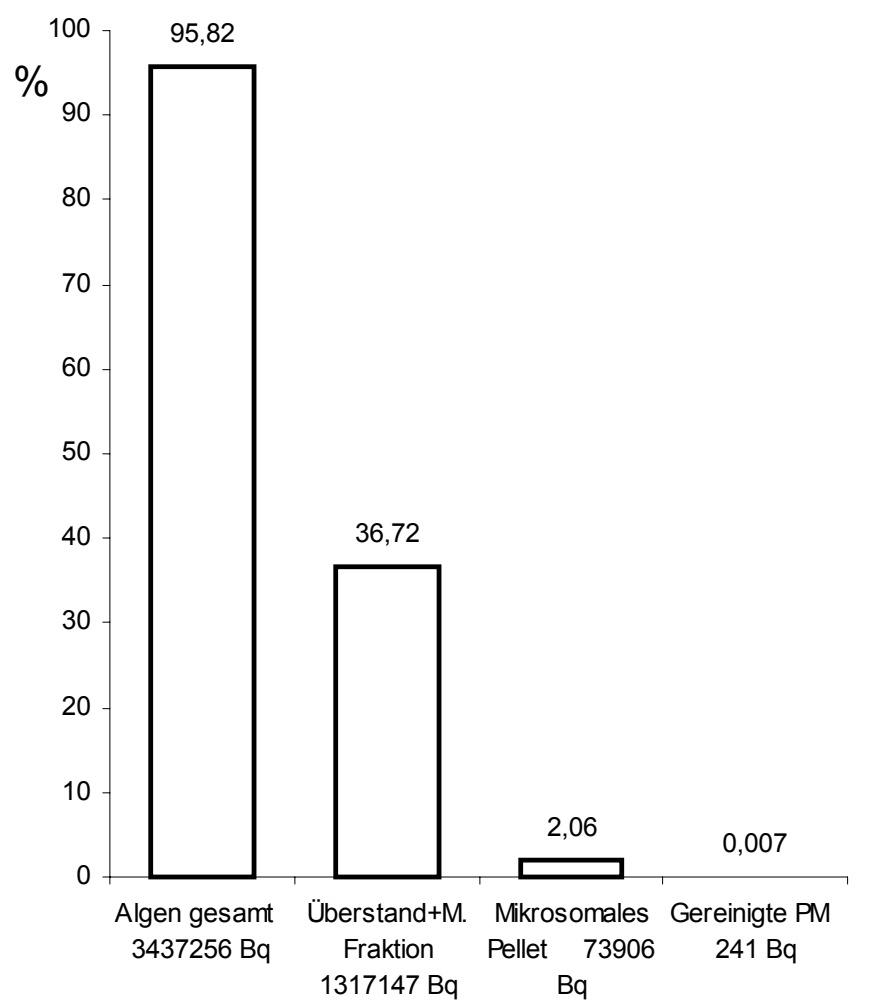

Abb. 7: Radioaktivität des ${ }^{35} \mathrm{~S}$ Methionins in den einzelnen Präparationsschritten der Plasmamembran-Gewinnung. Angegeben ist die insgesamt enthaltene Radioaktivität der einzelnen Fraktionen. Sie ist als prozentualer Anteil an der zu Induktionsbeginn eingesetzten Aktivität $(3,587 \mathrm{MBq}=100 \%)$ angegeben. Dargestellt sind gemittelte Werte aller Ansätze $\left(\mathrm{NO}_{3} ; \mathrm{NH}_{4}^{+} ;\right.$Kontrolle). Für die gereinigte $P M$ ist eine Einzelbestimmung des $\mathrm{N}$-freien Kontrollansatz angegeben

$3 \mathrm{~h}$ nach Induktion mit $\mathrm{NO}_{3}$ wurden im Algenpellet 3,437 MBq gemessen; dies entsprach 95,82 \% der Aktivität des insgesamt zugesetzten ${ }^{35}$ S-Methionins $(3,587 \mathrm{MBq}=100 \%)$. Nach Aufbruch der Protoplasten im Resuspensionspuffer (Überstand mit Cytoplasma und Mikrosomaler Fraktion) wurden 1,317 MBq und damit $36,72 \%$ der ursprünglichen Aktivität in dieser Fraktion bestimmt. Im Mikrosomalen Pellet wurde eine Aktivität von $73,9 \mathrm{kBq}$ gemessen, entsprechend $2 \%$ der ursprünglichen Aktivität. In der daraus präparierten Plasmamembran waren $241 \mathrm{~Bq}$ und damit $0,007 \%$ der ursprünglich eingesetzten Radioaktivität enthalten. Insgesamt wurden je Ansatz ca. 80 $\mathrm{gg}$ Plasmamembran-Protein gewonnen. 


\subsubsection{PM-Proteine der wässrigen Phase des TX114-Systems}

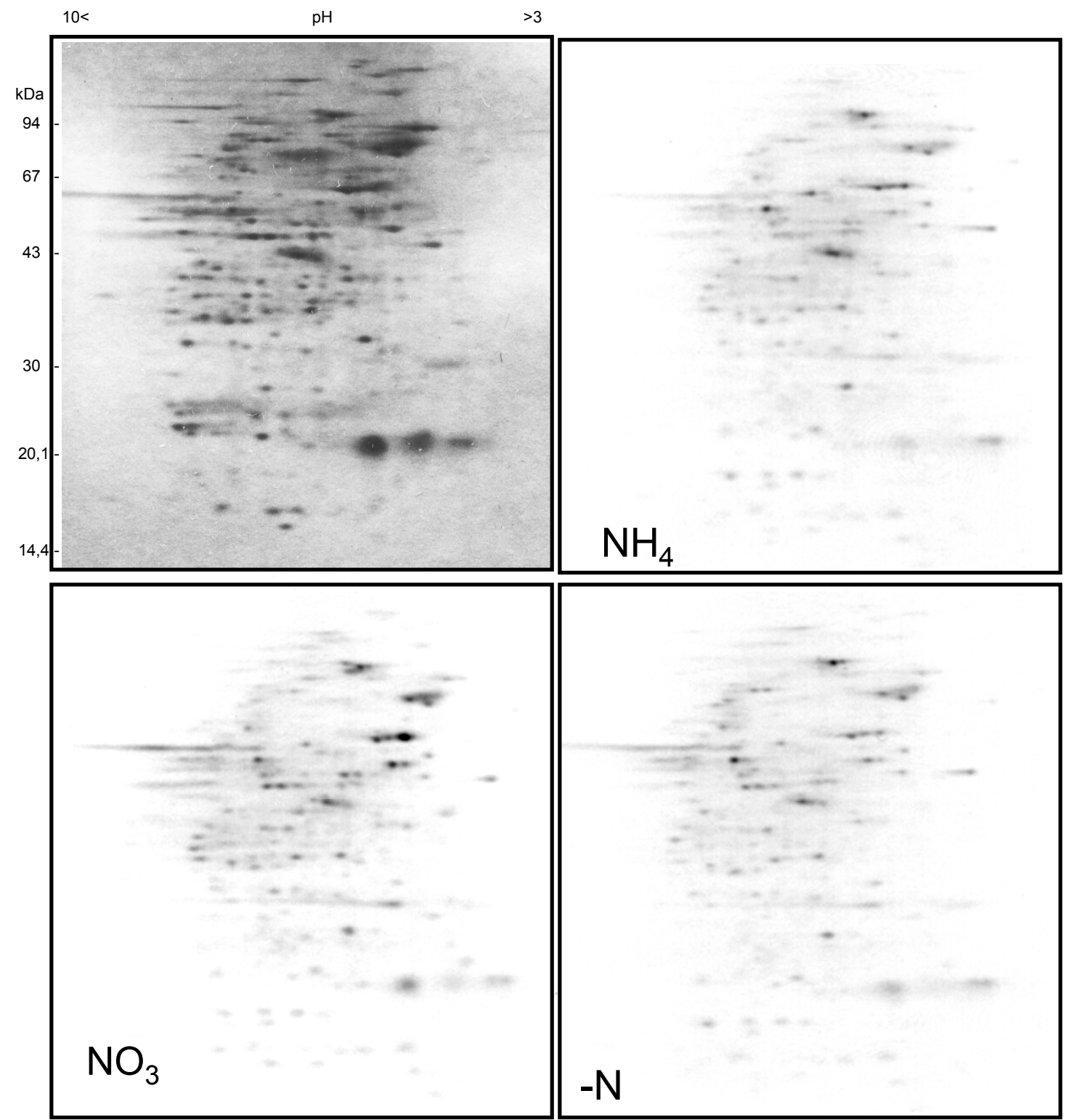

Abb. 8: 2D-SDS-PAGE der Plasmamembran-Proteine der wässrigen Phase (WP) des TX114-Systems nach Induktion mit $\mathrm{NO}_{3}{ }^{-}$in Gegenwart von ${ }^{35}$ S-Methionin: Silberfärbung des Gels (oben links; gezeigt: $\mathrm{NO}_{3}{ }^{-}$) und Autoradiographien der ${ }^{35} \mathrm{~S}$ markierten Proteine der WP der Ansätze $\mathrm{NO}_{3}^{-}, \mathrm{NH}_{4}^{+}$und Kontrolle (-N).

Die Autoradiographien der nach N-Mangel mit verschiedenen Stickstoffquellen induzierten Algen zeigten eine große Zahl ${ }^{35}$ S-Methionin-markierter Plasmamembran-Proteine in der wässrigen Phase des TX114-Systems. Dies galt auch für den $\mathrm{N}$-freien Kontrollansatz. Markierte Proteine traten über den gesamten Molekulargewichtsbereich auf. Um alle radioaktiv markierten PMProteine der wässrigen Phase zu erfassen und diese in der 2D-Proteinkarte zuzuordnen, wurden zunächst die Autoradiographien und silbergefärbten Gele von Kontrolle, $\mathrm{NH}_{4}{ }^{+}$und $\mathrm{NO}_{3}{ }^{-}$graphisch überlagert. Qualitative und quantitative Unterschiede der autoradiographischen Signale siehe Kapitel 3.3.9. 


\subsubsection{Lokalisation der ${ }^{35} \mathrm{~S}$-markierten Proteine der WP in der 2D-SDS- PAGE}

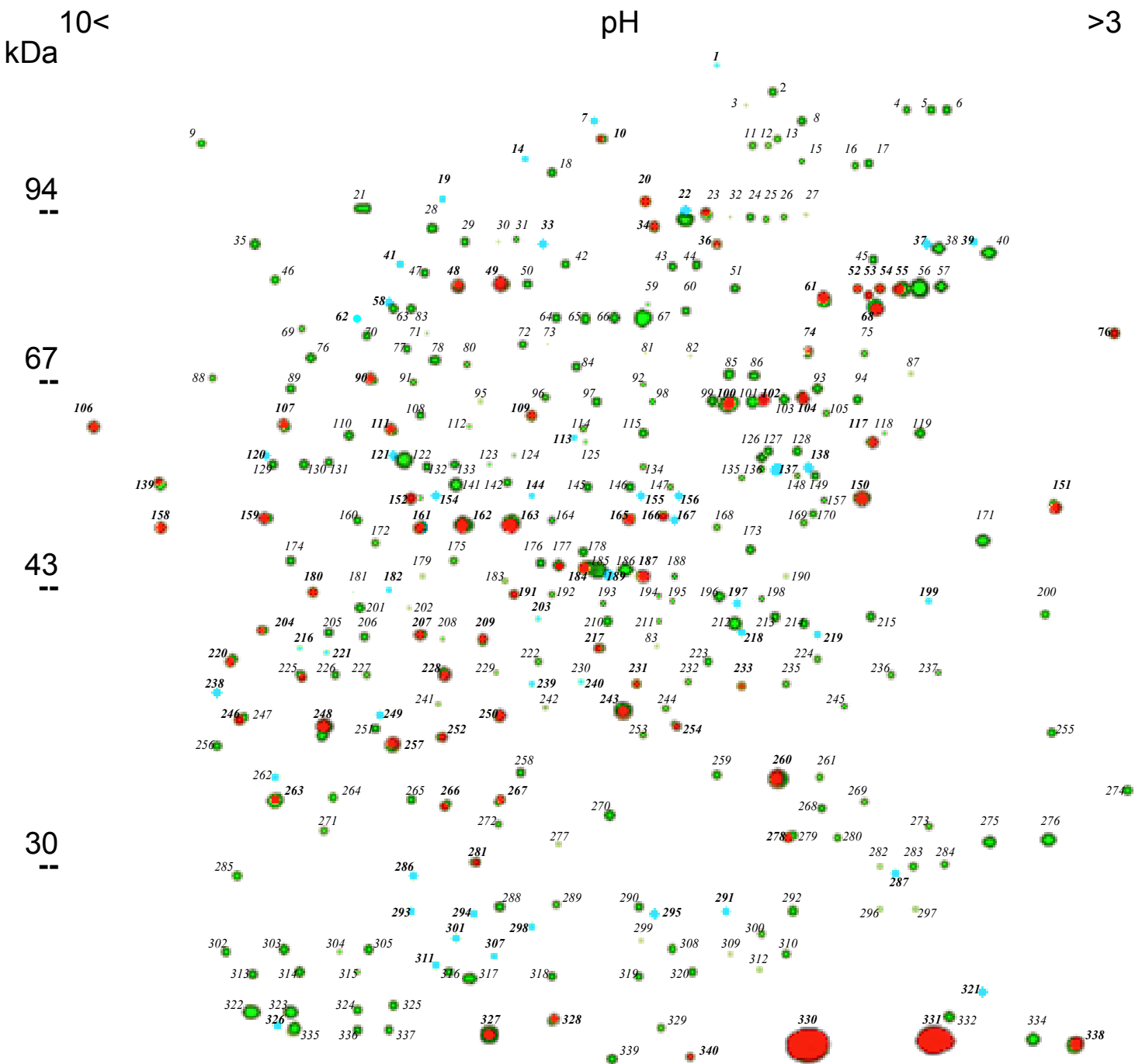

20,1

350

14,4

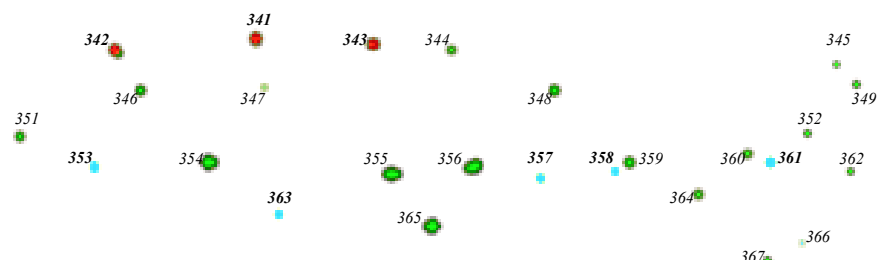

Abb.9: Durchlaufend nummerierte, ${ }^{35}$ S-markierte Plasmamembran-Proteine der wässrigen Phase des TX114-Systems nach Induktion mit verschiedenen Stickstoffquellen in der 2-dimensionalen Verteilungskarte.

Grün: silbergefärbtes, nicht induziertes Protein (keine ${ }^{35}$ S-Markierung in der Autoradiographie); rot: silbergefärbtes, ${ }^{35}$ S-markiertes Protein; blau: ${ }^{35}$ S-markiertes Protein, nicht silbergefärbt (kein korrespondierendes Protein im silbergefärbten $2 D$ Gel).

In der wässrigen Phase des TX114-Systems konnten durch Silberfärbung 316 Proteine nachgewiesen werden, durch ausschließlich autoradiographischen Nachweis wurden zusätzlich 51 Protein aufgefunden, so dass insgesamt 367 
Proteine aufgetrennt wurden. Insgesamt 121 Proteine trugen eine ${ }^{35} \mathrm{~S}$ Markierung; damit wurde ein Drittel aller nachgewiesenen Proteine der WP de novo gebildet.

Die Quantität der 51 nur durch ihre ${ }^{35}$ S-Markierung nachgewiesenen Proteinen unterschritt 5 ng je Protein (Nachweisgrenze der Silberfärbung gemäß Kap. 3.7). Diese konnten daher aufgrund ihrer geringen Konzentration in den vorhergehenden Experimenten nicht nachgewiesen werden. Von den höher konzentrierten und damit silbergefärbten Proteinen waren 70 der 316 Proteine ${ }^{35}$ S-markiert (silbergefärbt und ${ }^{35} \mathrm{~S}$-markiert). Dies entsprach einem Anteil von $22,2 \%$. Zur Ausdifferenzierung der ausschließlich durch $\mathrm{NO}_{3}{ }^{-}$induzierten Proteine wurden die Intensitäten der Signale der Autoradiographien untereinander verglichen.

\subsubsection{Stickstoff-Quellen-spezifisch ${ }^{35}$ S-markierte Proteine der WP}

Die qualitative und quantitative Charakterisierung der spezifisch $\mathrm{NO}_{3}$ induzierten Proteine gegenüber $\mathrm{NH}_{4}$ und Kontrolle gelang mit der Auswertungsoftware BASys von Biotech-Fischer nicht. Das Programm erlaubt weder eine Überlagerung der Images der silbergefärbten Gele bzw. Autoradiographien, noch konnten Positionsschwankungen der Proteine innerhalb der einzelnen Gele korrigiert werden. Zur Auswertung qualitativer und halbquantitativer Unterschiede wurden daher die silbergefärbten Gele bzw. Autoradiographien mit einem vektoriellen Graphikprogramm (Corel PhotoPaint8) in Falschfarbenbilder konvertiert $\left(\mathrm{NO}_{3}{ }^{-}=\right.$rot; $\mathrm{NH}_{4}{ }^{+}=$blau; Kontrolle/-N = grün). Eine additive Überlagerung der Falschfarbenbilder erlaubte die Charakterisierung: Die Farbreinheit eines Proteinspots wächst, je stärker er gegenüber den gleichen Signalen anderer Farbe überwiegt. Je reiner (rot; grün; blau) eine der drei Farben einen entsprechenden Proteinspot repräsentierte, desto spezifischer war er der jeweiligen N-Quelle zuzuordnen.

Unterschieden wurde zwischen $\mathrm{NO}_{3}{ }^{-}$-induziert de novo-synthetisierten Proteinen sowie einer quantitativer $\mathrm{Zu}$ - oder Abnahme bereits vorhandener Proteine. Daher wurden die durch $\mathrm{NO}_{3}$ induziert de novo-synthetisierten Proteine als qualitativ induzierte Proteine bezeichnet. Diese stehen den nach $\mathrm{NO}_{3}$-Induktion lediglich in der Konzentration quantitativ veränderten Proteinen gegenüber. Diese sind als quantitativ $\mathrm{NO}_{3}$-induziert bezeichnet. Der Begriff der Induktion wurde verwendet, um die $\mathrm{N}$-Quellen-spezifisch beeinflußten Proteine gegen die in allen Ansätzen $\left(\mathrm{NO}_{3}{ }^{-}, \mathrm{NH}_{4}{ }^{+},-\mathrm{N}\right)$ gleich stark radioaktiv markierten Proteine abzugrenzen. 


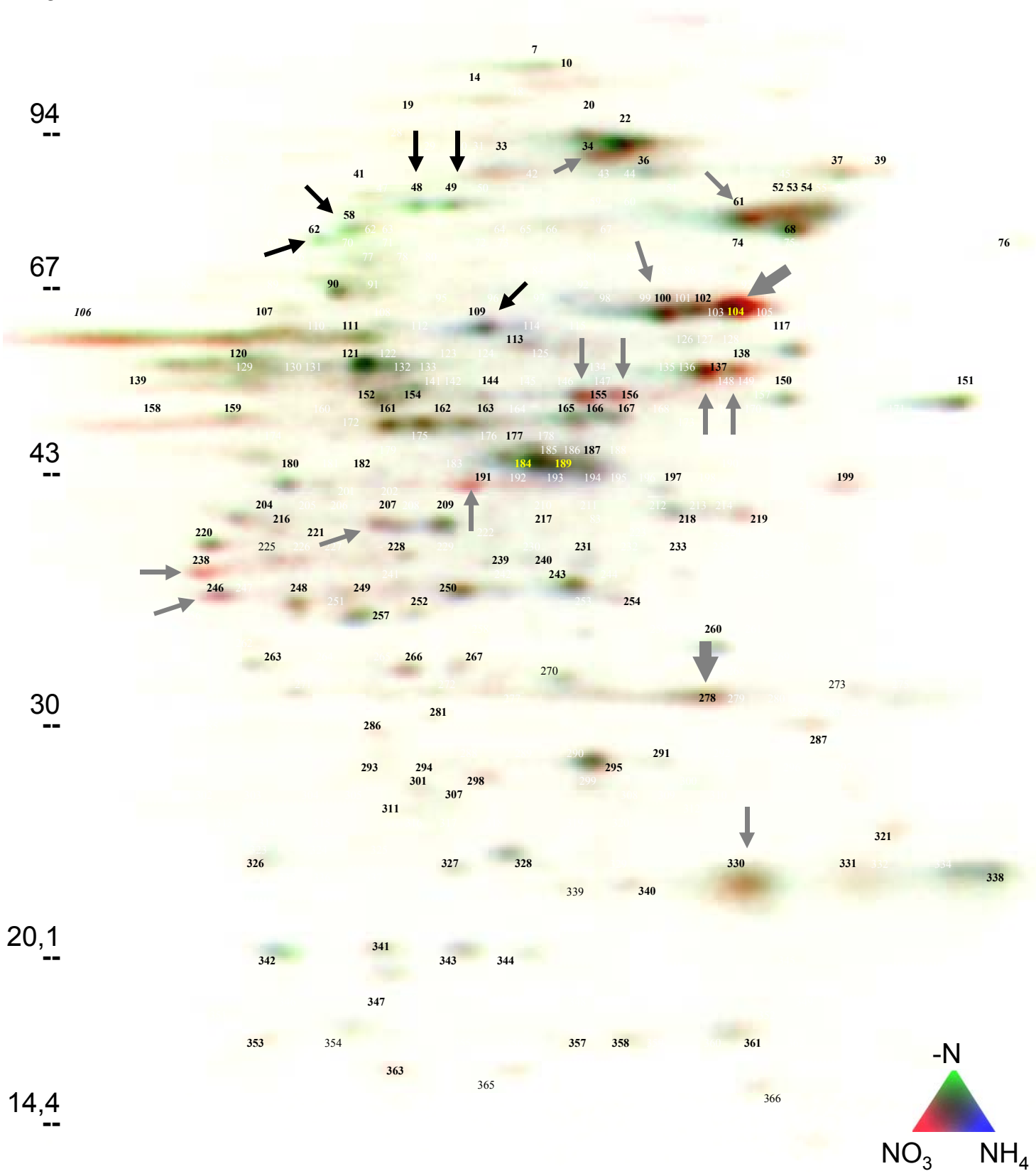

Abb. 10: Überlagerte Autoradiographien der ${ }^{35}$ S-markierten Plasmamembran-Proteine der wässrigen Phase des TX114-Systems nach Induktion mit verschiedenen Stickstoffquellen. Die Autoradiographien sind in Falschfarben dargestellt und additiv überlagert (siehe Farbverlaufsdreieck in der Abb. unten rechts).

$\mathrm{NO}_{3}{ }^{-}$-induzierte Proteine sind rot; $\mathrm{NH}_{4}{ }^{+}$-induzierte Proteine blau, Proteine der Kontrolle (-N) grün dargestellt. Die Durchnummerierung der Proteine ist entsprechend der Abb. 9; ${ }^{35}$ S-markierte Proteine sind mit schwarzen oder gelben Ziffern bezeichnet. Graue Pfeile kennzeichnen einen unter $\mathrm{NO}_{3}^{-}$quantitativ betonten ${ }^{35} \mathrm{~S}$-Einbau, schwarze Pfeile entsprechend nach $\mathrm{NH}_{4}^{+}-$Induktion bzw. der Kontrolle. Fett gedruckte graue Pfeile markieren ansequenzierte Proteine

Keines der Plasmamembran-Proteine der wässrigen TX114-Phase zeigte ein ausschließlich auf den $\mathrm{NO}_{3}{ }^{-}$-induzierten Ansatz beschränktes Auftreten und 
damit eine $\mathrm{NO}_{3}{ }^{-}$-spezifische de novo-Synthese. Es korrespondierten stets entsprechende Signale des gleichen Proteins bei $\mathrm{NH}_{4}{ }^{+}$-Gabe oder Kontrolle. Es traten aber erhebliche quantitative Unterschiede in der Signalstärke der ${ }^{35} \mathrm{~S}$ Methionin markierten Proteine auf. Eine erhebliche $\mathrm{NO}_{3}^{-}$-induzierte Zunahme der Signalstärke (hohe Farbreinheit) zeigten die Proteine WP \# 191 und WP \# 238 mit einem Molekulargewicht von 41,3 bzw. 36,8 kDa; das Protein WP \# 191 wurde nicht durch Silber angefärbt. Den stärksten Einbau von ${ }^{35} \mathrm{~S}-M e t h i o n i n$ von allen Proteinen wies das 64,4 kDa-Protein WP \# 104 nach $\mathrm{NO}_{3}{ }^{-}$-Gabe auf. Dieses Protein und das nur geringfügig $\mathrm{NO}_{3}^{-}$-induzierte (schwach ${ }^{35} \mathrm{~S}$ Methionin-markierte) 32,8 kDa-Protein WP \# 278 wurden ansequenziert.

Das silbergefärbte 60,2 kDa-Protein WP \# 109 war das einzige Protein der WP mit einer $\mathrm{NH}_{4}{ }^{+}$-betonten Zunahme der Radioaktivität. Die Proteine WP \# 48 und \# 49 (beide 86,6 kDa) sowie WP \# 58 und \# 62 (81,1 und 78,9 kDa) zeigten bei Anwesenheit einer $\mathrm{N}$-Quelle $\left(\mathrm{NO}_{3}^{-}\right.$bzw. $\left.\mathrm{NH}_{4}{ }^{+}\right)$gegenüber der Kontrolle ein deutlich verminderten ${ }^{35}$ S-Einbau. Die Proteine WP \# 161 und \# 162 (beide 47,3 $\mathrm{kDa}$ ) waren $\mathrm{NH}_{4}{ }^{+}$-reprimiert.

In der Tabelle 1 (Kapitel 3.3.4). sind die Stickstoff-Quellen beeinflußten Plasmamembran-Proteine der wässrigen- und Detergenz-Phase zusammengefasst. Zur deulicheren Abgrenzung gegen die Proteine der Detergenz-Phase des TritonX114-Systems sind die WP-Proteine kursiv gestellt. 


\subsubsection{PM-Proteine der Detergenz-Phase des TX114-Systems}

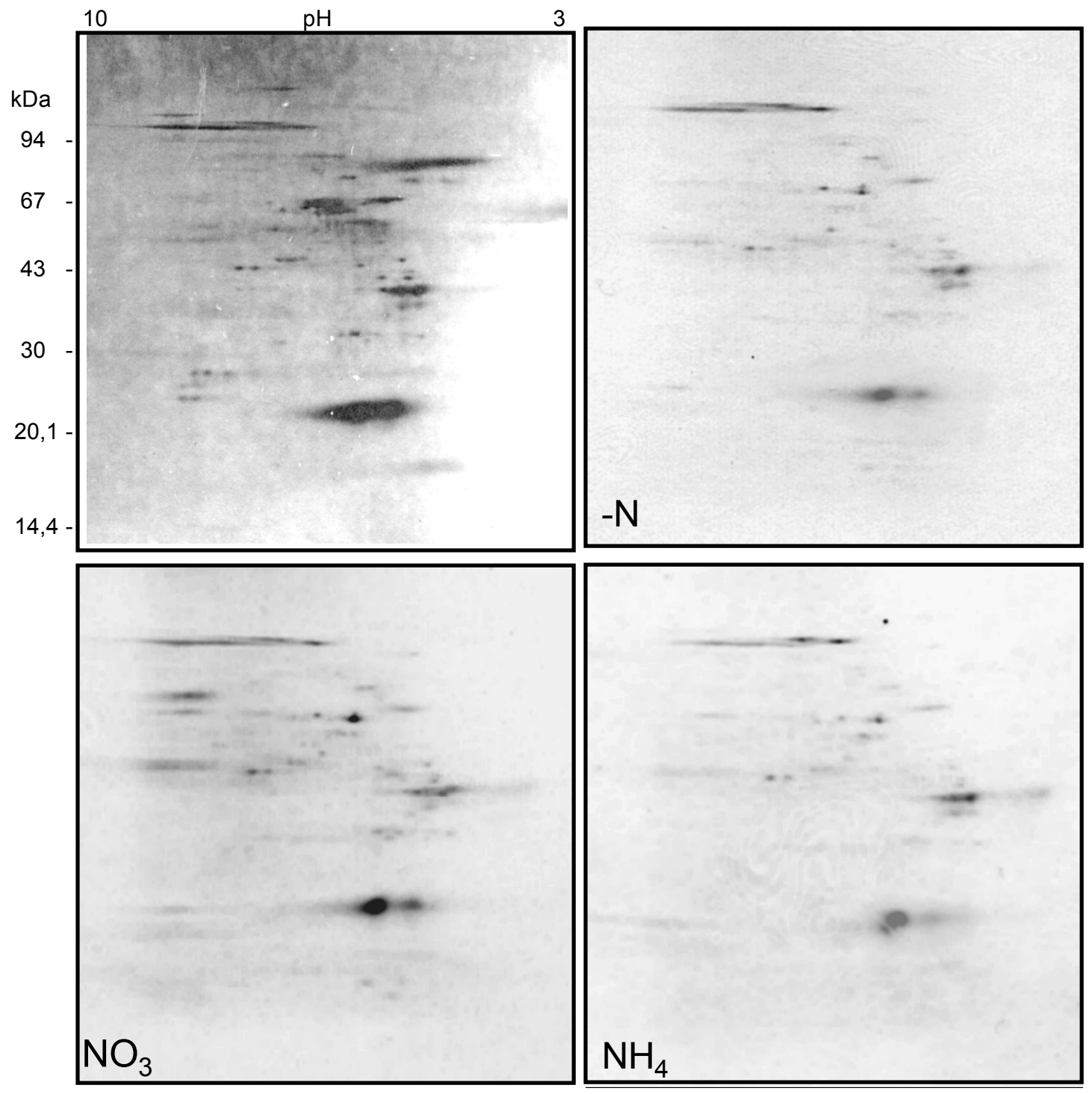

Abb. 11: 2D-SDS-PAGE der Plasmamembran-Proteine der Deterenz-Phase des TX114-Systems nach Induktion mit $\mathrm{NO}_{3}^{-}$in Gegenwart von ${ }^{35} \mathrm{~S}-M e t h i o n i n:$ Silberfärbung des Gels (oben links; gezeigt: $\mathrm{NH}_{4}^{+}$) und Autoradiographien der ${ }^{35} \mathrm{~S}$ markierten Proteine der DP der Ansätze $\mathrm{NO}_{3}^{-}, \mathrm{NH}_{4}^{+}$und Kontrolle (-N).

Analog zu den PM-Proteinen der wässrigen Phase des TX114-Systems wurden die hydrophoben Proteine der TX114-Detergenz-Phase aufgetrennt. Auch bei den Proteinen der Detergenz-Phase wurden eine große Zahl unter Einbau von ${ }^{35}$ S-Methionin markierter Plasmamembran-Proteine aufgetrennt. Im N-freien Kontrollansatz traten ebenfalls markierte Proteine über den gesamten Molekulargewichts-Bereich auf. Im Gegensatz zur WP zeigte die Autoradiographie Neubildungen bei $\mathrm{NO}_{3}$-Induktion (siehe Tabelle 1, Kap. 3.3.4). Die Signale der Autoradiographie konnten eindeutig den Proteinen des silbergefärbten Geles zugeordnet werden und eine 2D-Karte wurde erstellt: 


\subsubsection{Lokalisation der ${ }^{35} \mathrm{~S}$-markierten Proteine der DP in der 2D-SDS- PAGE}

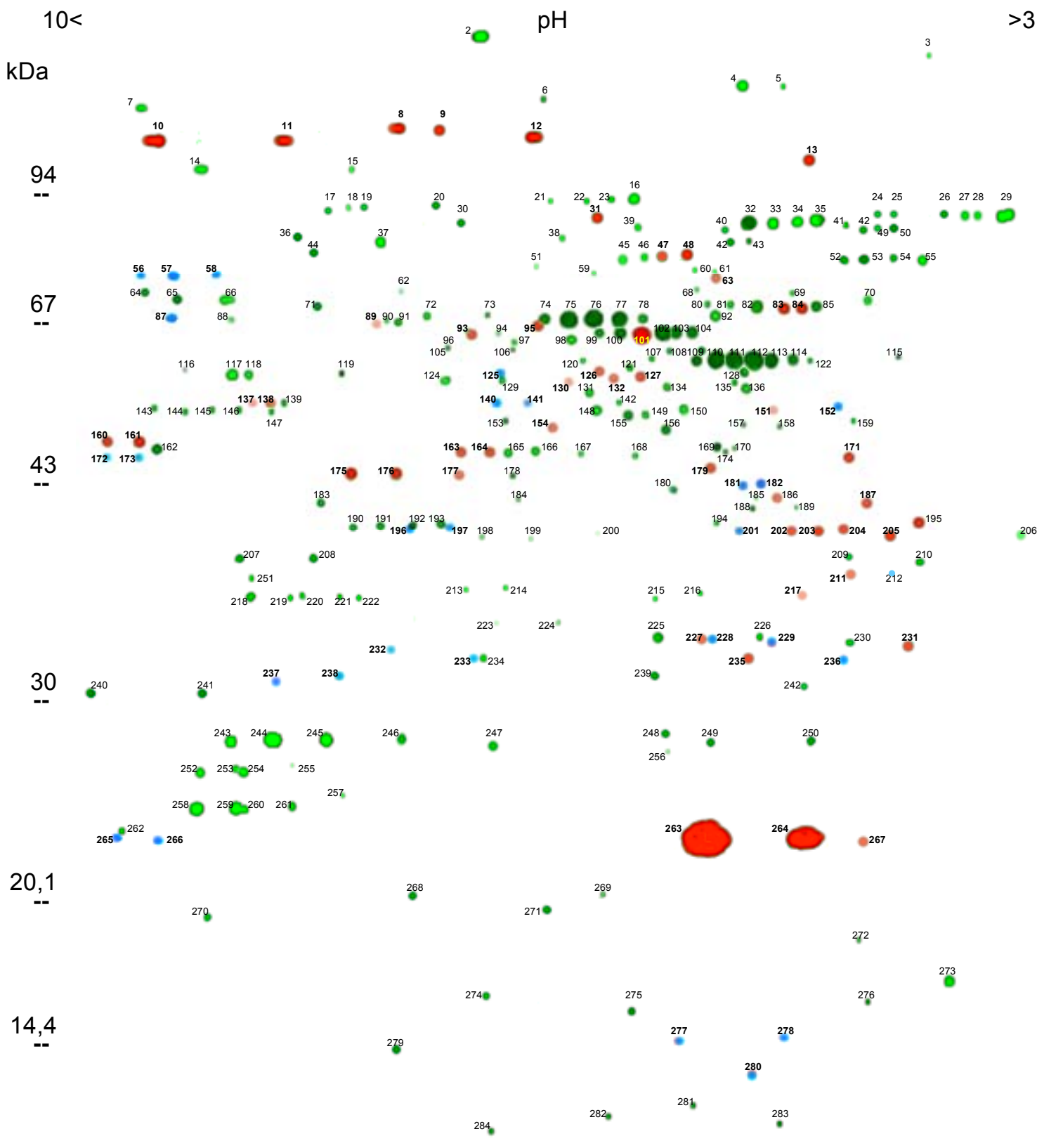

Abb. 12: Durchlaufend nummerierte, ${ }^{35}$ S-markierte Plasmamembran-Proteine der TX114-Detergenz-Phase nach Induktion mit verschiedenen Stickstoffquellen in der 2DVerteilungskarte. Grün: silbergefärbtes, nicht induziertes Protein (keine ${ }^{35} \mathrm{~S}$ Markierung); rot: silbergefärbtes, ${ }^{35}$ S-markiertes Protein; blau: ${ }^{35} \mathrm{~S}$-markiertes Protein, nicht silbergefärbt (kein korrespondierendes Protein im silbergefärbten 2D-Gel).

Es wurden 257 Proteine nachgewiesen, durch Autoradiographie wurden zusätzlich 27 nicht silbergefärbte Proteine detektiert, so dass insgesamt 284 Proteine aufgetrennt wurden. 75 Proteine der DP trugen eine ${ }^{35}$ S-Markierung. Damit wurde ca. ein Viertel (26,4 \%) aller nachgewiesenen Proteine der Detergenz-Phase Stickstoffquellen-spezifisch quantitativ verändert. 27 Proteine 
unterschritten die Nachweisgrenze der Silberfärbung ( $<5 \mathrm{ng}$ je Protein) und wurden nur durch ihre ${ }^{35} \mathrm{~S}-$ Markierung nachgewiesen.

\subsubsection{Stickstoff-Quellen-spezifisch ${ }^{35}$ S-markierte Proteine der DP}

$10<$

$\mathrm{pH}$

$\mathrm{kDa}$

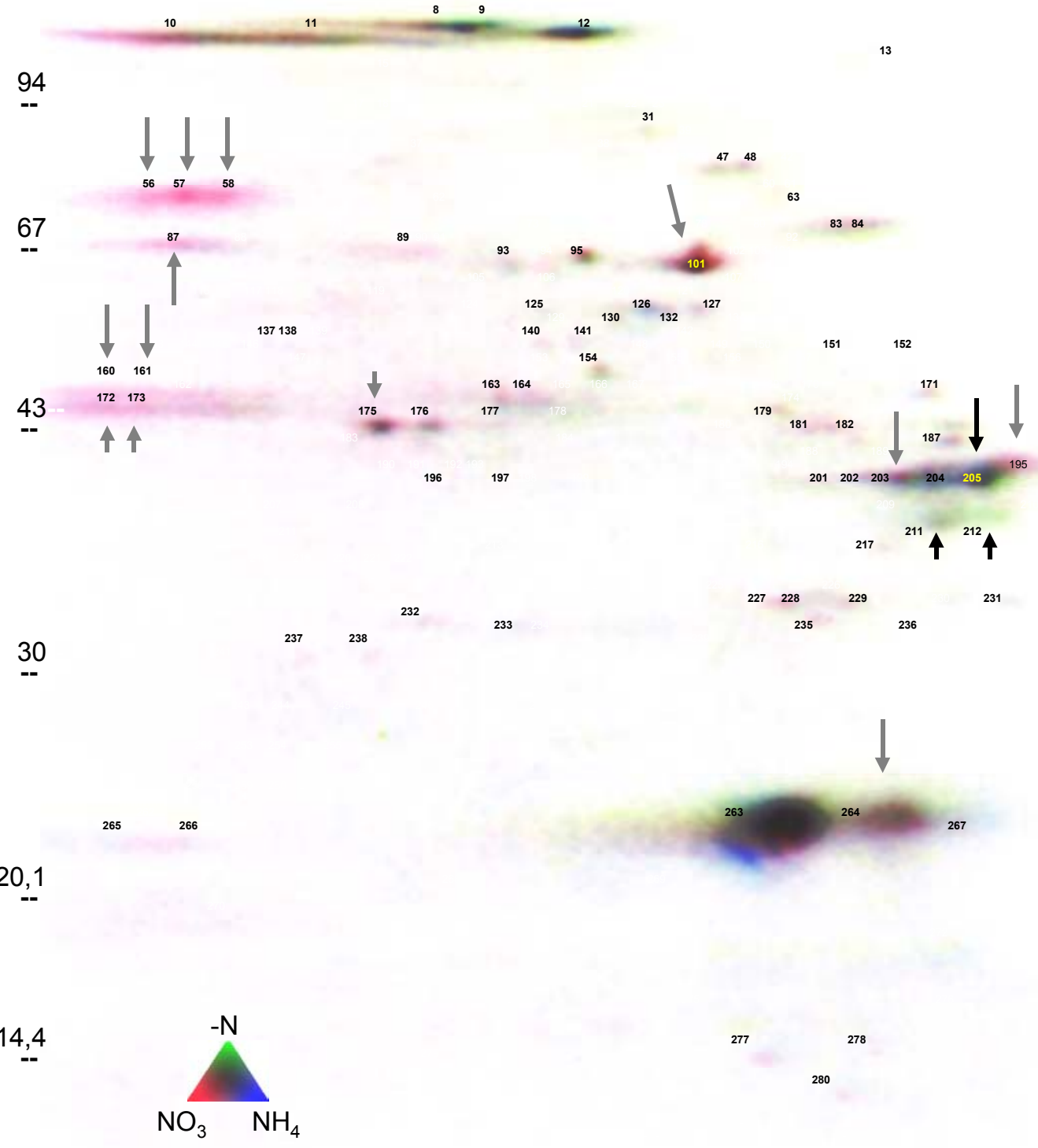

Abb.: 13: Überlagerte Autoradiographien der ${ }^{35}$ S-markierten Plasmamembran-Proteine der Detergenz-Phase des TX114-Systems nach Induktion mit verschiedenen Stickstoffquellen. Die Autoradiographien sind in Falschfarben dargestellt und additiv überlagert; die Durchnummerierung ist entsprechend der Abb. 12; ${ }^{35}$ S-markierte Proteine sind mit schwarzen oder gelben Ziffern bezeichnet.

$\mathrm{NO}_{3}{ }^{-}$-induzierte Proteine sind rot; $\mathrm{NH}_{4}{ }^{+}$-induzierte Proteine blau, Proteine der Kontrolle $(-N)$ grün dargestellt. Graue Pfeile kennzeichnen quantitativ betonten ${ }^{35} S$-Einbau nach $\mathrm{NO}_{3}^{-}$-Induktion; schwarze Pfeile nach $\mathrm{NH}_{4}{ }^{+}$-Induktion bzw. in der Kontrolle betonte ${ }^{35} \mathrm{~S}$ Markierung.

Wie unter 3.3.2.2 beschrieben, wurde unterschieden zwischen $\mathrm{NO}_{3}{ }^{-}$-induziert de novo-synthetisierten Proteinen sowie einer quantitativen $\mathrm{Zu}$ - oder Abnahme 
bereits vorhandener Proteine. Daher wurden die durch $\mathrm{NO}_{3}{ }^{-}$-induziert de novosynthetisierten Proteine als qualitativ induzierte Proteine bezeichnet. Diese stehen den nach $\mathrm{NO}_{3}{ }^{-}$-Induktion lediglich in der Konzentration quantitativ veränderten Proteinen gegenüber. Diese sind als quantitativ $\mathrm{NO}_{3}$-induziert bezeichnet. Der Begriff der Induktion wurde verwendet, um die N-Quellenspezifisch beeinflußten Proteine gegen die in allen Ansätzen $\left(\mathrm{NO}_{3}{ }^{-}, \mathrm{NH}_{4}{ }^{+},-\mathrm{N}\right)$ gleich stark radioaktiv markierten Proteine abzugrenzen.

In der TX114-Detergenz-Phase wurden mehrere, qualitativ $\mathrm{NO}_{3}$-induzierte (de

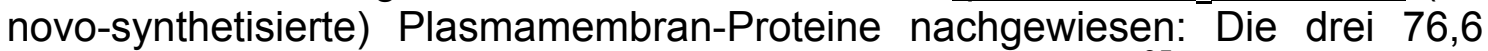
kDa-Proteine \# 56; 57; 58 zeigten einen hohen Einbau von ${ }^{35}$ S-Methionin. Ein entsprechendes Signal fehlte bei $\mathrm{NH}_{4}{ }^{+}$und $-\mathrm{N}$ (Kontrolle). Die qualitativ $\mathrm{NO}_{3}{ }^{-}$ induzierten Proteine \# 56, 57, 58 fokussierten mit basischem IEP ( $\mathrm{pH} ~ 8)$. Ebenfalls basisch fokussiert $(\mathrm{pH} \sim 9)$ und qualitativ auf $\mathrm{NO}_{3}{ }^{-}$beschränkt waren die 45,9 kDa-Proteine \# 172 und 173. Die Proteine waren durch Silberfärbung nicht nachweisbar. Dies galt auch für das 67,8 kDa-Portein \# 87. Dieses Protein wurde allerdings auch im $\mathrm{NH}_{4}{ }^{+}$-Ansatz gefunden, darin aber in deutlich geringerer Konzentration. DP \# 87 ist daher nicht ausschließlich durch $\mathrm{NO}_{3}$ induziert, zeigte aber eine erheblich geringere Konzentration bei $\mathrm{NH}_{4}{ }^{+}-$ Ernährung.

Die stärkste quantitativ $\mathrm{NO}_{3}$-induzierte Markierung zeigte Protein \# 101 von 64,4 kDa. Dieses Protein korrespondierte mit dem Protein \# 104 der wässrigen Phase des TX114-Systems. Das Protein 263 von 23,3 kDa Molekulargewicht zeigte die höchste absolute Radioaktivität; der quantitative Unterschied gegenüber $\mathrm{NH}_{4}{ }^{+}$war aber geringer als bei \# 101 und dem benachbarten 23,3 kDa-Protein \# 264. (\# 263 erscheint bei $\mathrm{NH}_{4}{ }^{+}$durch einen $\mathrm{Riß}$ an entsprechender Stelle im Gel größer). Die Proteine \# 203 und \# 195 zeigten ebenfalls eine etwas stärkere ${ }^{35}$ S-Markierung bei $\mathrm{NO}_{3}{ }^{-}$als $\mathrm{N}$-Quelle. Das Protein \# 205 von 37,3 kDa zeigte eine Zunahme der ${ }^{35}$ S-Markierung bei $\mathrm{NH}_{4}{ }^{+}-$ als N-Quelle. Einen in Anwesenheit einer Stickstoff-Quelle geringeren ${ }^{35} \mathrm{~S}-$ Einbau zeigten die 36,4 kDa-Proteine \# 211 und 212. 


\subsection{4 ${ }^{35} \mathrm{~S}$-markierte Proteine in der Übersicht}

In Tabelle 1 sind die N-Quellen-spezifisch beeinflußten Proteine zusammengefaßt.

Bestimmt wurde das Molekulargewicht; der IEP der Proteine ist geschätzt, da das IEF mit Trägerampholyten durchgeführt wurde. Der erzeugte $\mathrm{pH}$-Gradient ist durch die im Gel mobilen Ampholyte nicht zeitstabil („Kathodendrift“).

\begin{tabular}{|c|c|c|c|c|c|}
\hline Nachweis & Stickstoffquelle & $\begin{array}{l}\text { \# des Proteins } \\
\text { WP-Proteine sind } \\
\text { kursiv gedruckt }\end{array}$ & $\begin{array}{c}\text { Beeinflussung durch } \\
\text { die Stickstoffquelle: } \\
\text { quantitativ / qualitativ } \\
\text { (=de novo) }\end{array}$ & $\begin{array}{c}\text { TX } \\
114- \\
\text { Phase }\end{array}$ & $\begin{array}{l}\mathrm{KDa} \\
\text { (IEP) }\end{array}$ \\
\hline $\begin{array}{l}\text { Silberfärbung } \\
\text { Autoradio- } \\
\text { graphie }\end{array}$ & $\begin{array}{c}\mathrm{NO}_{3} \text {-spezifisch } \\
\text { stärker }{ }^{35} \mathrm{~S} \text { - } \\
\text { markiert }\end{array}$ & $\begin{array}{c}\# 34 \\
\# 61 \\
\# 100 \\
\# 104 \\
\# 191 \\
\# 207 \\
\# 246 \\
\# 330 \\
\text { \# } 101 \\
\# 161,162 \\
\# 175 \\
\# 195 \\
\# 203 \\
\# 263,264\end{array}$ & $\begin{array}{c}\text { quantitativ } \\
\text { " } \\
\text { " } \\
\text { " } \\
\text { " } \\
\text { " } \\
\text { " } \\
\text { " } \\
\text { " } \\
\text { " }\end{array}$ & $\begin{array}{c}\text { WP } \\
\text { “ } \\
“ \\
“ \\
“ \\
\text { “ } \\
\text { DP } \\
\text { " } \\
\text { " } \\
\text { " }\end{array}$ & $\begin{array}{l}89,0(5) \\
80,2(5) \\
62,1(5) \\
64,4(5) \\
41,3(6) \\
38,4(6) \\
35,3(7) \\
22,6(5) \\
\\
64,4(5) \\
47,3(9) \\
44,6(6) \\
38,6(4) \\
37,8(4) \\
23,2(5)\end{array}$ \\
\hline $\begin{array}{l}\text { Silberfärbung } \\
\text { Autoradio- } \\
\text { graphie }\end{array}$ & $\begin{array}{c}\mathrm{NH}_{4} \text {-spezifisch } \\
\text { stärker }{ }^{35} \mathrm{~S}- \\
\text { markiert }\end{array}$ & $\begin{array}{l}\# 109 \\
\# 204 \\
\# 205\end{array}$ & $\begin{array}{c}\text { quantitativ } \\
\text { “ } \\
\text { “ }\end{array}$ & $\begin{array}{l}\text { WP } \\
\text { DP }\end{array}$ & $\begin{array}{l}60,2(6) \\
38,0(4) \\
37,3(4)\end{array}$ \\
\hline $\begin{array}{c}\text { Autoradio- } \\
\text { graphie }\end{array}$ & $\begin{array}{c}\mathrm{NO}_{3} \text {-spezifisch } \\
\text { stärker }{ }^{35} \mathrm{~S}- \\
\text { markiert }\end{array}$ & $\begin{array}{c}\# 138 \\
\# 137 \\
\# 155,156 \\
\# 238 \\
\\
\# 56,57,58 \\
\# 87 \\
\# 172,173\end{array}$ & $\begin{array}{c}\text { quantitativ } \\
\text { " } \\
\text { " } \\
\text { qualitativ } \\
\text { quantitativ } \\
\text { qualitativ }\end{array}$ & $\begin{array}{c}\text { WP } \\
\text { " } \\
\text { " } \\
\text { DP } \\
\text { " }\end{array}$ & $\begin{array}{l}55,7(5) \\
54,5(5) \\
48,8(6) \\
36,8(7) \\
\\
76,6(8) \\
67,8(8) \\
45,9(9) \\
\end{array}$ \\
\hline
\end{tabular}

Tabelle 1: Zusammenstellung der S35-markierten, durch die Stickstoffquelle beeinflussten PM-Proteine.

Die Proteine \# 56; 57; 58; 172; 173 (87) waren die einzigen durch $\mathrm{NO}_{3}{ }^{-}-$ induziert de novo synthetisierten Proteine („qualitativ induziert") und hatten hydrophoben Charakter (Anreicherung in der TX114-Detergenz-Phase). Ihr autoradiographisches Signal war von hoher Intensität, dennoch konnten sie durch Silberfärbung nicht nachgewiesen werden; an der Grenze des Silbernachweises lag \# 87.

Alle anderen Proteine beider TX114-Phasen zeigten eine Zunahme ihrer ${ }^{35} \mathrm{~S}$ Markierung nach $\mathrm{NO}_{3}{ }^{-}$- oder $\mathrm{NH}_{4}{ }^{+}$-Gabe („quantitativ induziert“). Den Proteinen der Untergruppe II und $\mathrm{V}$ war eine stärkere Markierung bei $\mathrm{NO}_{3}{ }^{-}$im Medium gemeinsam. Diese Proteine traten auch bei $\mathrm{NH}_{4}{ }^{+}$oder $\mathrm{N}$-freier Kontrolle auf, aber mit geringerer Intensität des ${ }^{35} \mathrm{~S}$-Signals. 
Die stärkste $\mathrm{NO}_{3}{ }^{-}$-induzierte Zunahme der radioaktiven Markierung gegenüber $\mathrm{NH}_{4}$ und $\mathrm{N}$-freier Kontrolle zeigte das Protein \# 104 der wässrigen Phase des TX-Systems mit einem Mol.-Gewicht von 64,4 kDa. Bei den Proteinen der Detergenz-Phase galt dies für die Proteine \# 101, ebenfalls 64,4 kDa und \# 263 $(23,2 \mathrm{kDa})$. Protein \# 101 korrespondierte mit dem WP-Protein \# 104 und verteilte sich als amphiphiles Protein zwischen beiden TX114-Phasen mit höherem Anteil in der wässrigen Phase. Das Protein wurde als NitratreduktaseProtein identifiziert (siehe Kap. 3.5). $\mathrm{NO}_{3}{ }^{-}$-reprimiert war das 37,3 kDa-Protein \# 205; es zeigte einen verminderten Einbau von ${ }^{35}$ S-Methionin bei $\mathrm{NO}_{3}^{-}$im Medium. Nicht in der Tabelle aufgeführt sind die durch Stickstoff-Gabe reprimierten WP-Proteine \# 48; 49; 58; 62; ihre Markierung nahm in Gegenwart von Stickstoff im Medium ab (siehe Abb. 10)

Eine Zunahme der eingebauten Radioaktivität bei $\mathrm{NH}_{4}{ }^{+}$als $\mathrm{N}$-Quelle zeigten die Proteine \# 109 (WP; 60,2 kDa) sowie \# 289 (DP; 35,5 kDa). $\mathrm{NH}_{4}{ }^{+}$-reprimiert waren die WP-Proteine \# 181, 182 und 183 (alle 43,4 kDa) sie zeigten gegenüber $\mathrm{NO}_{3}$ und Kontrolle einen verminderten Einbau der Radioaktivität.

Insgesamt wurden 651 Proteine der Plasmamembran durch die 2D-SDS-PAGE aufgetrennt. Nach Induktion der Algen mit unterschiedlichen $\mathrm{N}-$ Quellen $\left(\mathrm{NO}_{3}{ }^{-}\right.$ bzw. $\mathrm{NH}_{4}{ }^{+}$) in Gegenwart von ${ }^{35} \mathrm{~S}-$ Methionin waren 455 Proteine nicht ${ }^{35} \mathrm{~S}$ markiert. 196 Proteine wiesen eine ${ }^{35}$ S-Markierung auf.

78 der $196{ }^{35}$ S-markierten PM-Proteine wurden nicht durch Silberfärbung angefärbt. Diese lagen in einer Menge $<5 \mathrm{ng}$ je Spot vor. Von den $196{ }^{35} \mathrm{~S}$ markierten Proteine waren 99+67=166 Proteine auch im Kontrollansatz ohne Stickstoffquelle ${ }^{35}$ S-markiert. Von den ${ }^{35}$ S-markierten Proteine waren somit 85 $\%$ der Proteine unabhängig von der N-Quelle markiert. 27 Proteine zeigten durch Gabe von $\mathrm{NO}_{3}{ }^{-}$eine Zunahme der Proteinmenge (stärkeren ${ }^{35} \mathrm{~S}$-Einbau) oder traten erstmals auf (de novo gebildet). Ihr Anteil an der Gesamtzahl der Proteine betrug 4,1\%. 14 der $\mathrm{NO}_{3}$-spezifisch markierten Proteine wurden in der TX114-Detergenzphase der hydrophoben Proteine angereichert, darunter die Proteine \# 56, 57, 58, 172, 173.

Die ${ }^{35}$ S-Einbauraten aus den $\mathrm{NO}_{3}$ - bzw. $\mathrm{NH}_{4}{ }^{+}$-induzierten Ansätzen sowie $\mathrm{N}$ freier Kontrolle wurden auf der Grundlage gleicher, für die TX114Zweiphasenverteilung und 2D-SDS-PAGE der TX114-Phasen eingesetzter Proteinmengen verglichen. 


\subsection{Photoaffinitätsmarkierung durch ${ }^{14} \mathrm{C}-2,6$-Dinitrophenylazid (DNPA)}

\subsubsection{Zerfallskinetik und Spaltung von DNPA durch UV-Licht}

Das Aryl-Azid 2,6-DNPA ist ein kompetetiver Hemmstoff der Nitrataufnahme (Glogau, 1994). Die Azid-Gruppe ist instabil und wird bei Belichtung mit kurzwelligem Licht unter $\mathrm{N}_{2}$-Freisetzung abgespalten. Während des Zerfalls kann der Aryl-Rest mit der $\mathrm{NH}_{2}$-Gruppe einer Aminosäure zu einer AzoVerbindung reagieren; dadurch ist eine Photoaffinitätsmarkierung von unmittelbar benachbarten Aminosäuren möglich („nearest neighbour interaction“). Die Abspaltung der Azid-Gruppe war durch eine photometrisch messbare Verschiebung der Absorptionsmaxima des DNPA nachweisbar.
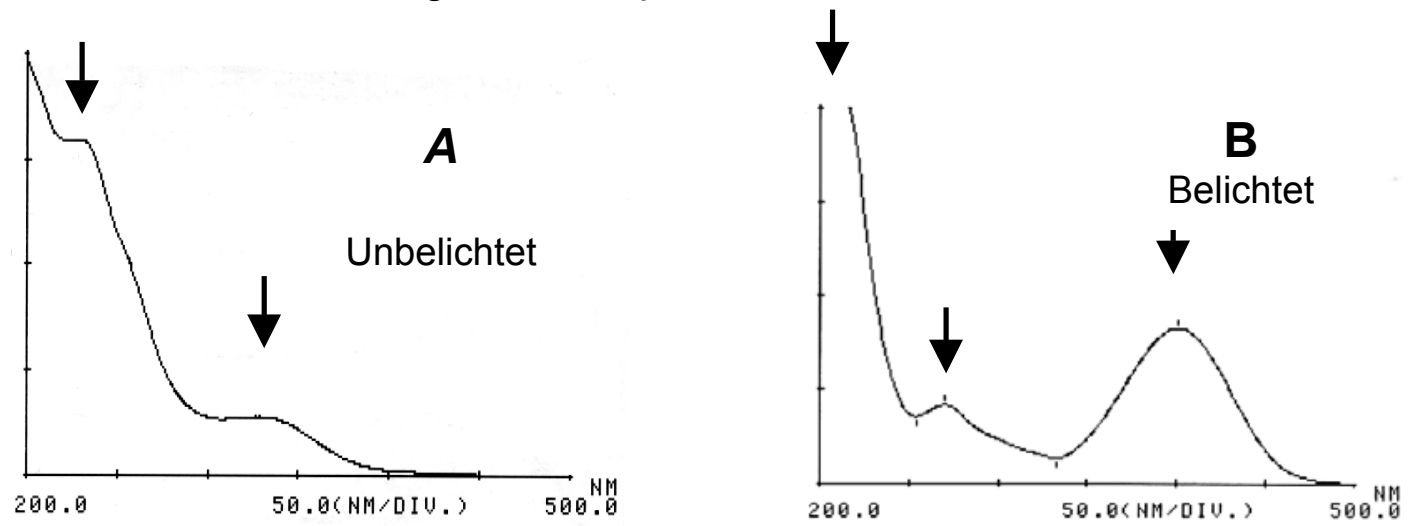

Abbildung 14: Kontinuierliche Spektren von 2,6-DNPA vor (A) und nach (B) 10 min Belichtung mit UV-Licht (364 nm). Im unbelichteten Zustand (A) Absorptionsmaxima bei 230,9 nm; $327 \mathrm{~nm}$ (Pfeile). Nach Belichtung (B) Absorptionsmaxima bei 214; 269, 5 und $402 \mathrm{~nm}$ (Pfeile)

Eine Lösung von 2,5 \% (w/v) 2,6-DNPA in einem Wasser/Ethanol-Gemisch $(40 / 1 \mathrm{v} / \mathrm{v})$ zeigte nach Bestrahlung mit UV-Licht $(364 \mathrm{~nm})$ eine photometrisch bestimmbare Verschiebung der Absorptionsmaxima. Im unbelichteten Zustand waren über einen Wellenlängenbereich von 200-500 nm Extinktionsmaxima zu verzeichnen bei $230,9 \mathrm{~nm} ; 327 \mathrm{~nm}$ sowie einem gerätebedingt nicht bestimmbaren Maximum < $200 \mathrm{~nm}$ Wellenlänge. Nach 3,5 min Bestrahlung traten Extinktionsmaxima bei 214; 269,5 und $402 \mathrm{~nm}$ auf. Diese nahmen bei Verlängerung der Bestrahlung über 10 min hinaus nicht mehr an Intensität zu. Die zur Bestrahlung alternativ eingesetzte Wellenlänge von $254 \mathrm{~nm}$ zeigte die gleiche Verteilung der Maxima bei etwas verzögertem Auftreten (Daten nicht gezeigt). Die Experimente zur Photoaffinitätsmarkierung wurden mit einem ${ }^{14} \mathrm{C}$ substituierten DNPA mit einer spezifischen Aktivität von $6 \mathrm{mCi} / \mathrm{mmol}$ durchgeführt.

\subsection{2 ${ }^{14} \mathrm{C}$-DNPA-Konzentration und ${ }^{14} \mathrm{C}$-Markierung von Plasmamembran- Proteinen}

Zur Bestimmung der geringsten benötigten ${ }^{14} \mathrm{C}$-DNPA-Konzentration für die Photoaffinitätsmarkierung von PM-Protein und ihre autoradiographisch erfassbare Markierung wurde je Ansatz $200 \mu g$ gereinigte PM mit Konzentrationen von 0,5; 5; 50 und $500 \mu \mathrm{M}{ }^{14} \mathrm{C}$-DNPA pro Ansatz versetzt. 


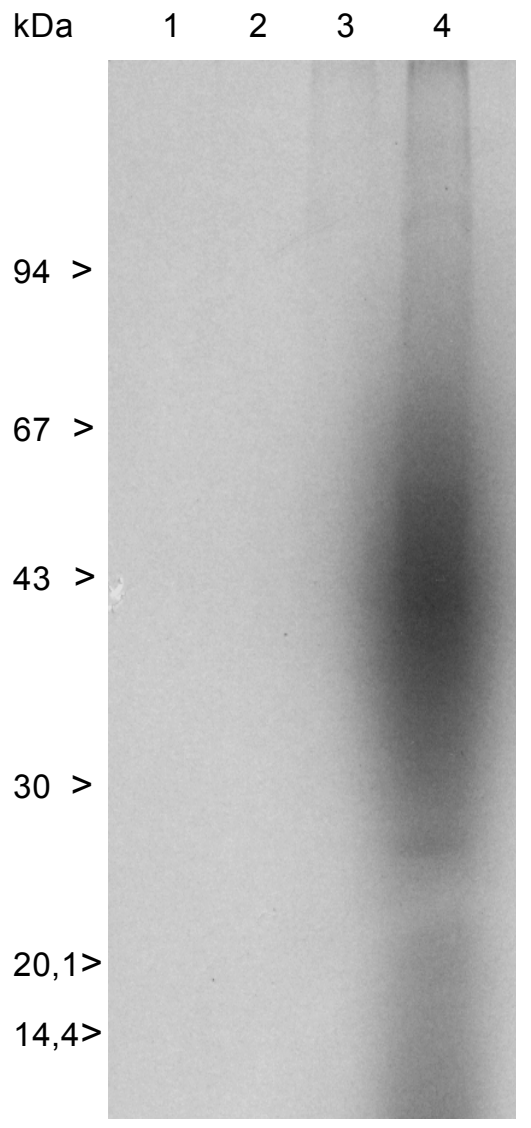

Abbildung 15: Autoradiographie
unterschiedlichen ${ }^{14}$ Konzentrationen

Spur 1 - 4: 0,5; 5; 50; $500 \mu M^{14} C-D N P A$

Die höchste eingesetzte Konzentration von 500 $\mu \mathrm{M}{ }^{14} \mathrm{C}$-DNPA zeigte eine diffuse Markierung von Plasmamembran-Proteinen bei starkem Hintergrundsignal. Die mit $50 \mu \mathrm{M}{ }^{14} \mathrm{C}$-DNPA markierten Proteine waren nach 10 d Expositionsdauer des Films neben der $500 \mu \mathrm{M}$-Spur nicht erkennbar.

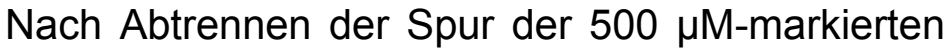
Proteine und erneuter Exposition (35 d) zeigte die Autoradiographie der $50 \mu \mathrm{M}{ }^{14} \mathrm{C}$-DNPA-markierten Proteine das gleiche Verteilungsmuster der Markierung (nicht gezeigt), die Markierung mit 0,5 bzw. $5 \mu \mathrm{M}{ }^{14} \mathrm{C}$-DNPA konnte nicht nachgewiesen werden. Für die nachfolgenden Experimente wurde daher eine Konzentration von $50 \mu \mathrm{M}$ eingesetzt. ${ }^{14} \mathrm{C}-\mathrm{DNPA}-\mathrm{markierte}$ Protein-Banden lagen in den Molekulargewichtsbereichen 26; 38; 40; 45; 53; 75 und $112 \mathrm{kDa}$.

Vergleich des Verteilungsmusters der ${ }^{14} \mathrm{C}$-DNPA-markierten PM-Proteine in der Silberfärbung und Autoradiographie

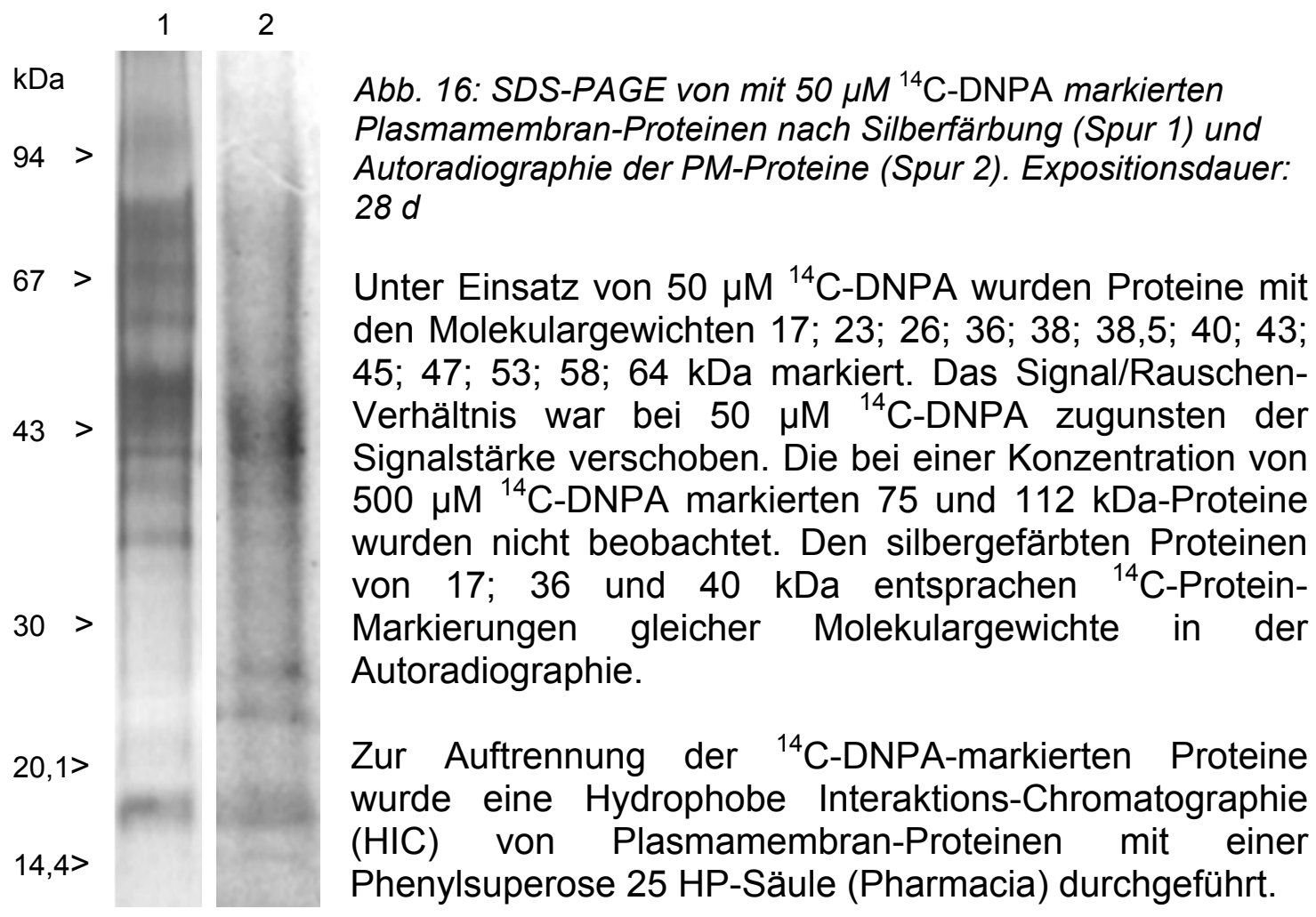




\subsection{3 ${ }^{14} \mathrm{C}$-DNPA-Markierung nach HIC der PM-Proteine}

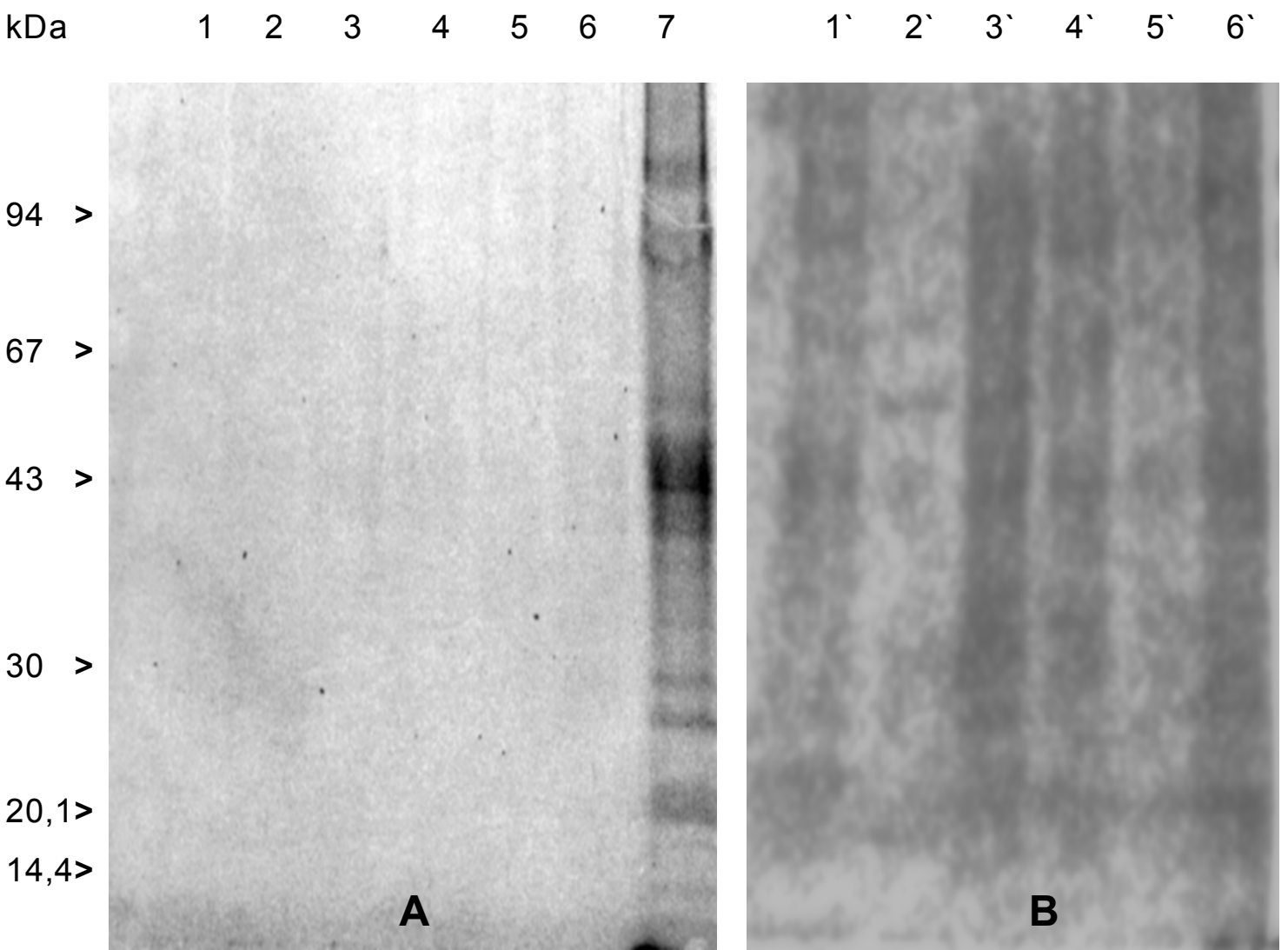

Abbildung 17: SDS-PAGE der HIC-Fraktionen von 1,5 mg Plasmamembran-Protein getrennt auf Phenylsuperose HP. A: Autoradiographie von mit $50 \mu \mathrm{M}{ }^{14} \mathrm{C}-D N P A-$ markierten Proteinen nach 26 d Exposition eines $\beta$-Max-Filmes. B: Dasselbe Gel nach Exposition einer Phospho-Imager-Platte; Abbildung nach digitaler Kontrastverstärkung, letzte Spur (Spur 7 =Kontrolle) überschwärzt und nicht abgebildet

Spur 1: nicht auf der Säule gebundene Proteine des Vorlaufes der HIC. Spur 2-5: Sammelfraktionen über den Harnstoff-Gradienten; Spur 2: bis 250 mM; Spur 3: bis 500 mM; Spur 4: bis 750 mM; Spur 5: bis 1 M Harnstoff. Spur 6: im Gradient nicht abgelöste, erst mit $50 \mathrm{mM} \mathrm{NaOH}$ eluierte Proteine. Spur 7: Kontrolle (150 $\mu \mathrm{g}$ unfraktionierte Plasmamembran-Proteine).

Die 45 HIC-Fraktionen wurden zunächst zu fünf Sammelfraktionen vereinigt und durch Membran-Filtration eingeengt. In den Fraktionen konnte durch Autoradiographie mit $\beta$-Max-Film keine quantitative Anreicherung eines ${ }^{14} \mathrm{C}$ DNPA-gelabelten Proteins nachgewiesen werden. Nach digitaler Kontraststeigerung der Signale mit einer Phospho-Imagerplatte (7 d Exposition; bei 10 fach höherer Empfindlichkeit gegenüber $\beta-M a x-F i l m$ entsprechend ca. $70 \mathrm{~d})$ waren diffuse Markierungen erkennbar. In Spur 2 trat dabei eine distinkte Bande von 53 kDa Molekulargewicht auf. Die Eingrenzung und Anreicherung dieses Proteins durch ${ }^{14} \mathrm{C}$-DNPA-Labeling in einer Einzelfraktion der HIC der PM-Proteine gelang nicht. Die SDS-PAGE der neun einzelnen, in Sammelfraktion 2 vereinigten HIC-Fraktionen zeigte nach Markierung mit $50 \mu \mathrm{M}$ ${ }^{14}$ C-DNPA keine Signale in der Autoradiographie. Das Protein eluierte somit über mehrere Fraktionen, die Nachweis-Empfindlichkeit des ${ }^{14} \mathrm{C}-\mathrm{DNPA}$ reichte bei der vorhandenen Proteinkonzentration je Fraktion nicht aus (nicht gezeigt). 


\subsection{4 ${ }^{14} \mathrm{C}$-DNPA in der 2D-SDS-PAGE: markierte Proteine und Einfluß auf das IEF}

Zur Eingrenzung und weiteren Charakterisierung der mit dem Hemmstoff der Nitrataufnahme ${ }^{14} \mathrm{C}$-DNPA markierten Proteine wurden die PlasmamembranProteine in der zweidimensionalen Gelelektrophorese (2D-SDS-PAGE) aufgetrennt. Die Gegenwart des ${ }^{14} \mathrm{C}-2,6-\mathrm{DNPA}$ in der 2D-SDS-PAGE führte konzentrationsabhängig zu starken Veränderungen des $\mathrm{pH}-$ Gradienten in der ersten Dimension (IEF) und damit des 2D-Elektropherogrammes der Proteine.

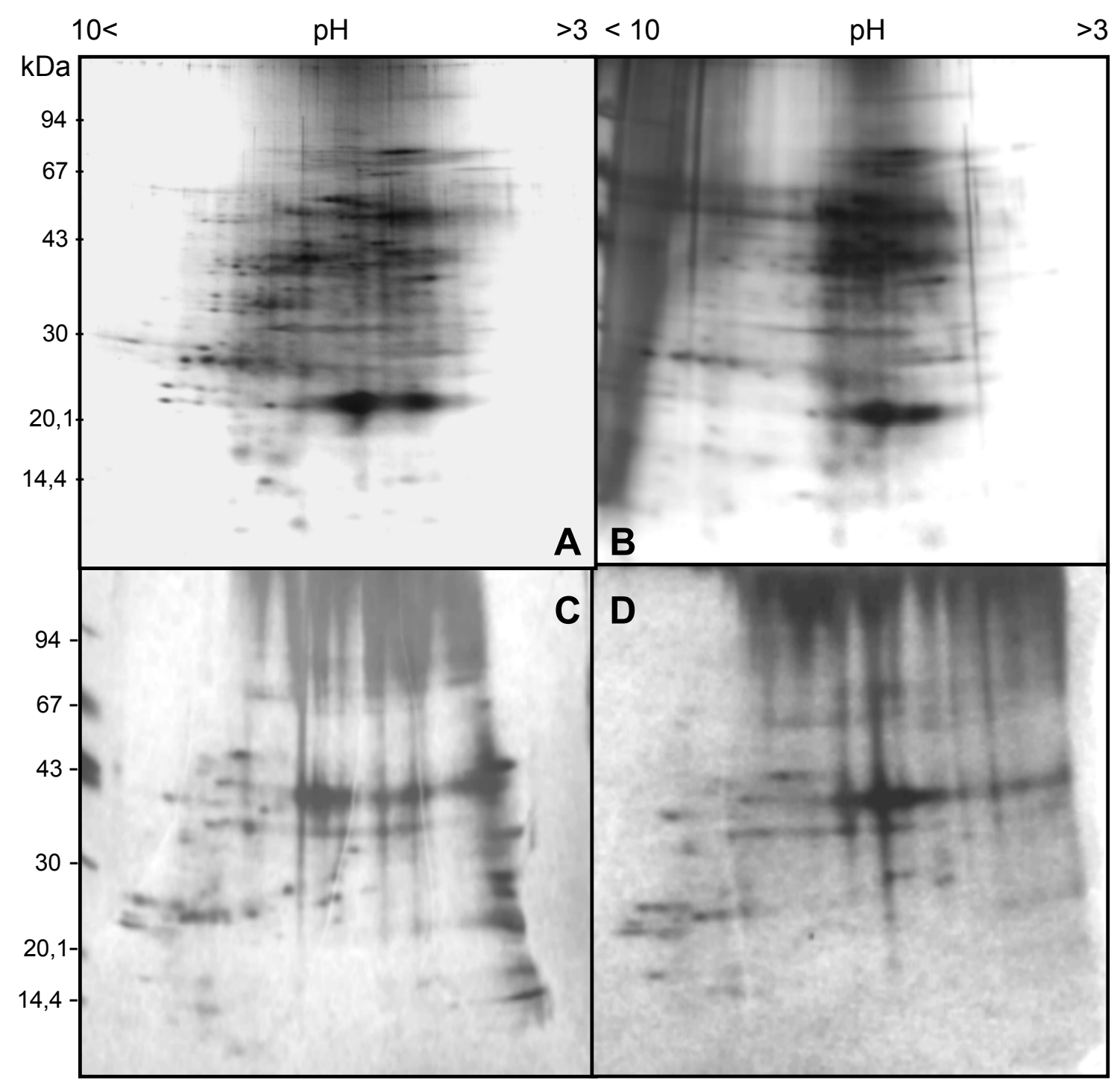

Abb. 18: Einfluß der Konzentration von ${ }^{14} C$-DNPA auf das $2 D$-Elektropherogramm der silbergefärbten Plasmamembran-Proteine. A: Kontrolle; B: $50 \mu \mathrm{M}$; C: $250 \mu \mathrm{M}$; D: 500 $\mu M^{14} C-D N P A$. Horizontal: IEF; vertikal: SDS-PAGE

Das ${ }^{14} \mathrm{C}$-DNPA beeinflußte die Stabilität des pH-Gradienten im IEF: Bei einer Konzentration von $50 \mu \mathrm{M}{ }^{14} \mathrm{C}$-DNPA im Reaktionsansatz fokussierten die Plasmamembran-Proteine zunächst unter Stauchung des neutralen Bereiches, gleichzeitig nahm die Trennschärfe des IEF deutlich ab (B). Bei einer Konzentration von $250 \mu \mathrm{M}{ }^{14} \mathrm{C}$-DNPA war der IEF-pH-Gradient im basischen und insbesondere im sauren Bereich stark gestaucht (C); bei $500 \mu \mathrm{M}$ unter Verlust von Proteinen des sauren Bereiches (D). Parallel trat mit steigender ${ }^{14} \mathrm{C}$ - 
DNPA-Konzentration eine zunehmende vertikale Schlierenbildung auf. Aufgrund der geringen spezifischen Aktivität $(6 \mathrm{mCi} / \mathrm{mmol})$ wurden die nachfolgenden Experimente mit $50 \mu \mathrm{M}{ }^{14} \mathrm{C}$-DNPA durchgeführt, da eine geringere Konzentration eine Proteindetektion durch Autoradiographie in einem noch interpretierbarem Signal-/Rauschen-Verhältnis nicht zuließ (überlange Exposition des Films). Die Bindung des ${ }^{14} \mathrm{C}$-DNPA an die Proteine war nicht stabil: Nach Fixierung/Silberfärbung waren keine markierten Proteine zu detektieren. Eine Entfernung des nicht gebundenen ${ }^{14} \mathrm{C}$-DNPA vor dem IEF durch Chloroform/Methanol-Fällung der markierten Proteine führte ebenfalls zu einem Verlust der Radioaktivität der markierten Proteine; diese waren in der Autoradiographie nicht mehr nachweisbar. Die Markierungsexperimente wurden daher mit $50 \mu \mathrm{M}{ }^{14} \mathrm{C}$-DNPA durchgeführt und die 2D-Gele ungefärbt getrocknet und exponiert, parallel wurden zur Zuordnung von Protein und Autoradiographiesignal mit den jeweils selben Probe 2D-Silberfärbungen angelegt und die Elektropherogramme mit den Radiographien nachträglich homologisiert.

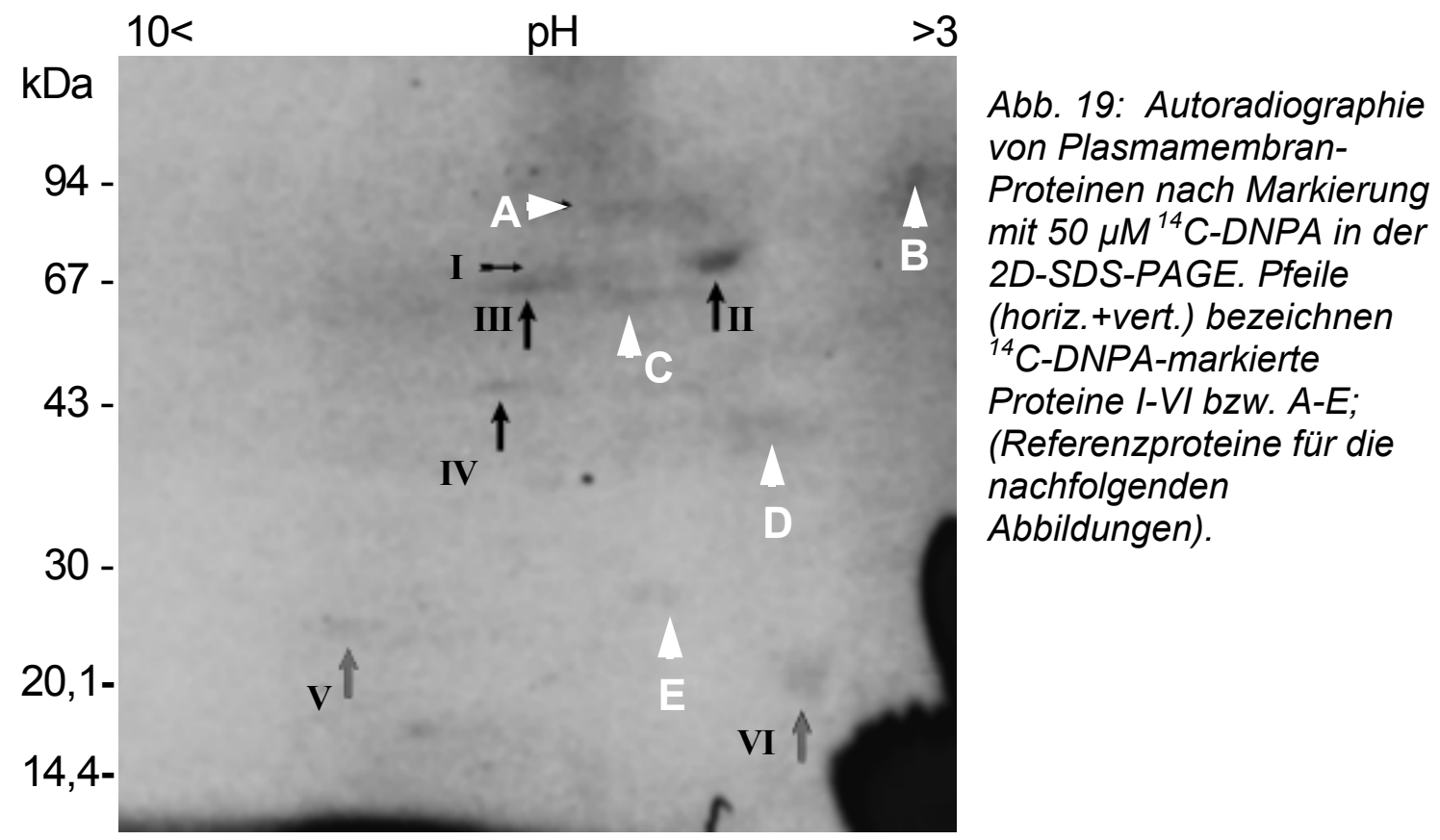

In der 2D-SDS-PAGE wurden ${ }^{14} \mathrm{C}$-DNPA-markierte Proteine der folgenden Molekulargewichte aufgetrennt: 23 kDa (Protein VI); 26 (V); 45 (IV); 64 (III); 71 (I); 75 (II). Diese dienten als Referenzproteine bei der Markierung von PMProteinen mit right side- und inside out-orientierten Vesikeln. Daneben wurden mit A-E bezeichnet, weitere Proteine markiert: 80 (A); 92 (B); 64 (C); 38 (D) und $28 \mathrm{kDa}(\mathrm{E})$. Zur Überprüfung der morphologischen Orientierung der markierten Proteine innerhalb der PM-Vesikel wurden Markierungsexperimente mit orientierten Vesikeln (inside-out und right side out) durchgeführt. Gleichzeitig wurde eine mögliche Kompetetion der ${ }^{14} \mathrm{C}$-DNPA-Markierung gegen einen 500 fachen Überschuß $\mathrm{NO}_{3}\left(10 \mathrm{mM} \mathrm{KNO}_{3}\right)$ im Reaktionspuffer geprüft. Die mit römisch I-VI gekennzeichneten, ${ }^{14} \mathrm{C}$-DNPA-markierten Proteine zeigten dabei unterschiedliche Verteilungseigenschaften in Abhängigkeit von der Orientierung der Plasmamembran-Vesikel. 


\subsubsection{PM-Vesikel-Orientierung und Kompetition durch $\mathrm{NO}_{3}$}

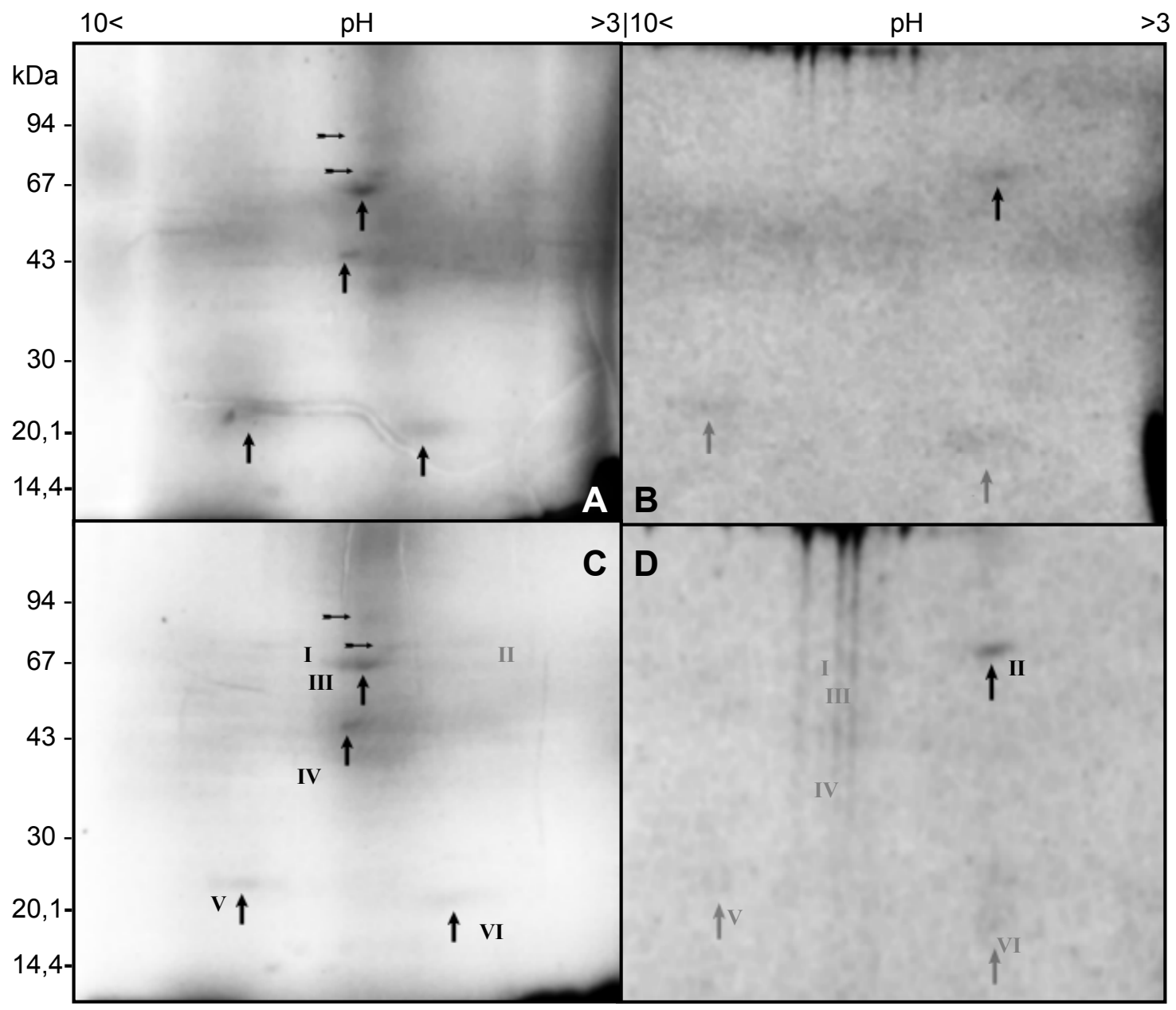

Abb. 20: Autoradiographien von inside out- und right side out-PlasmamembranVesikeln nach Markierung mit $50 \mu M^{14} \mathrm{C}$-DNPA mit und ohne $\mathrm{NO}_{3}$ im Reaktionspuffer. A: inside out-Vesikel; B: right side out-Vesikel; C: inside out Vesikel + $10 \mathrm{mM} \mathrm{NO}_{3}{ }^{-}, \mathrm{D}$ : right side out-Vesikel + $10 \mathrm{mM} \mathrm{NO}_{3}^{-}$.

In $C$ und $D$ sind zur Vereinfachung der Orientierung die ${ }^{14} C$-DNPA-markierten Proteine mit I-VI bezeichnet, das Vorhandensein eines Proteins ist durch schwarzen Pfeil gekennzeichnet, Fehlen durch grauen Pfeil. Die Radiographien $B$ und $D$ sind $\sim 10$ fach stärker kontrastiert.

Anzahl und Verteilung der ${ }^{14} \mathrm{C}$-DNPA-markierten Proteine zeigten eine Abhängigkeit von der Vesikel-Orientierung. In right side out-Vesikeln mit morphologisch korrekter Orientierung war fast ausschließlich das 75 kDaProtein II ${ }^{14} \mathrm{C}$-markiert. Die Proteine I; III; IV (71; 64; $\left.45 \mathrm{kDa}\right)$ waren nur in den inside out-Vesikeln ${ }^{14} \mathrm{C}$-markiert. Bei ${ }^{14} \mathrm{C}$-DNPA-Exposition der VesikelAussenseite (right side out) traten keine Signale dieser Proteine auf. In beiden Vesikel-Typen gleich verteilt waren Markierungen der 26 und 23 kDa-Proteine V und VI. Eine Kompetition durch einen 500fache Überschuß $\mathrm{NO}_{3}^{-}(10 \mathrm{mM})$ gegenüber ${ }^{14} \mathrm{C}$-DNPA vor der Photolysis (und kovalenten Bindung) des ${ }^{14} \mathrm{C}$ DNPA) trat nicht auf. Die ${ }^{14} \mathrm{C}$-Proteinmarkierung war unbeeinflußt. Das Verteilungsmuster der ${ }^{14} \mathrm{C}$-markierten Proteine in beiden Vesikelorientierungen änderte sich in Gegenwart von $\mathrm{NO}_{3}{ }^{-}$nicht. Das $\mathrm{NO}_{3}{ }^{-}$führte zu einer geringfügig stärkeren Markierung des 75 kDa-Proteins II. 


\subsubsection{Triton X114-Phasen-Verteilung der ${ }^{14} \mathrm{C}$-DNPA markierten Proteine}

Die ${ }^{14} \mathrm{C}$-DNPA-markierten Proteine wurde in der TX114-Zweiphasenverteilung fraktioniert. Nach Markierung von verschieden orientierten Vesikeln wurden diese zur Entfernung des TX114 gefällt, getrocknet und nach Resolubilisierung mit Harnstoff in der zweidimensionaler Gelelektrophorese aufgetrennt. Die Autoradiographie der ungefärbten 2D-Gele ( 40 $\mu$ g Protein je Kapillare) beider Triton-Phasen ergab keine Signale von ${ }^{14} \mathrm{C}$-markierte Proteinen. Die ${ }^{14} \mathrm{C}-\mathrm{DNPA}-$ Markierung war trotz Fällung der Proteine nicht ausreichend. Deshalb wurden die ${ }^{14} \mathrm{C}$-markierten Proteine der Detergenz- und wässrigen Phase des TX114Systems in einem $160 \times 200 \mathrm{~mm}$ SDS-Gel aufgetrennt $(\sim 150 \mu \mathrm{g}$ Protein je Tasche), um eine höhere Protein- $/{ }^{14} \mathrm{C}$-DNPA-Konzentration zu erreichen.

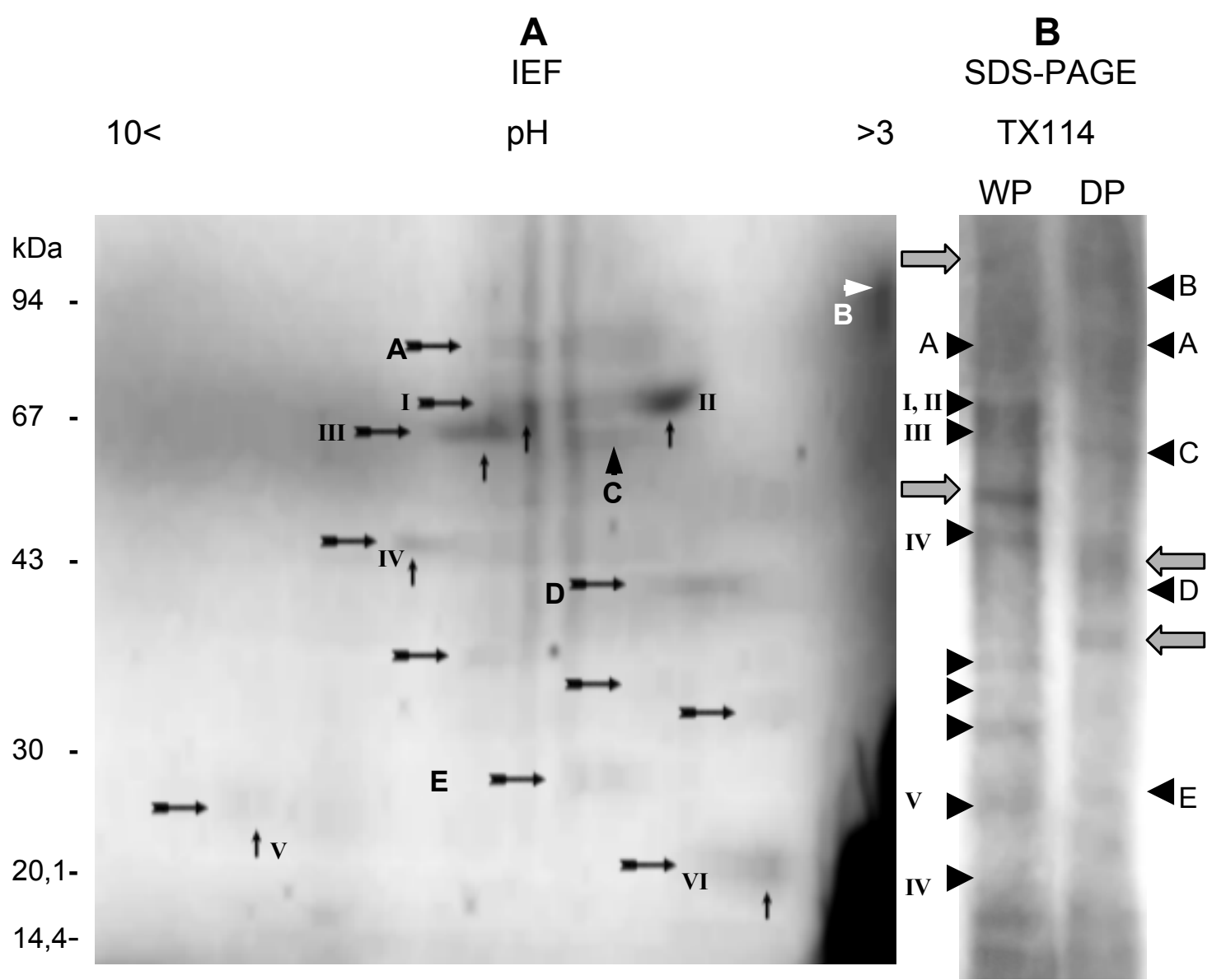

Abbildung 21: Autoradiographien von mit $50 \mu M{ }^{14} C$-DNPA-markierten Proteinen nach 2D-SDS-PAGE (A); nach TX114-Verteilung und SDS-PAGE der Proteine der TX114 wässrigen- und Detergenz-Phasen (B).

SDS-PAGE: Spur 1: Wässrige Phase (WP) des TX114-Systems; Spur 2: DetergenzPhase (DP) des TX114-Systems.

Die Proteine der 2D-SDS-PAGE sind zur Zuordnung von Proteinen gleichen Molekulargewichtes der SDS-PAGE mit Pfeilen versehen. Pfeilspitzen markieren in der SDS-PAGE wiedergefundene Proteine gleichen Gewichts. Graue Pfeile markieren nicht in der 2D-SDS-PAGE aufgefundene Proteine. Die Detergenz-bedingten Verwerfungen der TX114-DP-Spur im Gel (Graphik B) sind digital entzerrt.

Die Signale von 2D-SDS-PAGE und SDS-PAGE waren homologisierbar: Der Mehrzahl der autoradiographisch erkennbaren Signale der 2D-SDS-PAGE lagen entsprechende Signale gleichen Molekulargewichts der TX114-Phasen 
gegenüber. Dem right side out-orientierten 75 kDa-Protein II entsprach eine Bande gleichen Gewichts in der wässrigen TX114-Phase in der SDS-PAGE. Damit wurde die Zuordnung zum entsprechenden Spot der 2D-Karte möglich: Das 75 kDa-Protein II war homolog zu dem WP-Protein \# 76 (siehe unten; vergl. auch Kap. 3.3.2). Das $71 \mathrm{kDa}$-Protein I entsprach dem WP-Protein \# 74. Beide Proteine waren de novo-synthetisierte, aber nicht $\mathrm{NO}_{3}{ }^{-}$-induzierbare ${ }^{35} \mathrm{~S}$ markierte Proteine (turn-over < 4h). Die mit III-IV bezeichneten Signale lagen über einer größeren Anzahl 2D-getrennter Proteine ähnlicher Gewichte und IEP; ihre eindeutige Zuordnung war weder auf dem silbergefärbten Gel noch in der 2D-Karte möglich.

Protein III war homolog zu WP99-104 bzw. DP98-101 ( 64 kDa); WP104 zeigte nach $\mathrm{NO}_{3}^{-}$-Induktion den $\mathrm{NO}_{3}^{-}$-spezifisch stärksten ${ }^{35} \mathrm{~S}$-Einbau aller WPProteine (siehe Kap. 3.5).

Protein IV: WP 184-187 ( 45kDa);

Protein V: WP 302-305 ( 26 kDa);

Protein VI: WP 334, 338 ( 23 kDa).

Die Signale der Proteine A-E, die quantitativ untergeordnet auftraten, waren überwiegend in der Detergenz-Phase angereichert.
A: DP 45-48 bzw. WP62 ( 81 kDa);
B: DP 29 ( 91kDa);
C: DP 109-114 ( 59kDa);
D: DP 202-205 ( 38kDa);
E: DP 249 bzw. WP $292(\sim 28 \mathrm{kDa})$.

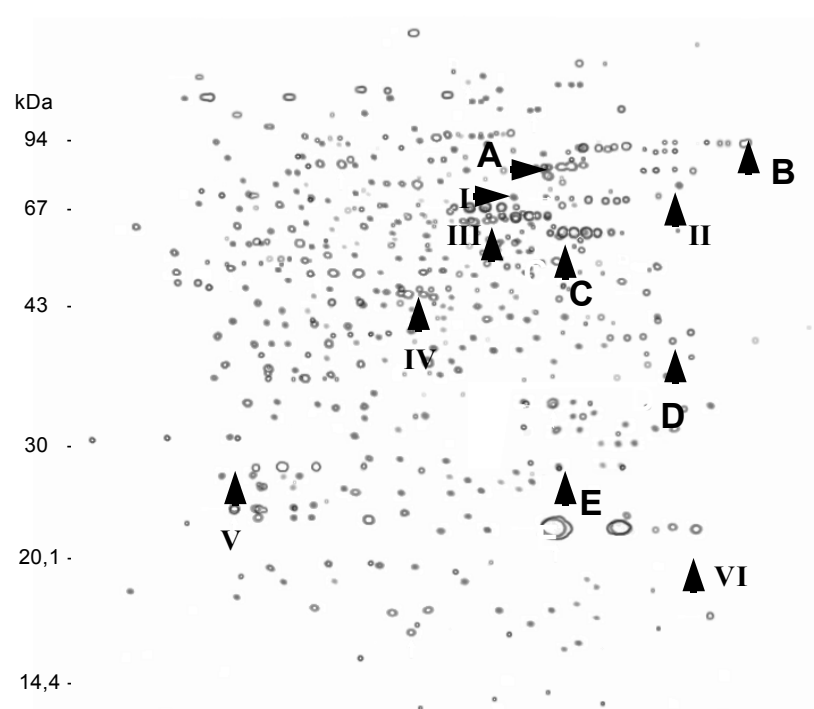

Abb. 22: Zuordnung der Autoradiographiesignale der ${ }^{14} \mathrm{C}$ DNPA markierten PlasmamembranProteinen in der 2D-Karte (entsprechend der Abb. 6). Pfeile (horiz.+vert.) bezeichnen die ${ }^{14} \mathrm{C}$ DNPA-markierten Proteine I-VI bzW. A-E.

Das einzige hochmolekulare, in right side out-Vesikeln markierte $75 \mathrm{kDa}$-Protein II hatte somit folgende Eigenschaften: geringer hydrophober Anteil (TX114: wässrige Phase), PM-Aussenseite-orientiert, ${ }^{14} \mathrm{C}$-DNPA-Affinität, saurer IEP, (turn-over < 4h). Einige, durch SDS-PAGE autoradiographisch nachgewiesene Proteine (graue Pfeile) wurden in der 2D-SDS-PAGE nicht nachgewiesen: Das 53 kDa-Protein mit dem stärksten autoradiographischen Signal der Wässrigen Phase des TX114-Systems wurde in der 2D-SDS-PAGE nicht aufgefunden, ein entsprechendes Signal fehlte. 


\subsection{Nitrat-Reduktase der PM in der 2D-SDS-PAGE}

Die Nitrat-Reduktase der PM (PM-NR) wurde als $\mathrm{NO}_{3}$-induzierbares Protein durch 2D-Gelelektrophorese aufgetrennt. Die als NR identifizierten Proteine wurden in Abhängigkeit von der Trennleistung der 2D-SDS-PAGE immunologisch untersucht.

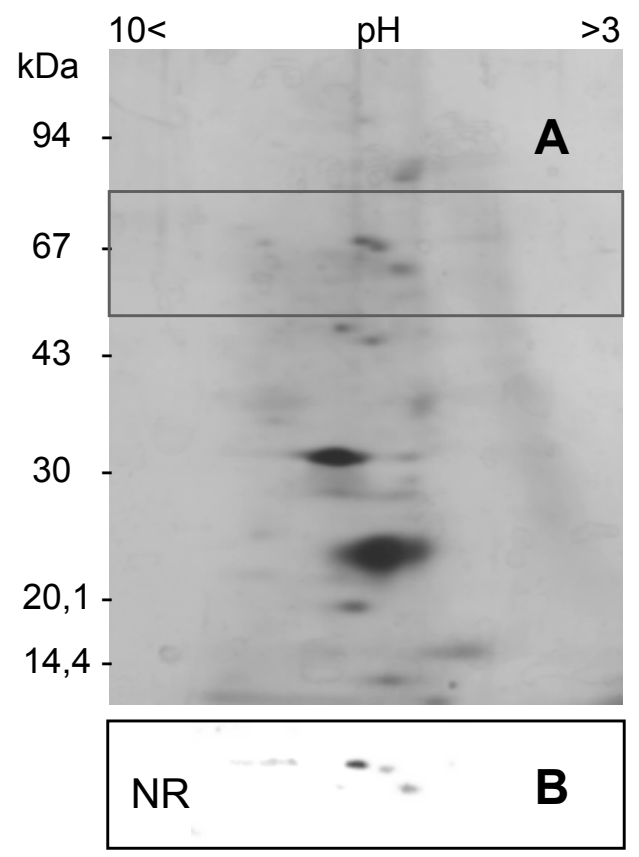

Abb. 23: Plasmamembran-Proteine unter niedrig auflösenden Elektrophoresebedingungen der 2DSDS-PAGE. Silberfärbung im $\mathrm{Gel}$ (A) und immunologischer NR-Nachweis (B).

B: Western-Blot der NR der gleichen Probe. Der Ausschnitt des Blots $\boldsymbol{B}$ entspricht dem grau umrandeten Feld des silbergefärbten 2D-Geles.

Unter nicht-optimierten Elektrophorese-Bedingungen fokussierten die Proteine der PM stark gestaucht und unter Auflösung nur weniger Proteine (A; vergl. Kap. 3.2.1). Der Westernblot der NR (B) der Plasmamembran zeigte unter diesen Bedingungen drei Proteine von 67,3; 64,4 und 58,9 kDa. Im basischen Bereich des IEF traten mehrere Proteine mit gleichem Molekulargewicht von 71,0 kDa quantitativ untergeordnet auf (DP-Proteine \# 71; 72; 73).

Unter optimierten, hochauflösenden Elektrophorese-Bedingungen sollte die 2DSDS-PAGE eine differenzierte Einordnung der immunologisch NR-markierten Proteine in die 2D-Proteinkarte ermöglichen. Dazu wurden zunächst Referenzproteine zur Wiederfindung festgelegt (Abb. 24) und die NR unter hochauflösenden SDS-PAGE-Bedingungen aufgetrennt (Abb. 25).

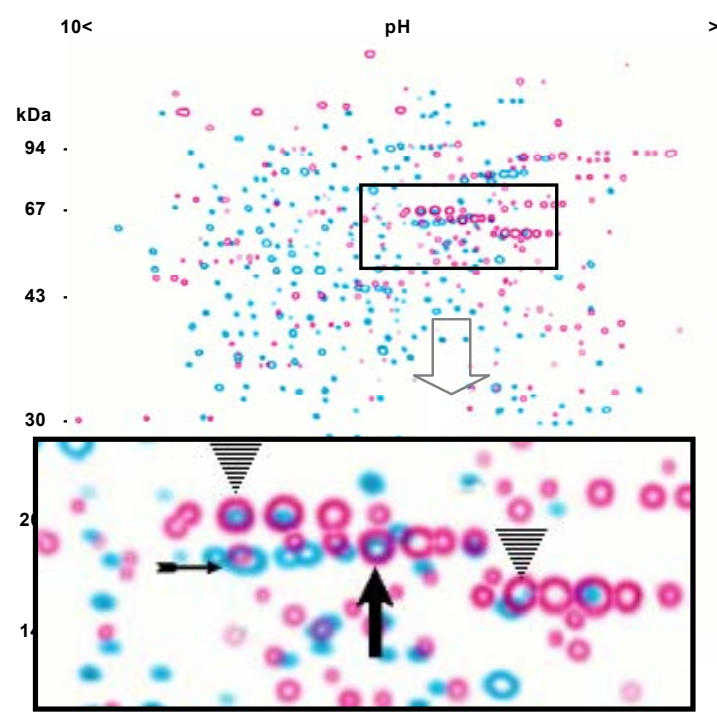

Abb. 24: Zur Lokalisation der durch den Nitrat-Reduktase-AK immunologisch nachgwiesenen Proteine in der 2D-Proteinkarte ausgewählte Referenz-Proteine (verkleinerte 2D-Karte der Proteine der TX114Phasen gemäß Abb. 6). In der Ausschnittsvergrößerung durch vertikalen Pfeil und schraffierte Dreiecke markiert: Ausgewählte Referenzproteine DP \# 75 (=WP \# 85); \# 101 (=WP \# 104, vertikaler Pfeil); \# 110 (=WP \#118); Reihenfolge gemäß ihres abnehmenden Mol.Gewichts). Horizontaler Pfeil: WP- Protein \# 100 (=DP \# 98). 


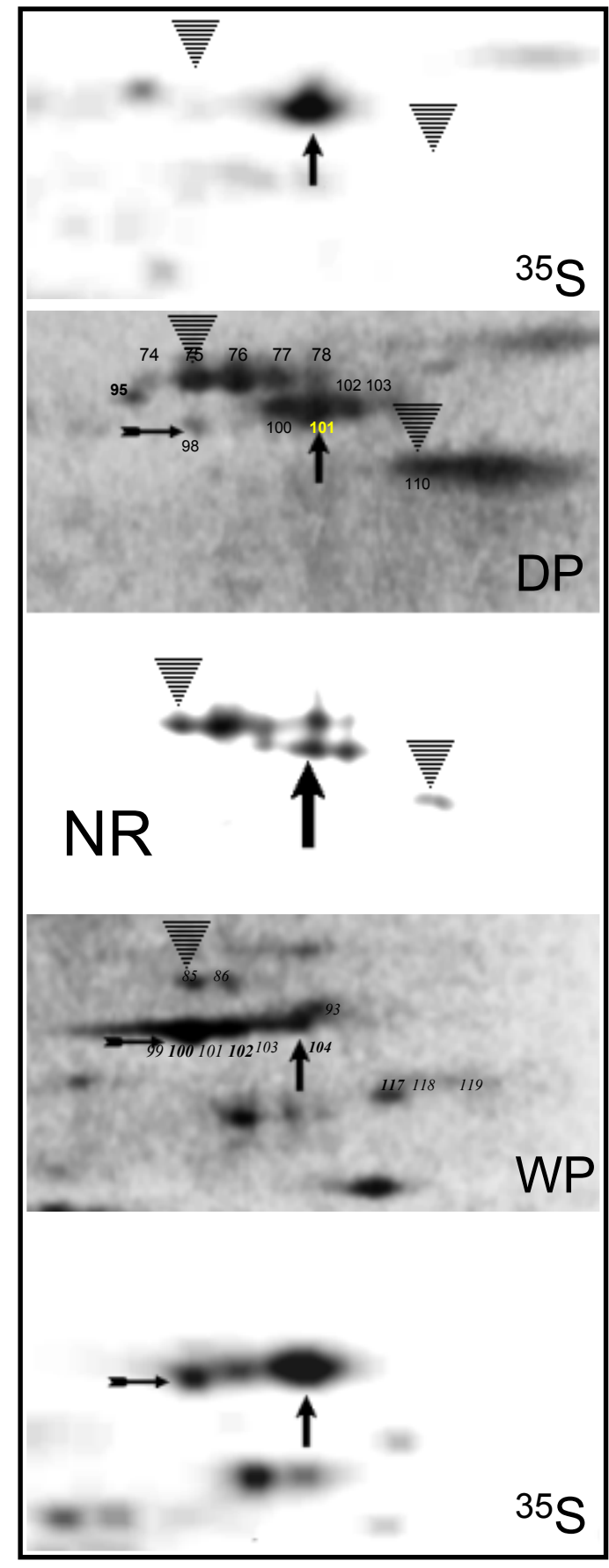

Abb. 25: 2D-SDS-PAGE: Lokalisation der immunologisch nachgewiesenen Proteine der NR innerhalb der TX114-Phasen und Autoradiographien der $\mathrm{NO}_{3}^{-}$-induzierten, ${ }^{35} \mathrm{~S}$ markierten Proteine. Die mittlere Graphik (NR) zeigt die immunologisch detektierten NR-Proteine. Oberhalb davon Silberfärbung und Autoradiographien der DP-Proteine; unterhalb des NR-Blots WP-Proteine nach Silberfärbung und Autoradiographie. Dargestellt ist jeweils der Ausschnitt entsprechend der Abb. 24.

Vertikaler Pfeil markiert sowohl durch NRAK, als auch durch Silberfärbung im $\mathrm{Gel}$ sowie Autoradiographie nachgewiesenes Protein DP \# 101 (=WP \# 104). Schraffierte Dreiecke zeigen auf Referenzproteine, horizontaler Pfeil zeigt WP-Referenzprotein; die ausgewählte Proteine waren jeweils in diesen Phasen angereichert. Dreiecke und Pfeile wie in Abb. 24.

Die drei bei gering trennender 2D-SDSPAGE aufgelösten NR-Proteine wurden in jeweils mehrere Proteine gleichen Molekulargewichts mit eng beieinander liegendem IEP aufgetrennt. Durch immunologischen Nachweis NRantigener Proteine wurden bis auf DP \# 101 verstärkt in der TX114Detergenzphase angereicherte Proteine detektiert. Dies waren die DP-Proteine \#75; 76; 77; 78 von 67,3 kDa Molekulargewicht; die 64,4 kDa-Proteine \# 100; 101; 102 sowie das 58,9 kDaProtein \# 110. Das quantitativ untergeordnete, basisch fokussierte 71,0 kDa-Protein wurde als DP \# 64; 65; 66 bestimmt (nicht gezeigt).

Das 64,4 kDa DP-Protein \# 101 war das einzige NR-Polypeptid, das eine ${ }^{35} \mathrm{~S}$ Markierung trug und somit durch $\mathrm{NO}_{3}{ }^{-}$induzierbar war. Es ist dem WP-Protein \# 104 homolog in Molekulargewicht; IEP und $\mathrm{NO}_{3}^{-}{ }^{-}$Induzierbarkeit. Die als NR detektierten Proteine von 67,3 kDa zeigten keine ${ }^{35} \mathrm{~S}-M a r k i e r u n g$. Das Protein DP \# 101 / WP \# 104 war in beide Triton-Phasen verteilt, mit einer geringfügig stärkeren Anreicherung in der WP. Durch Abgleich von Western-Blot, silbergefärbten Proteinen im Gel und ${ }^{35}$ S-markierten Proteinen konnte DP \# 101/WP \# 104 eingegrenzt werden: Es war das einzige $\mathrm{NO}_{3}$-induzierte Protein innerhalb der Gruppe der immunologisch als Nitrat-Reduktase identifizierten Proteine. 


\subsection{Herstellen von Antikörpern gegen Nitrat-Transporter-Proteine}

Ziel war die Gewinnung eines polyklonalen Antikörpers zum immunologischen Nachweis eines Nitrat-Transporters in Chlorella saccharophila.

\subsubsection{Zur Peptidsynthese ausgewählte Aminosäure-Sequenzen}

Durch Alignment bekannter Nitrat-Transporter anderer Spezies wurden Bereiche der höchsten Homologie der Aminosäuresequenzen als geeignete Antigene zur Immunisierung herausgesucht. Taxonomisch entfernte Gattungen (Staphylococcus; Pseudomonas) wurden, da keine Informationen zum Transporterprotein in Chlorella vorlagen, miteinbezogen. Ebenfalls Proteine, die anstelle von Nitrat Nitrit transportieren, um hochkonservierte Bereiche innerhalb der Nitrat- Nitrit-Porter- (NNP-) Familie (Poa et al., 1998) zu erfassen.

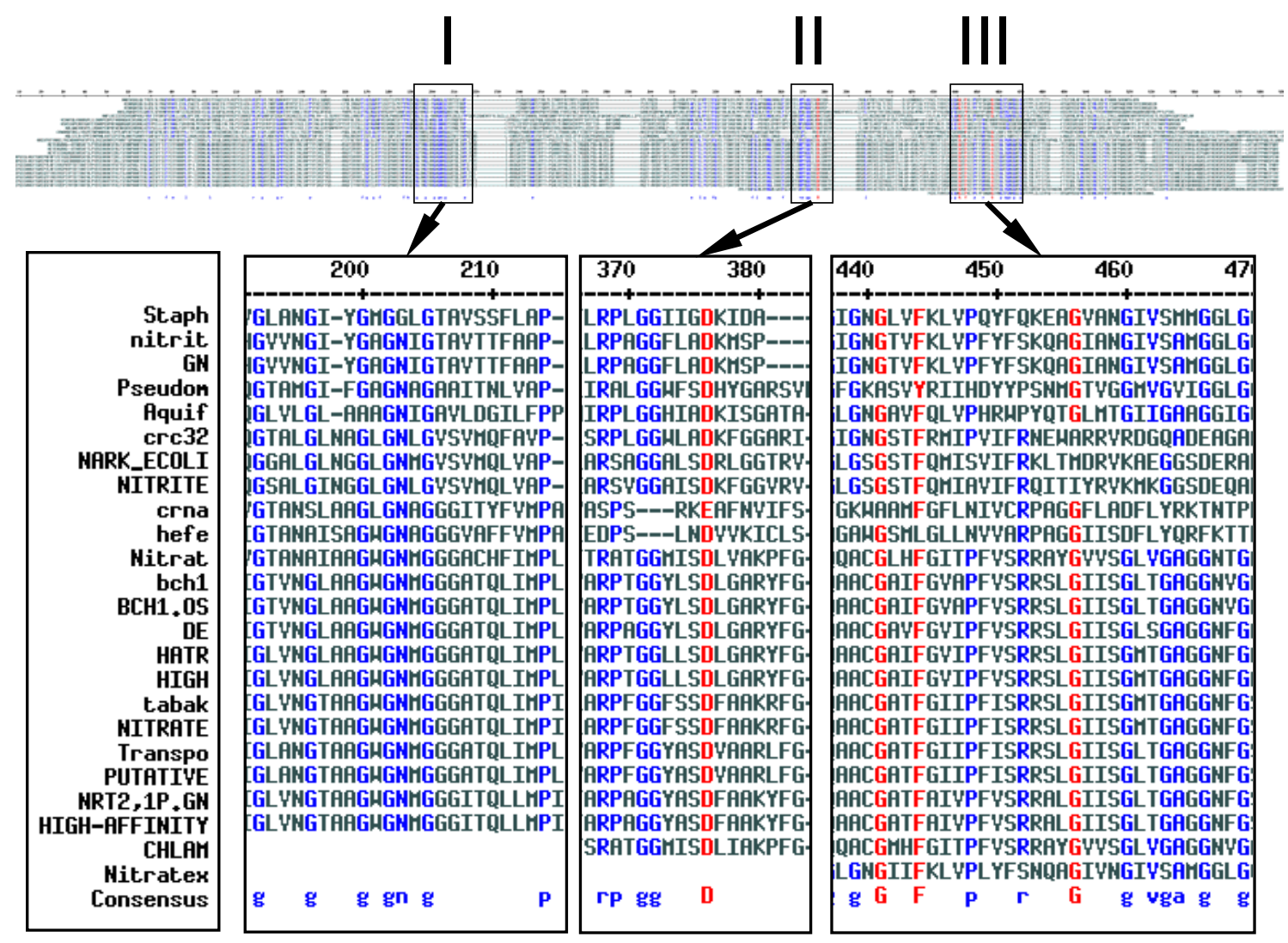

Abb. 26: Aminosäure-Alignment von bekannten $\mathrm{NO}_{3}^{-}-\left(\mathrm{NO}_{2}^{-}{ }^{-}\right)$Transporter-Proteinen (der NNP-Familie) aus höheren und niederen Pflanzen, Pilzen und Bakterien. In DetailAusschnitten die Bereiche I-III der höchsten Homologien mit Consensus-Aminosäuren (blau bzw. rot); die zur Immunisierung zusammengestellten Peptide I-III enthielten die Consensus-AS dieser drei Bereiche. Proteine siehe Text.

Aus den Bereichen I-III der höchsten Homologie wurden, den gezeigten Bereichen zugeordnet, Peptide von 15, 10 und 15 Aminosäuren Länge für die Immunisierung ausgewählt. Bei der Auswahl der Aminosäuren wurden Häufigkeit der jeweiligen Aminosäure und Diversität des zu synthetisierenden Peptids hinsichtlich unterschiedlicher taxonomischer Herkunft der Sequenz 
berücksichtigt (Sequenzen aus Arabidopsis, Glycine, Nicotiana, Oryza, Hordeum Triticum, Chlamydomonas, Escherichia, Staphylococcus, Pseudomonas, Aspergillus, Aquifex, Candida, etc.). Dazu wurden Alignments der AS-Sequenzen aller bekannten Transporter erstellt und die Häufigkeiten der einzelnen, die Consensus-AS umgebenden AS verglichen und nichtconsensus-AS nach Häufigkeit (Peptid I und III) bzw. niedriger Organisationshöhe (Chlamydomonas; Peptid II) ausgewählt (nicht gezeigt). Aus der Sequenz von Transportern höherer Pflanzen wurden mögliche Transmembran-Helices und die wahrscheinliche räumliche Orientierung des Proteins in der Plasmamembran errechnet: Peptid I und II lagen in einwärts gerichteten Schleifen des Proteins mit relativ geringerer Hydrophobizität und theoretischer Lage im Cytosol; Peptid III im Bereich hoher Hydrophobizität und war überlappend transmembranär/Aussenseite-orientiert (Plot nicht gezeigt). Die Peptide enthielten einen hohen Anteil lipophiler AS; dies war unvermeidlich, da diese Bestandteile der Consensus-Sequenzen waren. Die C-Termini der Transportproteine wiesen keine verwertbaren Consensus-Bereiche auf (siehe Abb. 26 obere Graphik, rechter Teil: C-Termini). Die aus den ConsensusBereichen zusammengestellten Peptide waren:

Peptid I: WGNMGGGATQLIMPL (AS 184-208)

Peptid II: RPTGGMISDL (AS 332-341)

Peptid III: RAYGIISGLVGAGGN (AS 406-420)

(in Klammern angegeben: Position der Peptide innerhalb der AminosäureSequenz des Nitrat-Transporters in Glycine). Die drei synthetischen Peptide wurden nach Cystein-Kopplung als Gemisch zu gleichen Teilen zwei Kaninchen \# 58 und \# 29 injiziert. Kaninchen \# 29 starb vor dem Zeitpunkt des $2^{\text {nd }}$ Bleeding. Ein acht Wochen nach Erstimmunisierung von \# 29 und 58 immunisiertes, drittes Kaninchen \# 119 (als Ersatz für \# 29) starb ebenfalls vor dem $2^{\text {nd }}$ Bleeding. Drei Prä-Immunseren sowie drei Seren \# 29; \# 58; \# 119 wurden gewonnen; von \# 58 auch $2^{\text {nd }}$ Bleeding.

\subsubsection{Peptidspezifität: Dot-Blot der Seren und PM-Proteine im Western Blot}

Die Seren \# 58 und \# 29 wurden durch Dot-Blot einer Verdünnungsreihe der Peptide I-III auf ihre Peptidspezifität getestet. Gleichzeitig wurden die für Western Blots geeigneten Serum-Konzentrationen ermittelt. Die PräImmunseren von \# 29 und \# 58 bildeten die Negativ-Kontrolle; sie wurden in den Konzentrationen 1:500 und 1:2500 eingesetzt. Der sekundäre, APkonjugierte Antikörper wurde in einer Konzentration von 1:3000 in TBS eingesetzt.

Die Peptide I und III waren schwer löslich: Nach 1 min Ultraschallbehandlung und Kochen in 1:500 verdünntem SDS-Beladungspuffer für 3 min sedimentierte bei Abkühlung wieder ein Peptidniederschlag. Die Verdünnungsreihen der Peptide wurden daher mit den noch heißen Peptidlösungen angesetzt. Durch die schnelle Ausfällung der Peptide I und III war die auf dem Dot Blot aufgebrachten Peptidmenge möglicherweise geringer als angegeben. 


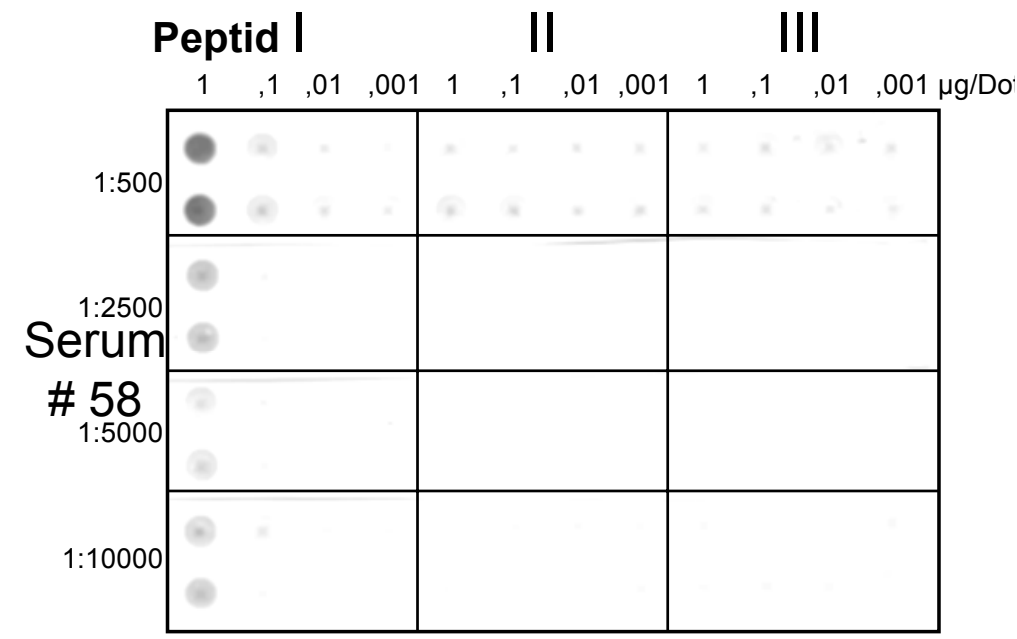

Abb. 27: Peptid-Spezifität der Seren \# 29 und \# 58. Auf den Dot Blot aufgebracht wurden Verdünnungsreihen der Peptide I-III, angegeben ist die Peptidmenge je Dot. Die Blots wurden gemäß den links angegebenen Serum- Verdünnungen inkubiert. Die Kontrollen (Prä-Immunseren) wurden in den beiden höchsten Konzentrationen $(1: 500$ bzw. 1:2500) eingesetzt.

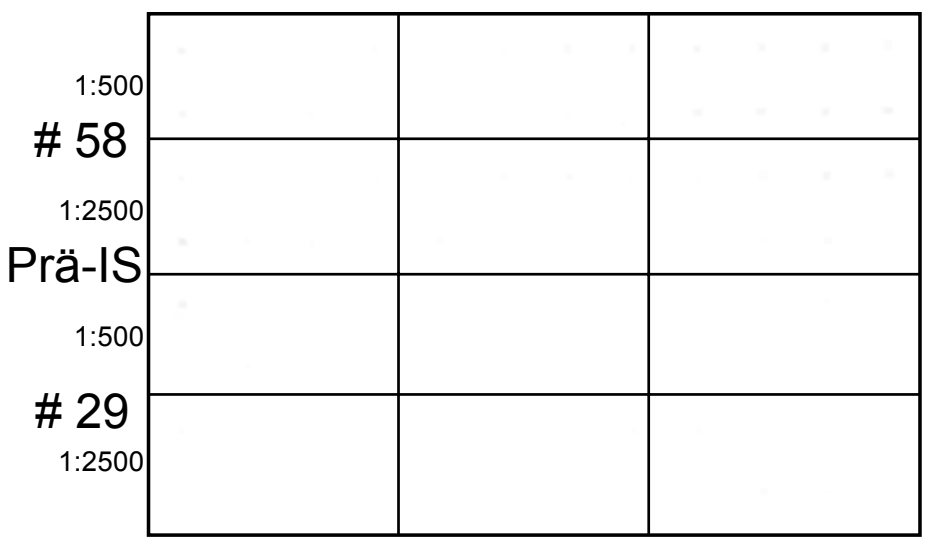

Serum \# 29 und Serum \# 58 zeigten eine konzentrationsabhängige Immunreaktion auf das Antigen Peptid I. $1 \mu \mathrm{g}$ Peptid I wurde noch von Serum in einer Verdünnung von 1:5000 (\# 29) bzw. 1:10000 (\# 58) detektiert. Die Farbintensität der Dots entsprach der Konzentrationsabnahme des Peptids. Die Peptide II und III wurden von beiden Seren nur in der höchsten Serumkonzentration detektiert; dabei trat keine Korrelation zwischen Konzentration und Anfärbung auf. Bei den Prä-Immunseren trat keine AntigenAntikörper-Reaktion in den beiden höchsten eingesetzten Verdünnungen auf.

Zur Überprüfung der Seren wurden Western Blots von SDS-PAGEaufgetrennten PM-Proteinen angefertigt. 


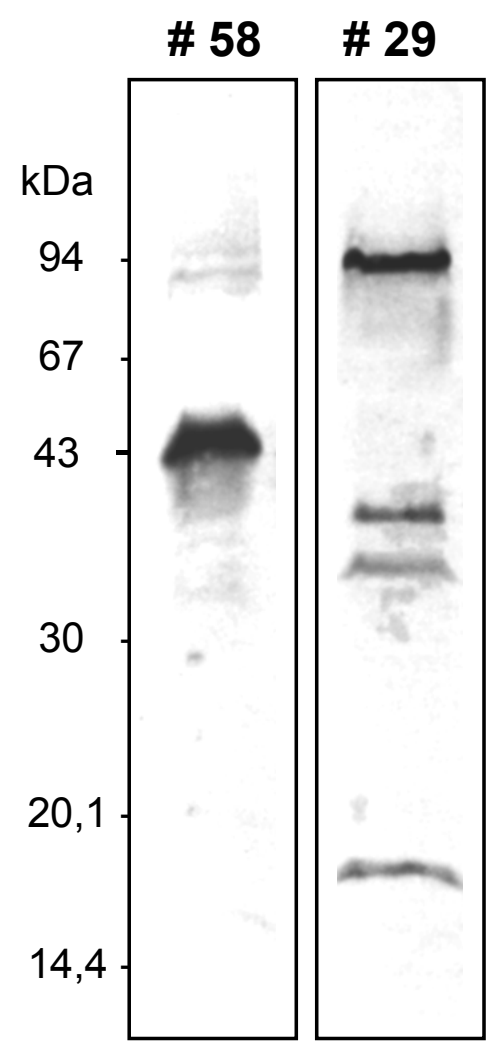

Abb. 28: Western-Blot der Immunodetektion von Plasmamembran-Proteinen durch die Seren \# 29 und \# 58 (1:2500). Aufgetragen: $100 \mu \mathrm{g} /$ Spur.

Die Seren \# 29 und \# 58 detektierten PM-Proteine der Molekulargewichte: 17; 34; 37; 44 und 91 kDa (hervorgehoben: von \# 29 markierte Proteine). Ein 91 kDa-Protein erschien bei \# 58 als von der Färbung seiner Ränder flankiertes Negativ. Die gezeigten Proteine mit Ausnahme des 17 kDa-Proteins wurden auch durch das jeweilige Prä-Immunserum markiert. Das später nachgelieferte Serum 119 wies ebenfalls keine Unterschiede zwischen Prä-Immun- und Immunserum auf (Daten nicht gezeigt), die Kaninchen \# 119 und \# 58 zeigten somit keine Antigenbildung gegen die injizierten Peptide.

Ein 64 kDa-Protein wurde in PM mit starker Verunreinigung (grüne PM) durch Chloroplasten-Hüllmembranen (Thylakoidmembranen) immunologisch nachgewiesen. Dieses Protein zeigte eine Konzentrationszunahme nach $\mathrm{NO}_{3}^{-}-$ Induktion. Die Verunreinigung durch Membranen des Chloroplasten trat infolge des Zellaufbruchs der $\mathrm{NO}_{3}^{-}$-induzierten Algen durch eine Zellmühle auf. Das Protein fehlte in Chloroplastenmembran-freier PM (Daten nicht gezeigt).

Nach 2D-SDS-PAGE wurden zusätzlich die ebenfalls vom NR-AK detektierten Proteine der Molekulargewichte 67,3 kDa; 64,4 kDa und 58,9 kDa detektiert; daneben ein 80 und 83 kDa-Protein der wässrigen TX114-Phase im sauren $\mathrm{pH}-$ Bereich (nicht gezeigt). 


\subsubsection{Nitrat-Transporter-Antikörper (Antigen aus Hordeum vulgare)}

Ein Antiserum gegen den Nitrat-Transporter in Hordeum vulgare wurde gegen Plasmamembran-Proteine aus Chlorella geprobt.

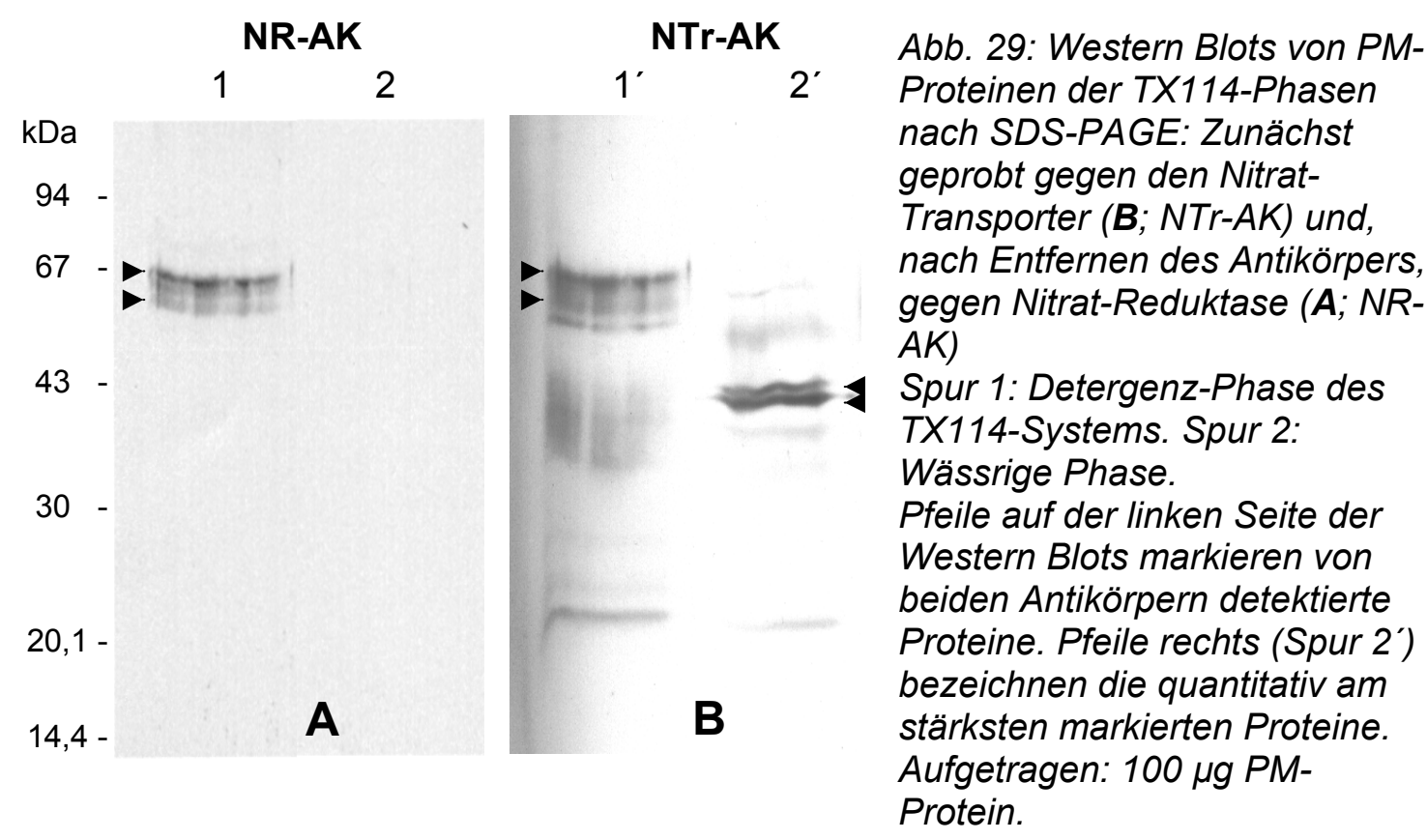

Der Antikörper gegen Nitrat-Reduktase markierte Proteine von 67; 64 und 59 kDa Molekulargewicht in der Detergenzphase. Der Antikörper gegen den NitratTransporter aus Hordeum vulgare markierte ebenfalls ein 67; 64; 59 und 55 kDa Protein der Detergenz-Phase. In der wässrigen Phase wurde ein 64 kDaProtein markiert, sowie zwei Proteinbanden der Molekulargewichte 43 und 41 kDa; diese zeigten die höchste Affinität zum Antikörper (intensivste Schwärzung des Films). In beiden TX114-Phasen wurde ein 22 kDa-Protein markiert.

Eine 2D-Auftrennung der PM-Proteine zur Einordnung der durch SDS-PAGE und Western Blot nachgewiesenen Proteine gemäß 2D-Karte wurde durchgeführt. Aufgetrennt wurde $\mathrm{PM}$ aus $\mathrm{NH}_{4}{ }^{+}$-vorkultivierten Algen. Diese wurden nach $24 \mathrm{~h} \mathrm{~N}-$ Mangel und $\mathrm{NO}_{3}^{-}$-Induktion zu den Zeitpunkten 2 und $4 \mathrm{~h}$ nach Induktion durch Aufbruch in der Zellmühle geerntet und von der präparierten PM 2D-Western Blots angefertigt.

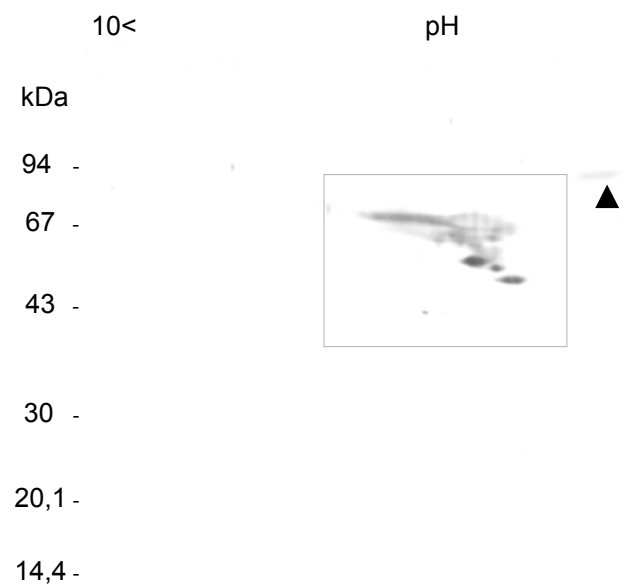

Abb. 30: 2D-SDS-PAGE: Western Blot von Nitrat-Transporter-AK detektierten Proteinen nach $\mathrm{NO}_{3}-$ Induktion (2h). Oberer Pfeil markiert 91 kDa-Protein, untere Pfeile zwei $64 \mathrm{kDa}$-Proteine mit IEP im sauren pH-Bereich des Gradienten. Graues Feld: Ausschnittsbereich der folgenden Abbildung 31. 
Zwischen den Western Blots der durch SDS-PAGE- und 2D-SDS-PAGE aufgetrennten Proteine traten erhebliche Unterschiede auf: Distinkte Banden des Western Blots nach SDS-PAGE erschienen im 2D-SDS-PAGE-Western Blot als diffuse Bereiche. Proteine der SDS-Page fehlten als Protein-Spot im 2D-Blot $(22 ; 24 ; 35 ; 41$ kDa). Der Nitrat-Transporter-AK (Hordeum vulgare) detektierte nach 2D-SDS-PAGE ein $91 \mathrm{kDa}$-Protein im sauren $\mathrm{pH}$-Bereich sowie zwei $64 \mathrm{kDa}$-Proteine mit einem apparenten IEP von annähernd $\mathrm{pH} 3$. Das 91 kDa-Protein DP \# 29 wurde auch durch ${ }^{14} \mathrm{C}-\mathrm{DNPA}$ markiert. Im Ausschnittsbereich umfasste Proteine zeigten zum Teil $\mathrm{NO}_{3}^{-}$-induzierte Beeinflussung:

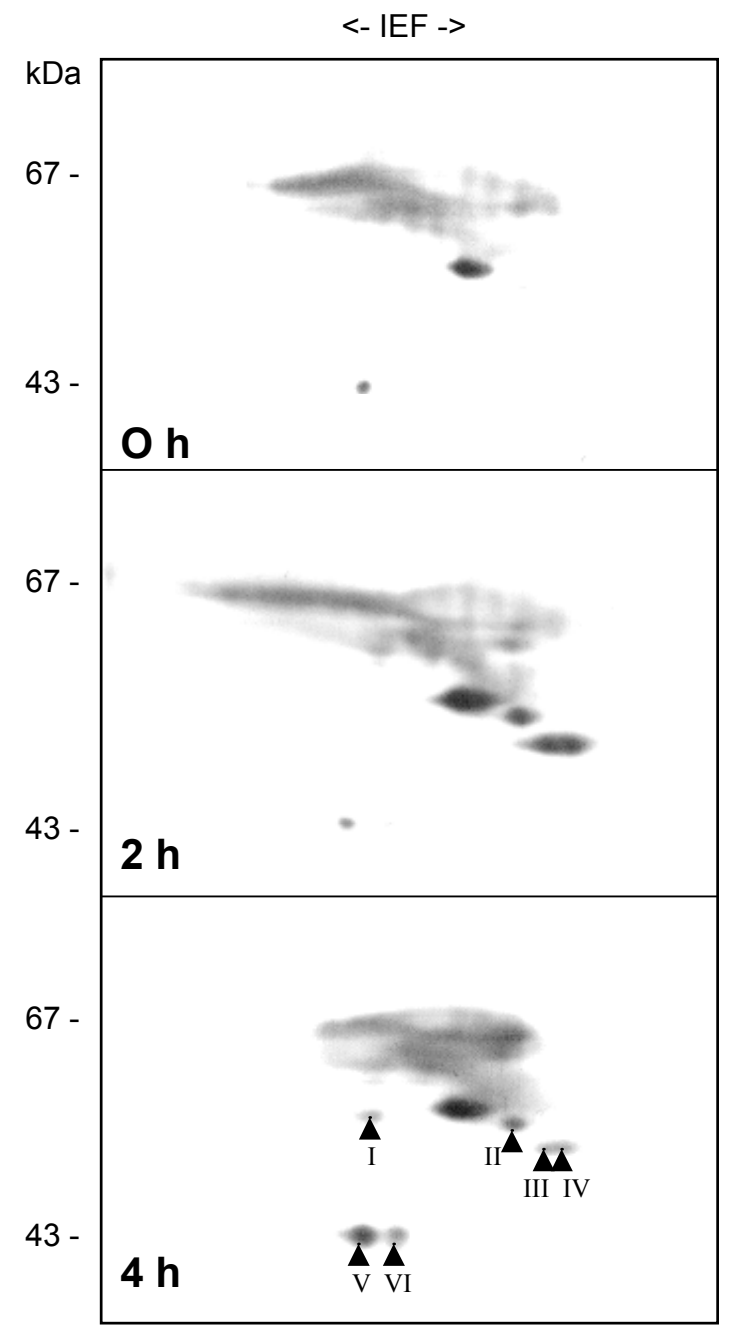

Abb. 31: Western Blots von 2D-SDSPAGE aufgetrennten PM-Proteinen, geprobt mit einem AK gegen den NitratTransporter in Hordeum vulgare.

Ausschnitts-Vergrößerungen der Western Blots zu den Zeitpunkten $0 \mathrm{~h}$ (Kontrolle) und 2 und $4 \mathrm{~h}$ nach $\mathrm{NO}_{3}^{-}$-Induktion $\mathrm{N}$ verarmter Algen. Pfeile markieren $\mathrm{NO}_{3}{ }^{-}$ induzierte Proteine, römische Ziffern siehe Text.

Mit dem Nitrat-Transporter-AK wurden im 2D-SDS-PAGE-Western Blot $\mathrm{NO}_{3}^{-}$ induzierbare Proteine nachgewiesen (Pfeile I-VI). Die Proteine II, III und IV zeigten nach vorübergehender Induktion ein wieder abnehmendes Signal nach $4 \mathrm{~h}$. Die Signalstärke der Proteine I; $\mathrm{V}$ und VI war nach $4 \mathrm{~h}$ maximal. Die Proteine I-VI waren sämtlich in der wässrigen TritonX114Phase angereichert: Die Zuordnung der Signale des ECL-Films zum silbergefärbten Kontrollgel (nicht gezeigt) ergab homologe Molekulargewichte und IEPe von Protein I = WP 134; II = WP 138; III = WP 157; IV = WP150; $\mathrm{V}=W P$ 187; $\mathrm{VI}=$ WP 188. Übereinstimmungen einer $\mathrm{NO}_{3}{ }^{-}$-Induzierbarkeit lagen bei den Proteinen WP 138; 150; 187 vor; diese waren ebenfalls nach $\mathrm{NO}_{3}^{-}$-Induktion in Gegenwart von ${ }^{35} \mathrm{~S}-$ Methionin ${ }^{35} \mathrm{~S}$ markiert (siehe Abb. 10).

Der Antikörper detektierte auch die vom NR-AK nachgewiesenen 67,3 und 64,4 kDa-Proteine (wolkig mit negativ kontrastierten Proteinspots, verschmiert im basischen $\mathrm{pH}$-Bereich). Daneben weitere Proteine in diffusen Anfärbungen von nicht eindeutiger Lokalisation.

Durch das Serum \# 29 und den (Hordeum vulgare-) Nitrat-TransporterAntikörper wurden verschiedene Proteine immunologisch nachgewiesen. Diese 
zeigten zum Teil $\mathrm{NO}_{3}^{-}$-Induzierbarkeit. Homolog zu NR-AK-detektierten Proteinen wurden ${ }^{35} \mathrm{~S}$-markierte Proteine der wässrigen TX114-Phase ebenfalls vom Nitrat-Transporter-AK detektiert. Sowohl durch den Nitrat-TransporterAntikörper (Hordeum vulgare), als auch durch Serum \# 29 nachgewiesen und zusätzlich ${ }^{14} \mathrm{C}$-DNPA-markiert war Protein DP 29 von 91 kDa Molekulargewicht; dieses Protein war nicht ${ }^{35}$ S-markiert.

\subsection{Proteinisolierung aus 2D-SDS-PAGE-Gelen}

Ziel war die Isolierung von Proteinen der Plasmamembran nach Auftrennung durch 2D-SDS-PAGE und Elektro-Blotting auf PVDF-Membran in einer zur Ansequenzierung ausreichenden Menge und Reinheit. Die N-terminale Sequenzierung der Proteine erfolgte bei der GBF in Braunschweig; die dort zur Sequenzierung erforderliche Mindestmenge wurde mit 1-5 pmol Protein angegeben. Zur Abschätzung der jeweiligen Proteinmenge der auf der PVDFMembran vorliegenden Proteinspots wurde zunächst die Relation zwischen Proteinmenge und Anfärbbarkeit durch verschiedene Färbemethoden bestimmt.

\subsubsection{Quantitätsabschätzung der durch 2D-SDS-PAGE getrennten Proteinspots}

Zur Abschätzung der Proteinmenge der im 2D-Gel getrennten Proteinspots wurden die Nachweis-Empfindlichkeiten von Coomassie Brillant Blue und Silberfärbung miteinander verglichen.

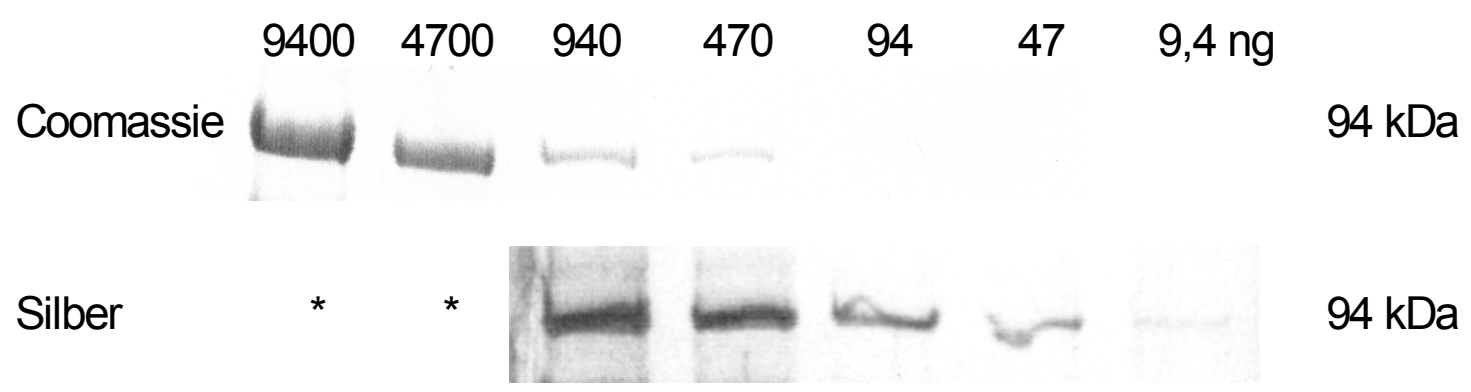

Abb. 32: Vergleich der Sensitivität von Coomassie Brillant Blue und Silberfärbung nach Blum et al. (1989) durch Proteinanfärbung eines 94 kDa-Proteins nach SDS-PAGE im Gel.

Aufgetragen wurden Proteinmengen äquivalent 100; 50; 10; 5; 1; 0,5; 0,1 pmol (94 kDa Protein aus Molekulargewichts-Standard LMW, Pharmacia). *stark überfärbte Proteinbanden, vom $\mathrm{Gel}$ abgetrennt und nicht abgebildet.

Durch Coomassie Brillant Blue wurden 940 ng oder 10 pmol deutlich, 470 ng oder 5 pmol je Proteinbande des 94 kDa-Proteins noch erkennbar angefärbt. Die Sensitivität der Silberfärbung war ca. 50x höher; mit dieser Färbemethode wurden 0,1 pmol oder 9,4 ng Protein detektiert. Die Anfärbung der, einer SDSPAGE-Proteinbande vergleichbaren Fläche eines Proteinspots $\leq 94 \mathrm{kDa}$ im 2DSDS-PAGE durch Coomassie entsprach somit einer Menge von ca. 5pmol Protein. 


\subsection{2 „large scale“ 2D-SDS-PAGE: Präparatives IEF}

Zur quantitativen Anreicherung der nach der $\mathrm{NO}_{3}-$-induzierten und/oder ${ }^{14} \mathrm{C}$ DNPA-markierten Proteine wurde ein präparatives IEF in 3,2 $\mathrm{mm}$ Gelstäben durchgeführt. Eingesetzt wurden $450 \mu \mathrm{g}$ Plasmamembran-Protein, das nach TX114-Verteilung, Fällung und Resuspendierung der Proteine der jeweiligen Phasen aufgetrennt wurde. Die zur Ansequenzierung ausgewählten Proteine wurden zunächst im SDS-Gel durch Coomassie angefärbt, ausgestanzt und gesammelt. Eine Elektoelution der Gelstückchen zur Vereinigung des Proteins auf einen gemeinsamen PVDF-Blot zeigte eine sehr geringe Ausbeute; diese reichte zur Ansequenzierung nicht aus (Daten nicht gezeigt). Daher wurden die Gele vollständig auf PVDF-Membran geblottet und die Proteine auf dem Blot mit Coomassie Brillant Blue angefärbt.

$10<$

$\mathrm{pH}$

$\mathrm{kDa}$

$94-$

67

43

$30-$

$20,1-$

$14,4-$
$>3$
Abb. 33: 2D-SDS-PAGE der TX114-DetergenzPhase von $450 \mu \mathrm{g}$ PMProtein im 3,2 mmGelstab. Proteine geblottet auf PVDFMembran und mit Coomassie Brillant Blue angefärbt. Durch Pfeile markiert: Zur Ansequenzierung ausgewählte Proteine (Proteine siehe Text).

Durch Coomassie G250 wurden gegenüber der Silberfärbung nur sehr wenige Proteine angefärbt, die in einer Konzentration von $\geq 5 \mathrm{pmol}$ je Spot vorlagen. Die Proteine fokussierten im 3,2mm-Gelstab nicht mehr punktförmig, sondern unter Schlierenbildung. Im silbergefärbten Kontrollgel traten starke Überfärbungen von Proteinen eng benachbarter IEPe auf. Eine intensive Silberfärbung der Proteine korrelierte nicht mit entsprechender Anfärbung durch Coomassie Brillant Blue: Einzelne, intensiv silbergefärbte Proteine wurden durch Coomassie Brillant Blue nicht angefärbt; die Verteilung und Intensität der Färbungen korrelierten nicht (nicht gezeigt). Zur Ansequenzierung wurden die mit Pfeilen gekennzeichneten Proteine ausgeschnitten:

Nr. 1.) durch $\mathrm{NO}_{3}{ }^{-}$quantitativ stärker ${ }^{35}$ S-markiertes TX114-DP-Protein \# 263 $(23,2 \mathrm{kDa})$ 
Nr. 3: ${ }^{14} \mathrm{C}$-DNPA markiertes Protein C $(58,9 \mathrm{kDa}$; homolog zu TX114-DP \# 110/112 bzw. WP \# 118; 119).

Nr. 4.) durch $\mathrm{NO}_{3}^{-}$quantitativ stärker ${ }^{35}$ S-markiertes TX114-DP-Protein \# 101/WP 104

Nr. 5.) NR-Ak-detektierte, nicht $\mathrm{NO}_{3}$-induzierte TX114-DP-Proteine DP \# 75, 76 $(67,3 \mathrm{kDa})$

Nr. 7.) ${ }^{14}$ C-DNPA-markiertes 91 kDa-Protein (homolog zu TX114-DP-Protein DP \# 29)

Nicht isoliert werden konnten die de novo $\mathrm{NO}_{3}{ }^{-}$-induzierten, in niedriger Konzentration vorliegenden Proteine DP \# 56; 57; 58; 172; 173 (87) der TX114Detergenz-Phase. Diese konnten nicht in einer Menge von $\geq 5 \mathrm{pmol}$ je Spot angereichert werden. Es wurde daher eine 2D-SDS-PAGE der TX114-Phasen von insgesamt $1500 \mu \mathrm{g}$ PM-Protein in $6 \mathrm{~mm}$-Gelstäben durchgeführt.

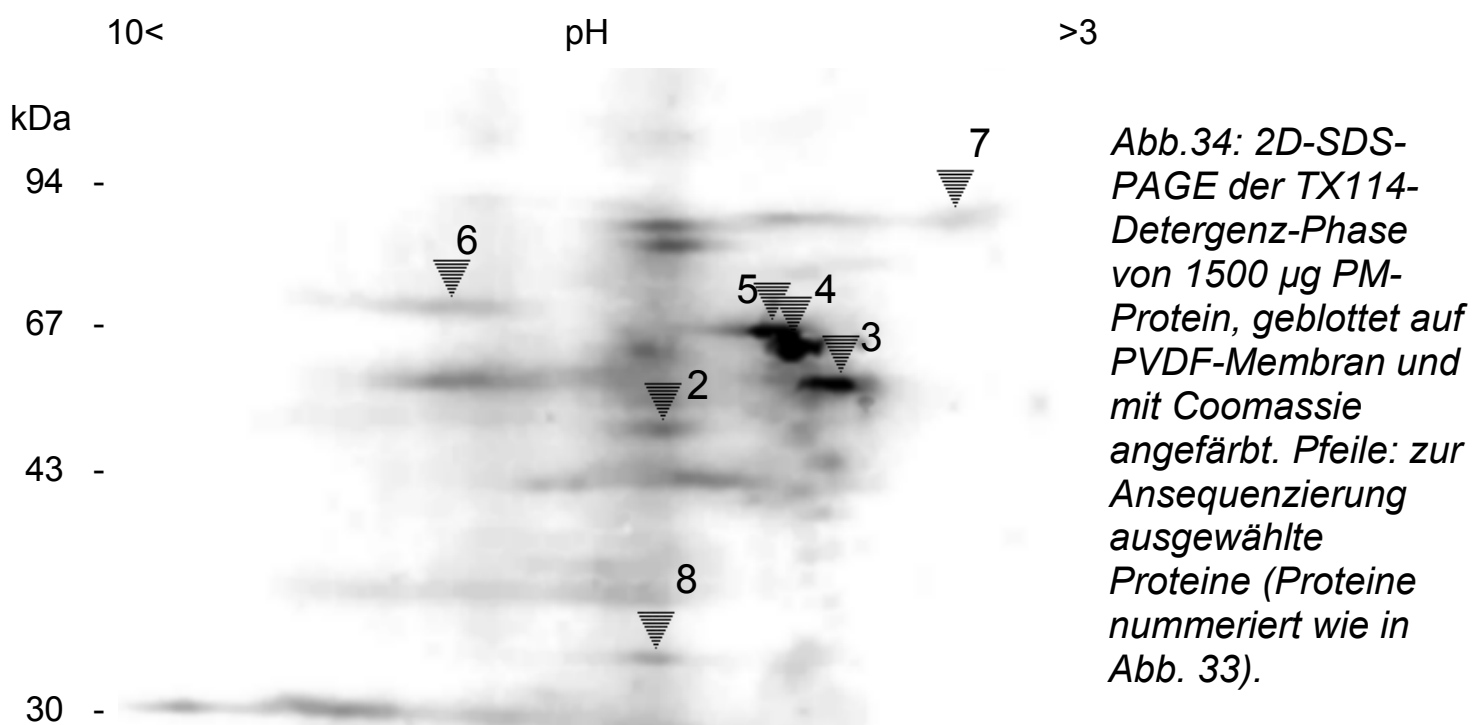

$20,1-$

$14,4-$

Ein in 6mm-Gelstäben durchgeführtes IEF der TX114-Phasen aus $1500 \mu \mathrm{g}$ PMProtein trennte die 30fache Proteinmenge der $1,5 \mathrm{~mm}$-Gelstäbe auf. Im Vergleich zu den 3,2 mm-Gelen wurde eine größere Zahl von Proteinen durch Coomassie angefärbt: Mit Protein Nr. 2 wurde das ${ }^{14} \mathrm{C}$-DNPA-markierte Protein IV von $45 \mathrm{kDa}$ präparativ dargestellt; mit Nr. 8 das quantitativ $\mathrm{NO}_{3}$-induzierte Protein DP \# 227/WP \# 260 von 32,8 kDa. Die Proteine fokussierten schlierenförmig; der pH-Gradient war -wie bereits bei den 3,2 mm-Gelen- im basischen Bereich gestreckt. Die qualitativ $\mathrm{NO}_{3}$-induzierten DP-Proteine \# 56; 57; 58 konnten nicht angefärbt werden: Alle ${ }^{35}$ S-markierten Proteine, die nur durch Autoradiographie nachgewiesen wurden, waren auch im präparativen IEF 
nicht in einer zur Ansequenzierung ausreichenden Menge anzureichern. Das Protein Nr. 6 entsprach nicht den $\mathrm{NO}_{3}$-induzierten DP-Protein \# 57 (76,6 kDa), sondern dem DP-Protein \# 66 mit 73,4 kDa. Es wurde zur Ansequenzierung ausgewählt, da es dem Nitrat-Transporter im sauren IEP und ähnlichem Molekulargewicht annähernd entsprach. Aus den Blots der wässrigen Phase wurde das Protein WP \# 104 mit 64,4 kDa isoliert (= Nr. 4; DP \# 101). Die ${ }^{14} \mathrm{C}-$ DNPA-markierten Proteine II und III konnten nicht isoliert werden, da ihre Menge nicht zur Coomassie-Färbung ausreichte. Die Blots der WP-Proteine zeigten eine größere Proteinzahl gegenüber der DP bei höherer Trennschärfe (punktförmiger Trennung), gleichzeitig eine noch stärkere Streckung des basischen $\mathrm{pH}$-Bereiches (Daten nicht gezeigt). Eine Anreicherung mit $\geq 5 \mathrm{pmol}$ Protein je Spot gelang für die überwiegende Zahl der $\mathrm{NO}_{3}{ }^{-}$-induzierten Proteine nicht; insgesamt wurden 8 Proteine zur Ansequenzierung isoliert.

\subsection{Ansequenzierung von PM-Proteinen}

Durch Edman-Abbau können N-terminale Sequenzabschnitte von bis zu mehreren Dutzend Aminosäuren Länge durch schrittweisen Abbau des Proteins und Aminosäure-Analyse bestimmt werden.

\subsubsection{Zur Ansequenzierung ausgewählte Proteine}

Aus den PVDF-Blots der "large scale" 2D-Gele wurden Proteine nach den Kriterien der $\mathrm{NO}_{3}$-Induzierbarkeit, ${ }^{14} \mathrm{C}$-DNPA-Markierung, NR-AK-Nachweis ausgestanzt. Ausgewählt waren die in den Kapiteln 3.3 und 3.4 gemäß den 2DSDS-PAGE-Verteilungskarten der TX114-Phasen bzw. der ${ }^{14} \mathrm{C}$-DNPAMarkierung bezeichneten Proteine. In der Gesellschaft für Biotechnologische Forschung Braunschweig, Abteilung Strukturforschung wurde die Ansequenzierung durch Edman-Abbau durchgeführt. Der Abbau wurde bis zu einer maximalen Länge von 30 Aminosäuren durchgeführt. Ansequenziert wurden acht Proteine:

- Nr. 1) durch $\mathrm{NO}_{3}{ }^{-}$quantitativ stärker ${ }^{35} \mathrm{~S}$-markiertes TX114-DP-Protein \# 263 $(23,2 \mathrm{kDa})$

- Nr. 2) ${ }^{14}$ C-DNPA-markiertes 45 kDa-Protein IV (TX114-WP \# 184-187)

- Nr. 3) ${ }^{14} \mathrm{C}$-DNPA markiertes Protein C $(58,9 \mathrm{kDa}$; homolog zu TX114-DP \# 110/112 bzW. WP \# 118; 119).

- Nr. 4) durch $\mathrm{NO}_{3}^{-}$quantitativ stärker ${ }^{35} \mathrm{~S}$-markiertes TX114-DP-Protein \# 101/WP 104

- Nr. 5) NR-Ak-detektierte TX114-DP-Proteine DP \# 75, 76 (67,3 kDa)

- Nr. 6) Basisches 73,4 kDa-Protein (DP \# 66)

- Nr. 7) ${ }^{14} \mathrm{C}$-DNPA-markiertes $91 \mathrm{kDa}$-Protein homolog zu TX114-DP-Protein DP \# 29

- Nr. 8) durch $\mathrm{NO}_{3}{ }^{-}$quantitativ stärker ${ }^{35} \mathrm{~S}$-markiertes TX114-WP-Protein (WP \# 260 / DP \# 227) (32,8 kDa) 


\subsubsection{Protein-Sequenzen: Ein Porin in Chlorella}

Dargestellt sind Alignments der ermittelten Sequenzen mit dem jeweils höchsten Homologien, Scores und sowie kleinsten Expect-values. Die Alignments wurden durch Abgleich mit der Datenbank Swiss-Prot ermittelt.

\section{Protein Nr. 8}

Nr. 8.) durch $\mathrm{NO}_{3}$ quantitativ stärker ${ }^{35}$ S-markiertes TX114-WP-Protein (WP \# 260 / DP \# 227) (32,8 kDa)

Die Sequenz wurde bis zur 30. Aminosäure des Proteins bestimmt:

\section{QGQGAVEGQL FYKKQYNDSV KHIEDGFNPG 30}

Je Aminosäure eluierten zwischen 9,9 und 2,0 pmol. An den Positionen 16 (=Y) bzw. $23(=I)$ eluierten parallel Aminosäure F bzw.T in geringerer Konzentration.

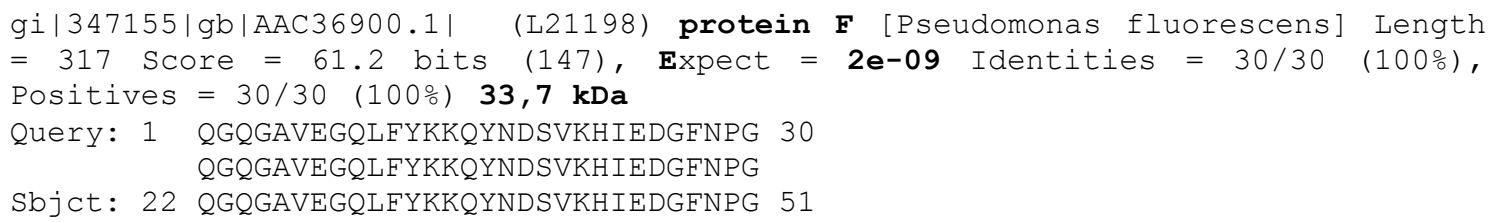

gi|585710|sp|P37726|PORF PSEFL adhesin) gi|5668610|gb|AAD45981.1|

Length $=326$ Score $=60.8$ bits

(96\%), Positives $=30 / 30$ (99\%)

Query: 1 QGQGAVEGQLFYKKQYNDSVKHIEDGFNPG 30 QGQGAVEG+LFYKKQYNDSVKHIEDGFNPG

Sbjct: 25 QGQGAVEGELFYKKQYNDSVKHIEDGFNPG 54
Outer membrane porin $\mathbf{F}$ precursor (Root

(AF115334) OprF [Pseudomonas fluorescens]

(146), $\mathbf{E x p e c t}=\mathbf{3 e - 0 9}$ Identities $=29 / 30$

Das Alignment ergab eine $100 \%$ Homologie der gesamten Sequenz zu einem Porin F aus Pseudomonas fluorescens. Die Gewichte der vollständigen Proteine stimmten $\pm 1 \mathrm{kDa}$ überein. Das Protein aus Chlorella wirkte nicht als Antigen zu einem Aquaporin-Antikörper gegen ein Aquaporin aus Nicotiana tabacum (Antikörper freundlicherweise zur Verfügung gestellt von Prof. Dr. R. Kaldenhoff, Würzburg): Ein immunologischer Porin-Nachweis gelang mit dem Antikörper nicht.

\section{Proteine Nr. 1-7.}

Bei den Sequenzierungen der Proteine 1-7 wurden mit jedem Zyklus des Edman-Abbaues bis zu sechs Aminosäuren parallel freigesetzt. Diese eluierten in geringerer, teilweise gleicher Konzentration. Es lagen somit mehrere Proteine in der Probe vor. Es wurde dennoch ein Alignment mit den an der jeweiligen Positionen in der höchsten Konzentration vorliegenden Aminosäure durchgeführt. Je Aminosäure eluierten zwischen 1,0 und 0,1 pmol. Die Leseweite umfasste maximal 18 Aminosäuren. Der Expect Value ist gegenüber Nr. 8 bei allen Alignments um mehr als zehn Zehnerpotenzen größer: die Wahrscheinlichkeit eines zufälligen Auffindens einer ähnlichen Sequenz in einer Datenbank wuchs entsprechend dieser Größenordnung an. 
Protein Nr. 1: durch $\mathrm{NO}_{3}{ }^{-}$quantitativ stärker ${ }^{35}$ S-markiertes TX114-DP-Protein \# $263(23,2 \mathrm{kDa})$

\section{AETRADVTFLAGDARA 16}

Mit Ausnahme der Positionen 14 und 15 eluierten parallel weitere Aminosäuren in geringerer Konzentration; an Position $16(=A)$ eluierte Aminosäure $L$ in gleicher Konzentration. Das Ergebnis des Alignments bei Austausch A gegen $L$ wurde dadurch nicht beeinflußt.

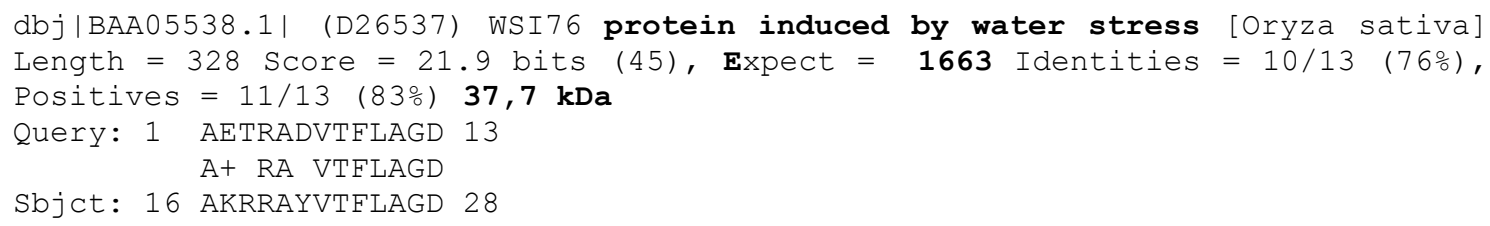

Im Alignment zeigte ein Wasserstreß-induziertes Protein aus Reis die größte Ähnlichkeit. Es gab keine Überstimmung der Molekulargewichte.

Protein Nr. 2: ${ }^{14}$ C-DNPA-markiertes 45 kDa-Protein IV (TX114-WP \# 184-187)

\section{DPPGDITELQARLD 14}

An allen Positionen eluierten parallel weitere Aminosäuren in geringerer Konzentration.

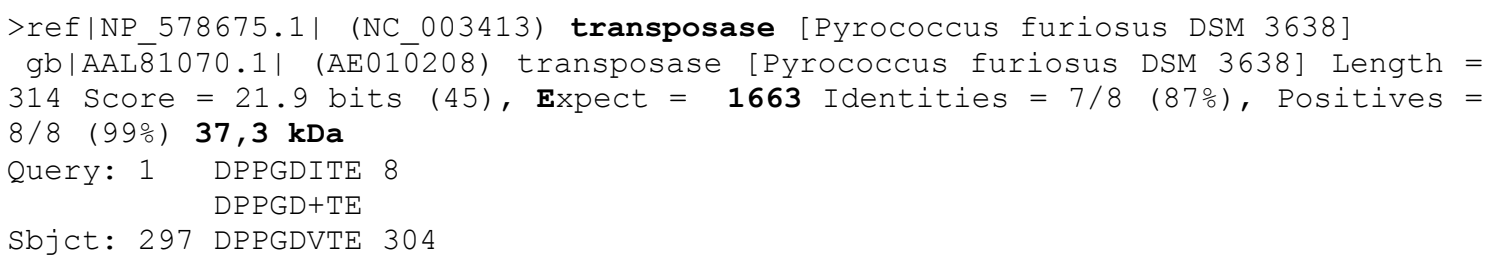

Im Alignment zeigte eine Transposase die größte Ähnlichkeit. Es gab keine Überstimmung der Molekulargewichte.

Protein Nr. 3: ${ }^{14} \mathrm{C}-\mathrm{DNPA}$ markiertes Protein C (58,9 kDa; homolog zu TX114DP \# 110/112 bzw. WP \# 118; 119).

\section{PPGDITELQAALYWEAEG 18.}

An allen Positionen eluierten parallel weitere Aminosäuren in geringerer Konzentration.

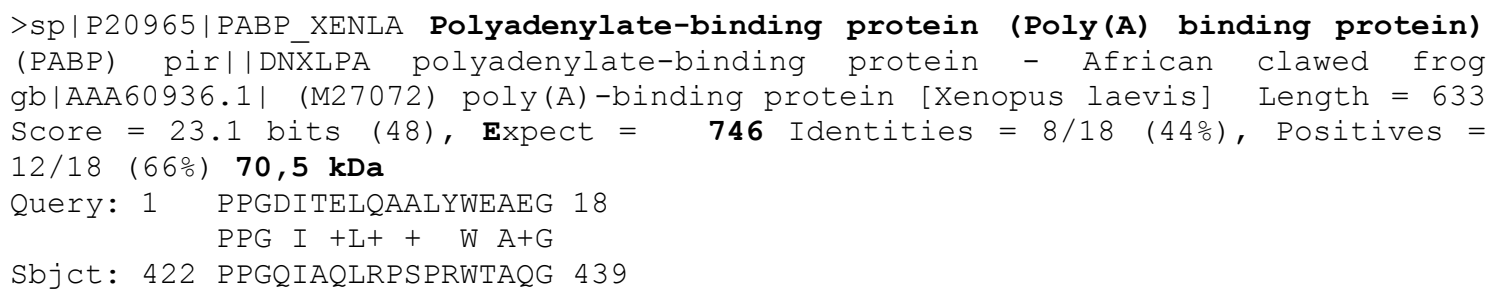


In der Wiederholung der Ansequenzierung wurde die Sequenz bis zur 16. Aminosäure bestimmt: 1 TAPGDATTLQALASEL 16. An allen Positionen eluierten parallel weitere Aminosäuren in geringerer Konzentration.

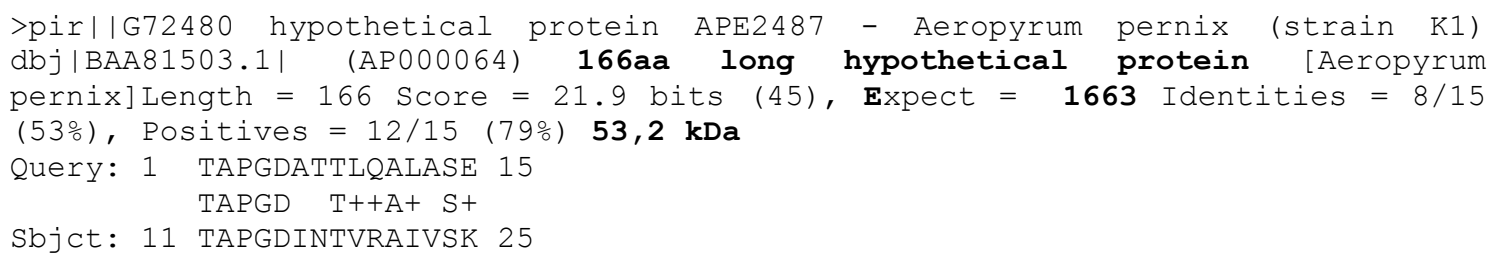

Die Wiederholung der Ansequenzierung zeigte ein abweichendes Ergebnis der Sequenz. Übereinstimmend waren die sieben fett gedruckten Aminosäuren:

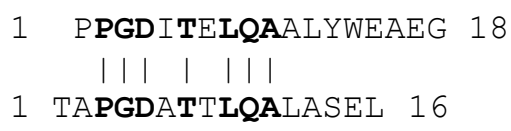

Die Alignments der jeweiligen Sequenzen in der Datenbank zeigten zwischen der Erstsequenzierung und der Wiederholung keine Übereinstimmungen. Die Alignments ergaben Ähnlichkeiten mit Proteinen mit unterschiedlichen Molekulargewichten. Das Molekulargewicht des 166aa long hypothetical protein [Aeropyrum pernix] wich um ca. $2 \mathrm{kDa}$ ab von dem des ansequenzierten Proteins ab; das des polyA-binding protein um $15 \mathrm{kDa}$.

Protein Nr. 4: durch $\mathrm{NO}_{3}{ }^{-}$quantitativ stärker ${ }^{35} \mathrm{~S}$-markiertes TX114-DP-Protein \# 101/WP 104

\section{RGDYGFGYEAFARMVE-VN 19}

Mit Ausnahme der Positionen 7; 15; 16; 19 eluierten parallel weitere Aminosäuren in geringerer Konzentration.

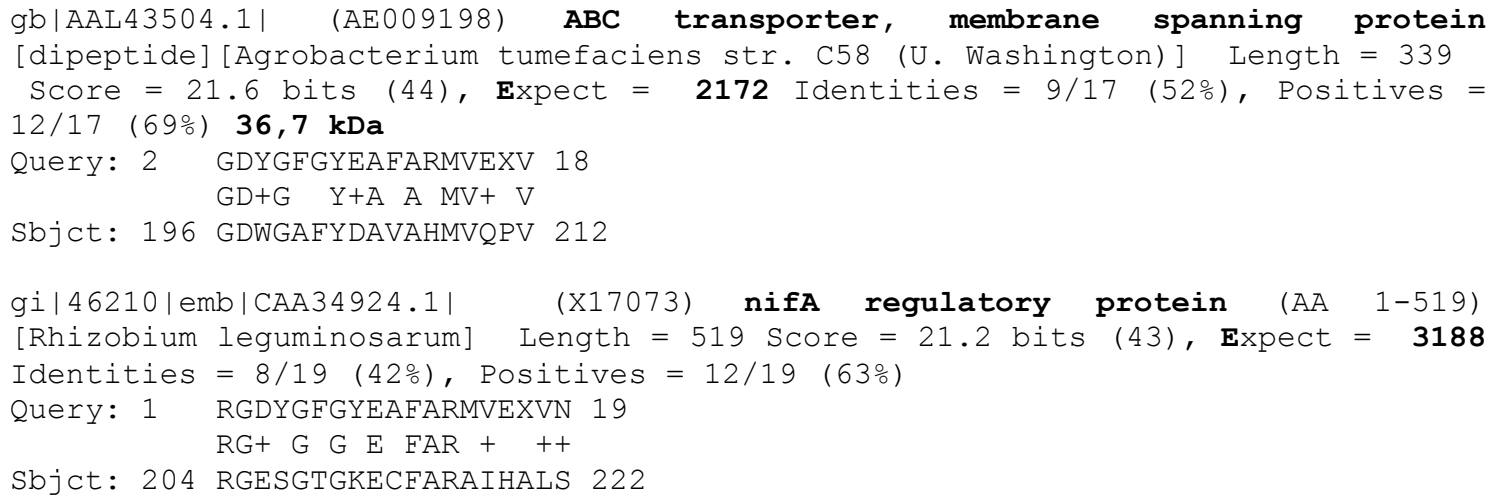

Im Alignment zeigten transmembranäre Transportproteine und NifA-Proteine die größte Ähnlichkeit. Es gab keine Überstimmung der Molekulargewichte.

Protein Nr. 5: NR-Ak-detektierte TX114-DP-Proteine DP \# 75, 76 (67,3 kDa)

1 K-PPPAATDLEDL 13

An allen Positionen eluierten parallel weitere Aminosäuren in geringerer Konzentration. 


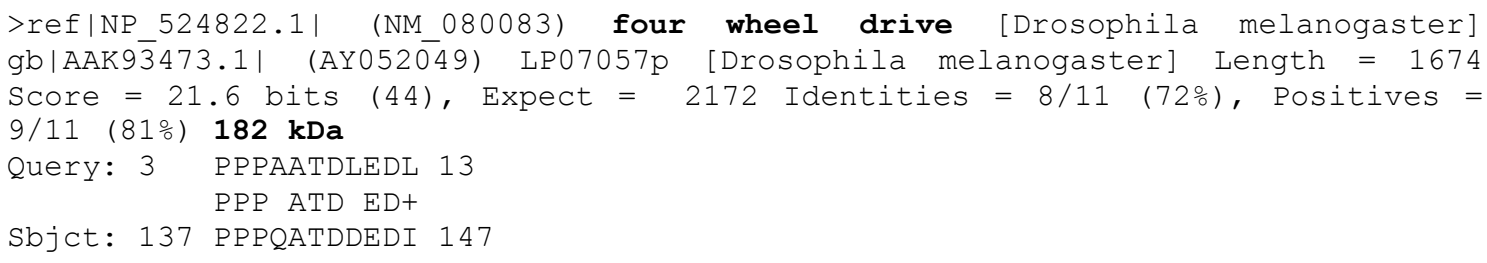

Im Alignment zeigte ein sehr hochmolekulares „Vierrad-Antrieb“-Protein aus der Fruchtfliege die größte Ähnlichkeit. Es gab keine Überstimmung der Molekulargewichte.

Protein Nr. 6: Basisches 73,4 kDa-Protein (DP \# 66)

Das Protein konnte trotz ausreichender Konzentration nicht ansequenziert werden: blockierter N-Terminus.

Protein Nr. 7: ${ }^{14}$ C-DNPA-markiertes 91 kDa-Protein (homolog zu TX114-DPProtein DP \# 29)

\section{ALFIGLGGG 9}

An allen Positionen eluierten parallel weitere Aminosäuren in geringerer Konzentration.

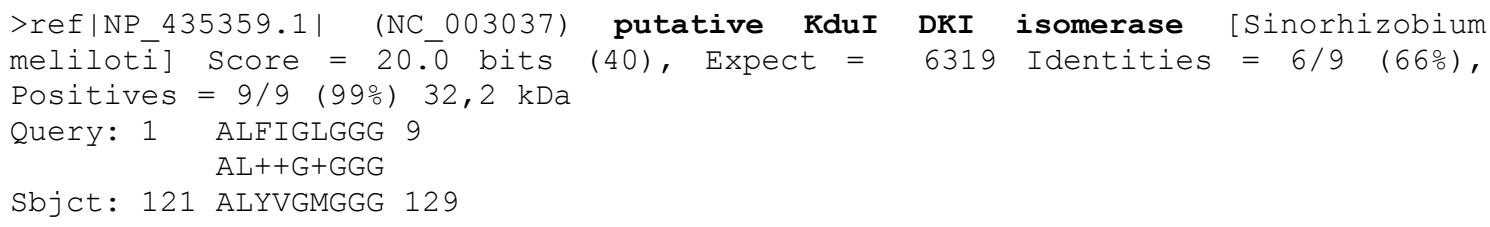

Im Alignment zeigte eine putative Isomerase die größte Ähnlichkeit. Es gab keine Überstimmung der Molekulargewichte. 


\subsection{Molekularbiologische Untersuchungen zum Nitrat-Transporter}

\subsubsection{Primerauswahl und Primer-Paarungen}

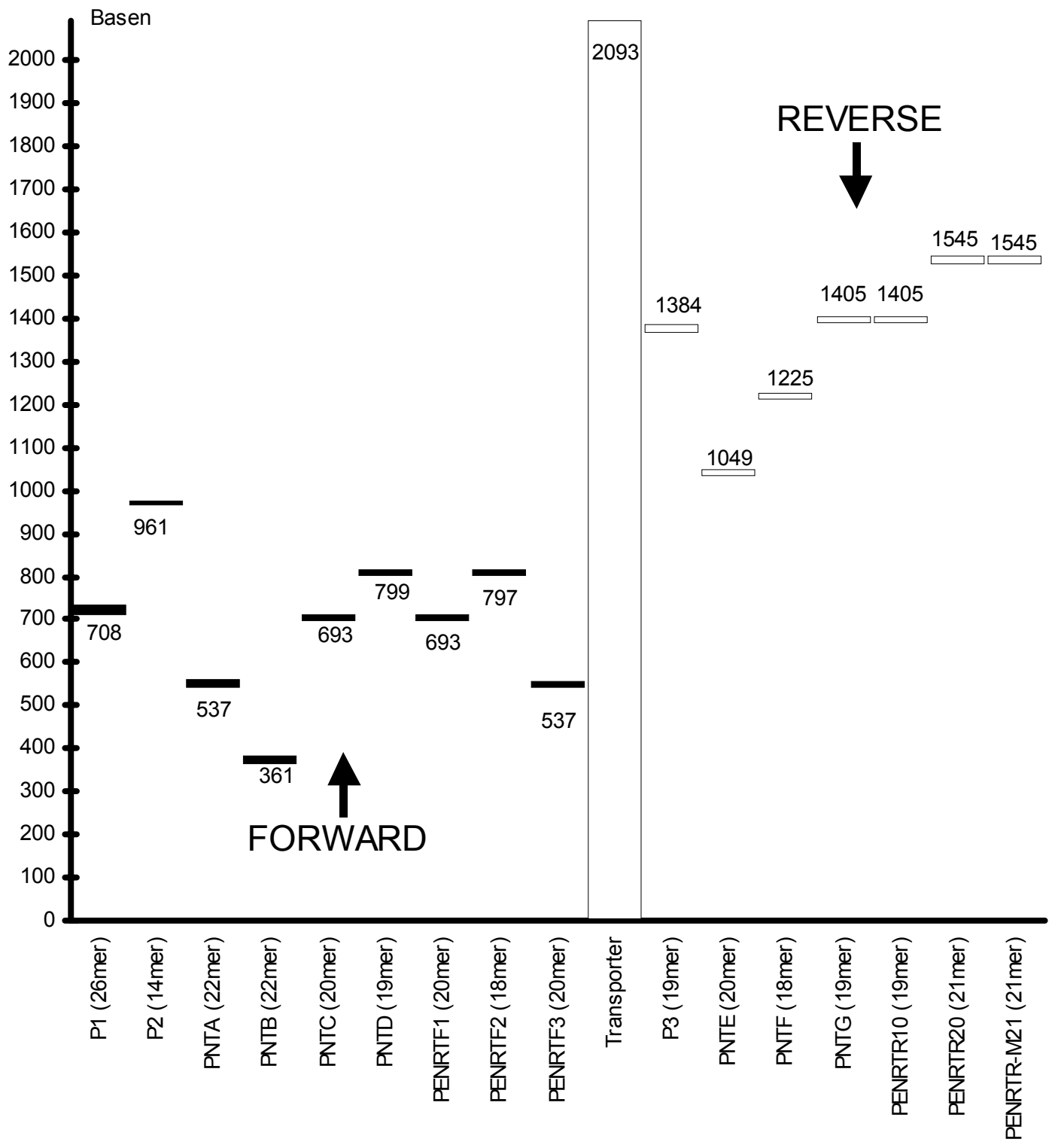

Abb. 35: Lokalisation der für die PCR eingesetzten forward und reverse Primer; in der Abbildung ist für die forward Primer die erste Base innerhalb der Transporter-Sequenz angegeben, für die reverse Primer die letzte. Die theoretische Basenlänge der PCRProdukte errechnet sich durch Subtraktion der Basenzahl reverse-/forward-Primer der jeweiligen Paarungen. Ein Alignment aus verschiedenen Nitrat-Transporter-Sequenzen (3.6.1) diente als Grundlage für die Längenangabe der Basensequenz des Transporters.

Die aus der Kombination der verschiedenen Primer zu erwartende Produktgröße konnte aus der Karte abgelesen werden. 


\subsubsection{RT-PCR und PCR-Produkte}

\section{RNA-Extraktion und RT-PCR}

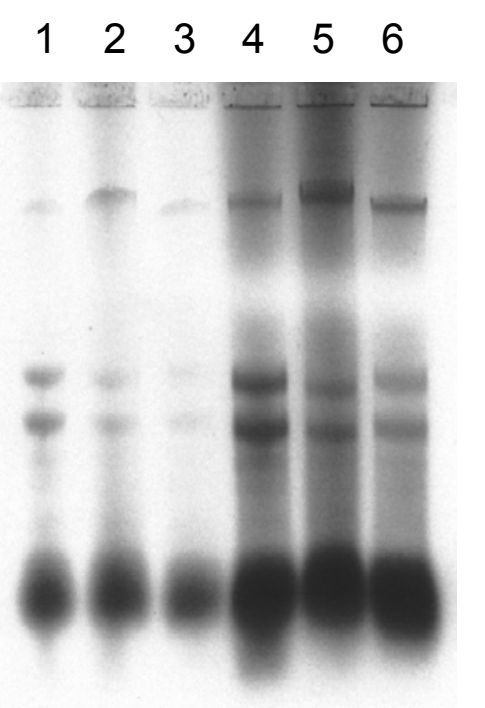

Abb. 36: Total-RNA-Extraktion nach Logemann et al. (1987)(Spuren 1-3) und mit TRIZOL (Spuren 4-6). Extrahiert wurde nach Induktion der Algen mit $\mathrm{NO}_{3}{ }^{-}$ (Sp. 1; 4); $\mathrm{NH}_{4}^{+}$(Sp. 2; 5); Kontrolle (Sp. 3; 6).

Die Extraktion von total-RNA erbrachte mit dem TRIZOL-System bei gleicher Frischgewichtsmenge Algen höhere Ausbeuten intakter RNA gegenüber der Methode nach Logemann et al (1987). Die Gesamtmenge der isolierten RNA variierte, nach $\mathrm{NO}_{3}^{-}$-Induktion war die Ausbeute an Total-RNA am höchsten. Die $\mathrm{NO}_{3}$-induzierten Fraktionen wurden für die nachfolgende RT-PCR eingesetzt.

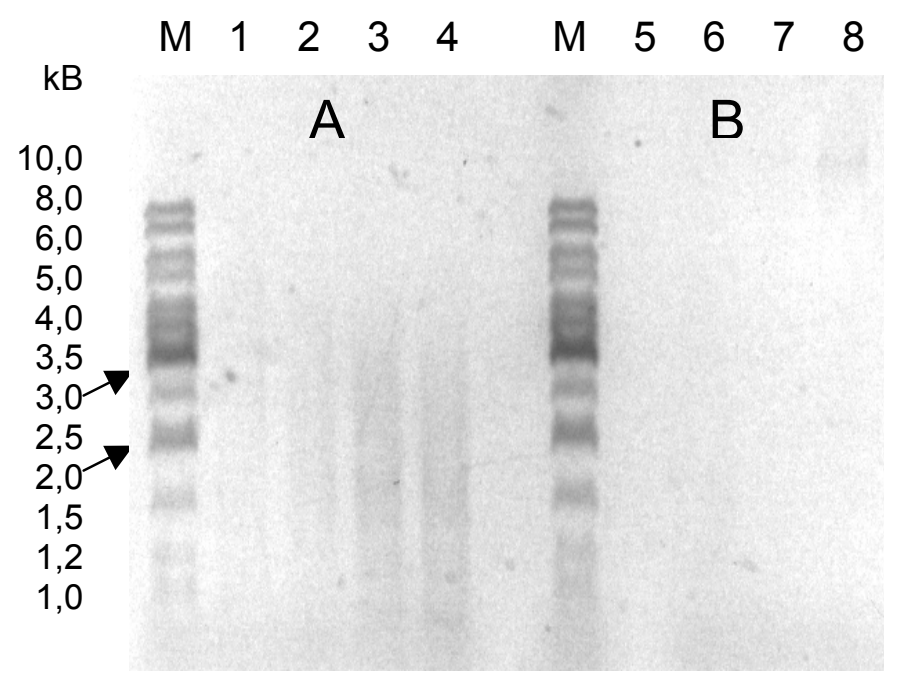

Abb. 37: Einfluß der eingesetzten Primer und Temperaturen bei der cDNA-Synthese aus mRNA. A: cDNA-Synthese mit Oligo-dT-Primern bei $50{ }^{\circ} \mathrm{C}$ (Spur $\left.1+2\right) ; 42{ }^{\circ} \mathrm{C}$ (Spur $3+4)$. B: cDNA-Synthese mit gen-spezifischen Primern (PNTC/PNTG) bei $50{ }^{\circ} \mathrm{C}$ (Spur $5+6) ; 42{ }^{\circ} \mathrm{C}($ Spur $7+8)$.

Die cDNA-Synthese der RT-PCR mit Oligo-dT-Primern zeigte eine Temperaturabhängigkeit der Ausbeute: Bei einer Annealingtemperatur von 50 ${ }^{\circ} \mathrm{C}$ gegenüber $42{ }^{\circ} \mathrm{C}$ war die Ausbeute an cDNA (als DNA-Schmier über einen breiten Massenbereich) deutlich reduziert. 
Bei cDNA-Synthese mit Nitrat-Transporter-spezifischem Primerpaar enstanden temperaturunabhängig keine distinkten RT-PCR-Produkte. Eine zur Kontrolle mit diesem Ansatz durchgeführte PCR unter Austausch des 3'- bzw. 5'-Primers gegen weitere Gen-spezifische Primer lieferte ebenfalls keine PCR-Produkte.

Eine vorherige Extraktion der mRNA aus der Total-RNA führte wiederholt zur Degeneration der RNA, die cDNA-Synthese der RT-PCR wurde daher mit Total-RNA durchgeführt (Daten nicht gezeigt). In den nachfolgenden PCRExperimenten wurde die bei $42{ }^{\circ} \mathrm{C}$ Annealing und mit Oligo-dT-Primern synthetisierte cDNA eingesetzt.

\section{PCR-Produkte mit Gen-spezifischen Primern}

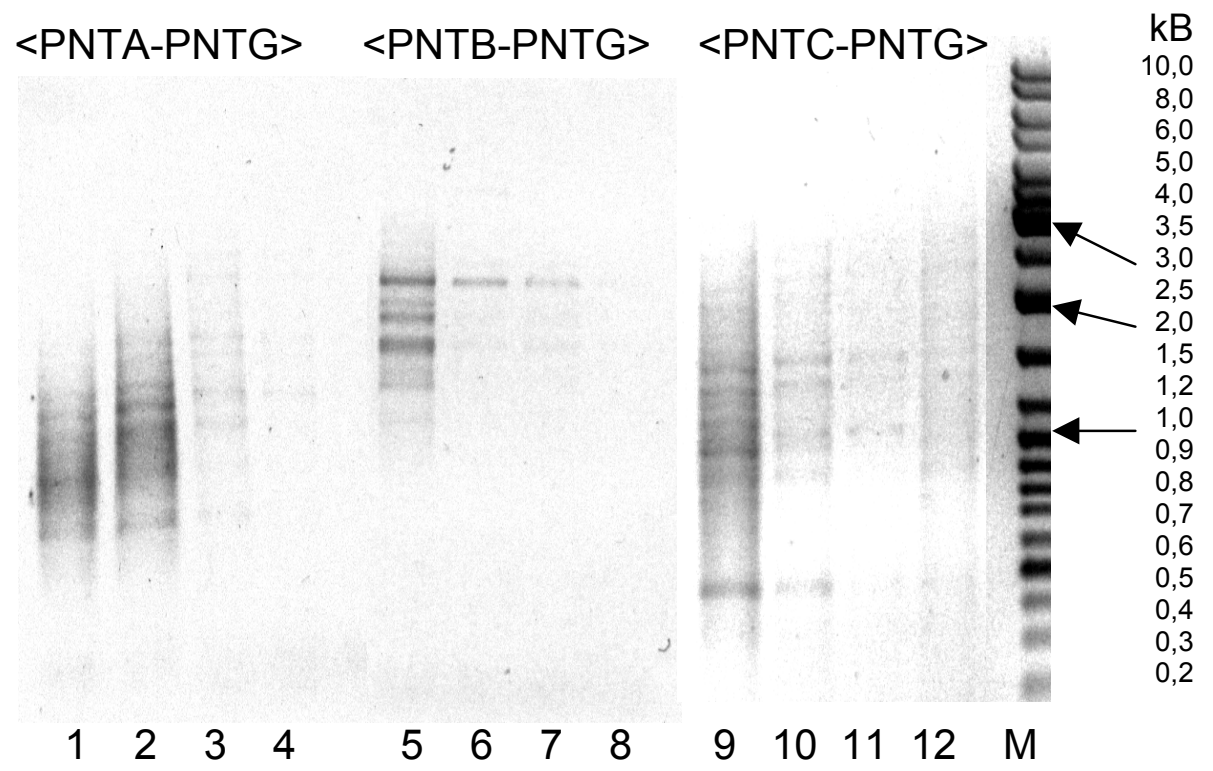

Abb. 38: PCR-Produkte von Nitrat-Transporter-spezifischen Primerpaarungen; eingesetzt wurde cDNA aus Oligo-dT-Primer-spezifisch amplifizierter mRNA. Die PCR wurde in je vier Ansätzen mit zunehmender Annealing-Temperatur durchgeführt: Spur 1-4 / 5-8 / 9-12: 56,$2 ; 57,8 ; 60,8 ; 62,5^{\circ} \mathrm{C}$

In allen durchgeführten Ansätzen traten eine Reihe von Produkten unterschiedlicher Größen auf. Die theoretisch zu erwartende PCRProduktgröße der eingesetzten Paarungen war 0,87 kB (PNTA-PNTG); 1,04 kB (PNTB-PNTG); 0,71 kB (PNTC-PNTG). In keinem der Ansätze wurde ein Produkt der zu erwartenden Größe gefunden. 


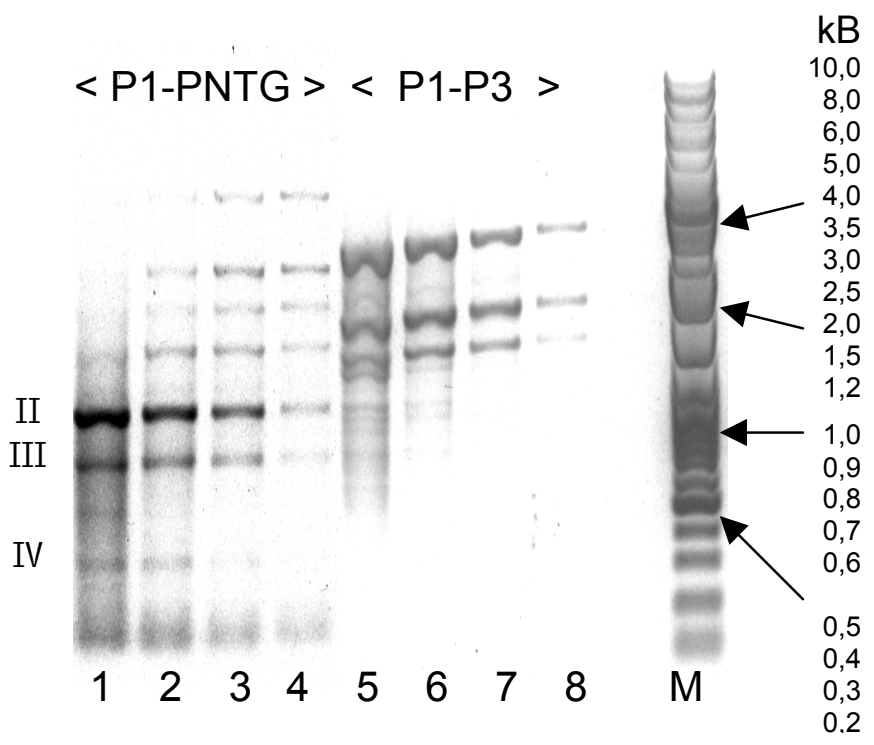

Abb. 39: PCR-Produkte von Nitrat-Transporter-spezifischen Primerpaarungen. Die $P C R$ wurde in je vier Ansätzen mit zunehmender Annealing-Temperatur durchgeführt: Spur 1-4 / 5-8: 56,2; 57,8; 60,8; $62,5{ }^{\circ} \mathrm{C}$. Römische Ziffern: Zur Transfektion und nachfolgenden Ansequenzierung isolierte Produkte.

Mit der Primerpaarung P1-PNTG wurden Produkte unterschiedlicher Größen gebildet, nicht jdoch ausschließlich in der zu erwartenden Größe von 0,68 kB kB quantitativ generiert. Das mit III markierte Produkt entsprach der erwarteten Größe. Bei der Primer-Paarung P1-P3 war das hohe Gewicht und die Quantität der gebildeten Produkte auffallend, ein Produkt der bei dieser Paarung zu erwartenden Größe von 0,7 kB trat nicht auf.
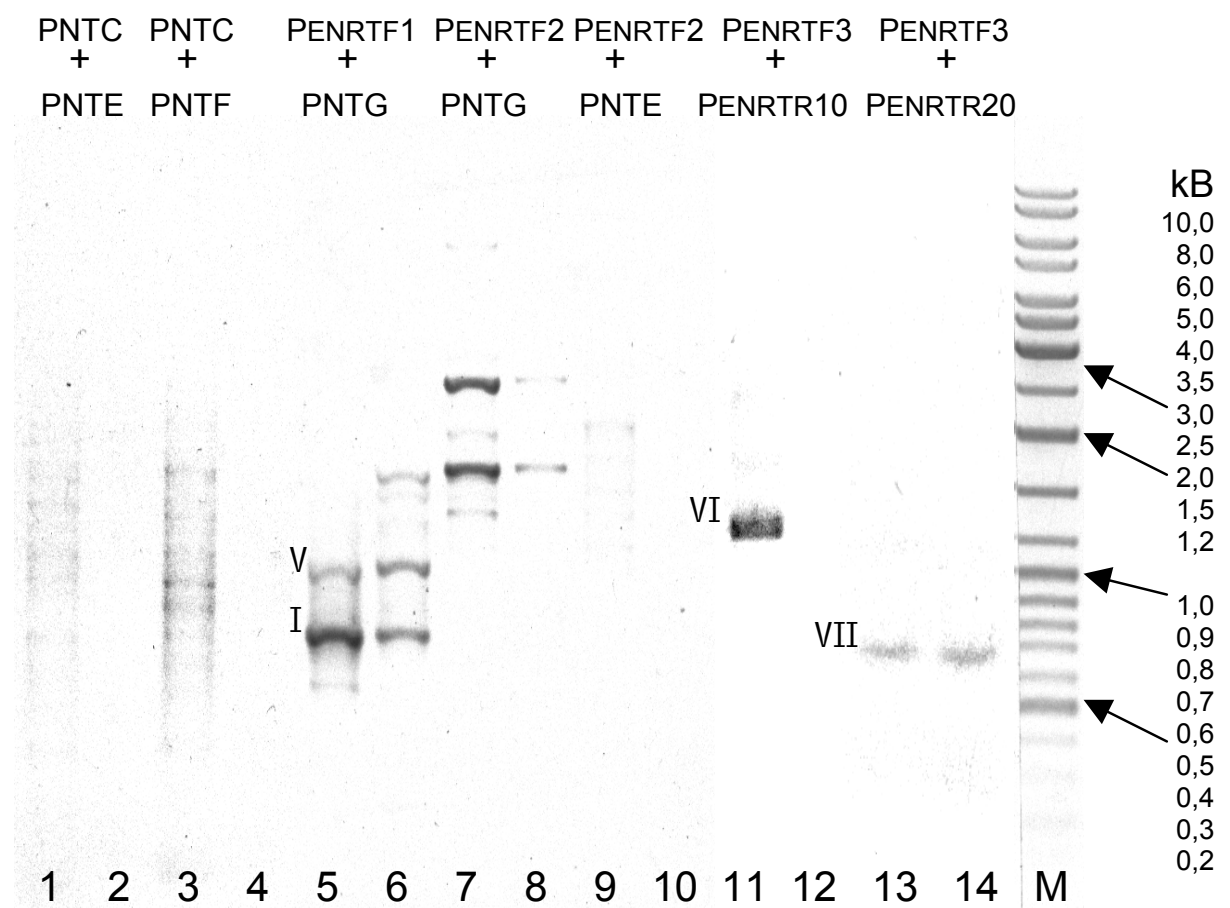

Abb. 40: PCR-Produkte von Nitrat-Transporter-spezifischen Primerpaarungen. Die PCR wurde bei Annealing-Temperaturen von 56,2 ${ }^{\circ} \mathrm{C}$ (ungerade Ziffer) bzw. bei 58,6 ${ }^{\circ} \mathrm{C}$ (gerade Ziffer) durchgeführt. Römische Ziffern: Zur Transfektion und nachfolgenden Ansequenzierung isolierte Produkte. 
Die theoretisch zu erwartenden Produkte der Primerpaarungen hatten die Größen: 0,36 kB (Spur 1, 2); 0,71 kB (Spur 3, 4); 0,71 kB (Spur 5, 6); 0,61 kB (Spur 7, 8); 0,25 kB (Spur 9, 10); 0,87 kB (Spur 11, 12); 1,01 kB (Spur 13, 14). Nur in der Primer-Paarung PENRTF1-PNTG (Spur 5, 6) trat das Produkt I der erwarteten Größe von 0,71 kBa auf, daneben ein schwereres Produkt $\mathrm{V}$. Die mit der Primerpaarungen PENRTF3 mit PENRTR10/20 gewonnenen Produkte wurden trotz fehlender Übereinstimmung mit der theoretischen Größe ansequenziert, da sie als Einzelprodukte der PCR auftraten.

\section{$\underline{\text { Transfektion von kompetenten E. coli Zellen und Sequenzierung }}$}

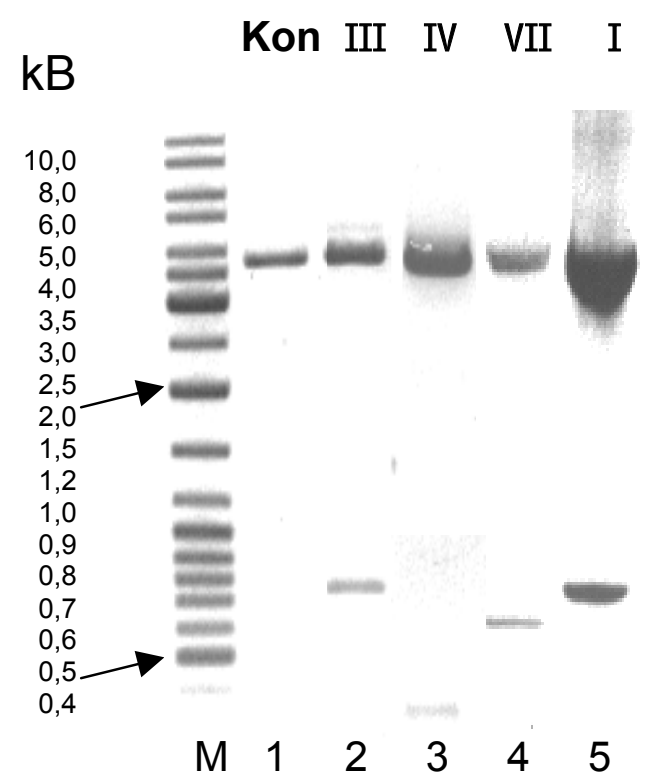

Abb. 41: Plasmid-Verdau (EcoR1) nach Transfektion der Zellen mit den PCR-

Produkten I; III; IV; VII (Spur 2; 3; 4; 5) Spur 1: Kontrolle (Nicht-transfiziertes Plasmid)

Die mit I-VII nummerierten PCR-Produkte wurden nach dem Ausschneiden aus dem Plasmid mit EcoR1 durch Sequenzierungs-PCR mit T3/T7-Primern und „Big Dye“-Terminatoren (ABI) ansequenziert.

\subsubsection{Sequenzierung und Alignments}

Parallel zu den Basensequenzen (5'- 3'-Richtung) der PCR-Produkte I-VII ist die Aminosäure-Sequenz mitangegeben; angegeben wurde das Leseraster, welches der Aminosäure-Sequenz des mitamplifizierten Primers entsprach. Die Alignments innerhalb der in den Datenbanken (Swiss-Prot, EMBL) archivierten Sequenzen wurden mit BLASTp auf Aminosäure-Ebene durchgeführt, da dies längere Leseweiten und Überbrückung nicht zweifelsfreier Basenidentifizierung in der Sequenzierung erlaubte. Zu den den PCR-Produkten werden die jeweils ersten fünf Aminosäure-Sequenzen des Alignments angegeben und das Protein mit der höchsten Homologie im Sequenz-Alignment dargestellt. 


\section{PCR-Produkt I}

ctcagggcacctgcaaggcttcgcacgacataactt

$\begin{array}{lllllllllllllll}L & R & A & P & A & R & L & R & T & T & X & L\end{array}$

caatggcgctcgtgggctctatggtctatagccctctgctgctgcatgatccagctcaga

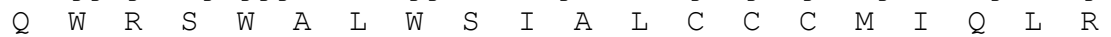

ttgccagtatgatcccaaagtggtggacataacggctgtatgggccggncagngagcgtg $\begin{array}{lllllllllllllllllllll} & L & P & V & X & S & Q & S & G & G & H & N & G & C & M & G & R & X & X & S & V\end{array}$ gatgggatcaagagcacagcgaggcaagctggagagcctaggacgggcctgcgtntgctg $\begin{array}{llllllllllllllllllll}D & G & I & K & S & T & A & R & Q & A & G & E & P & R & T & G & L & R & X & L\end{array}$ gctcatgacctcggagacccagacgaagtagatgaactgttgctgcgg
$\begin{array}{llllllllllllllll}A & H & D & L & G & D & P & D & E & \text { V } & \text { D } & \text { E } & \text { L } & \text { L } & \text { L } & R\end{array}$
264 Basen

\section{Alignment}

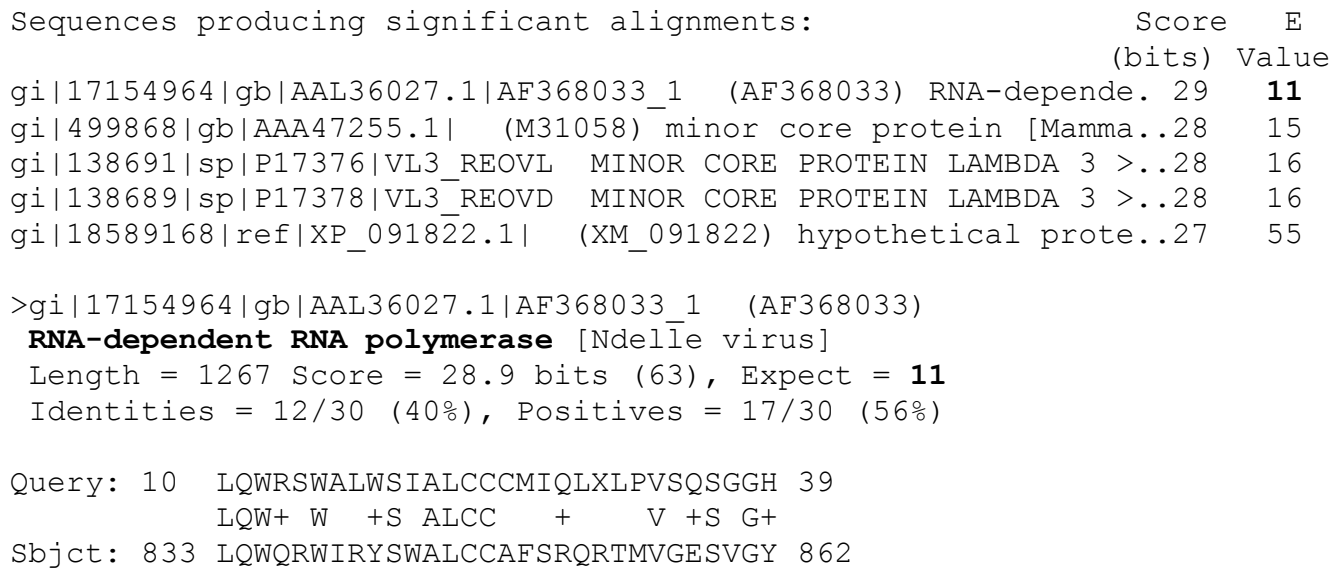

\section{PCR-Produkt II}

agctgcgccttggaggtggaggtgccetggegcgcgctgcagtgcetgacgcccgacgcc

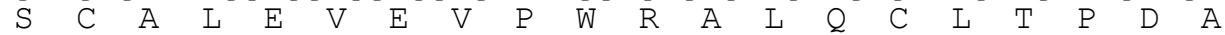
atgcagctggcagacccaacgttgccgcccgcgccatcccctttccctccgccgecctca $\begin{array}{llllllllllllllllllll}M & Q & L & A & D & P & T & L & P & P & A & P & S & P & F & P & P & P & P & S\end{array}$ ccatcgccaccgccgccctcaccatcgccaccgcctccgggtccccttcccetccgccac $\begin{array}{lllllllllllllllllllll}P & S & P & P & P & P & S & P & S & P & P & P & P & G & P & L & P & L & R & H\end{array}$ cttcgccgtctccaccgccgccgtcaccattgcetccgncgccttccccttcccctccgc $\begin{array}{llllllllllllllllllll}\mathrm{L} & \mathrm{R} & \mathrm{R} & \mathrm{L} & \mathrm{H} & \mathrm{R} & \mathrm{R} & \mathrm{R} & \mathrm{H} & \mathrm{H} & \mathrm{C} & \mathrm{L} & \mathrm{X} & \mathrm{R} & \mathrm{L} & \mathrm{P} & \mathrm{L} & \mathrm{P} & \mathrm{L} & \mathrm{R}\end{array}$ Ctccgtctc
L $\quad \mathrm{R} \quad \mathrm{I}$
249 Basen

\section{Alignment}

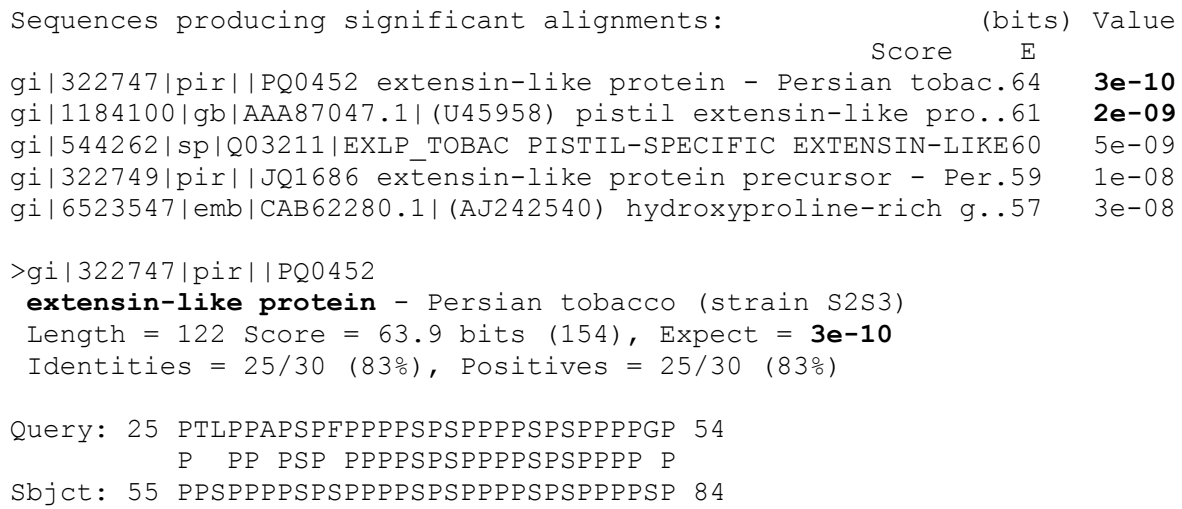




\section{PCR-Produkt III}

agctcgcagacgtacgcttttgcagcccggtc $\begin{array}{lllllllllllll}S & S & Q & T & Y & A & F & C & S & P & V\end{array}$ gaccccccctcctgctgggcctaccccgagcatcaggaagcggcaggcaacaccgtcaag

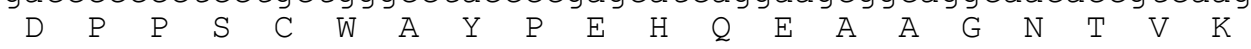
cacactggcggcggcctcgggcttggggtctcagcccaccgtccaggtcctgcgcggcgc gctgagtgcagtgacagcagatccgcagctgcggcagccgacgccacagccaacaccac $\begin{array}{llllllllllllllllllll}A & E & C & S & D & S & R & I & R & S & C & G & S & R & R & H & S & Q & H & H\end{array}$ tgccgctgaaacccccccccttgtcagccaacagggcaggcagcgaatgccgattcccca $\begin{array}{lllllllllllllllllllll}C & R & - & N & P & P & P & C & Q & P & T & G & Q & A & A & N & A & D & S & P\end{array}$ gcgctcagcagcgcgctgttgcagggcgcggcagccgcagcgaacgcagcctttggcatg A L $\quad S \quad S$ A $L$ L $Q$ G A A A A A $A$ A A acagctcgcetggtcaacggatcaggcetcatcccetcgtctgccccancc

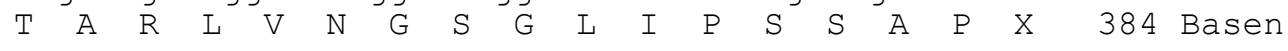

\section{Alignment}

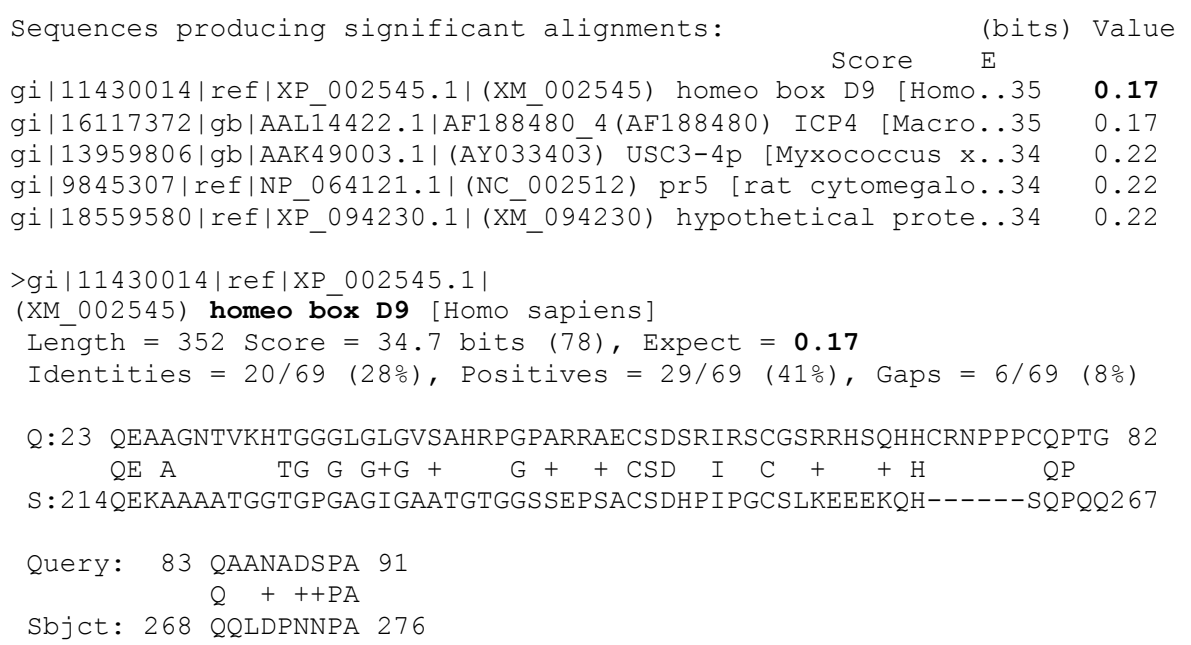

\section{PCR-Produkt IV}

$\operatorname{agtagc}$

S S

tgctcccaagcttcctcgctgccetgcacgaaagcttgctgcatgnencgcetccactgc $\begin{array}{llllllllllllllllllll}C & S & Q & A & S & S & L & P & C & T & K & A & C & C & M & X & R & L & H & C\end{array}$ tgcgcgctccttggcgcccaccetctgcagcacggtgccagccagactcagccagcectt $\begin{array}{llllllllllllllllllllllllllll}C & A & L & L & G & A & H & P & L & Q & H & G & A & S & Q & T & Q & P & A & L\end{array}$ tccaaagatggtcctacaacagaggtcgggtgaagagagcaccgagtatggctcgcaccC $\begin{array}{llllllllllllllllllll}S & K & D & G & P & T & T & E & V & G & - & R & E & H & R & V & W & \text { L } & P\end{array}$ gtgcctggcgggtgctgccattggcagcgccaccgtcggcagtctgcccgccgatgtaat $\begin{array}{llllllllllllllllllll}V & P & G & G & C & C & H & W & Q & R & H & R & R & Q & S & A & R & R & C & N\end{array}$ ccaccatttgaagcacatcctgccgtaatcacttgcctgctgtcagaacttacgtatgc $\begin{array}{llllllllllllllllllll}\mathrm{P} & \mathrm{P} & \mathrm{F} & \mathrm{E} & \mathrm{A} & \mathrm{H} & \mathrm{P} & \mathrm{A} & \mathrm{V} & \mathrm{N} & \mathrm{H} & \mathrm{L} & \mathrm{P} & \mathrm{A} & \mathrm{V} & \mathrm{R} & \mathrm{T} & \mathrm{Y} & \mathrm{V} & \mathrm{C}\end{array}$ agcgccacatcgtgataggcagatcataatgatgataggcacaatcaccatgactgca $\begin{array}{lllllllllllllllllllllll}\mathrm{S} & \mathrm{A} & \mathrm{T} & \mathrm{S} & - & - & \mathrm{A} & \mathrm{D} & \mathrm{H} & \mathrm{N} & \mathrm{D} & \mathrm{D} & \mathrm{R} & \mathrm{H} & \mathrm{N} & \mathrm{H} & \mathrm{H} & \mathrm{D} & \mathrm{C} & & 364 & \text { Basen }\end{array}$

\section{Alignment}

Sequences producing significant alignments: (bits) Value

Score E

gi|7320895|emb|CAB82015.1|(AL161755) putative serine/threo...33 0.59

gi|15610172|ref|NP_217551.1|(NC_000962) hypothetical prote...32 1.3

gi|9954412/gb|AAG0 $9046.1 \mid$ AF288463_1(AF288463) PTH/PTHrP ty...32 1.3

gi|18076428|emb|CAC82379.1|(AJ294544) Esau protein [Rattus...30 5.0

gi|11359377|pir||T48726conserved hypothetical protein [imp...30 5.0

>gi | 7320895 | emb | CAB82015.1|(AL161755) 
putative serine/threonine protein kinase [Streptomyces coelicolor A3] Length = 979 Score $=32.7$ bits (73), Expect $=0.59$ Identities $=29 / 89$ (32\%), Positives $=39 / 89$ $(43 \%), \operatorname{Gaps}=15 / 89(16 \%)$

Q:2 GTSPAGLNEFALGATQLSSCSQASSLPCTKACCMETXRLH-----CCALLGAHPLQHGAS 56 $\mathrm{GT}+\mathrm{PAGL}+\mathrm{L} \mathrm{A}+++\mathrm{A}++\quad+\mathrm{A} \quad \mathrm{R}+\quad \mathrm{AL}$ GA P GA +

S:269 GTAPAGLAPASLDAAADARAARAGAIAAYRAGARAAARIQEAQNGRAALPGARPAPDGAT 328

Query: 57 QTQPALSKDGPTTEVGXREHRVWLAPVPG 85

$\begin{array}{llllll} & \text { Q } & \text { GP } & \text { T } & \text { G } & \text { R LAP PG } \\ 329 & \text { QA------GGPGTSGG----RPGLAPGPG } 347\end{array}$

\section{PCR-Produkt V}

gcggtcaggctcccgctggtcctgctgcaggacatg

A V R L P L V L L Q D M

acccacatcgtnnaggttgagatccacgagcgcgaccgctttacggacttcctgctgatt

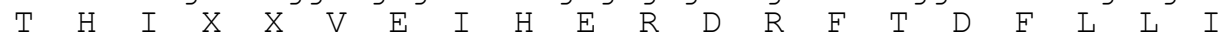

ctgctgcgggacgcgctcccggcacacccggcgctgcgcctggtcctcatgagcgccacc

$\begin{array}{lllllllllllllllllllllllllllll}L & \mathrm{R} & \mathrm{D} & \mathrm{A} & \mathrm{L} & \mathrm{P} & \mathrm{A} & \mathrm{H} & \mathrm{P} & \mathrm{A} & \mathrm{L} & \mathrm{R} & \mathrm{L} & \mathrm{V} & \mathrm{L} & \mathrm{M} & \mathrm{S} & \mathrm{A} & \mathrm{T}\end{array}$

ctgcacacggacctgttctctggctacttcggcggctgcccgattgtccaggttccgggc

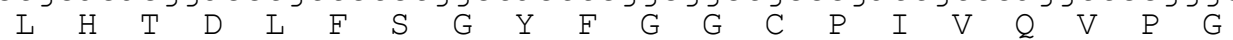

ttcacccacccggtggaagacttccacctagaggtacagccttggcacgcccctggaggc

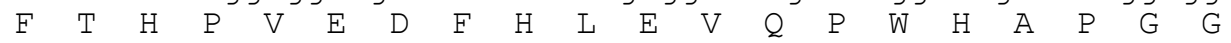

ccctaattgcttgccagtcatggtgattgtgcctatcaatcattatgatctgcctatca

$\mathrm{P}-\mathrm{I}$ A $\mathrm{C} Q \mathrm{Q}$ S $-\mathrm{T}$ C L S I I M I C I

ccggatgtggcgctgcatacgtaagttctgacagcaggcaagtgatttacggcaggatgt

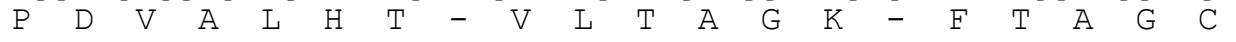
gcttcaaatggtgggttacatcggcgggcagactgccgacggtggcgctgtcaatggcag $\begin{array}{llllllllllllllllllll}A & S & N & G & G & L & H & R & R & A & D & C & R & R & W & R & C & Q & W & Q\end{array}$ cacccgccaggcacgggtgcnagccatactcggtgctctc
$\mathrm{H} P \mathrm{P}$

\section{Alignment}

Sequences producing significant alignments:

(bits) Value

Score E

gi|15227240|ref|NP_180638.1|(NM_128633) putative RNA helic.104

gi|1353239|gb|AAB01660.1|(U10245) putative RNA helicase A .104

gi|15221547|ref|NP 172152.1|(NM 100544) DEIH-box RNA/DNA h.103

gi|5881579|dbj|BAA 4364.1 (D842525) DEIH-box RNA/DNA helica.103

gi|6692694|gb|AAF24828.1|AC007592 21 (AC007592) F12K11.4 [A..99 2e-20

$3 e-22$

$3 e-22$

$6 e-22$

$6 e-22$

>gi|15227240|ref|NP_180638.1| (NM_128633)

putative RNA helicāse A [Arabidopsis thaliana]

Length $=1299$ Score $=104$ bits (260), Expect $=\mathbf{3 e - 2 2}$

Identities $=46 / 75$ (61\%), Positives $=61 / 75$ (81\%)

Q:10 LQDMTHIXXVEIHERDRFTDFLLILLRDALPAHPALRLVLMSATLHTDLFSGYFGGCPIV 69

+ D+THI EIHERD ++DF+L ++RD LP++P LRL+LMSATL + FSGYFGGCP+V

S:304 VSDITHIIVDEIHERDCYSDFMLAIIRDLLPSNPHLRLILMSATLDAERFSGYFGGCPVV 363

Query: 70 QVPGFTHPVEDFHLE 84

$+\mathrm{VPGFT}+\mathrm{PV}+\mathrm{LE}$

Sbjct: 364 RVPGFTYPVRTLYLE 378 


\section{PCR-Produkt VI}

ggtgggcgtgttgcg

G G R V A

ttgtgtttcggtctgcaacgctagccgcatgaaacagcccaacctgggagcccaaacaac $\begin{array}{llllllllllllllllllll}\mathrm{L} & \mathrm{C} & \mathrm{F} & \mathrm{G} & \mathrm{L} & \mathrm{Q} & \mathrm{R} & - & \mathrm{P} & \mathrm{H} & \mathrm{E} & \mathrm{T} & \mathrm{A} & \mathrm{Q} & \mathrm{P} & \mathrm{G} & \mathrm{S} & \mathrm{P} & \mathrm{N} & \mathrm{N}\end{array}$ cgtggcaaccaaggcatccaccgtcgtgcagatccgtcgcacaaagccactacaatagcg $\begin{array}{llllllllllllllllllll}R & G & N & Q & G & I & H & R & R & A & D & P & S & H & K & A & T & T & I & A\end{array}$ cgccttcgccgttggcgctcgctcctgacaccccgtgcaggcgcatgcctcccgctgcac $\begin{array}{llllllllllllllllllll}R & L & R & R & W & R & S & L & L & T & P & R & A & G & A & C & L & P & L & H\end{array}$ tccagaagccccaatcctatgatgtcaaacgcctgcggcgtcgatttcggcacgtccaac $\begin{array}{lllllllllllllllllllll}S & R & S & P & N & P & M & M & S & N & A & C & G & V & D & F & G & T & S & N\end{array}$ tccaccgtcggctggctgagaccggacgcgcccaccctgctgccgetcgaagacggcaag $\begin{array}{llllllllllllllllllllllllll}S & T & V & G & W & L & R & P & D & A & P & T & L & L & P & L & E & D & G & K\end{array}$ gctacgctgccttccgtcatctettcatgccgaagacccgacggtcagctacgggcgg $\begin{array}{llllllllllllllllllllllllllllllllll}A & T & L & P & S & V & I & F & F & H & A & E & D & P & T & V & S & Y & G & R\end{array}$ gccgcgctggccgactatcttgccggctacgagggccgcctgatgcgctcgctcaagagc $\begin{array}{llllllllllllllllllllll}A & A & L & D & Y & L & A & G & Y & E & G & R & L & M & R & L & K\end{array}$ ctgctcgacacatcgatgatggacgacagcaccgaggtcatgggccaagccatgcctttc

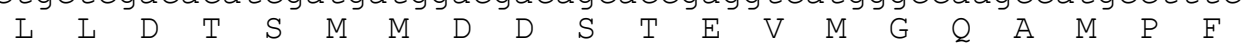
cgcaagctgctggcgcatttcattggC

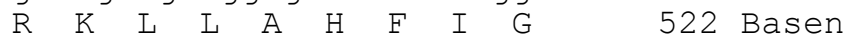

\section{Alignment}

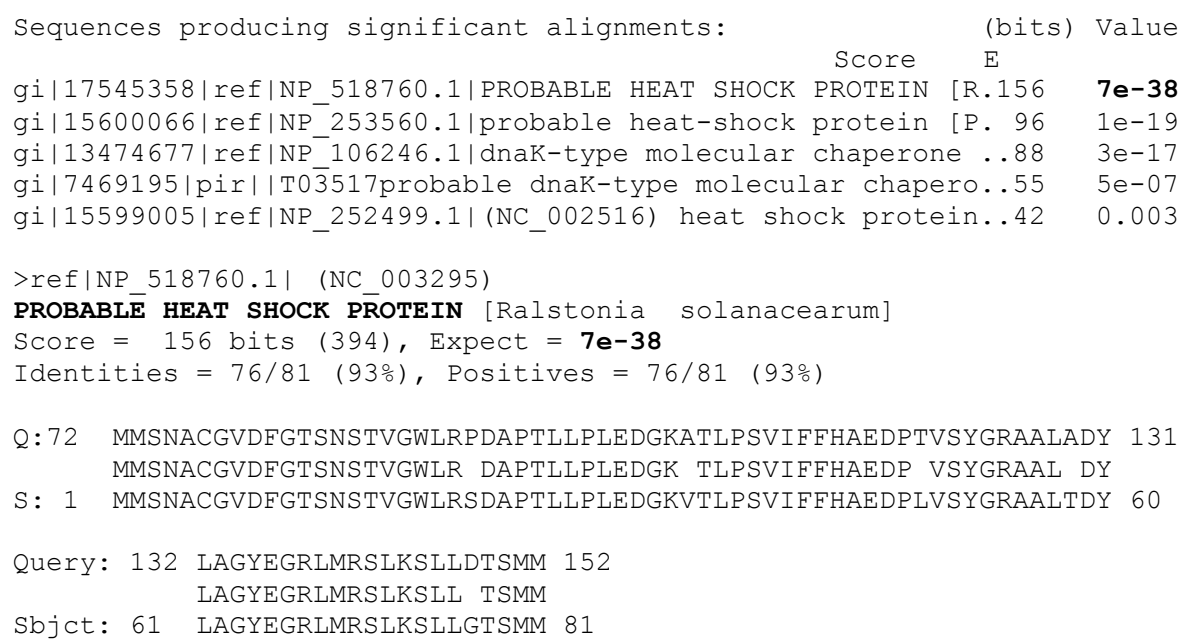

\section{Alignment auf Basensequenz}

Sequences producing significant alignments:

gi|17427566| emb|AL646060.1|Ralstonia solanacearum ...

Strand $=$ Plus / Minus

Q:107 gatccgtcgcacaaagccactacaatagcgcgccttcgccgttggcgctcgctcctgaca 166 ||||||||||||||||||||||||||||||||||||||||||||||||||||||| |

S: 86337 gatccgtcgcacaaagccactacaatagcgeccettcgccggtggegcecgetcctgata 86278

Q:167 ccccgtgcaggcgcatgcctcccgctgcactccagaagccccaatcctatgatgtcaaac 226 ||||||||||||||||||||||||||||||| ||||||| ||||||||||||||||||| $S: 86277$ tCCCgtgcaggcgcatgcctccCgctgcactcgagaagccacaatcctatgatgtcaaac 86218

Q:227 gcctgcggcgtcgatttcggcacgtccaactccaccgtcggctggctgagaccggacgcg 286

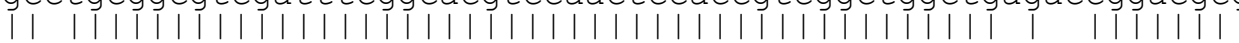

S: 86217 gcttgcggcgtcgatttcggcacgtccaactccaccgtcggctggctgcgctcggacgca86158 
Q:287 cccaccctgctgccgctcgaagacggcaaggctacgctgccttccgtcatcttctttcat 346

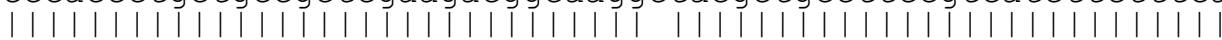

S: 86157cccaccetgctgccgetcgaagacggcaaggttacgctgccttccgtcatcttctttcac86098

Q:347 gccgaagacccgacggtcagctacgggcgggcegcgctggccgactatcttgccggctac 406 |||||||||||| |||||||||||| || ||||||||| ||||||||||||||||||||

S: 86097 gccgaagacccgctggtcagctacggccgtgccgcgctgaccgactatcttgccggctac 86038

Q:407 gagggccgcctgatgcgctcgctcaagagcetgctcgacacatcgatgatggacgacagc 466 |||||||||||||||||||||||||||||||||||||||||||||||||||||||| $\mid$

$S: 86037$ gagggcegcctgatgcgctcgctcaagagcetgctcggcacgtcgatgatggacgagagc 85978

Query:467 accgaggtcatgggccaagccatgcctttccgcaagctgctggcgcatttcat 519

||||||||||||||||| |||||||| ||||||||||||||||||||||||||

Sbjct: 85977 accgaggtcatgggccaggccatgcccttccgcaagctgctggcgcatttcat 85925

\section{PCR-Produkt VII}

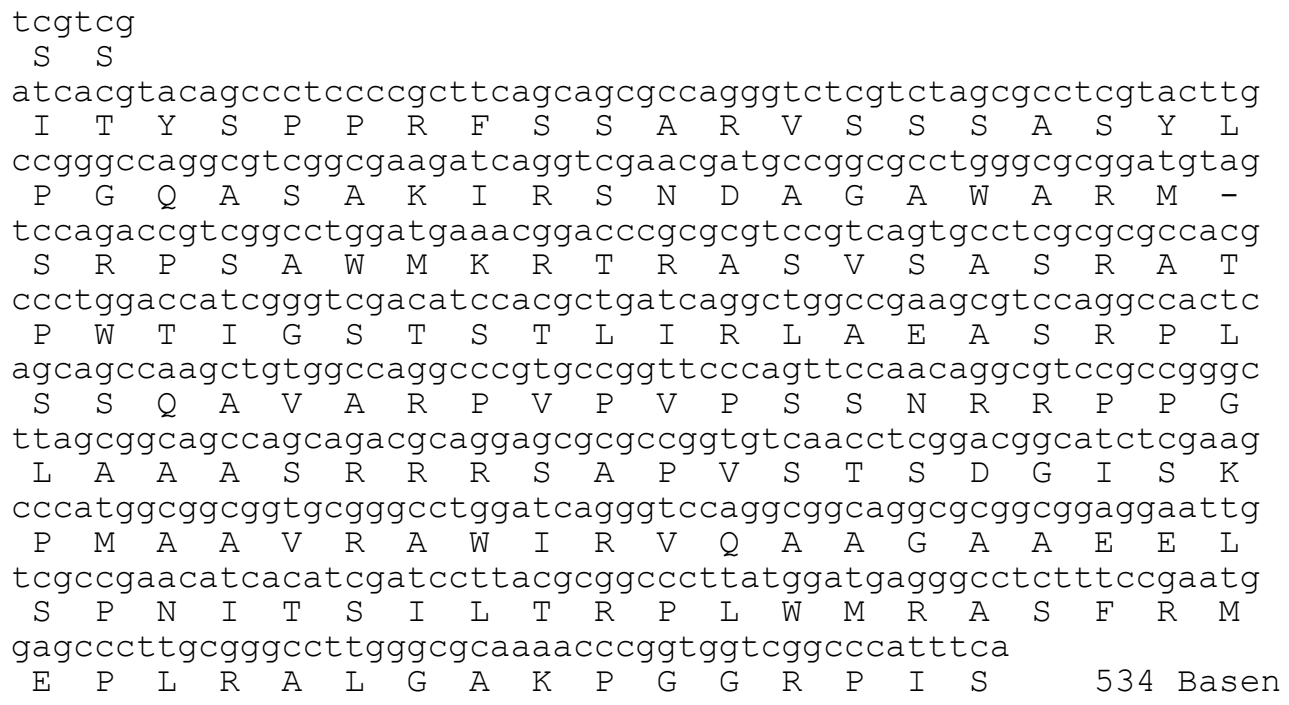

\section{Alignment}

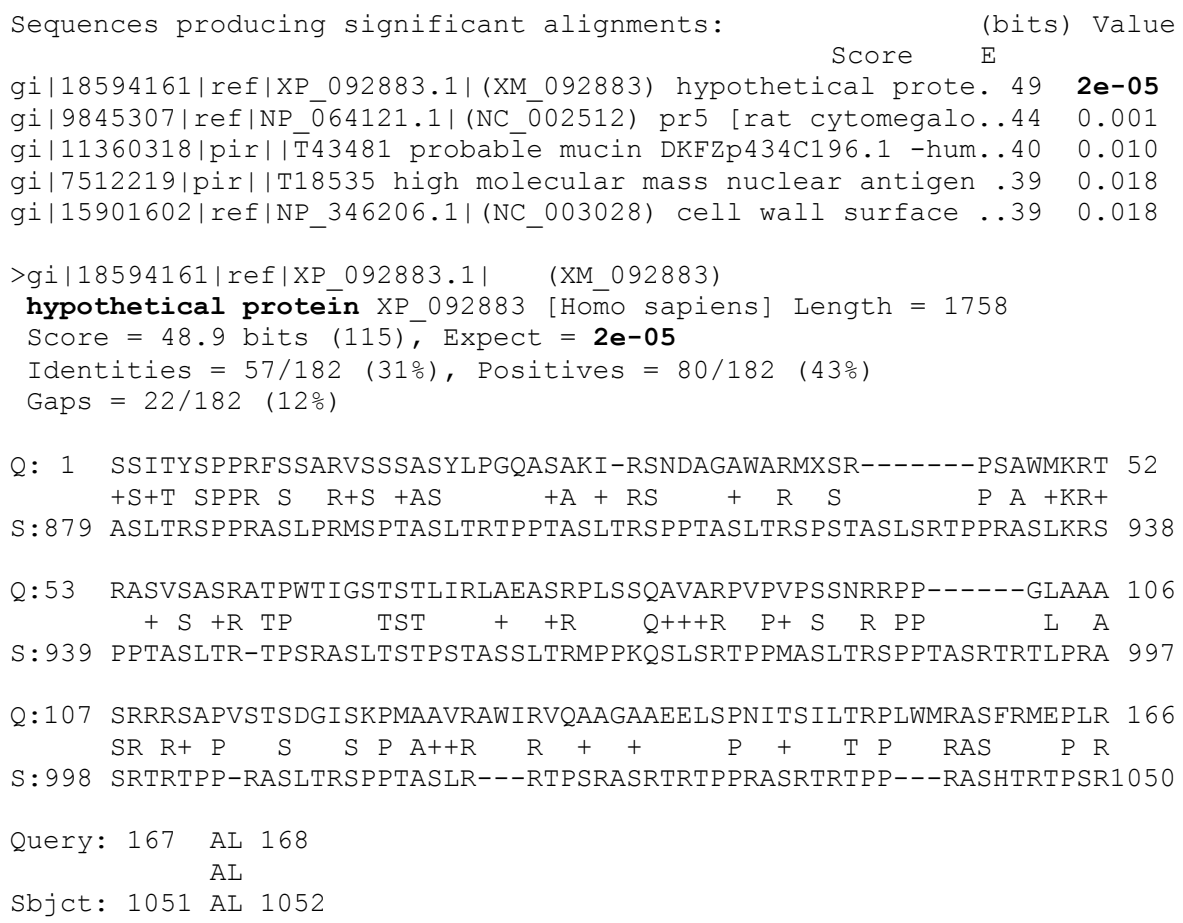




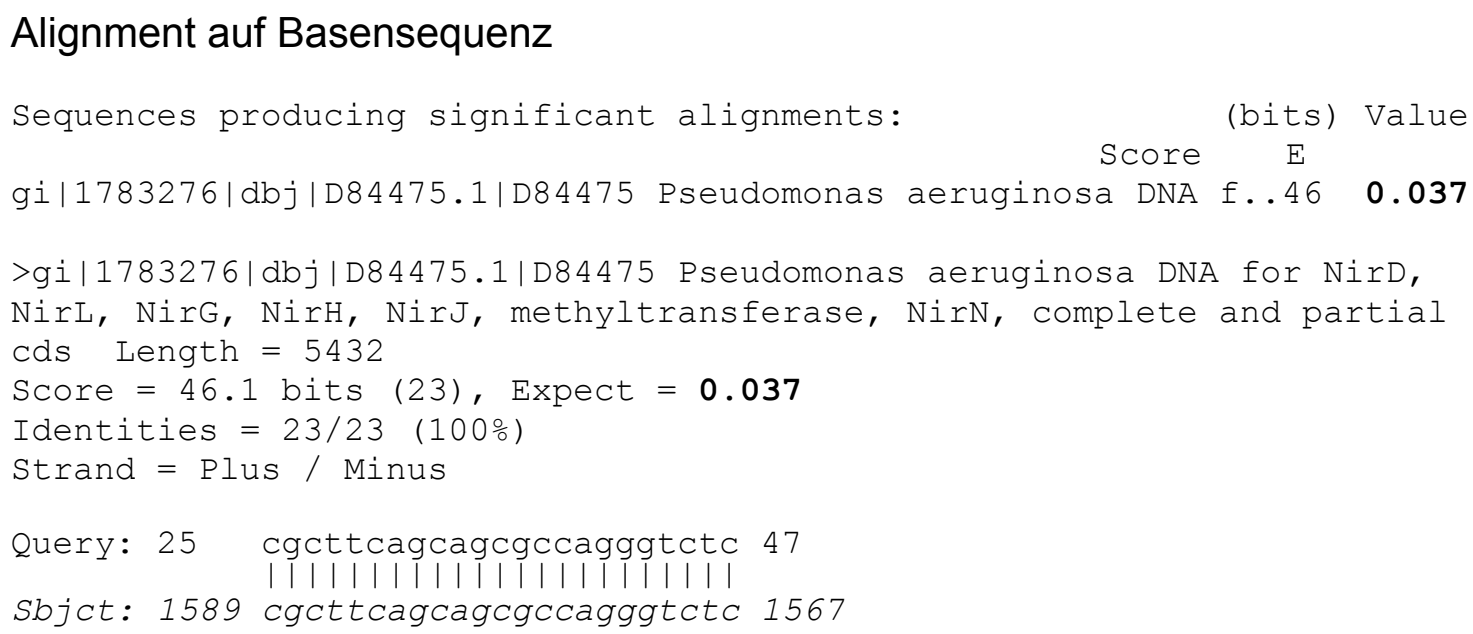

Zusammenfassung PCR-Produkte I-VII:

Mit den eingesetzten genspezifischen Primern gelang es nicht, in der PCR einem bekannten Nitrat-Transporter ähnliche oder homologe Produkte zu erhalten. Den durch PCR erhaltenen Sequenzen entsprechend wurde in Chlorella saccharophila homologe Proteine $\mathrm{zu}$ folgenden Proteinen nachgewiesen: Hitzeschock-Protein (PCR-Produkt VI; Score $=156$ bits, Expect $=7 \mathrm{e}-38$ ); putative RNA-Helicase $\mathrm{A}$ (PCR-Produkt V; Score $=104$ bits, Expect $=$ 3e-22); Extensin-artiges Protein (PCR-Produkt II; Score $=63.9$ bits, Expect $=$ 3e-10); Humanes hypothetisches Protein (PCR-Produkt VII; Score $=48.9$ bits, Expect $=2 \mathrm{e}-05)$. Eine kurze, der DNA-Sequenz für die Gene NirD, NirL, NirG, $\mathrm{NirH}$ etc. in Pseudomonas aeruginosa übereinstimmende Sequenz enthielt ebenfalls PCR-Produkt VII. Den kleinsten Expect value bei höchstem Score zeigte die Basensequenz des ansequenzierten Produktes VI: Die Sequenz zeigte eine Übereinstimmung der Basen mit dem entsprechenden Abschnitt aus Ralstonia solanacearum zu $94 \%$.

Deutlich höhere Expect values lagen bei den PCR-Podukten I-IV vor; Humanes homeo box domain Protein (III; Score $=34.7$ bits, Expect $=0.17$ ); putative Ser/Thr-Kinase (IV; Score $=32.7$ bits, Expect $=0.59)$; RNA-abhängige RNAPolymerase $(\mathrm{l}$; Score $=28.9$ bits, Expect $=11)$. 


\section{DISKUSSION}

\subsection{Anzuchtverfahren}

Die Anzucht der Algen in den 4,5 I-Penicilliumflaschen steigerte die erzeugte PM-Menge erheblich. Zunächst auftretende Probleme $z$. B. lange Autoklavierdauer (bedingte das Ausflocken von Präzipitaten in der $\mathrm{NH}_{4}$-haltigen Nährlösung) sowie ein Absterben der Algen nach Inokulation der PenicilliumFlaschen mit Stammkulturen wurden überwunden. Die Algen zeigten nach dem Einbringen in die Penicillium-Flaschen eine sehr lange lag-Phase. Die Anpassungsphase von Stammkulturen (fest, Kolonien) auf Flüssigkultur ist kritisch. Deshalb wurden die Kulturen zunächst bei Raumtemperatur, geringer Belüftung und niedriger Lichtintensität in den Penicillium-Flaschen kultiviert. Nach erkennbarer Zunahme der Zelldichte (einsetzende log-Phase) wurden die Algen in Standardkulturbedingungen überführt. Die PM-Ausbeute war, bezogen auf das Volumen der Algensuspension, im Verhältnis zu der Kultur in $300 \mathrm{ml}-$ Kulturröhren etwas geringer. Der Verlust war durch den Einsatz größerer 32gTrennsysteme (anstelle von 8g-Systemen) zum Two-Phase-Partioning des Mikrosomalen Pellets bedingt. Bei den 32g-Systemen verblieb ein Teil der PM in der Dextran-Phase. Dies konnte nicht durch verlängertes Ausschütteln kompensiert werden. Der Einsatz von 8g-Systemen hätte zwar die Ausbeute verbessert, war aber bei den großen Mengen mikrosomalen Pellets nicht praktikabel.

Die Kombination von Massenkultur mit dem Einsatz großer Trennsysteme deckte den hohen PM-Bedarf insbesondere bei präparativen IEF-Gelen. Das Verfahren ist mehrfach adaptiert und verbessert worden, eine detailierte Beschreibung gab Brenner (1998).

\subsection{D-SDS-PAGE mit Trägerampholyten}

\subsubsection{Methodenauswahl und -vergleich}

Die Proteine der Plasmamembran konnten auf gelelektrophoretischem Weg durch eine zweidimensionale SDS-Gelelektrophorese (2D-SDS-PAGE) aufgetrennt werden. Dies wurde durch eine 2D-SDS-PAGE mit Trägerampholyten in Anlehnung an Dunbar et al. (1990) erreicht.

Die zweidimensionale SDS-Gelelektrophorese ist die höchstauflösende Technik zur Proteintrennung (Herbert, 1999). Sie beruht auf den methodischen Grundlagen von O'Farrell (1975) und Shapiro (1967). Mit der 2D-SDS-PAGE ist eine Trennung von mehreren hundert bis Tausenden von Proteinen auf einem einzigen Gel möglich. Eine Überlagerung von Polypeptiden gleichen Molekulargewichts -ein häufiges Problem bei der SDS-PAGE (Finean und Michell, 1981)- ist durch die zweite Trenndimension annähernd auszuschließen. Zur Trennung der Proteine in der ersten Dimension der 2D-SDS-PAGE, dem isoelektrischen Fokussieren (IEF), existieren zwei verschiedene Verfahren. Diese werden im Folgenden verglichen.

Das IEF mit immobilisierten $\underline{p} H$-Gradienten (IPG-IEF) steht dem IEF mit Trägerampholyten (ㅡarrier Ámpholytes, CA-IEF) gegenüber. Die von O'Farrell 
(1975) ausgearbeiteten Bedingungen für das IEF werden fast unverändert (CAIEF; Shimazaki et al., 1999) oder modifiziert (IPG-IEF; Görg et al., 2001), bis heute eingesetzt. Das Trägerampholyt-IEF hat gegenüber dem IEF mit immobilisierten pH-Gradienten (IPG-IEF) zwei erhebliche Nachteile.

Erstens eine nicht zu gewährleistende vollständige Reproduzierbarkeit des IEF. Die Ampholyte sind als Gemisch von niedermolekularen OligoaminoOligocarbonsäuren (Vesterberg, 1969) chargenabhängigen Variationen ihrer Komponenten unterworfen. Die 2D-Elektrophoretogramme (2D-ProteinPatterns) können daher variieren und sind nicht labor-unabhängig reproduzierbar.

Zweitens der als „Kathodendrift" bezeichnete Effekt. Der mit Trägerampholyten erzeugte $\mathrm{pH}$-Gradient ist nicht zeitstabil, obwohl das IEF theoretisch eine Gleichgewichtsmethode darstellt. Die Trägerampholyte wandern im elektrischen Feld zunächst zu ihren jeweiligen isoelektrischen Punkten (IEP) und erzeugen einen $\mathrm{pH}-$ Gradienten im Gel. Dieser $\mathrm{pH}-$ Gradient wandert aber mit zunehmender Fokussierungsdauer und unter Verlust seiner Linearität, in Richtung der Kathode (Righetti et al., 1987). Ein Equilibrium stellt sich nicht ein. Darüberhinaus führen hohe lokale Proteinkonzentrationen zu Verwerfungen des $\mathrm{pH}-$ Gradienten.

Im IPG-IEF wird der pH-Gradient durch puffernde Acrylamid-Derivate erzeugt, die an der Acrylamid-Matrix co-polymerisiert sind. Dadurch ist der pH-Gradient im Gel immobilisiert und zeitstabil. Ein Equilibrium wird erreicht. Das IPG-IEF ist auch gegenüber hohen Protein-Konzentrationen stabiler. Daher ist das Trägerampholyt-IEF hinsichtlich der genannten Nachteile dem IPG-IEF unterlegen (Görg et al. 2001).

Trotz der genannten Vorteile des IPG-IEF basiert das gegenwärtig höchstauflösende 2D-PAGE-System auf Trägerampholyten. Zur ProteomAnalyse werden durch Trägerampholyt-IEF und SDS-PAGE bis zu maximal 15000 Proteine in einem 30x40 cm-Gel aufgetrennt (pers. Mittlg. A. Köpke, WITA-Proteomics, Berlin; www.wita-proteomics.de). Diese zur kommerziellen Proteom-Analyse entwickelten, höchstauflösenden 2D-Gele werden in einem Set von 3-10 Gelen je Proteom (z. B. einer Tumor-Zelllinie) angefertigt. Pharmakon-induzierte Unterschiede im Proteinverteilungsmuster werden ausgewertet, relevante Proteine ausgestochen und diese mit MS-MS und MALDI-ToF analysiert. Das Beispiel zeigt, daß die Wahl eines IEF-Verfahrens vom gewünschten Zweck abhängt. Bei dem von WITA durchgeführten Trägerampholyt-IEF zur Auffindung von induzierten Proteinen ist eine laborunabhängige Reproduzierbarkeit unerheblich. Ebenso die Kathodendrift des $\mathrm{pH}$-Gradienten, wenn trotzdem eine hoch differenzierende 2D-PAGE erreicht wird. Das Träger-Ampholyt-IEF gestattet WITA eine extrem hohe Trennleistung und zumindest innerhalb eines Sets von Gelen, eine Gel-zu-GelReproduzierbarkeit. Das IPG-IEF von PM-Proteinen ist problematisch. Adessi et al. (1997) zeigten an Membranproteinen aus verschiedenen Objekten (Spinacea oleracea und Dictyostelium discoideum) einen Verlust von Proteinen bei IPG-IEF; dieser trat bei Trägerampholyt-IEF nicht auf. Darüberhinaus tendierten die Proteine bei Übertragung der IPG-IEF-Streifen auf die SDSPAGE zu einem Verbleib der Proteine im Streifen und damit vertikaler Schlierenbildung. Daher wurden speziell für das IPG-IEF von PlasmamembranProteinen Lysisbedingungen und geeignete Detergenzien ermittelt; dazu liegen 
eine Vielzahl von Untersuchungen vor (Überblick in: Rabilloud, 1997; Santoni et al., 2000). Eine allgemeine Aussage hinsichtlich eines geeigneteren IEFSystems zur Trennung von PM-Proteinen kann daher nicht getroffen werden. Entscheidend ist, unabhängig vom System, stets die Gewährleistung ausreichender Solubilisierung und Gel-Eintrittes der zu untersuchenden Proteine. Dazu muß jeweils ein individuell geeignetes Protokoll erarbeitet werden. Im Rahmen der vorliegende Untersuchung erwies sich das Trägerampholyt-IEF in Kapillargelen als bestgeeignetes Verfahren zur Trennung von Plasmamembran-Proteinen. Gegenüber dem IPG-IEF (Vorversuche nicht gezeigt) hatte es eine Reihe praktischer Vorteile:

- Schnelle Bereitstellung: Die Kapillargele waren innerhalb einer Stunde hergestellt und einsetzbar, die Gele konnten nach Fokussierungsabschluß unmittelbar aufgearbeitet (SDS-PAGE) oder bei Bedarf in der Glaskapillare verbleibend, eingefroren werden.

- Einfache Handhabung und hoher Probendurchsatz: Die lysierten Proteine konnten direkt von der Kathodenseite auf das Gel aufgeladen und umgehend fokussiert werden; Vorfokussieren, Öl-Überschichtung, Equilibrierung oder Rehydratisierung der Gele im Proteingemisch bzw. ein (störanfälliges) sample cup-loading entfielen; die Gefahr der Proteindegradation durch lange Lagerung bei Raumtemperatur war minimiert. Bis zu acht Kapillargele wurden parallel aufgearbeitet.

- Gute Eignung für radioaktives Arbeiten: Insbesondere im Hinblick auf den Einsatz der 2D-SDS-PAGE für radioaktives Arbeiten mit dem ${ }^{14} \mathrm{C}$-markierten DNPA sowie den ${ }^{35}$ S-markierten Proteinen erlaubten die geringen, für das Kapillar-IEF mit Trägerampholyten benötigten Volumina der Puffer und die kleinen, mit radioaktivem Material in Berührung kommenden Oberflächen eine erhebliche Vereinfachung der Arbeitsprotokolle. Daneben eine erhebliche Zeitersparnis bei der Gerätereinigung und VersuchsNachbereitung.

\subsubsection{Optimierung}

Die Anzahl und Trennleistung der PM-Proteine im 2D-Gel war zunächst unbefriedigend, der pH-Gradient war stark gestaucht (Abb. 2 A,B). Durch Variationen der Detergenz-(NP40-) und Ampholyt-Konzentration im IEF konnte die Auflösung erheblich verbessert werden. Als solubilisierende Agenzien wirken NP40 als nicht-ionisches Detergenz sowie hochmolare HarnstoffLösungen gegenüber SDS nur mäßig solubilisierend. Dennoch kann ein zwitterionischer Effekt und eine Solubilisierung vergleichbar z.B dem häufig für immobilisierte $\mathrm{pH}$-Gradienten (IPG) eingesetzten zwitterionischen Detergenz CHAPS (Görg et al., 1988; 2001) durch ein geeignetes Verhältnis von NP40 (= Igepal CA630) zu Ampholyten nachgeahmt werden. NP40 bildet in Abhängigkeit vom stöchiometrischen Verhältnis und der Ladungsdichte NP40/Ampholyte verschiedene Mizellentypen, die dem Verhalten von zwitterionischen Detergenzien entsprechen können (Satta et al., 1984).

Gemäß der Zielsetzung der vorliegenden Untersuchung, ein möglichst breit gefächertes Spektrum von PM-Proteinen zu erfassen, wurde vermieden, die Eingangsbedingungen der 2D-SDS-PAGE ausschließlich auf hydrophobe 
Proteine zu optimieren. Bei dem empirisch ermittelten Verhältnis von $2 \%$ NP40 zu 4\% Ampholyten pH3-10 war eine optimale Streckung des basischen bis neutralen Bereiches aller PM-Proteine erreicht: Die Proteine fokussierten weitgehend punktförmig und Proteine mit IEP im sauren $\mathrm{pH}-$ Bereich blieben noch innerhalb des pH-Gradienten (Abb. 2 D). Bei der Auswahl der Trägerampholyte mit breitem pH-Bereich pH3-10 wurden zwei Faktoren berücksichtigt: Die überwiegende Zahl der Proteine fokussiert in einem Bereich zwischen $\mathrm{pH} 4$ und $\mathrm{pH}$ 7. Der IEP von pflanzlichen Transporterproteinen für Ionen bzw. lösliche Verbindungen liegt hingegen im alkalischen Bereich von größer pH 8 (Santoni et al., 1999). Mit den eingesetzten Trägerampholyten pH 3-10 war somit gewährleistet, keine Proteine in den basischen und sauren Randbereichen zu verlieren. Das hier erarbeitete IEF-Protokoll für Plasmamembran-Proteine stellt einen guten Kompromiß dar, und trennte eine hohe Zahl von Proteinen auf (Abb. 4 A, B). Trotzdem werden auch hier Proteine verloren gehen, da zu große Unterschiede im Löslichkeitsverhalten der verschiedenen PM-Proteine bestehen. Eine Vielzahl von Untersuchungen belegen dieses generelle Problem der 2D-SDS-PAGE: An Proteinen der Plasmammembran aus Arabidopsis thaliana zeigten Santoni et al. (1999) nach TX114-Fraktionierung und Solubilisierung mit CHAPS das Fehlen verschiedener hydrophober Proteine im 2D-Gel. Erst nach Waschen der PM mit einem alkalischem Carbonat-Puffer und Solubilisierung der Proteine mit dem zwitterionischen Detergenz C8Ф waren diese aufgetrennt. Dies aber wiederum unter Verlust von weniger hydrophoben, membran-peripheren Proteinen. Die gleichen Autoren (Santoni et al, 2000) fanden eine Korrelation zwischen Lipidkonzentration der PM und der Löslichkeit hydrophober Proteine in einem jeweiligen Detergenz. Zur Optimierung der Löslichkeit ist damit entweder die jeweilige Detergenz-Konzentration oder ein Ersatz durch ein stärker oder schwächer solubilisierend wirkendes Detergenz empirisch zu ermitteln. Entsprechend der beschriebenen Schwierigkeiten brachte auch das vorliegende Solubilisierungsprotokoll nicht alle Plasmamembran-Proteine in Lösung. Dies geht u.a. aus den Ergebnissen des Photo-Affinity-Labelling hervor: Eine Reihe von ${ }^{14} \mathrm{C}$-markierten Proteinen der SDS-PAGE traten nicht im IEF-SDS-PAGE auf (Abb. 21). Da der Fokus der Untersuchung auf der Erfassung eines möglichst breit gefächerten Proteinspektrums der Plasmamembranen lag, wurden die Solubilisierungsbedingungen nicht geändert. Dies hätte zu den o. g. Einschränkungen geführt. Protokolle zu Probenvorbereitungen und Lysisbedingungen sind verfügbar unter www.expasy.ch/ ch2d/protocols/ protocols.fm1.html; Arbeitsgruppe Angelika Görg (IPG-2D-SDS-PAGE): www.weihenstephan.de/blm/deg.

Zur Lösung dieser Probleme sind zwei methodische Strategien denkbar:

1. Fraktionierte Fällung von Proteinen und Elektrophorese in SDS-Systemen.

2. Verknüpfung von Trennsystemen unterschiedlicher Methodik.

$\mathrm{Zu}$ 1.) Wird die Detergenz-Phase des Triton $X 114-S y s t e m s$ (Proteine höherer Detergenzbindung/Hydrophobizität) bei Raumtemperatur oder unterhalb des TX114-cloud points zentrifugiert (10 min, $14000 \times \mathrm{g}$ ), so sedimentieren einzelne Proteine geringerer oder fehlender TX114-Löslichkeit. Die 2D-SDS- 
PAGE dieses Pellets zeigte allerdings keine qualitativ neu aufgetretenen Proteine (Abb. 42).

$\begin{array}{cl}10<- & \mathrm{pH} \\ \mathrm{kDa} & \\ 94- & \text { Abb. 42: Durch Zentrifugation (14000xg, } \\ 67- & 10 \mathrm{~min} \text { sedimentierte, schwerlösliche } \\ 43- & \text { Proteine der Detergenz-Phase des } \\ 30- & \text { TX114-Systems. }\end{array}$

$20,1-$

14,4 -

Nach NP40-/Harnstoff-Solubilisierung dieser TX114-schwerlöslichen Proteinfraktion sind in der 2D-SDS-PAGE wiederum nur die entsprechend NP40+Harnstoff-löslichen Proteine enthalten. Die wenigen aufgetrennten Proteine sind der Anteil der schlecht TX114-löslichen Proteine, der gerade noch mit Harnstoff/NP40 gelöst werden kann. Dies erklärt auch, warum ein Vergleich mit dem Gel der TritonX114-Detergenz-Phase (Abb. 4 B) nur Anreicherungen einzelner, bereits kartierter Proteine zeigte, aber keine weiteren, neuen Proteine (Daten nicht gezeigt). Durch erneute Zentrifugation würden die TX114/Harnstoff-/NP40-unlöslichen Proteine sedimentieren. Dies sind die in der 2DSDS-PAGE nicht repräsentierten Proteine, die in TX114/Detergenz/Harnstoff unlöslich sind. Durch Aufschluß dieser Proteine mit SDS-Beladungspuffer sind sie schließlich in einer SDS-PAGE aufzutrennen. Bei der zu erwartenden, nur noch geringen Zahl der sehr schlecht solubilisierbaren PlasmamembranProteine könnte die Trennleistung des SDS-PAGE bereits ausreichen. Durch diese Kombination (2D-SDS-PAGE und SDS-PAGE) würden auch die schwerlöslichen Plasmamembran-Proteine höchster Hydrophobizität erfasst und zumindest ausreichend getrennt (SDS-PAGE) werden können.

Zu 2.) Verknüpfung von Trennsystemen unterschiedlicher Methodik: Ist die Zahl der TX114/Harnstoff/Detergenz-unlöslichen Proteine sehr hoch, wären zu ihrer Auftrennung für besonders hydrophobe Proteine geeignete Verfahren einzusetzen, wie z.B. die BAC-Elektrophorese. Damit wird eine scheinbar zweidimensionale Trennung erreicht (Hartinger et al., 1996). Dies würde die Erfassung der schwerlöslichen Proteine mit einer gegenüber der SDS-PAGE höheren Auflösung gewährleisten. Eine Verbindung von 2D-SDS-PAGE und BAC-Elektrophorese würde ein breites Spektrum der Auftrennung gewährleisten. Zunächst erfolgt eine 2D-SDS-PAGE zur Auftrennung der im TX114/Harnstoff/Detergenz-System löslichen Proteine. Nach der Abtrennung der darin unlöslichen Proteine erfolgt deren Elektrophorese durch das für sehr hydrophobe Proteine geeignete BAC-System. Bei ausschließlicher Trennung der PM-Proteine durch die BAC-Elektrophorese nimmt die Wahrscheinlichkeit erheblich zu, einzelne Proteinfraktionen (hydrophile Proteine) nicht oder nicht ausreichend zu trennen. 


\subsubsection{Gelfärbung}

Die Anfärbung der Proteine im Gel erfolgte durch Silberfärbung nach Blum et al. (1987). Die Silberfärbung ist das empfindlichste Protein-Färbeverfahren; radioaktive Markierung oder Nachweis spezifischer Proteine durch Laseranregung z.B. des GFP (Richards et al., 1999a) sind zwar sensitiver, aber keine direkten Färbeverfahren. Die untere Nachweisgrenze der Silberfärbung liegt bei ca. 0,1 ng Protein/Spot (Görg et al. 2001). Dieses Limit wurde in eigenen Untersuchungen nicht erreicht. Gut erkennbar waren ca. 10 ng (Abb. 32) ; 5 bis $1 \mathrm{ng}$ stellten die untere Grenze der Unterscheidbarkeit zum Hintergrund dar. Die hohe Sensitivität der Silberfärbung stellte sicher, daß eine maximale Anzahl von PM-Proteinen nachgewiesen werden konnten. Die Sensitivität war abhängig vom Alter der Färbelösung und beeinflußte die Sensitivität durch Kontrastabnahme. Nur frische Silberfärbe-Lösung $\left(\mathrm{AgNO}_{3}-\right.$ Lsg.) erzeugte eine konstrastreiche Schwarzbraun-Färbung der Proteine. Ein Nachteil der Silberfärbung war der geringe dynamische Bereich der Färbung: Während Proteine geringerer Konzentration (low copy-Proteine) gerade angefärbt wurden, waren höher konzentrierte Proteine häufig bereits stark überfärbt. Diese bildeten große Höfe und überdeckten umliegende Proteine (Abb. $18 \mathrm{~A}$ ). Dies führte wiederholt zu Positionierungsproblemen einzelner Proteine der jeweiligen TX114-Phasen (Abb. 4 A, B) innerhalb der 2D-Karte als Referenzsystem (Abb. 6). Eine Klärung erlaubte in diesen Fällen erst die erneute 2D-SDS-PAGE der gleichen Probe in geringerer Konzentration. Eine Alternative zur Silberfärbung mit den genannten Limitationen sind die von Molecular Probes entwickelten Fluoreszenz-Farbstoffe SYPRO Ruby (-Orange, -Red). SYPRO Ruby ermöglicht eine lineare Anfärbung von Proteinen über mindestens drei Konzentrations-Größenordnungen, Überfärbungseffekte treten nicht auf (Patton, 2000). Diese sind aber gegenüber Silberfärbung etwa 20x weniger empfindlich und sehr teuer, da auf Basis von Platinmetallen. Zusätzlich benötigen sie zur Fluoreszenz und dem Scannen/Imaging der Gele eine Anregung durch Laser und ein entsprechendes Scanner-System. Ein entsprechendes System stand nicht zur Verfügung. (Eine Gegenüberstellung der Silber/Fluoreszenz-Färbung ist zu finden in: Lopez et al., 2000).

\subsubsection{Triton X114-Phasen und 2D-SDS-PAGE-Auswertung}

Pryde (1986) entwickelte die Triton X114-Zweiphasen-Verteilung zur Trennung und Anreicherung hydrophober und hydrophiler PM-Proteine. Die Partitionierung mit TX114 erlaubt z.B. eine differenzielle Abtrennung sehr hydrophober Proteine (Wissing et al., 2000); den Nachweis von Veränderungen der Hydrophobizitätseigenschaften von GPI-verankerten Proteinen (Kunze et al, 1997; Gouin et al. 1996) und der Identifizierung membrangebundener Rezeptoren (Hoa et al., 2002). In der vorliegenden Arbeit wurden beide TritonPhasen berücksichtigt, da die Detergenz-Phase auch hydrophile Proteine anreichern kann; umgekehrt auch membran-integrale Proteine in die wässrige Phase verteilt sein können (Pryde und Philips, 1986). Auch wenn z. B. der Nitrat-Transporter aufgrund seiner vorherzusagenden transmembranen Domänen eine hohe Detergenz-Bindungskapazität erwarten läßt, wurden beide TritonX114-Phasen für die Konstruktion der 2D-Protein-Verteilungskarten (2DProtein-Patterns) berücksichtigt (Abb. 5 A, B). Die unterschiedlichen 
Hydrophobizität der PM-Proteine zeigte der Vergleich der 2D-Gele der beiden TX114-Phasen. Gegenüber dem Referenzgel (Abb. 3) lagen zwei völlig unterschiedliche Proteinmuster vor: hydrophobe und hydrophile Proteine waren scharf gegeneinander abzugrenzen. Die Wiederfindung und Zuordnung der Proteine der beiden Phasen im Referenzgel war durch Proteine mit amphiphilem Verhalten erleichtert, da sie in beide Phasen verteilt waren. Mehr als 30 solcher Proteine traten mit unterschiedlichen Quantitäten in beiden Phasen auf, wie z.B. das als NR identifizierte Protein WP104/DP101 (Abb. 24) oder die Proteine WP85/86 mit den homologen DP-Proteinen DP75/76. Diese amphiphilen Proteine sind in Abb. 6 kenntlich durch übereinanderliegende Spots von WP und DP. Aus der Größe der Spots geht gleichzeitig ihre ungefähre quantitative Verteilung in den Phasen hervor. Über ein Auftreten von Proteinen mit amphiphilem TX114-Verhalten bei der Isolierung von $\mathrm{Ca}^{2+}$ abhängigen Phosphoproteinen aus synaptischen Membranen berichten auch Perrone-Bizzozero et al. (1988). Ein weiteres Problem war das horizontale Verschmieren nicht punktförmig fokussierender Spots. Besonders ausgeprägt trat es bei Proteinen hoher Molekulargewichte und Lage des IEPs in den Randbereichen des pH-Gradienten auf (Abb. 4 B) und verhinderte eine genaue Bestimmung von Lage und Anzahl der darin enthaltenen Proteine. Dies ist ein typisches Problem bei der Auswertung von 2D-Gelen und erzwingt bei allen 2DAnalytikprogrammen ein Nacheditieren der vom Programm durchgeführten Spot-Detektion (mündl. Mittlg. B. Schöne, Bio-Rad Deutschland). Im manuellen Nacheditieren der Gele als digitale Images kann jedoch nur die Anzahl unsicher bestimmter Proteine verringert werden. Dieser system-immanente Fehler der 2D-Analytik kann durch Optimierung der 2D-Bedingungen lediglich verkleinert, aber nicht völlig aufgehoben werden.

Bei der Konstruktion einer Proteinverteilungskarte der einzelnen TX114-Phasen (Abb. 5 A, B) trat ein weiteres Problem der 2D-Analytik auf: die Set-zu-SetVariationen der Position der Proteine. Dies waren geringe horizontale Verschiebungen der IEPe, bedingt durch das Non-Equilibrium der Trägerampholyte. In der 2. Dimension kam es zu geringen vertikalen Verschiebungen durch leicht variierende Acrylamid-Gradienten der SDSGradientengele, die ebenfalls manuell hergestellt wurden. Diese Variationen der Protein-Positionen in Richtung der $\mathrm{X}$ - und Y-Achse erforderten eine zeitaufwendige Bearbeitung zum Zuordnen der Proteinpostionen.

Das 2D-Spot-Quantifizierungs-Programm von Biotech-Fischer konnte nicht zum quantitativen Vergleich der Spots eingesetzt werden. Denn das Programm setzt identische Protein-Positionen voraus; dies wird selbst im IPG-IEF kaum erreicht. Die Gele mußten daher graphisch entzerrt und die als Markerproteine ausgewählten amphiphilen Proteine zur Deckung gebracht werden. Der in der nachfolgenden Abbildung 43 gezeigte Ausschnitt macht die Verschiebung der Protein-Positionen von zwei Gelen der wässrigen TX114-Phase deutlich. 


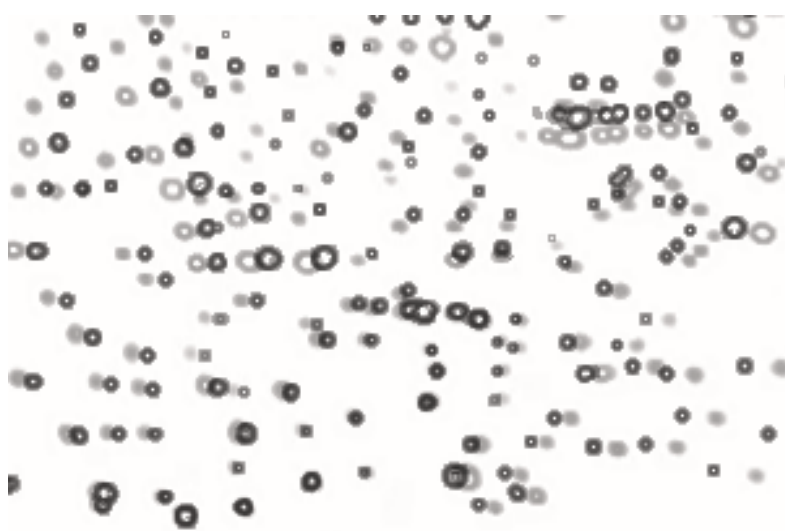

Abb. 43: Positionsverschiebungen von Proteinen in $X$ - und $Y$-Achsenrichtung von zwei experimentellen Sets (grau/schwarz; dargestellt ist ein Auschnitt aus der 2D-Verteilungskarte der Wässrigen TX114-Phase)

Nach Korrektur der Proteinpositionen konnten die Proteine zur Deckung gebracht und fortlaufend nummeriert werden. Die (sehr teuren) zur ProteomAnalyse eingeführten 2D-Analyseprogramme wie z.B. PDQuest, Melanie, Phoretix2D etc. ermitteln und korrigieren die auch zwischen den hochstandartisierten IPG-Dalt-Gelen stets auftretenden Positionsverschiebungen. Dies erfolgt anhand eines algorhitmischen Vergleiches der Spot-Topographie um die Positionen von als Referenzspots festgelegten Proteinen. Bis zum Erreichen der höchstmöglichen Übereinstimmung zweier Gele bzw. Gel und Referenzgel werden die digitalen Images der Gele bis zur Kongruenz gezerrt (sog. „Matching“ der Spots). Ein solches Programm stand nicht zur Verfügung, daher wurde das spot-matching durch Überlagerung der falschfarbigen Gel-Images mithilfe eines GraphikProgrammes (Corel Photo-Paint 8) durchgeführt. Die Gele wurden damit als digitale Images solange durch das Verzerren eines über das Gel gelegten Maschennetzes verzogen, bis die Proteine von Gel zu Gel identische Positionen einnahmen (Abb. 43). Vergleichsgele, deren TX114-Phasen zusätzlich mit nicht-TX114-verteilten PM-Proteinen versetzt waren („Spiking“ der Proben), gewährleisteten eine zusätzliche Absicherung der Zuordnung und richtigen Lokalisation. Die graphische Nachbearbeitung der 2D-Gele war sehr zeitaufwendig, erlaubte aber eine dem IPG-IEF vergleichbare Reproduzierbarkeit durch Träger-Ampholyt-IEF zu erzielen. Dadurch konnten die Proteine der Plasmamembran von Chlorella mit den o.g. Vorteilen des Träger-Ampholyt-IEF in einer 2D-Karte zusammengefaßt und eingeteilt nach Detergenz-Bindungskapazität, kartiert werden.

\subsection{In vivo ${ }^{35}$ S-Methionin markierte Plasmamembran-Proteine}

Um $\mathrm{NO}_{3}{ }^{-}$-induzierbare Proteine der Plasmamembran aufzufinden, wurden Algen nach $\mathrm{N}$-Verarmung in Gegenwart der radioaktiven Aminosäure ${ }^{35} \mathrm{~S}$ Methionin mit $\mathrm{NO}_{3}$ induziert. Mit der zuvor erstellten 2D-Kartierung der Proteine der TX114-Phasen war die wichtigste Voraussetzung zu ihrer Auffindung erfüllt: Eine individuelle Erfassung qualitativer und quantitativer Veränderungen von PM-Proteinen. Die Markierung von Proteinen mit dem radioaktiven SchwefelIsotop ${ }^{35} \mathrm{~S}$ ist eine seit langem in der Analytik etablierte ProteinNachweismethode. ${ }^{35}$ S-Methionin wird bei der de novo-Synthese von Proteinen einem unmarkierten Methionin gleichwertig eingebaut; durch autoradiographischen Nachweis können die de novo-synthetisierten Proteine mit sehr hoher Empfindlichkeit detektiert werden. Damit sind spezifische Ursache- 
Wirkungsbeziehungen auf Proteinebene zu verfolgen; daneben wird die ${ }^{35} \mathrm{~S}$ Markierung zur Verbesserung von Visualisierung und Lokalisierbarkeit von Proteinen im IPG-IEF zur Proteomanalyse eingesetzt (Westbrook et al., 2001).

\subsubsection{Induktionsbedingungen und Einbau des ${ }^{35}$ S-Methionins}

Die für die $\mathrm{NO}_{3}{ }^{-}$-Induktionsexperimente gewählten Bedingungen: Anzucht der Algen in $\mathrm{NH}_{4}{ }^{+}-\mathrm{NL}, 12 \mathrm{~h} \mathrm{~N}$-Verarmung, 3h NO${ }_{3}^{-}$-Induktion (Clarkson, 1986; Stöhr, 1988; Hole et al., 1990, Aslam et al., 1993) stellten sicher, daß

- keine $\mathrm{NH}_{4}$-bedingte Reprimierung eines $\mathrm{zu}$ induzierenden NitratAufnahmesystems (-Transporters) bzw. von weiteren gleichartig regulierten, Nitrat-induzierten Proteinen vorliegt;

- die lag-Phase des Nitrat-Aufnahmesystems nach $\mathrm{NO}_{3}^{-}$-Induktion überschritten und damit

- de novo-synthetisierte Proteine in einer zur Autoradiographie ausreichenden Menge gebildet werden.

Über den Einbau des ${ }^{35}$ S-Methionins in die PM-Proteine kann die durchgeführte Szintillationszählung der Präparationsschritte keinen Aufschluß geben. Dennoch gibt die in den einzelnen Schritten gemessene Radioaktivität Aufschluß über die Verhältnisse der Proteinkonzentrationen in Mikrosomaler Fraktion und PM. Das angebotene ${ }^{35}$ S-Methionin wurde im Verlauf der dreistündigen Inkubation annähernd vollständig von den Algen inkorporiert (Abb. 7; im Algenpellet wurden $96 \%$ der je Ansatz eingesetzten Radioaktivität gemessen), was dem am gleichen Algenstamm von Stöhr (1988) ermittelten Wert von $92 \mu \mathrm{Ci}$ im Algenpellet von $100 \mu \mathrm{Ci}$ total je Ansatz nahekommt. Auf membranöse Zellbestandteile (Mikrosomales Pellet) entfielen $2 \%$ der ursprünglichen Aktivität. Der Anteil der Radioaktivität der neugebildeten, in oder an der PM lokalisierten Proteine war sehr gering: In der PM waren nur 0,007 \% der ursprünglich eingesetzten Aktivität des ${ }^{35}$ S-Methionins wiederzufinden.

Die im Algen- wie auch im Mikrosomalen Pellet gemessene Radioaktivität dürfte zu einem erheblichen Teil durch freies ${ }^{35}$ S-Methionin verursacht sein. Obwohl der Anteil der PM am Mikrosomalen Pellet durchschnittlich ca. $10 \%$ (Kap. 3.1.1) betrug, war der Einbau von ${ }^{35}$ S-Methionin in neu synthetisierte Proteine der PM damit fast 30fach kleiner als theoretisch zu erwarten. Des weiteren sind Verunreinigungen durch die in PM-Vesikel eingeschlossenen cytoplasmatischen Proteine mit einem Volumenanteil von ca. $3 \%$ zu erwarten (Pupillo und Del Gross, 1981), die die Radioaktivität in Richtung höheren Wertes verschieben dürften. Dennoch gibt das Einbauverhältnis Aufschluß über die zur Erfüllung der physiologischen Funktionen der PM ausreichenden Proteinkonzentrationen. Da Lipide die Hauptkomponente der PM bilden, sollten mit dem ${ }^{35}$ S-Einbau (neben den von Vesikeln umschlossenen cytoplasmatischen Proteinen und freiem ${ }^{35}$ S-Methionin) lediglich PM-inserierte und -assoziierte Proteine repräsentiert sein. Ihr Mengenverhältnis gegenüber cytoplasmatischen Proteinen hoher Konzentration („high abundant“) wie z.B. der Rubisco geht dabei aus der geringen Radioaktivität hervor. Die an der lasmamembran vermittelten Prozesse wie z.B. Wasseraufnahme (Frangne et al., 2001), Aminosäure-, Peptid- und Zuckeraufnahme (Langhans et al., 2001), Interaktion zwischen Cytoskelett/Zellwand, sowie Signalperzeption und -Transduktion (Wang et al., 2001) werden mit weniger als dem 
Zehntausendsten Teil des von den Algen aufgenommenen und zur Proteinsynthese metabolisierten ${ }^{35} \mathrm{~S}-$ Methionins gesteuert.

\subsubsection{Auswertung der Radiographien der ${ }^{35}$ S-markierten Proteine}

Die Stickstoff-Quellen-spezifisch ${ }^{35}$ S-markierten Proteine der TX114-Phasen wurden durch Falschfärbung ihrer Autoradiographien (rot, grün, blau) identifiziert (Abb. 10; Abb. 13). Ein solches Verfahren wird bei verschiedenen 2D-Analytikprogrammen wie z.B. Z3 (www.2dgels.com) und Delta2D (www.decodon.com) angewandt (Schrattenholz, 2001). Das Verfahren erlaubt, mehrere Autoradiographien in einer einzigen Abbildung parallel zu betrachten. Unterschiede in der Signalstärke zwischen den Proteinen sind farblich auffällig und können sofort spezifisch zugeordnet werden. Der Nachteil des zur Darstellung von Intensitätsunterschieden sehr gut geeigneten Verfahrens war die fehlende Quantifizierbarkeit. Die Auswertung beruht auf einem subjektiven Kriterium: Die Abschätzung zwischen reiner Farbe (rot-grün-blau) und ihren durch Mischung hervorgehenden Farben. Klassifiziert wurde das Ja/Nein der $\mathrm{NO}_{3}^{-}-$bzw. $\mathrm{NH}_{4}{ }^{+}$-Induzierbarkeit entsprechend der starken bzw. schwachen Zunahme von Signalstärke und Farbreinheit. Daher wurden als spezifisch $\mathrm{NO}_{3}^{-}-$ bzw. $\mathrm{NH}_{4}{ }^{+}$-induziert nur Proteine bezeichnet, die den reinen Farbton oder nur eine geringe Beimischung anderer Farbe(n) zeigten. Das Verfahren ist somit auf qualitative und subjektiv, halbquantitative Aussage beschränkt. Durch Integralbildung über Fläche und Intensität des Proteinspots (Radiographie) ist eine vergleichende quantitative Aussage möglich. Werkzeuge dazu sind in den 2D-Analytikprogrammen implementiert. Die Quantifizierung durch das BASysProgramm 2D von Biotech-Fischer war aus dem oben genannten Zwang zur Positionsidentität nicht möglich. Unabhängig von der Quantifizierung muß die Signifikanz der auftretenden Unterschiede der autoradiographischen Signale definiert werden. Dies bedingt, zumindest im Grenzbereich nur geringer Unterschiede der Signalstärke, wiederum das subjektive Kriterium eines Schwellenwertes.

Bei der quantitativen Auswertung zukünftiger Experimente sollten daher folgende Punkte berücksichtigt werden:

- Die Autoradiographien sollten auf Material aus der gleichen Zellzahl beruhen; zumindest aber auf gleichen PM-Proteinmengen. Bei der geringen Zahl der $\mathrm{NO}_{3}^{-}$bzw. $\mathrm{NH}_{4}{ }^{+}$-induzierten PM-Proteine scheint die induktionsbedingte Proteinzunahme von rund 5 \% (30 von 651 Proteinen) vernachlässigbar. Gleiche Radioaktivität sollten nicht eingesetzt werden. Dadurch würden Proteine im Ansatz mit der stärksten Radioaktivität $\left(\mathrm{NO}_{3}{ }^{-}\right.$Ansatz: de novo-Proteine und N-Metabolismus-hochgeregelte Proteine) quantitativ unterrepräsentiert.

- Es sollte ein radioaktiver Marker (radioaktive Tinte o. ä.) von gleicher Signalstärke auf allen Gelen sein (identischer Referenzwert für die Intensität eines Spots auf allen Gelen).

- Die Signifikanz einer Zunahme der Signalstärke kann durch ein bekanntes $\mathrm{NO}_{3}{ }^{-}$-induziertes Protein beurteilt und festgelegt werden. Dazu kann z.B. die PM-gebundene Nitrat-Reduktase in Chlorella dienen; das Protein DP \# 101 
wurde immunologisch als NR nachgewiesen (s. Kap. 3.5) und zeigte nach $\mathrm{NO}_{3}{ }^{-}$-Induktion die stärkste quantitative Radioaktivitätszunahme der Proteine der Detergenz-Phase (Abb. 13).

\subsubsection{Trennleistung und „low-abundant“-Proteine}

Rund ein Drittel aller nachgewiesenen Plasmamembran-Proteine aus der wässrigen und Detergenz-Phase des TritonX114-Systems war ${ }^{35}$ S-Methionin markiert: 196 von 651 Proteinen (Abb. 9 und 12). Zur Gewährleistung der wesentlichen Membranfunktionen werden ca. 500 Proteine bei Arabidopsis thaliana und ca. 750 Proteine bei Nicotiana tabacum geschätzt (Masson und Rossignol, 1995). Über eine Trennleistung der 2D-SDS-PAGE in vergleichbarer Größenordnung wird berichtet: mehr als 650 Proteine in Saccharomyces cerevisiae (Norbeck und Blomberg, 1996); 400-500 Proteine in Rinder-Oocyten (Goff et al., 2001). Rouquie et al. (1997) trennten 400 (Träger-Ampholyte) bzw. 600 Proteine (IPG) aus Nicotiana tabacum auf. Damit ist die Anzahl der getrennten PM-Proteine von Chlorella saccharophila gut zwischen diesen Werten anzusiedeln. Die große Zahl von ${ }^{35}$ S-Methionin markierten Proteinen, die unabhängig von der N-Quelle auftraten, ist auf den turn-over (Synthese und Degradation) der Proteine zurückzuführen. Dieser unterliegt der Proteinindividuellen Zeitabhängigkeit, die Anzahl der ${ }^{35}$ S-markierten Proteine nimmt entsprechend mit zunehmender Versuchsdauer zu. Klerk und Van Loon (1997) berichten nach 2D-SDS-PAGE der ${ }^{35}$ S-Methionin markierten Proteine von einem turn-over der Proteine in den ersten Blättern von Avena sativa, ohne jedoch eine Zahl zu nennen. Von mehreren Hundert verschiedenen, durch turnover markierten Proteinen berichten Vavra und Manahan (1999) bei Haliotis rufescens. Darüberhinaus sind durch die Beta-Strahlung des ${ }^{35}$ S-Isotopes selbst hervorgerufene Effekte denkbar, z.B. durch Radikalbildung oder DNAStrangbrüche (Hu et al., 2001) ausgelöste Veränderungen des Zellmetabolismus.

Als nachteilig im Sinn der großen Zahl markierter Proteine muß daher die lange, insgesamt zwischen Induktion mit Nitrat und Aufbruch der Algenprotoplasten verstrichene Zeit von $6 \mathrm{~h}$ bewertet werden. Bei zukünftigen Experimenten sollte unter Berücksichtigung der Aufnahmekinetik des Methionins geprüft werden, ob eine zeitversetzte Gabe von ${ }^{35}$ S-Methionin erst nach bereits begonnener NitratInduktion zur Markierung Nitrat-spezifischer Proteine ausreichend ist. Erst unmittelbar zur Translation der Nitrat-spezifisch gebildeten mRNA aufgenommenes ${ }^{35}$ S-Methionin könnte die Zahl der durch turn-over markierten Proteine einschränken und die Spezifität der Zellantwort auf Nitrat erhöhen. Das schnellere Verfahren des Zellaufbruchs durch eine Zellmühle bzw. French-

Press führte $\mathrm{zu}$ einer starken Kontamination der PM mit Chloroplastenmembranen (grüne $\mathrm{PM}$ ) durch $\mathrm{zu}$ starkes Zerscheren der Membranen bzw. passage-bedingter Erwärmung. Ganz abgesehen von den erheblichen praktischen Schwierigkeiten, die diese Aufbruchverfahren bei radioaktivem Arbeiten erzeugen (Undichtigkeiten, Abfall, Reinigung). Die Protoplastierung erwies sich daher trotz des genannten Nachteils als das geeignetste Verfahren zur PM-Gewinnung.

Die Zahl der aufgetrennten PM-Proteine scheint dennoch sehr begrenzt, wird die Größe des Proteoms von Chlorella als eukaryotische Zelle berücksichtigt. 
Zwar liegen zu dessen Größe keine Angaben vor, aber für die vollständig durchsequenzierten Genome von Escherichia coli und Saccharomyces cerevisiae wurde gezeigt, daß nur $5 \%$ der aus dem Genom vorherzusagenden Proteine im 2D-Gel aufgetrennt wurden, bei einer zusätzlichen Unterrepräsentanz der hydrophoben Proteine (Wilkens et al., 1996). Auch bei Plasmamembran-Proteinen ist zu berücksichtigen, dass in der 2D-SDS-PAGE aus diesem Kompartiment stark bevorzugt (fast $80 \%$ ) periphere und vergleichsweise gut lösliche Proteine aufgetrennt werden, wie dies für PM aus Arabidopsis thaliana gezeigt wurde (Santoni et al., 1999). Die Schwierigkeiten bei der Erfassung von einzelnen PM-Proteinen geringer Konzentration oder schlechter Solubilisierbarkeit wurden durch die hohe Sensitivität des autoradiographischen Nachweises deutlich. 78 de novo gebildete Proteine und damit ein gutes Drittel aller neugebildeten Proteine lagen unterhalb der Nachweisgrenze der Silberfärbung. Diese Proteine wurden somit ausschließlich durch ihre Radioaktivität detektiert und repräsentieren damit die genannte Proteingruppe der low abundant-Proteine. Auch eine geringe DetergenzLöslichkeit einzelner Proteine führt zu einer quantitativen Unterbewertung. Die geringe Konzentration verhinderte einerseits eine Isolierung dieser Proteine (siehe Kapitel 4.4.2.1), andererseits wurde erst durch die ${ }^{35} \mathrm{~S}$-Markierung ihre Existenz nachgewiesen. Dies zeigt noch einmal die Notwendigkeit der vorgeschlagenen, kombinierten Protein-Fraktionierungsverfahren. 


\subsection{Nitrat-induzierte PM-Proteine}

Durch $\mathrm{NO}_{3}{ }^{-}$als Stickstoff-Quelle ausgelöste Veränderungen bei den Proteinen der Plasmamembran werden unter zwei Aspekten erfaßt und diskutiert: 1.) qualitativ $\mathrm{NO}_{3}{ }^{-}$-induziert; 2.) quantitativ $\mathrm{NO}_{3}{ }^{-}$-induziert.

Ad 1.) Ein als "qualitativ $\mathrm{NO}_{3}^{-}$-induziert" bezeichnetes Protein tritt nach Gabe von $\mathrm{NO}_{3}{ }^{-}$als Neubildung erstmals auf. Es ist de novo synthetisiert; in der nicht induzierten Kontrolle fehlt das Protein.

Ad 2.) Ein als "quantitativ $\mathrm{NO}_{3}{ }^{-}$-induziert" bezeichnetes Protein zeigt nach Gabe von $\mathrm{NO}_{3}{ }^{-}$eine Zunahme der Proteinkonzentration. Das Protein ist bereits in der Kontrolle vorhanden, liegt aber nach $\mathrm{NO}_{3}{ }^{-}$-Gabe in höherer Konzentration vor.

\subsubsection{PM-Proteine der wässrigen Phase des TX114-Systems}

Der Vergleich der Autoradiographien der ${ }^{35}$ S-markierten Proteine (Abb. 10) zeigte insgesamt 14 Proteine, die, abhängig von der Stickstoff-Quelle, eine Zunahme der Radioaktivität aufwiesen (Zusammenstellung in Tab. 2). Aber weder $\mathrm{NO}_{3}{ }^{-}$, noch $\mathrm{NH}_{4}{ }^{+}$hat zur Synthese eines neuen, in der wässrigen Phase angereicherten Proteins geführt. In der wässrigen Phase des TX114-Systems sind periphere Proteine mit geringer Deterenz-Bindungskapazität angereichert, daneben können auch PM-integrale Proteine (Pryde, 1986) sowie Verunreinigungen durch lösliche Proteine des Cytoplasmas enthalten sein (Pupillo und Del Gross, 1981). Da keine de novo synthetisierten Proteine auftraten, snd alle PM-peripheren, von der Stickstoff-Quelle beeinflußten Proteine konstitutiv.

Das quantitativ $\mathrm{NO}_{3}{ }^{-}$-induzierte Protein mit der höchsten Radioaktivität war WP \#104 mit einem Molekulargewicht von 64,4 kDa. Dieses Protein wurde durch immunologischen Nachweis als Nitrat-Reduktase identifiziert. Eine PMgebundene NR wurde am gleichen Objekt von Stöhr et al. (1993) nachgewiesen. Eine ausführliche Erklärung zur NR in beiden TX114-Phasen (Wässrige Phase als WP \# 104; Detergenz-Phase als DP \# 101) erfolgt in Kapitel 4.6.

Eine Identifikation der $14 \mathrm{NO}_{3}{ }^{-}-$bzw. $\mathrm{NH}_{4}{ }^{+}$-spezifisch in ihrer Konzentration beeinflußten PM-Proteine durch MALDI-ToF-MS oder MS-MS wurde nicht durchgeführt, da ein entsprechendes System nicht zur Verfügung stand. Eine eindeutige Zuordnung zu bekannten Proteinen ist mit den jeweils bestimmten Proteineigenschaften nicht möglich:

PM-peripher

durch $\mathrm{NO}_{3}{ }^{-}$bedingte Konzentrationszunahme

Molekulargewicht

- IEP (abzuschätzen auf $\pm 1 \mathrm{pH}$-Einheit, da Trägerampholyt-IEF)

Dennoch wurde eine Eingrenzung auf mögliche Proteine mit gleichen oder ähnlichen Eigenschaften versucht. Mit dem Internet-Werkzeug „Tagldent“ wurde in der genomischen Datenbank Swiss-Prot (www.ExPASy.ch) nach vorherzusagenden Proteinen gesucht, auf die die genannten Kriterien zutreffen. Das Tagldent erlaubte eine Klassifizerung nach: Molekulargewicht; IEP; Pflanze; Membranprotein. Eine Eingrenzung auf „Plasmamembran-Protein“ war 
in Tagldent nicht möglich, die Suche war daher auf alle membranösen Kompartimente ausgedehnt.

\begin{tabular}{|c|c|c|c|}
\hline Nachweis & $\begin{array}{c}\text { \# des } \\
\text { Proteins }\end{array}$ & $\begin{array}{l}\mathrm{kDa} \\
\text { (IEP) }\end{array}$ & Mögliches Protein (Swiss-Prot) \\
\hline $\begin{array}{l}\text { Silberfärbung } \\
\text { und } \\
\text { Autoradiographie }\end{array}$ & $\begin{array}{l}\text { \# } 34 \\
\# 61 \\
\# 100 \\
\# 104 \\
\# 191 \\
\# 207 \\
\# 246 \\
\# 330\end{array}$ & $\begin{array}{l}89,0(5) \\
80,2(5) \\
62,1(5) \\
64,4(5) \\
41,3(6) \\
38,4(6) \\
35,3(7) \\
22,6(5)\end{array}$ & $\begin{array}{l}\text { Receptor like protein kinase ZMPK1 precrs pl: 6.29, MW: } 88,3 \\
\text { kDa } \\
\text { Ethylene receptor pl: } 6.53, \mathrm{MW}: 82,9 \mathrm{kDa} \\
\text { Probable glutamate carboxypeptidase II pl: 6.42, MW: } 77,2 \mathrm{kDa} \\
\text { Kinase associated protein phosphatase pl: } 6.45, \mathrm{MW}: 64,9 \mathrm{kDa} \\
\text { Peptide transporter PTR2-B (Histidine). pl: } 5.49, \mathrm{MW}: 64,4 \mathrm{kDa} \\
\text { Peptide transporter PTR2-A pl: } 5.28, \mathrm{MW}: 67,5 \mathrm{kDa} \\
\text { ATP synthase A chain pl: } 6.19, \mathrm{MW}: 43,0 \mathrm{kDa} \\
- \\
- \\
-\end{array}$ \\
\hline Autoradiographie & $\begin{array}{c}\# 138 \\
\# 137 \\
\# 155,156 \\
\# 238\end{array}$ & $\begin{array}{l}55,7(5) \\
54,5(5) \\
48,8(6) \\
36,8(7)\end{array}$ & $\begin{array}{l}\text { Hexokinase pl: 5.72, MW: 54,2 kDa } \\
\text { Hexokinase pl: 5.72, MW: 54,2 kDa } \\
\text { Presenilin homolog pl: 4.74, MW: 49,3 kDa } \\
\text { - }\end{array}$ \\
\hline $\begin{array}{l}\text { Silberfärbung } \\
\text { und Auto- } \\
\text { radiographie }\end{array}$ & \# 109 * & $60,2(6)$ & $\mathrm{H}(+) /$ hexose cotransporter pl: $6.84, \mathrm{MW}: 57,5 \mathrm{kDa}$ \\
\hline
\end{tabular}

Tabelle 2: Die quantitativ $\mathrm{NO}_{3}{ }^{-}$-induzierten Proteine der wässrigen Phase des TX-114Systems und dazu aus Swiss-Prot vorhergesagte Proteine gleichen oder ähnlichen Molekulargewichts und IEPes (Proteine gemäß Tab. 1). Der IEP ( $p I)$ ist als geschätzter Mittelwert angegeben; erlaubte Abweichung waren $\pm 2 \mathrm{pH}$-Einheiten, da das IEF auf Trägerampholyten basierte. Erlaubte Abweichung für das Molekulargewicht: $5 \%$.

* WP \#109 zeigte im $\mathrm{NH}_{4}{ }^{+}$-Ansatz eine Zunahme der Proteinkonzentration.

Tagldent ordnete den Proteinen der wässrigen Phase des TX114-Systems verschiedene, aus genomischen Sequenzen hergeleitete Proteine zu.

89 kDa-Protein WP \#34: Ein für eine Rezeptor-artige Proteinkinase codierendes Gen wurde von van der Knaap et al. (1999) in Oryza sativa beschrieben, homologe Gene sind aus Zea mays (ZMPK1) und Arabidopsis thaliana bekannt. Rezeptor-artige Proteinkinasen sind Ser-/Thr-phosphorylierend, autophosphorylierend und Bestandteil von Signaltransduktionsketten. Ein homologes Gen aus Nicotiana tabacum codiert für eine Serin/Threonin-Kinase mit einer einzelnen hydrophoben Domäne (Ito et al., 1994). Dies würde eine geringe Detergenzbindungskapazität und die Anreicherung in der wässrigen Phase des TX114-Systems erwarten lassen. Das Protein WP \# 34 könnte daher eine Rezeptor-artige Proteinkinase darstellen. 
80,2 kDa-Protein WP \# 61: Ein Ethylenrezeptor aus Lycopersicum esculentum vermittelt Ethylen-gesteuerte Prozesse wie z.B. Fruchtreifung (Whitelaw et al., 2002). Ethylenrezeptoren aus Arabidopsis thaliana haben Domänen mit HistidinKinase-Funktion. Sie besitzen eine einzelne hydrophobe Domäne (Gamble et al., 2002). Dies läßt ebenfalls eine Anreicherung überwiegend in der wässrigen TX114-Phase erwarten, wie dies auch für Protein WP \# 61 zutrifft. Ein für eine Glutamat Carboxypeptidase codierendes Gen ist aus Arabidopsis thaliana beschrieben worden, die Funktion ist unklar (Helliwell et al., 2001).

62,1 kDa-Protein WP \# 100: Das in unmittelbarer Nachbarschaft zum NRProtein WP \# 104 (siehe Kapitel 4.6) fokussierende Protein WP \# 100 zeigt Ähnlichkeiten zu einer Kinase-assozierten Protein-Phosphatase. Die NR selbst wird durch Protein-Kinasen, -Phosphatasen und 14-3-3 Proteine reguliert (Kaiser und Huber, 2001). Unter der Annahme, daß Protein WP \# 100 eine Phosphatase ist, könnte diese ein PM-NR assoziertes Protein der Blaulichtstimulierten Signaltransduktionskette (Stöhr et al., 1995, Mätschke et al., 1997) sein.

64,4 kDa-Protein WP \# 104: Das Protein wurde immunologisch als NR identifiziert und wird in Kapitel 4.6 beschrieben

41,3 kDa-Protein WP \# 191: Die ATP Synthase (A chain) ist ein mitochondriales Protein (Fontaine et al., 1995). Da das Two-Phase-Partioning sehr reine PM isoliert (Larsson, 1985), dürfte Protein \# 191 nicht mit einer ATP Synthase übereinstimmen.

38,4 kDa-Protein WP \# 207; 35,3 kDa-Protein WP \# 246; 22,6 kDa-Protein WP \# 330; 36,8 kDa-Protein WP \# 238: Diesen Proteinen konnte kein hypothetisches Protein der Datenbank Swiss-Prot zugeordnet werden. Möglicherweise repräsentieren die Proteine bislang nicht bekannte Proteine. Santoni et al., (2000) zeigten, daß viele PM-Proteine eine unbekannte Funktion haben, oder für entsprechende Proteine codierende Gene in genomischen Datenbanken nicht enthalten sind.

PM-Proteine, die nicht durch Silber angefärbt, aber $\mathrm{NO}_{3}{ }^{-}$-spezifisch eine erhebliche Konzentrationszunahme zeigten (quantitativ $\mathrm{NO}_{3}{ }^{-}$-induziert; intensive Rotfärbung in der Abb. 10), waren:

55,7 kDa-Protein WP \# 137; 54,5 kDa-Protein WP \# 138; 48,8 kDa-Protein WP \# 155 und 156; 36,8 kDa-Protein WP \# 238.

Den Proteinen WP \# 137 und 138 entsprach eine Hexokinase. An Arabidopsis thaliana wurde gezeigt, daß die Glucose phosphoryliernden Hexokinasen an der Repression von Photosynthese-Proteine codierenden Genen beteiligt sind (Xiao et al., 2000). Durch Hexokinase-abhängige Regulation werden Wachstums- und Stress-abhängige Gene in Oryza sativa gesteuert (Ho et al., 2001). Nitrat ist als Signal auch für den C-Metabolismus wirksam, z.B. im Metabolismus von organischen Säuren oder Stärke (Scheible et al., 1997) und viele Nitratregulierte Gene sind auch durch Zucker beeinflußt (Koch, 1996). Die Hexokinasen könnten somit Hinweise auf Nitrat-induzierte und den CMetabolismus beeinflussende Proteine an der PM von Chlorella saccharophila sein und ein Beispiel für eine koordinierte Regulation zwischen C- und NMetabolismus darstellen.

Den 48,8 kDa-Proteinen WP \# 155 und 156 entsprach ein Presenilin. Dieses 
wird mit der Alzheimer-Erkrankung des Menschen in Verbindung gebracht; bislang wurde nicht nach einem homologen Protein in Pflanzen gesucht.

Dem einzigen Protein, dass eine $\mathrm{NH}_{4}{ }^{+}$-spezifische Konzentrationszunahme zeigte (60,2 kDa-Protein WP \# 109), entsprach ein $\mathrm{H}+/$ Hexose-Cotransporter. Ein solcher Transporter wurde für Chlorella kessleri beschrieben (Übersicht in Poa et al., 1998). Hexose-Transporter sind PM-integrale Proteine, daher ist eine hohe Detergenzbindungskapazität zu erwarten. Eine Übereinstimmung mit dem Protein \# 109 der wässrigen Phase ist daher unwahrscheinlich. Eine mögliche Erklärung ist das von Pryde (1986) beschriebene Verhalten einiger integraler Proteine, dennoch in der wässrigen TX114-Phase anzureichern. Sollte dies auch für WP \# 109 als möglichen $\mathrm{H}+/$ Hexose-Cotransporter zutreffen, wäre dieses Protein ein weiterer Beleg für eine an der PM vermittelte Verknüpfung von C- und N-Metabolismus. Da Chlorella saccharophila fakultativ Hexosen zur Versorgung mit C-Skeletten aufnehmen kann, ist eine Verküpfung der Expression der dafür benötigten Gene mit ausreichender N-Versorgung zu erwarten. In diesem Zusammenhang sind die Proteine \# 48, 49, 58, 62 (Abb. 10) zu erwähnen, die bei N-Mangel stärker ${ }^{35}$ S-markiert waren. Diese Proteine wurden nicht identifiziert, eine Funktion als Rezeptorproteine für alternative Stickstoffquellen wie z. B. Aminosäuren oder Harnstoff ist denkbar.

\subsubsection{PM-Proteine der Detergenz-Phase des TX114-Systems}

\subsubsection{De novo $\mathrm{NO}_{3}{ }^{-}$-induzierte PM-Proteine: Nitrat-Transporter?}

Insgesamt 16 Proteine wiesen durch $\mathrm{NO}_{3}^{-}$(14 Proteine) bzw. $\mathrm{NH}_{4}{ }^{+}$(2 Proteine) als Stickstoffquelle eine Zunahme der radioaktiven Markierung gegenüber der Kontrolle auf (Abb. 13; Zusammenstellung in Tab. 1). Fünf dieser Proteine waren de novo $\mathrm{NO}_{3}{ }^{-}$-induziert (qualitativ $\mathrm{NO}_{3}{ }^{-}$-induziert).

Diese fünf Proteine \# 56, 57, 58; 172, 173 hatten eine hohe Detergenzbindungskapazität und entsprachen damit hydrophoben, PMintegralen Proteinen. Den Proteinen gemeinsam war ein basischer IEP von $\mathrm{pH}$ 8-9. Die Proteine \# 56, 57, 58 hatten unterschiedliche isoelektrische Punkte, aber das gleiche Molekulargewicht von 76,6 kDa. Dies galt auch für die 45,9 kDa-Proteine \# 172 und 173. Eine Sequenzierung konnte nicht durchgeführt werden, da die Konzentration dieser Proteine sehr gering war (Tab. 1). Eine präparative 2D-SDS-PAGE änderte dies nicht; die Konzentration war zur Coomassie-Färbung zu gering (Abb. 33 und 34). Die Identifikation konnte somit nicht erbracht werden. Das vermutliche Vorliegen eines Nitrat-Transporters wird aber durch mehrere Eigenschaften der Proteine unterstützt: $\mathrm{NO}_{3}$-induzierte de novo-Synthese; Anreicherung in der Detergenzphase, stark basischer IEP. Die Induktion der Nitrat-Transporter-Gene durch Nitrat ist vielfach belegt (z. B. Tsay et al., 1993; Trueman et al., 1996; Quesada et al., 1997; Amarasinghe et al., 1998). Ebenso der hohe Anteil hydrophober Domänen, der -wie der IEP- aus der Aminosäuresequenz der vorherzusagenden Proteinen abgeleitet werden kann. Zum Vergleich mit bekannten Nitrat-Transportern sind in Tabelle 3 Molekulargewicht und IEP verschiedener Nitrattransporter zusammengestellt. 


\begin{tabular}{|l|c|c|c|}
\hline Species & $\begin{array}{c}\text { Amino- } \\
\text { säuren }\end{array}$ & $\begin{array}{c}\text { Mol.- } \\
\text { Gewicht }\end{array}$ & IEP \\
\hline Triticum aestivum (Yin et al., 2000) & 507 & 54,70 & 8,53 \\
\hline Hordeum vulgare (Trueman et al., 1996) & 507 & 54,67 & 8,39 \\
\hline Nicotiana plumbaginifolia Nrt2;1(Quesada et al., 1997) & 530 & 57,46 & 9,21 \\
\hline Hordeum vulgare (Vidmar et al., 1999) & 507 & 54,59 & 8,54 \\
\hline Arabidopsis thaliana (Nakamura et al., 1998) & 527 & 57,76 & 9,04 \\
\hline Lotus japonicus (Forde, 2001) & 530 & 57,62 & 9,18 \\
\hline Lycopersicon esculentum NRT2;1 (Ono et al., 1998) & 530 & 57,41 & 9,33 \\
\hline Oryza sativa (Tanaka, 1998) & 533 & 57,23 & 8,43 \\
\hline Arabidopsis thaliana NRT2-1(Filleur und Daniel-Vedele, 1999) & 530 & 57,70 & 8,85 \\
\hline Chlamydomonas reinhardtii (Quesada et al., 1994) & 546 & 59,13 & 8,87 \\
\hline Cylindrotheca fusiformis (Hildebrand und Dahlin 1999) & 482 & 51,80 & 5,16 \\
\hline Thalassiosira weissflogii (Song und Ward, 2002) & 445 & 47,46 & 8,49 \\
\hline Skeletonema costatum (Song und Ward, 2002) & 487 & 52,25 & 7,42 \\
\hline Chlorella sorokiniana (Tischner et al., 2001) & 625 & 67,44 & 9,00 \\
\hline Synechococcus sp. (Sakamoto et al., 1999) & 534 & 58,15 & 8,13 \\
\hline Emericella (=Aspergillus) nidulans (Unkles et al., 2001) & 497 & 53,73 & 9,12 \\
\hline Pichia angusta (Avila et al. 1996) & 508 & 55,76 & 8,37 \\
\hline
\end{tabular}

Tabelle 3: Auswahl bekannter, Nitrat-Transporter codierender Gene aus höheren und niederen Pflanzen sowie Pilzen. Angegeben sind Anzahl der Aminosäuren und theoretisches Molekulargewicht sowie IEP. Fettgedruckt sind Höchst- und Kleinstwert des Molekulargewichtes der zu erwartenden Nitrat-Transporter-Polypeptide.

Allen vorherzusagenden Nitrat-Transportern in Tabelle 3 ist ein basischer IEP von durchschnittlich pH 8,5 gemeinsam. Dies steht in Übereinstimmung mit dem IEP von ca. pH 8 der Proteine \# 56, 57, 58 und dem IEP von ca. pH 9 der Proteine \# 172, 173. Die Molekulargewichte der Nitrat-Transporter in Tabelle 3 streuen von 67,4 kDa bei Chlorella sorokiniana bis zu minimal 47,5 kDa bei der marinen Diatomee Thalassiosira weissflogii. Die Molekulargewichte von 76,6 kDa der Proteine \# 56, 57, 58 sowie 45,9 kDa der Proteine \# 171, 172 überschreiten bzw. unterschreiten jedoch die Molekulargewichte der bekannten Nitrat-Transporter. Dennoch muß dies noch kein Ausschlußkriterium sein, da das Molekulargewicht eines Nitrat-Transportes in Chlorella saccharophila nicht bekannt ist. Welche gelelektrophoretischen Eigenschaften Nitrat-Transporter in der 2D-SDS-PAGE haben, ist bislang nicht bekannt. Dies verwundert bei der mehrfach gezeigten Expression von Nitrat-Transportern in Xenopus-Oocyten (Lin et al., 2000; Liu et al., 1999; Zhou et al., 1998; Huang et al., 1996; Tsay et al., 1993). Eine 2D-SDS-PAGE der Oocyten-PM-Proteine vor bzw. nach mRNAInjektion sollte das Transporter-Protein als theoretisch einziges de novo-Protein nachweisen lassen. Fehlende Untersuchungen dazu sind möglicherweise in den diskutierten Schwierigkeiten der 2D-SDS-PAGE von PM-Proteinen begründet. Die gelelektrophoretischen Eigenschaften der bekannten Transporter beruhen daher bislang auf Vorhersagen.

Von gelelektrophoretischen Untersuchungen $\mathrm{NO}_{3}{ }^{-}$-induzierter und ${ }^{35} \mathrm{~S}$-markierter PM-Proteine berichten McClure et al. (1987), Dhugga et al. (1988), Ni und Beevers ( 1994) und zuletzt Ageorges et al. (1996). Alle Untersuchungen wurden an Zea mays durchgeführt. Plasmamembran-Proteine von 31, 40, 70, 
95, $165 \mathrm{kDa}$ Molekulargewicht wiesen eine Zunahme der Konzentration nach $\mathrm{NO}_{3}{ }^{-}$-Induktion auf. Doch auch die jüngste 2D-SDS-PAGE-Analyse (Ageorges et al., 1996) zeigte nur eine Zunahme der Konzentration bereits vorhandener Proteine von 39 und $61 \mathrm{kDa}$. Die Autoren vermuten unter diesen Proteinen das Vorliegen eines Nitrat-Transporters. Auch die von Stöhr (1988) aus der PM von Chlorella saccharophila isolierten Proteine (22, 31, 48, 70, 140, 195 kDa) zeigten nur eine Zunahme der Konzentration nach $\mathrm{NO}_{3}^{-}-$Induktion. Die in vorliegender Untersuchung erreichte Spezifität (2D-SDS-PAGE; TX114Detergenzphase; de novo-Bildung; basischer IEP) wurde in keiner der vergleichbaren Untersuchungen erreicht. Die dadurch bestimmbaren Eigenschaften der Proteine \# 56, 57, 58 sowie \# 172, 173 deuten -mit Ausnahme des Molekulargewichtes- massiv auf induzierbare Nitrat-Transporter von 45,9 und 76,6 kDa Molekulargewicht in Chlorella saccharophila hin.

\subsubsection{Proteine mit $\mathrm{NO}_{3}{ }^{-}$-induzierter Konzentrationszunahme}

Neun Proteine zeigten eine Zunahme der Konzentration (Häufigkeit) nach Gabe von $\mathrm{NO}_{3}^{-}$, zwei Proteine nach Gabe von $\mathrm{NH}_{4}{ }^{+}$. Die Proteine konnten durch Silber angefärbt werden. Im Gegensatz zu den fünf $\mathrm{NO}_{3}{ }^{-}$-spezifisch de novogebildeten und als qualitativ $\mathrm{NO}_{3}{ }^{-}$-induziert bezeichneten PM-Proteinen sind diese 11 Proteine durch $\mathrm{NO}_{3}^{-}$bzw. $\mathrm{NH}_{4}^{+}$lediglich in der Konzentration beeinflußt. Diese 11 Proteine wurden, wie eingangs definiert, zur Abgrenzung als quantitativ induziert bezeichnet. Eine $\mathrm{NO}_{3}^{-}$-induzierte Konzentrationszunahme zeigte Protein \# 87 von $67,8 \mathrm{kDa}$. Dieses Protein hatte einen basischen IEP ( pH 8) und wich damit vom Nitrat-Transporter in Chlorella sorokiniana nur um ca. $1 \mathrm{pH}$-Einheit im IEP und 0,4 kDa im Molekulargewicht ab. Auch die Proteine \# 161 und 162 von 47,3 kDa und einem IEP von ca. pH 9 zeigten eine $\mathrm{NO}_{3}{ }^{-}$-induzierte Konzentrationszunahme und basischen IEP. Diese Proteine stimmten mit dem Nitrat-Transporter aus Thalassiosira weissflogii (47,5 $\mathrm{kDa}$ ) in Molekulargewicht und IEP gut überein.

Gegen die Identifikation als Nitrat-Transporter spricht aber die Synthese dieser Proteine in erheblich geringerer Konzentration im $\mathrm{NH}_{4}{ }^{+}$-haltigen Medium. $\mathrm{NH}_{4}{ }^{+}$ inhibiert die Nitrat-Transporter codierenden Gene z.B. in Chlamydomonas reinhardtii (Galvan et al.,1996; Quesada und Fernandez, 1994). Das diese Proteine einen $\mathrm{NH}_{4}{ }^{+}$-insensitiven, konstitutiven Nitrat-Transporter repräsentieren ist somit unwahrscheinlich. Allerdings wurde ein $\mathrm{NH}_{4}{ }^{+}$-insensitives NitratAufnahmesystem in der Hefe Hansenula polymorpha nachgewiesen (Machin et al., 2001). Auch in höheren Pflanzen wurde ein Nitrat-Transporter codierendes Gen GmNRT1-2 aus Glycine max beschrieben, dass zumindest graduell bei $\mathrm{NH}_{4}{ }^{+}$als N-Quelle exprimiert wird (Yokoyama et al., 2001). Gilt dies auch für niedere Pflanzen wie Chlorella saccharophila, wäre die fehlende $\mathrm{NH}_{4}{ }^{+}-$ Repression der Proteine \# 161, 162 und 87 kein Ausschlußkriterium.

Insgesamt liegen in Chlorella saccharophila somit vier mögliche NitratTransporter-Proteine vor. $\mathrm{NO}_{3}^{-}$-induziert de novo-synthetisiert die 45,9 kDaProteine \# 172, 173 und die 76,6 kDa-Proteine \# 56, 57, 58. Die Neusynthese deutet auf induzierbare Nitrat-Transporter hin. Sowie die 47,3 kDa-Proteine \# 161, 162 und das 67,8 kDa-Protein \# 87 mit einer $\mathrm{NO}_{3}{ }^{-}$-induzierten Zunahme der Proteinkonzentration. Die Zunahme der Proteinkonzentration deutet auf konstitutive Nitrat-Transporter hin. 
Bei $\mathrm{NH}_{4}{ }^{+}$als N-Quelle zeigten die Proteine \# 204 und 205 (38,0 und 37,3 kDa; IEP ca. pH 4) eine Zunahme der Konzentration. Eine Suche möglicher Proteine mit dem bereits genannten Swiss-Prot-Tool „Tagldent“ brachte keine Hinweise auf PM-integrale Proteine. Die aufgefundenen Proteine ähnlichen IEPs und Molekulargewichts waren Thylakoidmembran-Proteine. Diese sind in der PM nicht enthalten. $\mathrm{Zu}$ erwartende Ammonium-Transporter weichen in IEP und Molekulargewicht erheblich von Protein \# 204 und 205 ab (z.B. Arabidopsis AtAMT1;3 Ammonium-Transporter: pH 6.54; 55,75 kDa. Aus: Gazzarrini et al., 1999). Denkbar ist das Vorliegen proteolytischer Abbauprodukte eines größeren Transporter-Proteins.

Eine Reihe experimenteller Untersuchungen sollte sich anschließen. Zur Klärung eines externen Nitrat-Sensing sollten Phosphorylierungsexperimente an der PM mit ${ }^{32}$ P-ATP durchgeführt und die Proteine durch eine 2D-SDSPAGE aufgetrennt werden. Dies würde auch zeigen, ob und welche der hier aufgeführten ${ }^{35} \mathrm{~S}$-markierten Proteine Bestandteile von Signaltransduktionsketten sind oder einer Regulation durch Phosphatasen/Kinasen unterliegen. Insbesondere die Regulation der als DP \# 101 nachgewiesenen PM-NR und ihrer vermuteten Rolle als Blaulicht-Rezeptor könnte dadurch auf Proteinebene verfolgt werden.

Der schnellste Ansatz zur Bestimmung der gelelektrophoretischen Eigenschaften des oder eines Nitrattransportes wäre eine Xenopus-OocytenExpression. Dazu könnte die mRNA eines beliebigen Nitrat-Transporters dienen. Interessant wäre zunächst, inwieweit sich vorhergesagte und tatsächliche gelelktrophoretische Eigenschaften decken. Die vergleichende 2DSDS-PAGE der Xenopus-Proteine sollte die erstmalige Identifikation und Ansequenzierung eines Transporters durch MS-MS oder MALDI-ToF-MS erlauben. Die Isolierung des Transporter-Proteins sollte mögliche Regulationsmechanismen, Isoformen und Substratspezifitäten zugänglich machen. Diese sind bei der Vielzahl der mittlerweile beschriebenen Aufnahmekinetiken und Nitrat-Transporter-codierender Gene zu erwarten, die teilweilse überlappende Kinetiken zeigen und eine komplexe Regulation ähnlich der NR erwarten lassen.

\subsection{Photoaffinitätsmarkierung mit ${ }^{14} \mathrm{C}$-DNPA}

Zur Identifizierung von Transporterproteinen können Substratanaloga eingesetzt werden, die stabil am gesuchten Protein binden und daran detektiert werden können. Voraussetzungen dazu sind eine möglichst hohe Spezifität des Analogons und die Ausbildung einer stabilen, kovalenten Bindung an das Zielprotein. Verschiedene, als "Cross Linking Agents" bezeichnete Substanzklassen wie etwa Acylhalide, Isothiocyanate und Arylazide erlauben durch Aktivierbarkeit (z.B. durch Photolysis) und hohe Reaktivität der entstehenden Produkte eine kovalente Bindung (Findlay und Evans, 1987). Glogau (1994) zeigte eine kompetitive Hemmung der Nitrataufnahme $\left(K_{i}=1,6\right.$ $\mu \mathrm{M})$ von Chlorella saccharophila durch das Arylazid 2,6-Dinitrophenylazid (DNPA). DNPA ist photolysierbar und zerfällt bei Bestrahlung mit Licht (364 nm) unter Abspaltung von $\mathrm{N}_{2}$ in ein reaktives Nitren. Das Nitren kann mit unmittelbar benachbarten Lysinresten unter kovalenter Bindung reagieren („nearest neighbour interaction"). Zum Nachweis des DNPA wurde in vorliegender 
Untersuchung ein ${ }^{14} \mathrm{C}$-markiertes DNPA eingesetzt. Bei diesem war der Benzolring mit dem radioaktiven Kohlenstoff-Isotop ${ }^{14} \mathrm{C}$ substituiert. Der Nachweis der DNPA-markierten Proteine erfolgte durch Radiographie.

Zielsetzung bei diesen Experimenten war die in situ Markierung des NitratTransporters an der PM. Eine Inkubation der PM mit dem Nitratanalogon ${ }^{14} \mathrm{C}$ DNPA sollte die Nitrat-Bindungsstelle des Transporters zunächst reversibel mit ${ }^{14} \mathrm{C}$-DNPA besetzen. Anschließende Photolysis sollte das ${ }^{14} \mathrm{C}-\mathrm{DNPA}$ kovalent und irreversibel an der Nitrat-Bindungsstelle binden. Der Zerfall des DNPA war photometrisch durch Verschiebung der Absorptionsmaxima zu beobachten und war nach 10 min Belichtung (364 nm) abgeschlossen (Abb. 14).

Durch $50 \mu \mathrm{M}{ }^{14} \mathrm{C}$-DNPA im Reaktionsansatz war der Nachweis DNPAmarkierter PM-Proteine in einem vertretbaren Zeitraum der Expositionsdauer der Filme (21-28 d) möglich. Eine zehnfach höhere ${ }^{14} \mathrm{C}$-DNPA-Konzentration zeigte bei kürzerer Expositionsdauer zwar das gleiche Muster markierter Proteine. Dies führte aber zu einem sehr hohen Hintergrundsignal und beeinträchtigte bzw. verhinderte die Erkennung der Proteinbanden (Abb. 15). $50 \mu \mathrm{M}{ }^{14} \mathrm{C}$-DNPA entsprach dem fast Vierzigfachen des von Glogau (1994) bestimmten $K_{i}$ der Hemmung der Nitrataufnahme. Eine geringere ${ }^{14} \mathrm{C}$-DNPAKonzentration (5; 0,5 $\mu \mathrm{M}$ DNPA) reichte aber zu einem RadioaktivitätsNachweis nicht mehr aus (Abb. 15). Die zum autoradiographischen Nachweis benötigte ${ }^{14} \mathrm{C}$-DNPA-Konzentration von $50 \mu \mathrm{M}$ führte $\mathrm{zu}$ einer großen Zahl DNPA-markierter Proteine von 17; 23; 26; 36; 38; 38,5; 40; 43; 45; 47; 53; 58; 64; 75 und 112 kDa Molekulargewicht im SDS-Gel. Zum Teil entsprach das Muster der Markierung der Quantitätsverteilung der silbergefärbten Proteine im SDS-Gel (17, 36, 40 kDa-Protein; Abb. 16). Dies deutete auf sehr unspezifische ${ }^{14} \mathrm{C}-\mathrm{DNPA}-B i n d u n g$ hin und verhinderte die Eingrenzung eines möglichen NitratTransporters. Auch nach Hydrophober Interaktions-Chromatographie (HIC) von PM-Proteinen verringerte sich die Anzahl ${ }^{14} \mathrm{C}$-DNPA-markierter Proteine nicht. Die ${ }^{14}$ C-DNPA-markierten Proteine der HIC-Fraktionen waren durch Autoradiographie (Film-Exposition) nicht nachweisbar. Die Autoradiographie einer hochempfindlichen Phospho-Imager-Platte zeigte eine Vielzahl von sehr schwach markierten Proteinen (Abb. 17). Lange Präparationszeiten und dadurch mögliche Proteolysis sowie die durch HIC zerstörte in situ-Struktur der PM-Proteine vor ${ }^{14} \mathrm{C}$-DNPA-Markierung sind mögliche Ursachen der schwachen und unspezifischen Markierungen. Die HIC der radioaktiv markierten Proteine konnte nicht im Isotopenlabor durchgeführt werden, da die benötigte Anlage (FPLC-System) dort nicht zur Verfügung stand. Die PM-Proteine mußten deshalb zunächst solubilisiert und nicht-radioaktiv durch HIC getrennt werden. Erst die HIC-fraktionierten Proteine konnten mit ${ }^{14} \mathrm{C}$-DNPA radioaktiv markiert werden. Die Proteine lagen dann aber nicht mehr in Vesikeln vor, sondern waren in Detergenzmicellen solubilisiert. Die geringe Spezifität der Proteinmarkierung war hauptsächlich durch die niedrige spezifische Radioaktivität des ${ }^{14} \mathrm{C}$-DNPA von $6 \mathrm{mCi} / \mathrm{mMol}$ bedingt. Um DNPA-markierte Proteine autoradiographisch nachzuweisen, mußte die niedrige spezifische Radioaktivität durch eine höhere DNPA-Konzentration ausgeglichen werden. Um dennoch einen Nitrat-Transporter in der PM einzugrenzen, wurde eine 2DSDS-PAGE der ${ }^{14} \mathrm{C}-\mathrm{DNPA}-\mathrm{markierten}$ Proteine durchgeführt.

Das DNPA beeinflußte die Stabilität des $\mathrm{pH}$-Gradienten. Bei $50 \mu \mathrm{M}{ }^{14} \mathrm{C}$-DNPA im Reaktionsansatz war der neutrale $\mathrm{pH}$-Bereich $(\mathrm{pH} \mathrm{6-8)} \mathrm{gestaucht.} \mathrm{Höhere}$ ${ }^{14} \mathrm{C}$-DNPA-Konzentrationen $(250,500 \mu \mathrm{M})$ führten zu einer stark abnehmenden Trennleistung des IEF und Proteinverlusten (Abb. 18). Wechselwirkungen von 
überschüssigem ${ }^{14} \mathrm{C}$-DNPA mit den Träger-Ampholyten oder eine nachträgliche kovalente Bindung von nicht vollständig gespaltenem ${ }^{14} \mathrm{C}$-DNPA könnten die Pufferungskapazität des IEF herabgesetzt haben. Die Fällung der Proteine zur Entfernung des ungebundenen ${ }^{14} C$-DNPA verhinderte den autoradiographischen Nachweis der Proteine nach 2D-SDS-PAGE. Obwohl DNPA kovalente Bindungen ausbildet, scheint die DNPA-Markierung mit organischen Lösungsmitteln (in der Chloroform-Methanol-Fällung bzw. 50\% Ethanol-Lösung ( $\mathrm{v} / \mathrm{v})$ der Silberfärbung) entfernbar. Die Lipophilie des stark apolaren DNPA könnte eine mögliche Ursache sein. Daher wurde die 2D-SDSPAGE in Gegenwart des überschüssigen ${ }^{14} \mathrm{C}$-DNPA durchgeführt und die Beeinflussung des pH-Gradienten in Kauf genommen.

Die ${ }^{14} \mathrm{C}$-DNPA-Markierung der Proteine war jedoch von der Orientierung der PM-Vesikel abhängig. Wurden inside-out-Vesikel mit freigelegter cytoplasmatischer Seite der PM mit ${ }^{14} \mathrm{C}$-DNPA inkubiert, wurden hauptsächlich die mit I, III und IV bezeichneten Proteine von 71, 64, $45 \mathrm{kDa}$ markiert (Abb. 20 A). Deren DNPA-Bindungsstelle war somit auf der cytoplasmatischen Seite. Das 64 kDa-Protein III konnte der PM-NR zugeordnet werden. Bei den morphologisch richtig orientierten right-side-out-Vesikeln wurde ein $75 \mathrm{kDa}$ Protein DNPA-markiert (Abb. 20 B).

Die Markierung der genannten Proteine wurde aber durch $\mathrm{NO}_{3}{ }^{-}$nicht beeinflußt (Abb. $20 \mathrm{C}, \mathrm{D}$ ). Ein 500 facher $\mathrm{NO}_{3}{ }^{-}$-Überschuss im Reaktionsansatz reichte nicht aus, um eine Anlagerung des Nitrataufnahme-Hemmstoffs ${ }^{14} \mathrm{C}$-DNPA an der möglichen Nitrat-Bindungsstelle $\mathrm{zu}$ verhindern. Trotz des $\mathrm{NO}_{3}{ }^{-}$Überschusses führte die anschließende Photolysis unverändert zu einer kovalenten Bindung des ${ }^{14} \mathrm{C}$-DNPA an den gleichen Proteinen. Eine Kompetition lag somit nicht vor und hat zwei mögliche Ursachen. 1. Es liegt am Protein für Nitrat bzw. DNPA ein unterschiedlicher Bindungsort vor. 2. Die Affinität des DNPA zur Nitrat-Bindungsstelle ist gegenüber $\mathrm{NO}_{3}{ }^{-}$sehr viel größer. Dies ist unwahrscheinlich, da keine strukturelle Übereinstimmung zwischen DNPA-Nitrogruppen $\left(\mathrm{NO}_{2}\right)$ und $\mathrm{NO}_{3}{ }^{-}$als eigentlichem TransporterSubstrat vorhanden ist. Darüberhinaus läßt die große Zahl markierter Proteine auf der cytoplasmatischen PM-Seite nicht eine entsprechende Zahl Nitratbindender Proteine erwarten. Vermutlich sind daher bevorzugt solche Proteine markiert, wo eine Peptidschlaufe oder der C-Terminus in das Cytoplasma ragt und besonders exponiert ist. Dies ist z.B. bei PM-gebundenen Kinasen oder durch sie regulierte Proteine zu erwarten und wird durch die Markierung der PM-NR mit DNPA bestätigt. Für die PM-NR wird die Beteiligung an einer Signaltransduktionskette vermutet (Mätschke et al., 1997).

Durch die fehlende $\mathrm{NO}_{3}-$-Kompetition vor Photolysis und unveränderter ${ }^{14} \mathrm{C}$ DNPA-Markierung bei allen nachgewiesenen Proteinen ist das Vorliegen eines Nitrat-Transporters unwahrscheinlich. Damit ist auch das $75 \mathrm{kDa}$-Protein II mit ${ }^{14} \mathrm{C}$-DNPA-Bindungsstelle im periplasmatischen Raum nicht als möglicher Nitrat-Transporter anzusehen. Auch eine Sensorfunktion dieses Proteins für $\mathrm{NO}_{3}{ }^{-}$ist auszuschließen, da der $\mathrm{NO}_{3}{ }^{-}-$Überschuss das DNPA vor seiner Photolyse und kovalenten Bindung hätte verdrängen müssen.

Zur Auftrennung der ${ }^{14} \mathrm{C}$-DNPA-markierten Proteine nach Hydrophobizitätseigenschaften wurde eine TX114-Fraktionierung durchgeführt. Die damit notwendige Chloroform-Methanol-Fällung zur Extraktion der Proteine aus den TX114-Phasen verhinderte aus o.g. Gründen eine Auftrennung in der 2D-SDSPAGE. Daher wurden die TX114-Phasen in einer einfachen SDS-PAGE getrennt. Die Molekulargewichte der autoradiographischen Signale von SDS- 
PAGE und 2D-SDS-PAGE stimmten bis auf vier Proteine überein. Diese vier Proteine waren im 2D-SDS-PAGE nicht aufgetreten (Abb. 21, graue Pfeile). Dass gerade diese fehlenden Proteine Nitrat-Transporter sind, ist unwahrscheinlich, da auch hydrophile Proteine der wässrigen TX114-Phase fehlten. Diese Phase enthielt auch das von allen PM-Proteinen am stärksten ${ }^{14} \mathrm{C}$-DNPA-markierte 53 kDa-Protein. Dieses Protein wurde in der 2D-SDSPAGE nicht gefunden; Ursachen hierfür und mögliche Strategien zur Gewinnung sind in Kapitel 4.2.2 besprochen.

Die geringe spezifische Radioaktivität des DNPA und die fehlende Kompetition mit Nitrat verhinderten eine Eingrenzung eines Nitrat-Transporters der PM durch DNPA-Markierung. Die fehlende $\mathrm{NO}_{3}^{-}-$Kompetition der DNPA-Markierung steht im Widerspruch zu Glogau (1994), der eine Kompetition durch Messung der in vivo-Nitrataufnahme zeigte. Es sollte daher sowohl die Hemmung der $\mathrm{NO}_{3}{ }^{-}$-Aufnahme durch DNPA, als auch die $\mathrm{NO}_{3}{ }^{-}-$Kompetition durch Aufnahmemessungen mit einer lonen-sensitiven Elektrode überprüft werden.

Die DNPA-Synthese sollte mit einer Ausgangsverbindung mit höherem ${ }^{14} \mathrm{C}$ Anteil durchgeführt werden. Die Nachweis-Empfindlichkeit ist von der spezifischen Radioaktivität abhängig. So hatte das zur ${ }^{35}$ S-Markierung der PMProteine eingesetzte ${ }^{35}$ S-Methionin eine spezifische Radioaktivität von 1215 $\mathrm{Ci} / \mathrm{mMol}$. Der Nachweis der ${ }^{35} \mathrm{~S}-M e t h i o n i n-M a r k i e r u n g ~ w a r ~ d a d u r c h$ rund 200.000 fach empfindlicher.

DNPA scheint aber ein geeignetes Werkzeug zur Bestimmung der Proteinorientierung in der PM zu sein. Die unterschiedliche Markierung bei right-side-out- bzw. inside-out-Vesikeln zeigte dies. Sollte eine rein unspezifische nearest-neighbour-DNPA-Bindung vorliegen, würden damit bevorzugt aus der $\mathrm{PM}$ in das Cytoplasma ragende Peptidstrukturen nachgewiesen werden können. Dies ist denkbar als eine gemeinsame Eigenschaft der großen Zahl der durch DNPA nachgewiesenen Proteine. Die PM-NR ist ein DNPA-markiertes Protein. Möglicherweise ist ein erheblicher Anteil der DNPA-markierten Proteine an Signaltransduktionskaskaden beteiligt. Eine Übersicht über Verfahren der Photoaffinitätsmarkierung zur Identifikation und Lokalisation von an Signaltransduktionprozessen beteiligten PM-Proteinen gibt Dorman (2001). Durch Anheftung von Arylaziden an DNA und eine Photolyse nach Bindung von Polymerase-Proteinen konnten die am Aufbau von DNA-Polymerase-Transkriptionskomplexen beteiligten Polymerasen in Hefen identifiziert werden (Tate et al., 1998). 


\subsection{Plasmamembran-gebundene Nitrat-Reduktase}

Zur Untersuchung der ${ }^{35} \mathrm{~S}$-markierten Proteine, die nach $\mathrm{NO}_{3}{ }^{-}$-Induktion eine höhere Proteinkonzentration zeigten (quantitativ $\mathrm{NO}_{3}^{-}$-induziert), wurde ein immunologischer Nachweis der PM-gebundenen Nitrat-Reduktase (PMNR)(Stöhr et al., 1993; Tischner et al., 1989) durchgeführt. $\mathrm{NO}_{3}{ }^{-}$induziert die NR-Synthese (Daniel-Vedele und Caboche, 1996). Unter nicht optimierten 2DSDS-PAGE-Bedingungen wurden drei Proteine mit den Molekulargewichten 67,$3 ; 64,4$ und 58,9 kDa durch den NR-AK immunologisch nachgewiesen. Daneben traten im basischen $\mathrm{pH}$-Bereich des IEF schwächer detektierte Polypeptide mit $71 \mathrm{kDa}$ Molekulargewicht auf (Abb. 23). Dieses ProteinVerteilungsmuster der PM-NR entsprach dem von Stöhr (1993) gezeigten Western Blot der PM-NR am gleichen Objekt nach 2D-SDS-PAGE. Die von Stöhr (1993) bestimmten Molekulargewichte wichen von den vorliegend bestimmten ab, und waren 64, 60 und $55 \mathrm{kDa}$. Dies liegt innerhalb der 10 \%igen Streuung bei der Molekulargewichtsbestimmung in SDS-Gelen (Weber und Osborn, 1969).

Die für Plasmamembran-Proteine optimierte 2D-SDS-PAGE führte zum Nachweis des einzigen, $\mathrm{NO}_{3}^{-}$-induzierten Polypeptids der PM-NR. Die unter nicht optimierten 2D-SDS-PAGE-Bedingungen getrennten drei NR-Polypeptide von 67,3; 64,4 und 58,9 kDa erwiesen sich als Überlagerungen jeweils mehrerer Polypeptide gleichen Molekulargewichts (Abb. 25, NR-Blot). Die vier schwersten vom NR-Antikörper detektierten (NR-AK-antigenen) Polypeptide von 67,3 kDa waren in der Detergenz-Phase des TX114-Systems angereichert (DP \# 75; 76; 77; 78). In geringer Konzentration traten DP \# 75 und 76 auch in der Wässrigen Phase auf (darin als WP \# 85 und 86). Diese Polypeptide der NR verhielten sich somit amphiphil (Abb. 25, Silberfärbungen WP, DP). Der Vergleich des NR-Western-Blot mit den Autoradiographien der ${ }^{35}$ S-markierten Proteine zeigte aber ausschließlich das 64,4 kDa Protein DP \# 101 (WP \# 104) als sowohl NR-AK-antigen, als auch durch $\mathrm{NO}_{3}{ }^{-}$induziert ${ }^{35} \mathrm{~S}$-markiert (Abb. 25, ${ }^{35} \mathrm{~S}$, vertikaler Pfeil). Damit war das $64,4 \mathrm{kDa}$ Protein DP \# 101 das einzige $\mathrm{NO}_{3}{ }^{-}$ -induzierte und NR-AK-antigene Polypeptid. Die ebenfalls vom NR-AK detektierten Polypeptide von 67,3 und 58,9 kDa waren nicht radioaktiv markiert.

Die NR unterliegt einer vielfältigen Regulation: Genexpression, katalytische Aktivität und Degradation des Proteins (Kaiser und Huber, 2001). Der von Stöhr (1993) vermutete sukzessive Zerfall des 95 kDa-PM-NR-Monomers von Chlorella saccharophila in Fragmente von 67, 64 und $55 \mathrm{kDa}$ scheint nicht zutreffend. Wären die NR-Polypeptide von 67,$3 ; 64,4$ und 58,9 kDa Degradationsprodukte eines gemeinsamen NR-Monomers, so müßten alle durch Degradation entstandenen Polypeptide radioaktiv markiert sein. Da nur das 64,4 kDa-Polypeptid radioaktiv markiert ist, kann auch nur dieses Polypeptid ein mögliches Bruchstück einer neu synthetisierten NR darstellen. Das 64,4 kDa Polypeptid zeigt damit eine Regulation der NR-Aktivität auf transkriptioneller oder posttranskriptioneller Ebene durch Proteinneusynthese und nachfolgender Degradation. Eine Regulation der NR-Aktivität auf transkriptioneller oder posttranskriptioneller Ebene wird für die NR in Chlorella vulgaris gezeigt (Cannons, 2001; Cannons und Cannon, 2002). Die nicht neu synthetisierten (keine ${ }^{35}$ S-Markierung) NR-Polypeptide von 67,7 und 59,8 kDa lassen vermuten, dass diese einem anderen, höhermolekularen Polypeptid der 
NR enstammen, einen langsamen turn-over haben und einer posttranslationalen Regulation der NR unterliegen. In höheren Pflanzen (Nicotiana tabacum) liegen mehrere NR-codierende Gene vor (Scheible et al., 1997), was das Auftreten dieser Polypeptide erklären könnte. Die ausbleibende Neusynthese nach $\mathrm{NO}_{3}{ }^{-}$-Induktion geht möglichweise auf eine stark verzögerte Degradation zurück. Abbau und Halbwertszeit der cytosolischen NR scheinen von Phosphorylierungszustand und Bindung von 14-3-3-Proteinen abhängig zu sein; eine Aktivierung der NR führt zu einer erhöhten Stabilität (Kaiser und Huber, 2001).

Es ist nicht bekannt, ob das native 234 kDa-Holoenzym der PM-NR in Chlorella saccharophila (Stöhr, 1993) ein Homodimer darstellt, oder ob verschiedene Monomere daran beteiligt sind. In Nicotiana tabacum scheint die PM-NR von einem einzelnen Gen codiert zu sein (Wienkoop et al., 2001; Mol.-Gewicht nicht angegeben), die native PM-NR in Nicotiana tabacum hat ein Molekulargewicht von ca. 200 kDa (Stöhr et al., 2001). Welche der gezeigten NR-Polypeptide oder -Fragmente vermutlich die PM-NR in Chlorella saccharophila konstituieren, ergibt sich aus der Verteilung der Polypeptide in der TritonX114-Fraktionierung. Die Polypeptide von 67,3 und 58,9 kDa waren in der TX114-Detergenzphase erheblich stärker angereichert (Abb. 25, DP+WP Silberfärbung). Die PM-NR ist über einen Glykosyl-Phosphatidyl-Inositol-Anker in der PM verankert und tritt in der TX114-Detergenzphase auf (Stöhr, 1995a). Somit stellen die nichtradioaktiven Polypeptide von 67,3 und 58,9 kDa mit hoher Wahrscheinlichkeit Polypeptid-Bruchstücke der PM-NR dar und deuten eine gegenüber der löslichen NR abweichende Regulation an. Die vermutete Beteiligung der PMNR an Signaltransduktionsprozessen (Mätschke et al., 1997) unterstützt diese Annahme. Das radioaktiv markierte Polypeptid von 64,4 kDa (DP \# 101/WP \# 104) war in der wässrigen TritonX114-Phase stärker angereichert. Die cytoplasmatische NR ist -als Verunreingung in PM-Vesikeln eingeschlossenverstärkt in der wässrigen TX114-Phase zu erwarten. Dies würde auch den höheren Anteil des 64,4 kDa-Polypeptides in dieser Phase erklären. Damit scheint dieses Polypeptid ein Fragment der löslichen, cytoplasmatischen NR in Chlorella saccharophila darzustellen.

Nicht auszuschließen ist eine Kreuzreaktivität des NR-Antikörpers mit weiteren Proteinen der PM. Bei älteren Seren ist $\mathrm{zu}$ berücksichtigen, dass möglicherweise nur ein durch SDS-Gelektrophorese bis zur Homogenität gereinigtes Protein zur Immunisierung eingesetzt wurde. Darin können weitere Proteine gleichen Molekulargewichts enthalten sein, die dann ebenfalls antigen wirken und Kreuzreaktionen des Serums auslösen. Zu den NR-AK-detektierten Polypeptiden wurde eine Suche von Proteinen gleichen Molekulargewichtes und isoelektrischen Punktes mit dem Swiss-Prot Suchwerkzeug „Tagldent“ durchgeführt. Sowohl für die 67,3 wie auch die 64,4 kDa-Polypeptide wurden Gene für Peptid-Transporter der Plasmamembran gefunden (PTR2-A pl: 5.28, MW: 67,5 und PTR2-B (Histidin-Transporter) pl: 5.49, MW: 64,4 kDa), die fast identische gelelektrophoretische Eigenschaften zeigen.

Die gezeigte Herkunft der NR-Polypeptide von unterschiedlichen NRMonomeren und die zu vermutende unterschiedliche Regulation lassen in Chlorella saccharophila zwei NR-codierende Gene für PM-NR und NR [Cytosol] erwarten. Dass die PM-NR, abgesehen vom GPI-Anker, aus den gleichen Monomeren aufgebaut ist wie die cytoplasmatische NR scheint aufgrund der gezeigten Ergebnisse unwahrscheinlich. Von der Phosphorylierung/ Dephosphorylierung der NR und nachfolgender $\mathrm{Mg}^{2+} /$ Polyamine-abhängiger 
Bindung eines 14-3-3-Proteins an der phosphorylierten NR berichten Lillo und Appenroth (2001). Zur Klärung der NR-Holoenzym-Struktur und der Regulation der verschiedenen, gezeigten NR-Polypeptidfragmente sollten deren ${ }^{32} \mathrm{P}$ Phosporylierbarkeit und immunologisch, eine Interaktion mit 14-3-3-Proteinen durch hochauflösende 2D-SDS-PAGE geprüft werden. Eine Regulation der PMNR durch Degradation scheint auch deshalb unwahrscheinlich, weil die vermutete Funktion als Blaulichtrezeptor (Mätschke et al., 1997) eine schnelle Signaltransduktion erfordert. Möglicherweise wird dies über mitogen-aktivierte Protein-Kinasen (MAPK) vermittelt. Diese sind bekannt für eine Aktivierung durch extrazelluläre Stimuli (Baudouin et al., 2002). Ein immunologischer Nachweis von phosphorylierten MAPKn (Antikörper gegen MAPK von New England Biolabs/Transduction labs, USA) nach Blaulichtpulsen bzw. NitratInduktion sollte darüber Aufschluß geben.

\subsection{Immunologischer Nachweis eines Nitrat-Transporters}

Ein Nitrat-Transporter in Chlorella saccharophila sollte durch immunologischen Nachweis (Western Blot) identifiziert werden. Zur Herstellung eines NitratTransporter-spezifischen Antikörpers mußten zunächst geeignete Antigene zur Kaninchen-Immunisierung ausgewählt werden. $\mathrm{Da}$ über die Aminosäuresequenz eines Nitrat-Transporters in Chlorella saccharophila keine Informationen vorlagen, wurde auf die aus den Genen bekannter NitratTransporter (Beispiele in Tab. 3) abzuleitenden Aminosäuresequenzen zurückgegriffen. Um innerhalb der Nitrat-Transporter phylogenetisch möglichst hoch konservierte Regionen zu erfassen, wurden Nitrat- und Nitrit-Transporter höherer und niederer Pflanzen berücksichtigt, daneben solche aus Aspergillus (Emericella) nidulans und Escherichia coli. Die in Algen und Pflanzen vertretenen Nitrat-Transporter, sowie die aus $A$. nidulans und $E$. coli beschriebenen (CRNA und NarK) gehören zur Familie der Major Facilitator Superfamily (MFS) der Membrantransporter (Trueman et al., 1996). Die Nitratund Nitrit-Transporter wurden innerhalb der MFS von Poa et al. (1998) als Gruppe der Nitrat-Nitrit-Transporter (NNP) zusammengefasst. Durch ein Alignment der Aminosäuresequenzen der NNP nachgewiesen, bestehen zwischen NarK, CRNA und den pflanzlichen Nitrat-Transportern gemeinsame, hoch konservierte Aminosäuresequenzen: Das Motiv A-G-(w,I)-G-N-M-G tritt übergreifend auf und scheint an der Substrat-Erkennung beteiligt (Trueman et al., 1996). Zur Peptidsynthese und nachfolgenden Kaninchen-Immunisierung wurden aus einem Alignment von NNP-Aminosäuresequenzen die drei am höchsten konservierten Regionen ausgewählt, u.a. das obige Motiv (Abb. 26). Damit sollte sichergestellt werden, das mit einem auf Proteinvorhersagen beruhenden Antikörper auch solche Transporter detektiert werden, deren Aminosäuresequenz nicht im Alignment berücksichtigt war. Somit sollte auch ein Nitrat-Transporter in Chlorella saccharophila durch diesen Antikörper detektiert werden können.

Die Synthese der aus den ausgewählten, hochkonservierten Regionen ermittelten Peptide von 10 bzw. 15 Aminosäuren Länge sowie die Immunisierung der Kaninchen wurde von Herrn M. Benli der Fa. BioScience durchgeführt. Die Peptide enthielten einen hohen Anteil lipophiler Aminosäuren, diese waren als Bestandteile der Consensus-Bereiche unvermeidlich. Über Schwierigkeiten beim Auflösen der Peptide zur Immunisierung wurde von Fa. 
BioScence nicht berichtet. Dort führten aber Probleme in der Tierhaltung und Ausfall der immunisierten Tiere vor dem $2^{\text {nd }}$ Bleeding zu Verzögerungen und unvollständiger Serum-Gewinnung. Gewonnen wurden drei $1^{\text {st }}$ BleedingImmunseren: Serum \# 29, \# 58, \# 119, einschließlich der Prä-Immunseren. Nur Serum \# 58 lag auch als $2^{\text {nd }}$ Bleeding vor und war nach 2. (Boost-) Injektion entnommen. Die Seren \# 58 und \# 29 zeigten eine konzentrationsabhängige Immunreaktion auf das Peptid 1-Antigen und enthielten damit Peptid1spezifische Antikörper (Abb. 27). Eine Affinitäts-chromatographische Aufreinigung der gewonnenen Seren mithilfe der Peptide wurde auf Empfehlung von Herrn M. Benli der Fa. BioScience nicht durchgeführt. Dies sollte vermeiden, die Antikörper-Fraktion der höchsten Spezifität durch eine zu feste Bindung an das immobilisierte Peptid und eine dann erforderliche Elution unter möglicherweise denaturierenden Bedingungen zu verlieren. Peptide 2 und 3 wurden im Dot Blot nicht spezifisch detektiert und hatten somit keine Immunreaktion in den Kaninchen ausgelöst. Dies könnte durch die schlechte Löslichkeit der lipophilen Peptide bedingt sein. Diese bereiteten auch in der Auflösung für die Dot Blots Schwierigkeiten und könnten bei der Immunisierung der Kaninchen unbemerkt als Präzipitat vorgelegen haben.

Ein mit den Seren \# 29 und \# 58 geprobter Western-Blot von PM-Proteinen zeigte eine Reihe von Proteinen unterschiedlichen Molekulargewichts (Abb. 28). Da diese, wie auch bei dem nicht gezeigten Serum \# 119, ebenfalls vom PräImmunserum detektiert wurden, sind die Markierungen als unspezifische Kreuzreaktionen der Seren anzusehen. Ein 17 kDa-Protein wurde nur von Serum \# 29, nicht aber vom Prä-Immunserum detektiert und stellt damit das einzige Protein dar, das erst nach Immunisierung detektiert wurde. Somit war der Antikörper gegen dieses Protein durch Immunsierung induziert. Ob es sich dabei um ein Fragment eines Nitrat-Transporters handelt, konnte nicht geklärt werden. In der 2D-SDS-PAGE der $\mathrm{NO}_{3}{ }^{-}$-induziert ${ }^{35}$ S-markierten Proteine lag ein de novo synthetisiertes Protein entsprechenden Molekulargewichtes weder in der wässrigen Phase, noch in der Detergenz-Phase des TX114-Systems vor. Dies spricht gegen das Vorliegen eines möglichen Nitrat-TransporterFragmentes. Der Nachweis eines Nitrat-Transporters durch die hergestellten Antiseren gelang in Chlorella saccharophila somit nicht.

Serum \# 29 detektierte ein 64 kDa-Protein, das eine $\mathrm{NO}_{3}{ }^{-}$-induzierte Konzentrationszunahme zeigte. Das Protein wurde nur in Plasmamembranen gefunden, die durch Chloroplasten- bzw. Thylakoidmembranen grün gefärbt waren. Diese Verunreinigung trat nach Zellaufbruch mit einer Zellmühle auf, und ist vermutlich auf starkes Zerscheren der membranären (mikrosomalen) Fraktion bzw. Erwärmung zurückzuführen. Bei Aufbruch der Zellen durch eine Zellmühle lieferte das PEG/Dextran Two-Phase-Partioning stets grünlich gefärbte PM (reine PM ist durch Lipide gelb gefärbt). Das Fehlen des 64 kDaProteins in nicht verunreinigter PM (Blot nicht gezeigt) läßt es als einen Bestandteil des Chloroplasten vermuten. Da zur Immunisierung Regionen ausgewählt wurden, die auch in Nitrit-Transportern konserviert sind, könnte mit dem 64 kDa-Protein ein Nitrit-Transporter des Chloroplasten vorliegen. Das Gen Nar1 in Chlamydomonas reinhardtii codiert für ein integrales Protein der Chloroplasten-Hüllmembran, das am Nitrit-Transport beteiligt ist (Rexach et al., 2000). In Cucumis sativus codiert das NITR1-Gen für einen Nitrit-Transporter von 67,6 kDa (Takahashi und Sigiura, 2001). Nar1 wird als Bestandteil eines Gen-Clusters mit weiteren Genen für die $\mathrm{NO}_{3}{ }^{-}$-Assimilation in Chlamydomonas reinhardtii co-exprimiert (Galvan und Fernandez, 2001). Das $\mathrm{NO}_{3}{ }^{-}$-induzierbare 
64 kDa-Protein könnte somit ein möglicher Nitrit-Transporter in Chlorella saccharophila sein.

Serum \# 29 detektierte darüberhinaus in der 2D-SDS-PAGE die ebenfalls vom NR-AK detektierten Proteine von 67,3; 64,4 und 58,9 kDa. Sowohl PräImmunserum, als auch Immunserum reagierten mit diesen Proteinen. Dies deutet auf ein Immunglobulin, dass bereits vor Immunisierung vorhanden war und Affintät zur NR besitzt. Über nicht-induzierte, kreuzreaktive Antikörper gegen pflanzliche Proteine liegen keine Angaben in der Literatur vor.

Über den immunologischen Nachweis eines Nitrat-Transporters ist bislang nur zweimal berichtet worden. Von einem Antikörper gegen das NrtA-Protein des Nitrat-Aufnahmesystems von Synechococcus sp. (Cyanobakterium) berichten Sonoda et al. (1997). Das funktionelle Nitrat-Transportsystem in Synechococcus sp. wird von vier Genen codiert: NrtA, NrtB, NrtC, NrtD. NrtA codiert dabei für das Nitrat-bindende Protein. Der funktionelle Nitrat-Transporter gehört zur Familie der ATP-binding cassette-Superfamilie der aktiven Transporter (Omata, 1995). NrtA weicht damit strukturell von den protonencotransportierenden NRT1 und NRT2-Nitrat-Transportern der Nitrat-Nitrit-Porter (Poa et al., 1998) ab. Der zweite immunologische Nachweis eines NitratTransporters beruht auf unveröffentlichten Ergebnissen von Hansen, Dunn und Forde. Das Antiserum gegen das Hordeum vulgare NRT2-Polypeptid zeigte nach $\mathrm{NO}_{3}{ }^{-}$-Induktion von $\mathrm{N}$-verarmten Wurzeln eine mit der NRT2Genexpression correspondierende Zunahme immunreaktiven („cross-reacting“) Proteins (berichtet in Forde und Clarkson, 1999). Daraus geht nicht die Anzahl und das Molekulargewicht des oder der nachgewiesenen Proteine hervor. Das Antiserum gegen das Hordeum vulgare NRT2-Polypeptid wurde freundlicherweise von Herrn Brian Forde zur Verfügung gestellt und gelelektrophoretisch getrennte PM-Proteine in Chlorella saccharophila damit geprobt.

Das Antiserum gegen das Hordeum vulgare NRT2-Polypeptid markierte PMProteine von 67; 64; 59 und 55 kDa Molekulargewicht der Detergenz-Phase des TX114-Systems. Die intensivste Markierung zeigten aber zwei Proteine von 43 und $41 \mathrm{kDa}$ Molekulargewicht der wässrigen Phase. Daneben ein 64 kDaProtein mit schwachem Signal. In beiden TX114-Phasen gemeinsam wurde ein 22 kDa-Protein markiert (Abb. 29). Das Antiserum detektierte ebenfalls die mit dem NR-AK nachgewiesenen NR-Polypeptide von 67, 64 und 59 kDa. Auch Serum \# 29 führte zur Detektion dieser Proteine (nicht gezeigt). Damit wurde bei allen aus Kaninchen gewonnenen Seren die NR detektiert. Das unterstützt die o. g. Vermutung, dass die Nitrat-Reduktase stets mit schwachem Signal auch durch ein konstitutives, nicht erst durch Immunisierung induziertes Immunglobulin detektiert wird. Alternativ wäre die Kreuzreaktivität der Seren durch Erkennen des gleichen Proteinmotivs zu erklären. Beide Proteine (NR und Nitrat-Transporter) verfügen über eine Nitrat-Bindungsstelle. Ist die Erkennung des Nitrat-Bindungsstellen-Motivs den verschiedenen Antiseren gemeinsam, könnte dies im Western Blot durch eine mögliche Kompetition der Antikörper-Bindung gegen einen Nitrat-Überschuß geprüft werden.

Zur Lokalisation der zunächst durch SDS-PAGE getrennten Proteine im 2DSDS-PAGE-Elektropherogramm wurden $\mathrm{NH}_{4}{ }^{+}$-ernährte Algen $24 \mathrm{~h}$ Stickstoffverarmt und mit $\mathrm{NO}_{3}$ - induziert. Nach 2 und $4 \mathrm{~h} \mathrm{NO}_{3}^{-}$-Induktion wurden die Algen aufgebrochen, die extrahierten PM-Proteine nach 2D-SDS-PAGE durch Elektrotransfer auf NC-Folie übertragen und mit dem Nitrat-Transporter- 
Antiserum (Hordeum vulgare) geprobt. Im Western Blot der 2D-SDS-PAGE fehlte z.B. das 55 kDa-Protein des SDS-PAGE Western Blot. Das 55 kDaProtein war in der Detergenz-Phase angereichert, was auf ein hydrophobes Protein hindeutet. Da es im IEF nicht fokussierte, konnten keine weiteren Informationen zu einer möglichen Übereinstimmung mit den ${ }^{35} \mathrm{~S}$-markierten, $\mathrm{NO}_{3}{ }^{-}$-induzierten Proteinen gewonnen werden. Das NRT2-Polypeptid in Hordeum vulgare hat ein (vorherzusagendes) Molekulargewicht von 54,7 kDa (Trueman et al. 1996). Ob mit dem 55 kDa-Protein ein Nitrat-Transporter homologen Gewichts in Chlorella saccharophila detektiert wurde, müßten weitere Experimente mit den unter Kapitel 4.2.2 genannten Strategien der Elektrophorese klären.

Die Western Blots der 2D-SDS-PAGE zeigten 6 Proteine, deren Konzentration durch die $\mathrm{NO}_{3}{ }^{-}$-Induktion beeinflußt war. Dass diese Proteine einen möglichen Nitrat-Transporter darstellen, ist sehr unwahrscheinlich, da sie ausschließlich in der wässrigen Phase des TX114-Systems angereichert waren. Die Proteine II, III und IV wurden de novo gebildet und zeigten nach $2 \mathrm{~h} \mathrm{NO}_{3}{ }^{-}$-Induktion ein Konzentrationsmaximum, nach $4 \mathrm{~h}$ hatte die Konzentration wieder deutlich abgenommen. Die Proteine I und VI waren ebenfalls de novo gebildet, traten aber erst $4 \mathrm{~h}$ nach $\mathrm{NO}_{3}^{-}$-Induktion auf. Protein $\mathrm{V}$ zeigte eine starke Konzentrationszunahme nach $4 \mathrm{~h}$ (Abb. 31). Übereinstimmend vom Hordeum vulgare-NRT2-Antiserum detektiert und durch ${ }^{35}$ S-Markierung nachgewiesen (Abb. 10) waren: Protein II (55,7 kDa, WP \# 138); Protein IV (48,1 kDa, WP \# 150); Protein V (43,3 kDa, WP \# 187). Die Markierung dieser Proteine durch das Hordeum vulgare-Antiserum deutet auf strukturelle Ähnlichkeiten zwischen NRT2 und den markierten Proteinen hin. Es lagen keine Informationen vor über den (die) zur Immunisierung ausgewählten Bereich(e) der Aminosäuresequenz des Hordeum vulgare-NRT2. Damit wären Rückschlüsse auf ähnliche oder homologe Aminosäuresequenzen der Proteine I-VI möglich gewesen. Sollten die Immunglobuline des Antiserums an einer Sequenz mit regulatorischer Funktion für Aktivität oder Degradation binden, würde dies eine gleichartige Regulation dieser Proteine vermuten lassen. Beispiele für Regulationen sind Phosphorylierung und Bindung von 14-3-3-Proteinen. Die Halbwertszeit des NR-Proteins wird darüber beeinflußt (Kaiser und Huber, 2001), ebenso die von H+-ATPasen (Finnie et al., 2000). Da bei den Proteinen II, III und IV nach $4 \mathrm{~h}$ die Konzentration bereits wieder abgenommen hatte, scheint eine Regulation durch Degradation dieser Proteine vorzuliegen. Mögliche Ursache ist eine Feedback-Repression nach Anhäufung von Stickstoff-Assimilationsprodukten in der Zelle wie z. B. Glutamin. Glutamin scheint an der Feedback-Regulation der Nitrat-Aufnahme und -Assimilation beteiligt (Hoff et al., 1994; Quesada et al., 1997). Mit dem Hordeum vulgare-NRT2-Antiserum wurden eine Reihe von Proteinen detektiert wurden, doch ist die geringe Spezifität des Immunserums deutlich. Ebenso wie bei den mithilfe eines Alignments verschiedener NitratTransporter hergestellten Immunseren wurde weder ein distinktes Protein detektiert, noch wurden bevorzugt integrale Proteine der Detergenz-Phase des TX114-Systems detektiert. Der immunologische Nachweis eines NitratTransporters ist nicht zweifelsfrei zu führen. Die mit den verfügbaren Immunseren detektierten Proteine müssten sämtlich ansequenziert werden; bei der erheblichen Zahl der detektierten Proteine wäre dies sehr aufwendig und würde nicht notwendigerweise einen Nitrat-Transporter nachweisen. Dies ist nicht im Sinne einer spezifischen Detektion und erklärt vermutlich, warum 
bislang keine Berichte über einen immunologischen Nachweis eines NitratTransporters vorliegen.

\subsection{Präparative 2D-SDS-PAGE und ansequenzierte Plasmamembran- Proteine}

Eine Vielzahl verschiedener Plasmamembran-Proteine war durch eines oder mehrere der nachfolgenden Nachweisverfahren detektiert worden:

- Durch $\mathrm{NO}_{3}{ }^{-}$induziert de novo-synthetisiert (erstmals auftretend; qualitativ induziert) oder in der Protein-Konzentration zunehmend (quantitativ induziert)

${ }^{14}$ C-DNPA-markiert

Antikörper detektiert

Mit der 2D-SDS-PAGE lag ein für alle Proteine gleichermaßen geeignetes Verfahren zur Anreicherung vor. Die hohe Trennleistung der 2D-SDS-PAGE (siehe Kap. 4.3.3) sollte daher zur mikropräparativen Gewinnung von Plasmamembran-Proteinen in einer zur Ansequenzierung ausreichenden Menge und Reinheit ausgenutzt werden. Die zur N-terminalen Ansequenzierung durch Edman-Abbau erforderliche Proteinmenge war 1-5 pmol Protein. Daher wurde ein Kriterium gesucht, das ein Vorliegen dieser Proteinmenge in einem durch 2D-SDS-PAGE isolierten Proteinspot anzeigt. Eine Konzentrationsreihe eines 94 kDa Proteins (100-0,1 pmol je Geltasche) wurde durch SDS-PAGE getrennt und die Proteinbanden durch Silberfärbung im Gel bzw. nach elektrischem Transfer auf Polyvinyldifluorid- (PVDF-) Membran, durch Coomassie-Brillant-Blue angefärbt. Ein Vergleich der Nachweis-Empfindlichkeit von Silber- und Coomassie-Brillant-Blue-Färbung zeigte, daß die Coomassie-Brillant-Blue-Färbung ca. 50fach weniger empfindlich ist (Abb. 32). Die in einer Proteinbande von $470 \mathrm{ng}$ oder 5 pmol eines 94 kDa-Proteins enthaltene Proteinmenge wurde durch Coomassie gerade noch angefärbt. Die Anfärbung einer Proteinbande (oder eines Spots gleicher Fläche) auf PVDF-Membran durch Coomassie-Brillant-Blue gewährleistete das Vorliegen von mindestens 5 pmol eines Proteins von 94 kDa oder geringerem Molekulargewicht.

Zur präparativen Gewinnung wurde die 2D-SDS-PAGE in den für IEF und SDSPAGE eingesetzten Volumina maßstäblich vergrößert („large scale“). Für das IEF der 1. Dimension wurden anstelle der 1,5 mm-Gelstäbe solche von 3,2 mm und schließlich von $6 \mathrm{~mm}$ Durchmesser hergestellt. Nach 2D-SDS-PAGE von $450 \mu \mathrm{g}$ PM-Protein in 3,2 mm-IEF-Gelstäben wurden nur wenige Proteine durch Coomassie-Brillant-Blue angefärbt (Abb. 33). Obwohl damit bereits die zehnfachen Proteinmenge im Vergleich zu den silbergefärbten Gelen eingesetzt wurde. Erst mit $1500 \mu \mathrm{g}$ PM-Protein (6 mm-IEF-Gelstäbe) wurde eine größere Zahl von Proteinen in Spots mit mehr als 5 pmol Protein angereichert. (Nachweis durch Coomassie-Brillant-Blue-Färbung, Abb. 34). Durch präparatives IEF wurden insgesamt acht Proteine zur Ansequenzierung ausgewählt und isoliert, die eines oder mehrere der eingangs genannten Kriterien des Nachweises erfüllten $\left({ }^{35}\right.$ S-Markierung, ${ }^{14} \mathrm{C}-D N P A-M a r k i e r u n g$, immunologischer Nachweis, siehe Kapitel 3.8.1). Die Leseweite der Ansequenzierung betrug maximal 30 Aminosäuren; die ermittelten 
Peptidsequenzen wurden durch Alignment mit Proteinen der Datenbank SwissProt (www.expasy.ch) verglichen. Ein Algorithmus (z. B. nach Altschul und Erickson, 1985) sucht darin nach Aminosäure-Paarungen, bis deren Anzahl nicht mehr durch zusätzliche Ausdehnung über nicht gepaarte Lücken oder Paarung ähnlicher Aminosäuren vergrößert werden kann. Bei den so erhaltenen High Scoring Segment Pairs (HSPs) eines Alignments muß ihre statistische Signifikanz beachtet werden. Ob ein gegebenes Alignment eine hohe statistische Signifikanz besitzt und die Wahrscheinlichkeit einer zufälligen Übereinstimmung hoch oder niedrig ist, kann aus den Werten von Score, Length und Expect eingeschätzt werden: Je größer die Werte von Score und Length eines HSPs und je kleiner Expect, umso wahrscheinlicher ist das Vorliegen einer Homologie (stark vereinfacht; ausführliche Darstellung unter BLAST in www.expasy.ch; stochastisches Modell in: Karlin und Altschul, 1990).

Das Protein Nr. 8 (durch $\mathrm{NO}_{3}^{-}$quantitativ stärker ${ }^{35}$ S-markiertes $32,8 \mathrm{kDa}$ TX114-WP-Protein WP \# 260 / DP \# 227) wurde als einziges der ausgeschnittenen Proteine in der apparativ maximal möglichen Abbaulänge von 30 Aminosäuren ansequenziert. Die Aminosäuresequenz zeigte 100\% Identität zu einem 33,7 kDa-Porin $F$ aus Pseudomonas fluorescens, das Molekulargewicht stimmte mit einer Abweichung von 0,9 kDa überein. Bei dem HSP des 30 AS langen Sequenzabschnitts lag ein Expect value von $2^{-9}$ vor, was eine hohe Wahrscheinlichkeit der Homologie belegt. Damit besitzt Chlorella saccharophila mit hoher Wahrscheinlichkeit ein Porin, dass durch $\mathrm{NO}_{3}{ }^{-}$als $\mathrm{N}$ Quelle in seiner Proteinkonzentration zunimmt.

In Bakterien bilden Porine Kanalproteine in der äußeren Membran (Outer membrane pore forming protein oder Outer membrane porin), die die Permeabilität der Zellen für hydrophile Antibiotica beeinflussen (De et al., 2001; Chevalier et al., 2000; Lee et al., 1996). In Saccharomyces cerevisiae treten Porine in der Mitochondrien-Membran als mengenmäßig häufigstes Protein auf (Krimmer et al., 2001) und bilden darin spannungsabhängige Anionenkanäle (VDACs). Diese dienen dem Metabolit-Transport (Antos et al., 2001), dem Transport von Atmungskettensubstraten (Szczechowicz et al., 2001) und scheinen an der Aufrechterhaltung des lonengleichgewichts und der osmotischen Stabilisierung beteiligt zu sein (Sanchez et al., 2001). In höheren Pflanzen treten Porin-artige Kanäle in peroxisomalen Membranen als unspezifische Transportsysteme von Metaboliten auf (Reumann, 2000). In Cucumis sativus sind Porine in den Membranen von Glyoxisomen, Peroxisomen und Mitochondrien enthalten (Corpas et al., 2000). Daneben treten Aquaporine auf, die eine bidirektionale Passage von Wasser durch die Plasmamembran von Pflanzen erlauben (Hakman und Oliviusson, 2002). Diese molekularen Wasser-Kanäle erlauben eine Anpassung an veränderliche osmotische Bedingungen durch schnelle und spezifische Diffusion von Wasser und treten in Pflanzen, Algen, Pilzen und Bakterien auf (Ringler et al. 1999). Daneben scheinen Aquaporine zumindest in Chara spec. auch relativ große ungeladene organische Moleküle zu transportieren (Steudle, 1997) und auch an der Aufnahme von Kohlendioxid, Ammonium und Mikronährstoffen wie Borsäure beteiligt (Tyerman et al., 2002) zu sein.

Die hohe Homologie und statistische Signifikanz des HSP zwischen vorliegend nachgewiesenem Porin und Porin $F$ aus Pseudomonas fluorescens spricht für das Vorliegen eines Porins im Sinne eines VDAC in Chlorella saccharophila. Ein immunologischer Nachweis mit einem Antikörper gegen ein Aquaporin in 
Nicotiana tabacum gelang nicht, was für das Vorliegen eines Porins spricht. Für ein Porin in Algen liegt bislang nur ein indirekter Nachweis vor. Durch elektrophysiologische Charakterisierung eines lonenkanals im Flagellum der einzelligen Grünalge Spermatozopsis similis wurde dieser als typisch für Porinartige Kanäle beschrieben (Hill et al., 2000). Es liegen keine Untersuchungen $\mathrm{zu}$ einer möglichen Beeinflussung eines Porins oder Aquaporins durch $\mathrm{NO}_{3}{ }^{-}$ vor. Ob das Porin in Chlorella saccharophila an der $\mathrm{NO}_{3}{ }^{-}$-Aufnahme beteiligt ist, müssen weitere Untersuchungen klären. Von einem $\mathrm{Cu}^{2+}$-regulierten Kanalprotein (OprC) der äußeren Membran von Pseudomonas aeruginosa berichten Yoneyama und Nakae (1996) eine Derepression unter Anaerobiosis und Gegenwart von $\mathrm{NO}_{3}{ }^{-}$. Vorliegend wurde erstmals ein direkter Nachweis eines Porins in Algen erbracht.

Die Alignments der Aminosäuresequenzen der ansequenzierten Proteine Nr. 17 zeigten gegenüber dem Porin um mehr zehn Zehnerpotenzen größere Expect-Values und deutlich kleinere Scores. Gleichzeitig erhöhten die kürzeren Aminosäuresequenzen die Wahrscheinlichkeit einer zufälligen Homologie bei sehr viel geringerer statistischer Signifikanz. Die durch Alignment gewonnenen HSPs zu ähnlichen oder homologen Sequenzen wurden nachfolgend auf ihre Wahrscheinlichkeit geprüft. Die jeweiligen High Scoring Segments Pairs der Alignments ergaben für:

Nr. 1 (durch $\mathrm{NO}_{3}^{-}$quantitativ stärker ${ }^{35}$ S-markiertes 23,2 kDa TX114-DPProtein \# 263) ein in Swiss-Prot eingetragenes, aber nicht spezifiziertes Wasserstreß-induziertes Protein in Oryza sativa von 37,7 kDa. Der Expect-value $=1663$ und der niedrige Score von 21,9 Bits zeigten die geringe statistische Signifikanz des HSP, auch stimmten die Molekulargewichte nicht überein. Die Identität des Chlorella saccharophila-Proteins konnte somit nicht geklärt werden.

Nr. $2\left({ }^{14} \mathrm{C}\right.$-DNPA-markiertes 45 kDa-Protein IV (TX114-WP \# 184-187) ein HSP zu einer Transposase aus Pyrococcus furiosus. Transposasen ermöglichen innerhalb des Genoms ein Verschieben von Transposons, mobilen Elementen (Turkotte und Bureau, 2002). Da Transposasen Kernproteine sind, kann keine Überstimmung zu dem ansequenzierten PM-Protein vorliegen.

Nr. $3\left({ }^{14} \mathrm{C}-D N P A\right.$ markiertes Protein C (58,9 kDa; homolog zu TX114-DP \# 110/112 bzw.WP \# 118; 119) ein Polyadenylat-bindendes Protein aus Xenopus laevis. Polyadenylat-bindende Proteine sind evolutionär konservierte Proteine, die an den PolyA-Schwanz von mRNA binden (Gray, 2000). Auch bei diesem Protein ist eine Homologie auszuschließen, da ein Auftreten an der PM nicht zu erwarten ist.

Nr. 4 (NR-AK detektiertes, durch $\mathrm{NO}_{3}^{-}$quantitativ stärker ${ }^{35}$ S-markiertes TX114-DP-Protein \# 101/WP 104) einen ATP Binding Cassette (ABC-) Transporter aus Agrobacterium tumefaciens. Daneben, mit geringerer Signifikanz, ein nifA-regulatorisches Protein aus Rhizobium leguminosarum. Das Protein WP \# 104 / DP \# 101 wurde immunologisch als PM-NR identifiziert (siehe Abb. 25). Der in Agrobacterium tumefaciens nachgewiesene ABC-Transporter ist zwar ein transmembranes Protein, dient aber vermutlich der Glucose- und 
Galactose-Aufnahme (Kemner, 1997). Obwohl ABC-Transporter z.B. in Synechococcus sp. Strain PCC7943 der Nitrat- und Nitritaufnahme dienen (Kobayashi et al., 1997; Omata, 1995), wäre die Übereinstimmung zwischen Protein WP \# 104 / DP \# 101 und einem ABC-Transporter nur in einem Nitrat-Bindungsmotiv zu vermuten. Da aber eine Homologie zu einem Glucose-Transporter vorliegt, scheint dies unwahrscheinlich. NifL inhibiert in Stickstoff-fixierenden Bakterien (z.B. Azotobacter vinelandii, Klebsiella pneumoniae) oder Algen (z.B. Herbaspirillum seropedicae) die Aktivität des nif-spezifischen Transkriptionsaktivators nifA (Monteiro et al., 2001; Schmitz et al., 2002). NifL besitzt eine $\mathrm{N}$-terminale Bindungsstelle für FAD. FAD übermittelt als Redox-sensitiver Cofaktor die Signaltransduktion des internen Sauerstoff-Status' (Schmitz et al., 2002). Die NR ist ein FAD- (sowie Molybdän-Pterin und Cytochrom b 557) enthaltendes Protein (Barber et al., 2001). Übereinstimmungen zwischen NR und NifL ergeben sich daher anhand des FAD. Obwohl unwahrscheinlich ist, dass der FADNifL-Komplex unter den Bedingungen der SDS-Elektrophorese stabil ist, könnte die Homologie des als NR identifizierten Proteins mit NifL durch das FAD bedingt sein.

Nr. 5 (NR-AK-detektierte 67,3 kDa TX114-DP-Proteine DP \# 75, 76) ein „four wheel drive“-Protein aus Drosophila melanogaster. Die vom four wheel drive-Gen codierte Phosphatidylinositol 4-Kinase (PI 4-Kinase) in D. melanogaster wird zur Synthese des regulatorischen MembranPhospholipid 2 (PIP2) benötigt. Die PI 4-Kinase phosphoryliert Actin an Tyrosinresten und wird zur Ausbildung interzellulärer Brücken während der Meiosis benötigt (Brill et al., 2000). Die Detektion der Proteine DP \# 75, 76 erfolgte durch den NR-AK. Auch wenn die PM-NR über einen GPI-Anker in der PM inseriert (Stöhr, 1993), erklärt dies nicht die Detektion einer Phosphatidylinositol-phosphorylierenden Kinase durch den NR-Antikörper. Daher scheint die Homologie zu einer PI 4-Kinase unwahrscheinlich. Zu einem four wheel drive-Protein in Pflanzen wurden keine Hinweise in der Literatur gefunden.

Nr. 6 (Basisches 73,4 kDa-Protein DP \# 66) Das Protein war nicht, wie zunächst angenommen, das einen möglichen Nitrat-Transporter darstellende DP-Protein \# 57 von 76,6 kDa (Konzentration zu gering). Es wurde dennoch zur Ansequenzierung ausgewählt, da es in Molekulargewicht und basischem IEP sehr ähnlich war. Die Ansequenzierung gelang nicht, da vermutlich ein blockierter $\mathrm{N}$-Terminus vorlag. Hinweise auf eine mögliche Identität des Proteins konnte nicht gewonnen werden.

Nr. $7\left({ }^{14} \mathrm{C}\right.$-DNPA-markiertes 91 kDa-Protein homolog zu TX114-DP-Protein DP \# 29) eine putative Isomerase aus Sinorhizobium meliloti. ProteinDisulfid-Isomerasen sind an der Faltung von Proteinen beteiligt (Sargsyan et a., 2002). Das Molekulargewicht putativen Isomerase aus Sinorhizobium meliloti beträgt 32,2 kDa. Hinweise auf Trimerisierung, die ein höheres Molekulargewicht in Chlorella saccharophila erklären könnten, wurden nicht gefunden. Damit scheint eine Homologie des vorliegenden Proteins zu einer Isomerase unwahrscheinlich. 
Die Alignments der Proteine 1-7 lieferten im Alignment zu Proteinen der SwissProt-Datenbank keine statistisch signifikanten High Scoring Segment Pairs. Keiner der erhaltenen Hinweise auf ähnliche Proteine wurde durch die verfügbaren Informationen zu Funktion, Lokalisation oder gelelektrophoretischen Eigenschaften unterstützt. Bei den nur kurzen Aminosäure-Abschnitten sind die Homologien in hohem Maß zufällig möglich; für alle durch HSP ermittelten möglichen Proteine lagen Ausschlußkriterien vor. Das Fehlen eines HSPs von hoher statistischer Signifikanz kann aber auch bedeuten, daß ein entsprechendes homologes Protein in der Datenbank fehlt. In Hüllmembran-Proteinen von Trichoderma reesei fanden Lim et al. (2001) zwölf Proteine, deren MS-MS bestimmte Aminosäuresequenz keinem Protein der Datenbank zugeordnet werden konnte. Fehlende Datenbank-Einträge können daher das Fehlen einer ähnlichen oder homologen Sequenz erklären, dürften vorliegend aber nur untergeordnete Bedeutung haben. Das problematische Upscaling des IEF bis zum mikropräparativen Maßstab stand im Vordergrund. Zwar konnte in den $6 \mathrm{~mm}-$ Gelstäben gegenüber silbergefärbten Gelen eine ca. 30fach größere Proteinmenge aufgetrennt werden. Die ca. 50fach geringere Nachweis-Empfindlichkeit der Coomassie-Brillant-BlueFärbung wurde aber noch nicht kompensiert. Durch Silberfärbung an der unteren Nachweisgrenze detektierte Proteine fehlten. Die $\mathrm{NO}_{3}{ }^{-}$-induziert de novo gebildeten und nur durch Autoradiographie nachgewiesenen Proteine der TX114-Detergenzphase (z.B. DP \# 56, 57, 58) konnten nicht isoliert werden.

Die Trennschärfe zwischen den einzelnen Proteinspots war in den „large scale“2D-Gelen deutlich geringer. Die Proteine waren im IEF schlierenförmig getrennt und überlappten bei eng benachbartem IEP. Haupursache dafür war vermutlich eine zu hohe Temperatur während des IEF. Bei unzureichender Kühlung erwärmten sich die großen Gelstäbe im elektrischen Feld durch den erheblich schlechteren Wärmetransport bis hin zu einer Gasblasenbildung (Wasserdampf), teilweise unter Zerreißen des Gelstabes. Das im Verhältnis zur Oberfläche größere Volumen in den $6 \mathrm{~mm}$-Gelstäben war für die Wärmeabfuhr im Vergleich zu den 1,5 mm-Gelstäben erheblich ungünstiger. Obwohl die Glasröhren durch vollständiges Eintauchen in der Rotophorkammer gekühlt waren, war die Kühlung der Gelstäbe über die gesamte Dauer des IEF problematisch. Zu Beginn des IEF fließen höhere Ströme und erfordern stärkere Kühlung, bei nachlassender Wärmeentwicklung im weiteren Verlauf des IEF neigte aber der Harnstoff gleichbleibender Kühlung (Kühlraum) zum Auskristallisieren. Daher wurde das IEF bei Raumtemperatur durchgeführt, unter zunächst niedriger Spannung. Trotzdem scheinen die $6 \mathrm{~mm}$-Gelstäbe für einen ausreichend schnellen Wärmeabtransport bereits zu groß. Der GelstabDurchmesser von $6 \mathrm{~mm}$ stellte die Grenze der Handhabbarkeit dar: Ein noch größerer Durchmesser des IEF-Gelstabes der 1. Dimension konnte nicht mehr unbeschädigt in den $2,5 \mathrm{~mm}$ messenden Zwischenraum des SDS-Gels (2. Dimension) eingebracht werden. Zur präparativen Gewinnung von PMProteinen scheint ein maßstäblich vergrößertes Gelstab-IEF daher nicht geeignet. Auch die häufig parallele Elution weiterer Aminosäuren mit jedem Zyklus des Edman-Abbaus zeigte, dass die Proteine nicht ausreichend getrennt vorlagen. Obwohl das Träger-Ampholyt-IEF sehr gute Ergebnisse der silbergefärbten Gele im kleinen Maßstab ermöglichte, war das maßstäbliche Vergrößern nur im Fall des Porins erfolgreich. Die Vorteile des IPG-IEF hinsichtlich pH-Stabilität und der damit verbundenen, höheren Beladungskapazität (siehe Kapitel 4.2.1) dürften für eine präparative Gewinnung von PM- 
Proteinen besser geeignet sein und sollten bei zukünftigen Präparationen ausgenutzt werden.

\subsection{Molekularbiologische Untersuchungen}

Durch einen molekularbiologischen Ansatz sollte versucht werden, einen NitratTransporter in Chlorella saccharophila auf genomischer Ebene zu identifizieren. Dazu wurde eine PCR mit degenerierten Primern durchgeführt. Als Primer dienten 1.) die von Quesada (1997) zur Identifikation eines Nitrat-Transporters in Nicotiana tabacum eingesetzten Primer. Diese beruhten auf den am höchsten konservierten Sequenzen zwischen Nitrat-Transportern einer höheren Pflanze (Hordeum vulgare) und einer niederen Pflanze (Chlamydomonas reinhardtii). Mit einem Primerpaar der nachfolgend als PNT A,B,C...-G bezeichneten Primer gelang die Sequenzierung eines Nitrat-Transporters in Chlorella sorokiniana (Tischner et al., 2001). Aus dem zunächst verfügbaren Sequenzabschnitt des Nitrat-Transporters in Chlorella sorokiniana wurden 2.) mithilfe der Primer-Software Oligo 2.0 weitere, mit dem Prefix PENRTF bzw. PENRTR bezeichnete Primer ausgewählt. Zusätzlich wurden die Primer P1-3 synthetisiert, die den hoch konservierten und zur Immunisierung der Kaninchen ausgewählten Aminosäuresequenzen entsprachen (siehe Kap. 2.14.2). Diese waren weitgehend identisch zu den PNT-Primern.

Die für die PCR eingesetzte RNA wurde nach Logemann et al. (1987) präpariert und war, wie die rRNA-Banden zeigten, intakt (Abb. 36). Durch Reverse Transkriptase- (RT-) PCR mit den nach Quesada et al. (1997) synthetisierten Primern wurden keine PCR-Produkte bis zur Bildung einer sichtbaren DNABande angereichert (Abb. 37). Da dies auch unter niedrig stringenten Bedingungen $\left(42{ }^{\circ} \mathrm{C}\right)$ nicht gelang, die ein stärkeres Mismatching erlauben (Ibelgaufts, 1990), wurde eine RT-PCR mit oligo-dT-Primern durchgeführt. Damit wurde zunächst die gesamte mRNA in cDNA umgeschrieben, und die nachfolgenden PCR-Experimente mit dieser cDNA durchgeführt. Die PCR mit den PNT-Primern nach Quesada et al. (1997) führte wiederum nicht zur Gewinnung von PCR-Produkten der -gemäß der Primer-Karte- zu erwartenden Molekulargewichte (Abb. 35 und 38). Auch variierte Annealing-Temperaturen beeinflußten das Ergebnis nicht. Mit einer Primer-Paarung von P1 (forward) und PNTG (reverse) wurden drei Produkte (II, III, IV) in erheblicher Menge generiert. Das Produkt III entsprach der zu erwartenden Größe eines Nitrat-TransporterFragmentes dieser Primer-Paarung (Abb. 39). Eine PCR mit den Primern PENRT-F/R erzeugte ebenfalls mehrere Produkte in erheblicher Menge (Abb. 40); die PENRT-F/R Primer beruhten auf den Sequenzinformationen des NitratTransporters in Chlorella sorokiniana. Von den erzeugten Produkten I, V, VI, VII entsprach nur Produkt I der zu erwartenden Größe. Die Produkte V, VI, VII wurden trotzdem zur Ansequenzierung isoliert, da sie als einzige Produkte der jeweiligen Primerpaarung gebildet wurden (VI, VII) bzw. auch bei höherer Temperatur (=Stringenz) auftraten (I). Die mit den PCR-Produkten transfizierten Escherichia coli-Zellen zeigten nach EcoR1-Verdau das Vorliegen jeweils einzelner Produkte (Abb. 41). Mit den durch Ansequenzierung gewonnenen Basensequenzen der Produkten I-VII wurden in Aminosäuresequenzen übersetzt und mithilfe des BLASTp-Internet-Tools ein Alignment auf homologe Sequenzen in der Datenbank Swiss-Prot durchgeführt. Das Alignment wurde 
mit Aminosäuresequenzen durchgeführt, da innerhalb des degenerierten Basencodes unterschiedliche Tripletts gleiche Aminosäuren codieren können. Dies erlaubte gleichzeitig längere Leseweiten bei Überbrückung eines in der Ansequenzierung nicht zweifelsfreien Tripletts. Damit lag zwar eine geringere Stringenz der Suchbedingungen vor, diese erlaubte aber eine größere Zahl möglicher, ähnlicher Proteine im Alignment einzubeziehen.

Die PCR-Produkte II, V, VI, VII zeigten High Scoring Segment Pairs (HSPs) mit hoher Wahrscheinlichkeit der Homologie. Die Produkte I, III und IV HSPs zeigten solche von niedriger Wahrscheinlichkeit (Kap. 3.9.3). Zur Beurteilung der Aussagekraft und Signifikanz der High Scoring Segment Pairs dienen die Werte von Score und Expect. Je kleiner der Wert für Expect und je größer der Score, desto wahrscheinlicher ist das im HSP gepaarte Protein ein Homologon. Die Alignments ergaben für die PCR-Produkte II, V, VI, VII:

PCR-Produkt II (Primerpaar P1-PNTG): Extensin-artiges Protein. Extensinartige Proteine sind am Aufbau der Zellwand von Chlamydomonas reinhardtii, Volvox carteri, Nicotiana alata, Vigna unguiculata beteiligt (Bosch et al., 2001; Wössner et al., 1994; Arsenijevic et al., 1997). Daneben treten sie in Pollen von mono- und dicotylen Pflanzen auf (Stratford et al., 2001). Mit hoher Wahrscheinlichkeit wurde ein Gen für ein am Aufbau der Zellwand von Chlorella saccharophila beteiligtes Extensin-artiges Protein identifiziert. In der Literatur liegen bislang keine Hinweise auf ein Extensin-artiges Protein einer Chlorella spec. vor.

PCR-Produkt V (Primerpaar PENRTF1-PNTG): Putative RNA-Helicase A aus Arabidopsis thaliana. In Arabidopsis scheint eine RNA-Helicase A eine Rolle in der Nukleinsäuren-Entwindung innerhalb vaskulärer Zellen zu spielen (Wei et al., 1997). RNA-Helicase A bindet in humanen HeLa-Zellen an F-Actin des Zellkernskeletts und ist beteiligt an der Transkription, der RNA-Prozessierung und dem RNA-Transport (Zhang et al., 2002). In der Literatur wurden keine Hinweise auf eine RNA-Helicase $A$ in Algen gefunden.

PCR-Produkt VI (Primerpaar PENRTF3-PENRTR10): Wahrscheinliches Hitzeschock-Protein aus Ralstonia solanacearum. Hitzeschock-Proteine werden durch Hitze und osmotischen Streß induziert und haben thermoprotektive Wirkung (Park und Bong, 2002). In Arabidopsis thaliana hat das At-HSP17-6A-Gen Chaperon-Funktion (Sun et al., 2001). Der Nachweis eines Hitzeschock-Proteins ist neben Chlorella vulgaris und zofingiensis (Maki et al., 2000; Shen und Kun, 1997) vorliegend auch für Chlorella saccharophila gegeben.

PCR-Produkt VII (Primerpaar PENRTF3-PENRTR20): Hypothetisches Protein aus Homo sapiens. Dieses Protein lag als nicht spezifiziertes Protein in der Datenbank Swiss-Prot vor; die HSPs von geringerer Homologie ergaben Hinweise auf nicht miteinander verwandte Proteine, wie z.B. solche aus dem Cytomegalie-Virus der Ratte; Zellwandoberflächen-Protein; Mucin. Mit dem PCR-Produkt VII liegt vermutlich ein bislang nicht in Swiss-Prot vorhandenes Protein vor. 
Die Alignments der PCR-Produkte I, III, IV zeigten erheblich geringere Homologien in den HSPs:

PCR-Produkt I (Primerpaar PENRTF1-PNTG): virale RNA-abhängige RNAPolymerase. Doppelsträngige RNA ruft in Tieren wie Pflanzen nach Erkennung ein sequenzspezifisches, posttranskriptionelles Gen-Silencing hervor (Lee et al., 2002). Doppelstrang-RNA-Viren sind im Getreidepilz Fusarium graminearum mit dessen Hypovirulenz assoziert (Chu et al., 2002). Im Chlorella-Stamm NC64A wurden 42 Viren bestimmt, die diese Alge infizieren können (Zhang et al., 2001). Möglicherweise ist mit dem PCR-Produkt I ein Gen aus einem Chlorella-infizierenden Virus amplifiziert worden.

PCR-Produkt III (Primerpaar P1-PNTG): Homeo Box D9 aus Homo sapiens. Hier lag, wie bei PCR-Produkt VII, keine Spezifikation des HSP-Proteins vor. Daher liegt mit dem Produkt III vermutlich ebenfalls ein bislang nicht in Swiss-Prot vorhandenes Protein vor.

PCR-Produkt IV (Primerpaar P1-PNTG): Putative Ser/Thr-Proteinkinase aus Streptomyces coelicolor. Ser/Thr-Proteinkinasen sind an der SignalTransduktion und der Regulation metabolischer Prozesse beteiligt (Supori und Munshi, 1998). Phosphorylierung von PM-Proteinen in Chlorella saccharophila sind durch Mätschke et al. (1997) belegt; mit dem vorliegend ansequenzierten PCR-Produkt liegt ein Hinweis auf eine Ser/Thr-Kinase als daran beteiligtes Protein vor.

Die Alignments der ansequenzierten PCR-Produkte I-VII zeigten Homologien zu mehreren, bislang nicht aus Chlorella bzw. Grünalgen beschriebenen Proteinen. Homologien zu einem bekannten Nitrat-Transporter lagen nicht vor. Die verschiedenen zur PCR eingesetzten Primer waren, obwohl gegen hochkonservierte Regionen von Nitrat-Transportern gerichtet, nicht spezifisch in der Amplifikation der gezeigten Produkte. Durch PCR mit der vorliegend ebenfalls eingesetzten Primerpaarung (PNTC-PNTG; nach Quesada et al., 1997) wurde von Tischner und Koltermann (2001) zunächst ein Fragment eines Nitrat-Transporters in Chlorella sorokiniana amplifiziert. Mit dem PCR-Fragment als Sonde, wurde schließlich ein full length clone des gesamten Gens in einer Chlorella sorokiniana cDNA-library identifiziert und sequenziert. Dieser NitratTransporter zeigte eine Homologie von $55 \%$ zu anderen, bekannten NitratTransportern. Die phylogentische Verwandtschaft zwischen Chlorella saccharophila und Chlorella sorokiniana ist möglicherweise zu gering, um mit der gleichen Primerpaarung auch in Chlorella saccharophila ein NitratTransporter amplifizieren zu können. Die gegenüber Chlorella sorokiniana gute Protoplastierbarkeit von Chlorella saccharophila zeigt deren abweichenden Aufbau der Zellwand: Sporopollenin fehlt, es liegt anstelle eines Trilayer nur ein Monolayer mit geringem Gehalt an Pectin vor (Yamada und Sakagudi, 1982). Chlorella sorokiniana und $C$. vulgaris zeigen einen hohen Grad der Übereinstimmung des Syntheseverhaltens von Chlorophyllen und Carotinoiden nach Stickstoff-Verarmung und anschließender Vollmedium-Kultur. Demgegenüber zeigen $C$. saccharophila und $C$. elipsoidea zwar untereinander übereinstimmendes Verhalten, weichen darin aber signifikant von der erstgenannten Gruppe ab (Skoda, 1997). Eine molekulare Phylogenie der Gattung Chlorella innerhalb der Chlorophyta unter Einbeziehung von 18S 
rRNA-Sequenzen und biochemischen, physiologischen und ultrastrukturellen Merkmalen zeigte, daß die unter Chlorella zusammengefaßten Taxa über die beiden Klassen Trebouxiophyceae und Chlorophyceae verteilt sind. Chlorella vulgaris, kessleri, lobophora und sorokiniana bilden eine eigenständige Merkmalsgruppe gegenüber Chlorella saccharophila, luteoviridis, elipsoidea etc. (Huss et al. 1999).

Die genannten phylogenetischen Unterschiede könnten eine von Chlorella sorokiniana abweichende Sequenz des Nitrat-Transporters in Chlorella saccharophila erklären, was eine Identifizierung verhinderte. Der sehr guten Eignung von Chlorella saccharophila zur Protoplastierung und Charakterisierung von Plasmamembran-Proteinen steht möglicherweise ein zu C. sorokiniana erheblich abweichendes Genom gegenüber. Die Ergebnisse der Untersuchungen von $C$. saccharophila und die in der Literatur beschriebenen Unterschiede innerhalb der Gattung Chlorella deuten darauf hin. Untersuchungen anhand einer repräsentativen cDNA-library von $C$. saccharophila sollten eine molekularbiologische Charakterisierung und detailierte Aussagen zu phylogenetisch unterschiedlichen Entwicklungen erlauben. Damit würden Gen-spezifische Sonden aus höheren und niederen Pflanzen eingesetzt und unter milden Stringenzbedingungen, auch sehr heterologe Gene in Chlorella saccharophila identifiziert werden können. 


\section{ZUSAMMENFASSUNG UND AUSBLICK}

1. Zur Auftrennung von Plasmamembran-Proteinen aus Chlorella saccharophila wurde eine hochauflösende zweidimensionale SDSGelelektrophorese (2D-SDS-PAGE) mit Trägerampholyten etabliert. Um den hohen Bedarf an Plasmamembran-Proteinen zu decken, wurde ein Verfahren zur Massenkultur von Chlorella saccharophila eingeführt. Die 2DSDS-PAGE erlaubte die Auftrennung von insgesamt 651 PlasmamembranProteinen.

2. Die Hydrophobizitäts-Eigenschaften der Plasmamembran-Proteine wurden durch eine TritonX114-Zweiphasenverteilung bestimmt. 367 Proteine waren in der wässrigen Phase, 284 Proteine waren in der Detergenz-Phase des TritonX114-Systems angereichert. Die reproduzierbare 2D-SDS-PAGE erlaubte die Konstruktion einer zweidimensionalen Protein-Verteilungskarte (1. Dimension: IEF; 2. Dimension: SDS-PAGE) der in den Phasen des TX114-Systems enthaltenen Plasmamembran-Proteine.

3. Nach Induktion von Stickstoff-verarmten Chlorella saccharophila mit Nitrat bzw. Ammonium in Gegenwart von ${ }^{35}$ S-Methionin waren 196 Plasmamembran-Proteine radioaktiv markiert. 21 Plasmamembran-Proteine zeigten eine Zunahme der Proteinkonzentration durch die Gabe von NitratStickstoff; drei Proteine durch Ammonium-Stickstoff. Durch Nitrat induziert, wurden sechs Plasmamembran-Proteine de novo gebildet. Diese Proteine waren hydrophob und in der Detergenzphase des TX114-Systems angereichert. Sie hatten Molekulargewichte von 76,6; 67,8 und 45,9 kDa und repräsentieren aufgrund ihrer Hydrophobizität und den gelelektrophoretischen Eigenschaften mit hoher Wahrscheinlichkeit Polypeptide eines Nitrat-Transporters in Chlorella saccharophila.

4. Hochauflösende 2D-SDS-PAGE von ${ }^{35}$ S-markierten PlasmamembranProteinen und immunologischer Proteinnachweis der Plasmamembrangebundenen Nitrat-Reduktase (PM-NR) zeigten, dass nur ein einzelnes 64,4 kDa Polypeptid der PM-NR (Polypeptide von 67,3; 64,4 und 58,9 kDa) durch Nitrat induziert wird.

5. Durch Photoaffinitätsmarkierung mit 2,6-Dinitrophenylazid (DNPA), einem ${ }^{14} \mathrm{C}$-substituierten Hemmstoff der Nitrat-Aufnahme, wurden Plasmamembran-Proteine der Molekulargewichte 17; 23; 26; 36; 38; 38,5; 40; 43; 45; 47; 53; 58; 64; 71; 75 und 112 kDa markiert. Das 64 kDa-Protein wurde als PM-gebundenen Nitrat-Reduktase identifiziert. Die Markierung zeigte eine Abhängigkeit von der morphologischen Orientierung der Plasmamembran-Vesikel. An right side out-Vesikeln der Plasmamembran wurde fast ausschließlich ein hydrophiles $75 \mathrm{kDa}$-Protein markiert. Die geringe spezifische Radioaktivität des DNPA verhinderte einen Nachweis eines Nitrat-Transporters.

6. Aus einem Alignment der Aminosäure-Sequenzen verschiedener NitratTransporter codierender Gene wurden drei hochkonservierte Regionen ausgewählt und dazu homologe Peptide synthetisiert. Mit diesen Peptiden 
wurden drei Kaninchen zur Gewinnung eines Antiserums immunisiert. Nur ein Antiserum markierte Plasmamembran-Proteine von 17 und $64 \mathrm{kDa}$. Hinweise auf einen spezifisch detektierten Nitrat-Transporter lagen nicht vor. Mit einem Antiserum gegen einen Nitrat-Transporter in Hordeum vulgare wurden Plasmamembran-Proteine der Molekulargewichte 67; 64; 59; 55; 48; 43, 41, $22 \mathrm{kDa}$ detektiert. Plasmamembran-Proteine, die nach NitratInduktion eine Konzentrationszunahme zeigten, waren ausschließlich in der wässrigen Phase des TritonX114-Systems angereichert.

7. Durch eine präparative 2D-SDS-PAGE wurden Plasmamembran-Proteine angereichert und ansequenziert. Ein 32,8 kDa-Protein der TritonX114Detergenz-Phase zeigte hohe Homologie zu einem Porin aus Pseudomonas fluorescens.

8. Nach RT-PCR einer mit Nitrat-induzierten Transkripten angereicherten mRNA wurde eine PCR mit degenerierten, Nitrat-Transporter-spezifischen Primern durchgeführt. Amplifizierte Basensequenzen hatten Homologien zu folgenden Proteinen: Hitzeschock-Protein; putative RNA-Helicase A; Extensin-artiges Protein; putative Ser-/Thr-Kinase.

\section{AUSBLICK}

Das primäre Ziel der vorliegenden Untersuchung, die Identifikation und Ansequenzierung eines Nitrat-Transportes in der Plasmamembran von Chlorella saccharophila durch proteinbiochemische und molekularbiologische Techniken, wurde nicht erreicht. Die Gründe dafür liegen in den erheblichen Schwierigkeiten, die hydrophobe Plasmamembran-Proteine in der zweidimensionalen Gelelektrophorese bereiten, daneben auch im Fehlen eines spezifischen, funktionellen oder immunologischen Nachweises des NitratTransporterproteins. Die erstmalige Identifizierung eines Nitrat-Transporter codierenden Gens durch Unkles et al. (1991) liegt bereits mehr als zehn Jahre zurück. Bis heute ist aber trotz der hohen Zahl der mittlerweile bekannten, Nitrat-Transporter codierenden Gene (Übersicht in Galvan und Fernandez, 2001) keine Proteinbiochemische Charakterisierung des isolierten Proteins veröffentlicht. Die mit dem Nachweis des Nitrat-Transporterproteins verbundenen Schwierigkeiten und Limitierungen sind in vorliegender Untersuchung deutlich geworden. Die gewonnenen Kenntnisse schufen aber eine Reihe von methodischen Grundlagen zur vergleichenden Untersuchung und teilweise präparativen Darstellung von Plasmamembran-Proteinen. Die vorliegend etablierte, hochauflösende zweidimensionale Gelelektrophorese (2D-SDS-PAGE) hat sich als geeignetes Werkzeug zur Auftrennung auch hydrophober Plasmamembran-Proteine erwiesen. Mehrere der nachgewiesenen Proteine sind sehr wahrscheinlich NitrattransporterPolypeptide. Isoelektrischer Punkt, Molekulargericht, Nitrat-induzierte Protein de novo-Synthese und Hydrophobizität deuten auf einen induzierbaren NitratTransporter in Chlorella saccharophila hin. Die geringe Häufigkeit in der Plasmamembran reichte zu einer Ansequenzierung jedoch noch nicht aus. Hinweise auf Extensin-artige Proteine als Zellwand-Bestandteile von Chlorella saccharophila liegen erstmals vor; ebenso auf ein ansequenziertes Porin als 
Kanalprotein in der Plasmamembran. Wie am Beispiel der PM-NR nachgewiesen, erlaubt die 2D-SDS-PAGE Aussagen zu einer unterschiedlichen Regulation einzelner Polypeptide, auch in einem Set von ProteinAbbauprodukten. Die vorliegend erarbeiteten Verfahren sind auch für cytoplasmatische Proteine adaptierbar; bestehende Opimierungsmöglichkeiten wurden deutlich gemacht.

Die Kombination von 2D-SDS-PAGE mit einer BAC-SDS-PAGE zur Solubilisierung auch sehr hydrophober PM-Proteine sollte zur vollständigen Erfassung aller Plasmamembran-Proteine etabliert werden. Intrinsische Proteine wie z. B. der Nitrat-Transporter stehen dabei im Vordergrund; gerade die schlechte Löslichkeit dieser Proteine bietet sich zu ihrer Anreicherung an. Ein Vergleich von ${ }^{35}$ S-Methionin-markierten, Nitrat-induzierbaren Proteinen mit ${ }^{32}$ P-ATP-phosphorylierten Proteinen in der 2D-SDS-PAGE sollte einen besseren Einblick in die durch Nitrat ausgelösten Prozesse an der Plasmamembran geben. Nitrat-induzierte, Kinase/Phosphatase-vermittelte Signaltransduktionsprozesse sollten auf diese Weise untersucht werden, beteiligte Proteine sind durch die Radioaktivität mit hoher Sensitivität nachzuweisen und sollten ansequenziert werden können. Die auch für den Nitrat-Transporter vermutete Regulation durch den Phosphorylierungsstatus (Orsel et al., 2002) könnte als weiteres Kriterium zu seiner Identifikation herangezogen werden. Eine leistungsfähige 2D-Analysesoftware sollte zur qualitativen und quantitativen Auswertung zur Verfügung stehen. Zur molekularbiologischen Identifikation des Nitrat-Transporters sollte eine cDNAlibrary von Chlorella saccharophila angelegt werden. Die Suche könnte dann mit einer gegenüber PCR-Primern erheblich längeren, heterologen NitratTransporter-Sonde unter gering stringenten Bedingungen durchgeführt werden.

Die zweidimensionale gelelektrophoretische Proteintrennung erlaubt die Erfassung von post-translationalen Modifikationen; Protein-Isoformen, Neusynthese und Degradation zeigen gegenüber der molekularen Genetik den in vivo-Zustand der codierten Proteine. Die 2D-SDS-PAGE ist somit ein nicht substituierbares Gegenstück zur molekularen Genetik. Die Verbindung von hochauflösender Protein-2D-SDS-Gelelektrophorese mit dem Screening genomischer Microarray-cDNA-Banken läßt eine Fülle von neuen Einblicken in das Auftreten und die Regulation von Plasmamembran-Proteinen und die von innen vermittelten Prozesse erwarten. 


\section{LITERATURVERZEICHNIS}

Adessi C, Miege C, Albrieux C, Rabilloud T (1997) Two-dimensional electrophoresis of membrane proteins: A current challenge for immobilized pH gradients. Electrophoresis 18: 127-135.

Ageorges A, Morel MH, GRouzIS JP (1996) High resolution 2-D electrophoresis of polypeptides of maize root plasma membrane: Identification of polypeptides whose expression is regulated by nitrate. Plant Physiol Bioch 34(6): 863-870.

ALTSCHUL SF, ERICKSON BW (1985) Significance of nucleotide sequence alignments: a method for random sequence permutation that preserves dinucleotide and codon usage. Mol Biol Evol 2: 526-538.

Amarasinghe BH, de-Bruxelles GL, Braddon M, Onyeocha I, Forde BG, UDVARDI MK (1998) Regulation of GmNRT2 expression and nitrate transport activity in roots of soybean (Glycine max). Planta 206: 44-52

ANTOS N, BUDZINSKA M, KMITA H (2001) An interplay between the TOM complex and porin isoforms in the yeast Saccharomyces cerevisiae mitochondria. FEBS Lett 500: 12-16

Aparicio PJ, Witt FG, Ramirez JM, QUinones MA ANd BaLANDIN T (1994). Blue-light induced $\mathrm{pH}$ changes associated with $\mathrm{NO}_{3}{ }^{-}, \mathrm{NO}_{2}{ }^{-}$and $\mathrm{Cl}^{-}$uptake by the green alga Monoraphidium braunii. Plant Cell Environ 17: 13231330 .

ARSENIJEVIC MI, BRoughton WJ, KRAUSE A (1997) Rhizobia modulate roothair-specific expression of extensin genes. Mol Plant-Microbe Interactions 10: $95-101$

Aslam M, Travis RL and Huffaker RC (1992). Comparative kinetics and reciprocal inhibition of nitrate and nitrite uptake in roots of uninduced and induced barley (Hordeum vulgare L.) seedlings. Plant Physiol 99: 11241133

Aslam, M, Travis, R. L. And HuffakeR, R. C. (1993). Comparative induction of nitrate and nitrite uptake and reduction systems by arnbient nitrate and nitrite in intact roots of barley (Hordeum vulgare L.) seedlings. Plant Physiol 102: 811-819

AVILA J, PeREZ MD, BRIto N, GonZAlez C AND Siverio JM (1995) Cloning and disruption of the YNR1 gene encoding the nitrate reductase apoenzyme of the yeast Hansenula polymorpha. FEBS Lett 366: 137-142

Avila J, Gonzalez C, Brito N, Machin MF, Perez D, Siverio JM (2002) A second $\mathrm{Zn}(\mathrm{II})(2)$ Cys(6) transcriptional factor encoded by the YNA2 gene is indispensable for the transcriptional activation of the genes involved in nitrate assimilation in the yeast Hansenula polymorpha. Yeast 19: 537-544 
AVILA J, GonZALEZ C, BRITO N, SiVERIO JM (1998) Clustering of the YNA1 gene encoding a $\mathrm{Zn}(\mathrm{II}) 2 \mathrm{Cys} 6$ transcriptional factor in the yeast Hansenula polymorpha with the nitrate assimilation genes YNT1, YNI1 and YNR1, and its involvement in their transcriptional activation. Biochem J. 335: 64752

BARBER MJ, DESAI SK, MAROHNIC CC (2001) Assimilatory nitrate reductase: Lysine 741 participates in pyridine nucleotide binding via charge complementarity. Arch Biochem Biophys 394: 99-110

Baudouin E, Charpenteau M, Ranjeva R, Ranty B (2002) A 45-kDa protein kinase related to mitogen-activated protein kinase is activated in tobacco cells treated with a phorbol ester. Planta 214: 400-405

BLUM H, BEIER H, GRoss HJ (1987) Improved silver staining of plant proteins, RNA and DNA in polyacrylamide gels. Electrophoresis 8: 93-99

Bosch M, KNudsen JS, DeRksen J, MARIANI C (2001) Class III pistil-specific extensin-like proteins from tobacco have characteristics of arabinogalactan proteins. Plant Physiol 125: 2180-2188

BRADFORD MM (1976) A rapid sensitive method for the quantification of microgram quantities of protein utilizing the principle of protein-dye binding. Analytical Biochemistry 72: 248-254

BRENNER W (1998) Lichtinduzierte Änderungen des Phosphorylierungsstatus von plasmamembranassoziierten Proteinen in Chlorella saccharophila: Ereignisse in der Signaltransduktion zur Regulation des Stickstoffmetabolismus. Diplomarbeit Universität Göttingen

BriLl JA, HIME G, SchARER-Schuksz M, FULLER MT (2000) A phospholipid kinase regulates actin organization and intercellular bridge formation during germline cytokinesis. Development 127: 3855-3864

CAMPBELl WH UND SMARELLI J (1986) Nitrate reductase: Biochemistry and regulation. Biochemical basis of plant breeding, Vol. II. Ed. E. Neyra, C.A.

CANNONS AC, CANNON J (2002) The stability of the Chlorella nitrate reductase mRNA is determined by the secondary structure of the 5'-UTR: Implications for posttranscriptional regulation of nitrate reductase. Planta 214: 488-491

CANNONS AC, SHIFLETT SD (2001) Transcriptional regulation of the nitrate reductase gene in Chlorella vulgaris: Identification of regulatory elements controlling expression. Curr Genetics 40: 128-135

Cavicchioli R, Chlang RC, Kalman LV and Gunsalus RP (1996). Role of the periplasmic domain of the Escherichia coli NarX sensor-Transmitter protein in nitrate-dependent signal transduction and gene regulation. Mol Microbiol 21: 901-911 
Chevalier J, Mallea M, Pages JM (2000) Comparative aspects of the diffusion of norfloxacin, cefepime and spermine through the $F$ porin channel of Enterobacter cloacae. Biochem J 348: 223-227.

Chrispeels mu, holuigue L, latorre R, luan S, Orellana A, Pena-Cortes H, RaikHel NV, Ronald PC, TRewavas A (1999) Signal transduction networks and the biology of plant cells. Biol Res 32: 35-60

Chu YM, JeON JJ, YeA S, KIM YH, Yun SH, LEe YW, KIM KH (2002) Doublestranded RNA mycovirus from Fusarium graminearum. Appl Environ Microbiol 68: 2529-2534

CLARKSON DT (1986) Regulation of the absorption and release of nitrate by plant cells: a review of current ideas and methodology. In Fundamental, Ecological and Agriculural Aspects of Nitrogen Metabolism in Higher Plants (H. Lambers, J. J. Neeteson and 1. Stulen, eds.), pp. 3-27. Martinus Nijhoff, Dordrecht

Cock JM, KIM KD, MiLler PW, Hutson RG, Schmidt RR (1991) A nuclear gene with many introns encoding ammonium-inducible chloroplastic NADP-specific glutamate dehydrogenase(s) in Chlorella sorokiniana. Plant Mol Biol 17: 1023-1044

Corpas FJ, Sandalio LM, BRown MJ, DEL-RIO LA, TRELEASE RN (2000) Identification of porin-like polypeptide(s) in the boundary membrane of oilseed glyoxysomes. Plant Cell Phys 41: 1218-1228

CRAWFORD NM (1995) Nitrate: Nutrient and Signal for Plant Growth. Plant Cell 7: 859-868

CRAWFORD NM, GLASS ADM (1998) Molecular and physiological aspects of nitrate uptake in plants. Trends in Plant Science 3: 389-395

DANiEL-Vedele F AND CABOCHE M. (1996) Molecular analysis of nitrate assilation in higher plants. Comptes Rendus de l'Academie des Sciences Serie III.- Sciences de la Vie 319: 961-968

Daniel-Vedele F, Filleur S And Caboche M (1998) Nitrate Transport: a key step in nitrate assimilation. Curr Plant Biol 1: 235-239.

De E, Basle A, Jaquinod M, Saint N, Mallea M, Molle G, Pages JM (2001) A new mechanism of antibiotic resistance in Enterobacteriaceae induced by a structural modification of the major porin. Mol Microbiol 41: 189-198

DHUGga KS, WAINES JG AND LEONARD RT (1988). Correlated induction of nitrate uptake and membrane polypeptides in corn roots. Plant Physiol 87: 120-125

DORMAN G (2001) Photoaffinity labeling in biological signal transduction. Bioorganic Chemistry of biological signal transduction 211: 169-225 
DUNBAR BS, KIMmURA H, TIMmONS TM (1990) Protein analysis using high resolution two dimensional polyacrylamid gel electrophoresis. Methods Enzymol 182: 441-459

Ebel J, Mithoefer A (1998) Early events in the elicitation of plant defence. Planta 206: 335-348

Elzenga JTM, StAal M, PRINS-Hidde BA (2000) Modulation by phytochrome of the blue light-induced extracellular acidification by leaf epidermal cells of pea (Pisum sativum L.): A kinetic analysis. Plant J 22: 377-389

FilleuR S, DANiel-Vedele F (1999) Expression analysis of a high-affinity nitrate transporter isolated from Arabidopsis thaliana by differential display. Planta 207: 461-469

FINDLAY J. B. C. UND EVANS W. H. (1987) Biological membranes: a practical approach. IRL press Oxford Washington

FINEAN JB, MICHELL RH (1981) Isolation, composition and general structure of membranes. North Holland Biomedical Press, Elsevier

FINNIE C, BORCH J, COLLINGE DB (2000) 14-3-3 proteins: Eukaryotic regulatory proteins with many functions. Plant Mol Biol 40: 545-554

FLORENCIO FJ AND VEGA JM (1982) Regulation of the assimilation of nitrate in Chlamydomonas reinhardii. Phytochemistry 21: 1195-1200

Fontaine JM, Rousvoal S, Delaroque N, Loiseaux-De Goer S (1995) Characterization of the cox3, nad7 and atp6 genes from the mitochondrial genome of the grown alga Pylaiella littoralis. Plant Physiol Biochem 33: 605-609

FORDE BG (2000) Nitrate transporters in plants: structure, function and regulation. Biochim Biophys Acta 1465: 219-235

FORDE BG UND CLARKSON DT (1999) Nitrate and ammonium nutrition of plants: Physiological and molecular perspectives. Advances in Botanical Research 30: 1-90

Frangne N, Maeshima M, Schaffner AR, Mandel T, Martinoia E, Bonnemain $\mathrm{JL}$ (2001) Expression and distribution of a vaculoar aquaporin in young and mature leaf tissues of Brassica napus in relation to water fluxes. Planta 212: $270-8$

Frommer WB, Hummel S, Rentsch D (1994) Cloning of an Arabidopsis histidine transporting protein related to nitrate and peptide transporters. FEBS-Lett 347: 185-9

GALLING G (1963) Analyse des Magnesium-Mangels bei synchronisierten Chlorellen. Arch Microbiol 46: 150-184 
Galvan A UND FERNANDEZ E (2001) Eukraryotic nitrate and nitrite transporters. Cell Mol Life Sci 58: 225-233

Galvan A, Quesada A, Fernandez E (1996) Nitrate and nitrate are transported by different specific transport systems and by a bispecific transporter in Chlamydomonas reinhardtii. J Biol Chem. 271: 2088-92

Gamble RL, Qu X, SchalleR GE (2002) Mutational analysis of the ethylene receptor ETR1. Role of the histidine kinase domain in dominant ethylene insensitivity. Plant Physiol 128: 1428-1438

Gazzarrini S, Lejay L, Gojon A, Ninnemann O, Frommer WB, von-Wiren N (1999) Three functional transporters for constitutive, diurnally regulated, and starvation-induced uptake of ammonium into Arabidopsis roots. Plant Cell 11: 937-947

GLASS ADM AND SIDDIQI MY (1995). Nitrogen absorption by plant roots. In "Nitrogen nutrition in higher plants" (H. S. Srivastava and R. P. Singh, eds.), pp. 21-56. Associated Publishing Co., New Delhi

GLASS ADM, SIDDIQI MY, RUTH TJ AND RUFTY TW (1990). Studies of the uptake of nitrate in barley. II. Energetics. Plant Physiol 93: 1585-1589

GLOGAU U (1994) Untersuchung und Charakterisierung der Nitrataufnahme von Chlorella saccharophila. Diplomarbeit. Universität Göttingen

Goff AK, YANG Z, CORTVRIndt R, SMitz J, MiRon P (2001) Protein synthesis during maturation of bovine oocytes, effect of epidermal growth factor. Reproduction in Domestic Animals 36: 19-24

Golby P, Davies S, Kelly DJ, Guest JR, AndReWs SC (1999) Identification and characterization of a two-component sensor-kinase and responseregulator system (DcuS-DcuR) controlling gene expression in response to C-4-dicarboxylates in Escherichia coli. J Bacteriol 181: 1238-1248

Görg A, Obermaier C, Boguth G, Harder A, Scheibe B, Wildgruber R, WEISS W (2001) The current state of Two-dimensional Electrophoresis with immobilized $\mathrm{pH}$ Gradients. Review. TU Weihenstephan. www.weihenstephan.de

GÖRg A, POstel W, GÜNTHER S (1988) The current state of Two-dimensional Electrophoresis with immobilized pH Gradients. Electrophoresis 9: 531546

GouIn E, Segain JP, SAI P (1996) Proteins spontaneously released by rat insulinoma (RIN) cells are anchored on cell membrane by a glycosylphosphatidyl-inositol link and inhibit increased RIN cell adhesion of lymphocytes from type 1 diabetic patients and non-obese diabetic mice in vitro. Diabetes \& Metabolism 22: 439-450 
GOYAL SS AND HUfFAKER RC (1986). The uptake of NO3-, NO2- and NH4+ by intact wheat (Triticum aestivum) seedlings. I. Induction and kinetics of Transport systems. Plant Physiol 82: 1051-1056

GRAY NK, COLLER JM, DiCKSON KS, WiCKENS M (2000) Multiple portions of poly(A)-binding protein stimulate translation in vivo. EMBO J. 19: 47234733

Guo FQ, WANG R, CRAWFORD NM (2002) The Arabidopsis dual-affinity nitrate transporter gene AtNRT1.1 (CHL1) is regulated by auxin in both shoots and roots. J Exp Bot 53: 835-44

HAKMAN I, OLIVIUSSON P (2002) High expression of putative aquaporin genes in cells with transporting and nutritive functions during seed development in Norway spruce (Picea abies). J Exp Bot. 53: 639-649

hao Z, Wolkowicz MJ, Shetty J, Klotz K, Bolling L, Sen B, Westbrook VA, COONROD S, FLICKINGER CJ, HERR JC (2002) SAMP32, a testis-specific, isoantigenic sperm acrosomal membrane-associated protein. Biol Reprod. 66: $735-44$

HARTINGER J, Stenius K, Hogemann D, JAHN R (1996) 16-BAC/SDS-PAGE: A two-dimensional gel electrophoresis system suitable for the separation of integral membrane proteins. Anal Biochem 240: 126-133

Helliwell CA, Chin-Atkins AN, Wilson IW, Chapple R, Dennis es, Chaudhury A (2001) The Arabidopsis AMP1 gene encodes a putative glutamate carboxypeptidase. Plant Cell 13: 2115-2125

HERBERT B (1999) Advances in protein solubilisation for two-dimensional Electrophoresis. Electrophoresis 20: 660-663

HILDEBRAND M AND DAHLIN K (1999) Cloning of nitrate transporter genes from the marine diatom Cylindrotheca fusiformis: Control of expression by nitrogen source and during the cell cycle. In Swiss-Prot Datenbank

Hill K, Hemmler R, Kovermann P, Calenberg M, Kreimer G, Wagner R (2000) A Ca2+- and voltage-modulated flagellar ion channel is a component of the mechanoshock response in the unicellular green alga Spermatozopsis similis. Biochim Biophys Acta 1466: 187

HO SL, ChaO YC, TONG WF, YU SM (2001) Sugar coordinately and differentially regulates growth- and stress-related gene expression via a complex signal transduction network and multiple control mechanisms. Plant Physiol 125: 877-890

HoA NT, BRANNIGAN JA, CUtTING SM (2002) The Bacillus subtilis signaling protein SpolVB defines a new family of serine peptidases. J Bacteriology 184: 191-199 
HofF T, TRUONG HN AND CABOChE M (1994). The use of mutants and transgenic plants to study nitrate assimilation. Plant Cell Environ 17: 489506

Hole DJ, EmRAN AM, FARES Y. AND DRE MC (1990) Induction of nitrate Transport in maize roots, and kinetics of influx, measured with $13 \mathrm{~N}$. Plant Physiol 93: 642-647

Hu VW, HeIKKA DS, DIEFFENBACH PB, HA L, (2001) Metabolic radiolabeling: Experimental tool or Trojan horse? 35S-Methionine induces DNA fragmentation and p53-dependent ROS production. FASEB J 15: 15621568

HuANg NC, ChIANG CS, CRAWFord NM, TSAY YF (1996) CHL1 encodes a component of the low-affinity nitrate uptake system in Arabidopsis and shows cell type-specific expression in roots. Plant Cell 8: 2183-91

huss Var, Frank C, hartmann EC, Hirmer M, Kloboucek A, Seidel BM, WENZELER P, KESSLER E (1999) Biochemical taxonomy and molecular phylogeny of the genus Chlorella sensu lato (Chlorophyta).J Phycology 35: 587-598

IBELGAUfTS H (1990) Gentechnologie von A-Z. Weinheim, VCH

Ito Y, BanNo H, MoRiBe T, HinATA K, MAChIDA Y (1994) TI: NPK15, a tobacco protein-serine/threonine kinase with a single hydrophobic region near the amino-terminus. Molecular \& General Genetics 245: 1-10

JoY KW (1988) Ammonia, glutamate and asparagine: a carbon-nitrogeninterface. Can J Bot 66: 2103-2109

KAISER WM, HUBER SC (2001) Post-translational regulation of nitrate reductase: Mechanism, physiological relevance and environmental triggers. J Exp Bot 52: 1981-1989

KARLIN S, ALTSCHUL SF(1990) Methods for assessing the statistical significance of molecular sequence features by using general scoring schemes. Proc Natl Acad Sci USA 87:2264-2268

Kemner JM, LiAng X, Nester EW (1997) The Agrobacterium tumefaciens virulence gene chvE is part of a putative $A B C$-type sugar transport operon. J Bacteriology 179: 2452-2458

KLERK H, VAN-LOON LC (1997) Characteristics of protein turnover in the developing first leaf of oats (Avena sativa L.). Plant Physiol 151: 176-187

KLobus G, JeRZYKIEWICZ J, BuCZEK J (1998) Characterization of the nitrate transporter in root plasma membranes of Cucumis sativus L. Acta Physiologiae Plantarum. 20: 323-328 
KoBAYASHI M, RODRIgUEZ R, LARA C, OMATA T (1997) Involvement of the Cterminal domain of an ATP-binding subunit in the regulation of the ABCtype nitrate/nitrite transporter of the cyanobacterium Synechococcus sp. strain PCC 7942. J Biol Chem 272: 27197-27201

KocH KE (1996) Carbohydrate-modulated gene expression in plants. Plant Mol Biol 47: 509-540

Krapp A, Fraisier V, Scheible WF, Quesada A, Gojon A, Stitt M, Caboche M AND DANIELVEDELE F (1998). Expression studies of Nrt2:1Np, a putative high-affinity nitrate transporter: evidence to its role in nitrate uptake. Plant J 14: 723-731

Krimmer T, Rapaport D, RyAn MT, Meisinger C, KASSENBROCK CK, BLACHLYDyson E, Forte M, Douglas MG, Neupert W, Nargang FE, Pfanner N (2001) Biogenesis of porin of the outer mitochondrial membrane involves an import pathway via receptors and the general import pore of the TOM complex. J Cell Biology 152: 289-300

KUHL A. (1962) Zur Physiologie und Speicherung kondensierter anorganischer Phosphate in Chlorella. Vortr Ges Geb Bot, N.F., 1: 157-166

Kunze M, Riedel J, LANGe U, HuRWitz R, Tischner R (1997) Evidence for the presence of GPI-anchored PM-NR in leaves of Beta vulgaris and for PMNR in barley leaves. Plant Physiol Biochem 35: 507-512

Lam HM, Coschigano KT, Oliveira IC, Melo-Oliveira R and Coruzzi GM (1996) The molecular genetics of nitrogen assimilation into amino acids in higher plants. Annual Review of Plant Physiology and Plant Molecular Biology 47: 569-593

LÄMMLI UK (1970) Cleavage of structural proteins during assembly of the of bacteriophage t4. Nature 227: 680-685

Langhans M, RatajCZak R, LutZelschwab M, Michalke W, Wachter R, FISCHER-SCHLIEBS E, ULLRICH Cl (2001) Immunolocalization of plasmamembrane $\mathrm{H}+$-ATPase and tonoplast-type pyrophosphatase in the plasma membrane of the sieve element-companion cell complex in the stem of Ricinus communis L. Planta 213: 11-19

LARSSON C (1985) Plasma membranes. In Linskens HF und Jackson JF: Modern methods of plant analysis. Vol. 1, Cell components, Springer Verlag Berlin

Lee EH, Collatz E, Podglajen I, Gutmann L (1996) A rob-like gene of Enterobacter cloacae affecting porin synthesis and susceptibility to multiple antibiotics. Antimicrobial Agents and Chemotherapy 40: 20292033 
Lee NS, Dohjima T, Bauer G, Li H, LI M, Ehsani A, Salvaterra P, Rossi J (2002) Expression of small interfering RNAs targeted against HIV-1 rev transcripts in human cells. Nature Biotechnology 20: 500-505

LILLO C, APPENROTH KJ (2001) Light regulation of nitrate reductase in higher plants: Which photoreceptors are involved? Plant Biology 3: 455-465

Lim D, Hains P, Walsh B, Bergquist P, Nevalainen H (2001) TI: Proteins associated with the cell envelope of Trichoderma reesei: $A$ proteomic approach. Proteomics 1: 899-910

LIN CM, KoH S, Stacey G, Yu SM, LIN TY, TSAY YF (2000) Cloning and functional characterization of a constitutively expressed nitrate transporter gene, OsNRT1, from rice. Plant Physiol 122: 379-88

LIU KH, HUANG CY, TSAY YF (1999) CHL1 is a dual-affinity nitrate transporter of Arabidopsis involved in multiple phases of nitrate uptake. Plant Cell 11: 865-74

LOGEMANN J, SCHELL J, WILLMITZER L (1987) Improved method for isolation of RNA from plant tissues. Anal Bioch 163: 16-20

Lopez MF, Berggren K, Chernokalskaya E, Lazarev A, Robinson M, Patton WF (2000) A comparison of silver stain and SYPRO Ruby Protein Gel Stain with respect to protein detection in two-dimensional gels and identification by peptide mass profiling. Electrophoresis 21: 3673-3683

Machin F, Perdomo G, Perez MD, Brito N, Siverio JM (2001) Evidence for multiple nitrate uptake systems in the yeast Hansenula polymorpha. FEMS Microbiol Lett 194: 171-174

Maeda S, Okamura M, Kobayashi M, Omata T (1998) Nitrite-specific active transport system of the cyanobacterium Synechococcus sp. strain PCC 7942. J Bacteriol. 180: 6761-6773

MAGNUSSON G, LARSSON C, AXELSSON L (1996) Effects of high CO-2 treatment on nitrate and ammonium uptake by Ulva lactuca grown in different nutrient regimes. Scientia Marina 60 (Suppl 1): 179-189

Maki S, Ohta Y, Noutoshi Y, FuJie M, Usami S, Yamada T (2000) TI: Mapping of cDNA clones on contig of Chlorella chromosome I. Journal of Bioscience and Bioengineering 90: 431-436

MARSCHNER, M. (1995) Mineral nutrition of higher plants. $2^{\text {nd }}$ Ed. London Academic Press

MAsson F, Rossignol M (1995) Basic plasticity of protein expression in tobacco leaf plasma membrane. Plant J 8: 77-85 
MÄTSCHKE M, RIEDEL J, TISCHNER R (1997) Evidence for Signal Transduction in the stimulation of Nitrate uptake by Blue light for chlorella saccharophila. Photochemistry and Photobiology 66: 128-132

McCluRE PR, Kochian LV, SPANSWICK RM UND SHAFF JE (199) Evidence für cotransport of nitrate and protons in maize roots. I effects of nitrate on the membrane potential. Plant Physiol 93: 281-289

McClure PR, Omholt TE, Pace GM and Bouthyette Py (1987) Nitrate induced changes in protein synthesis and translation of RNA in maize roots. Plant Physiol 84: 52-57

MilleR AJ, ZhOU JJ (2000) Xenopus oocytes as an expression system for plant transporters. Biochim Biophys Acta 1465: 343-58

MISTRIK I AND ULLRICH CI (1996). Mechanism of anion uptake in plant roots. Quantitative evaluation of $\mathrm{H}+/ \mathrm{NO} 3-$ and $\mathrm{H}+/ \mathrm{H} 2 \mathrm{P} 04$ stoichiometries. Plant Physiology and Biochemistry 34: 629-636

Monteiro RA, de-Souza EM, Wassem R, Yates MG, Pedrosa Fo, Chubatsu LS (2001) Inter-domain cross-talk controls the NifA protein activity of Herbaspirillum seropedicae. FEBS L 508: 1-4

Nakamura Y, Sato $\mathrm{S}$, Asamizu E, Kaneko T, Kotani H, Miyajima N and Tabata $S$ (1998) Structural analysis of Arabidopsis thaliana chromosome 5. VII. DNA Res 5: 297-308

Navarro Mt, Prieto R, Fernandez E and Galvan A (1996) Constitutive expression of nitrate reductase changes the regulation of nitrate and nitrite transporters in Chlamydomonas reinhardtii. Plant J 9: 819-827

Neuhoff V, Stamm R, EIBL H (1985) Clear background and highly sensitive protein staining with Coomassie Blue dyes in polyacrylamide gels: $A$ systematic analysis. Electrophoresis 6: 427-448

NI M AND BEEVERS L (1994). Nitrate induced polypeptides in membranes from com seedling roots. J Exp Bot 45: 355-365

Norbeck J, Blomberg A (1996) Protein expression during exponential growth in $0.7 \mathrm{M} \mathrm{NaCl}$ medium of Saccharomyces cerevisiae. FEMS Microbiol Lett 137: $1-8$

O'FARELL PH (1975) High resulation two-dimensional electrophoresis of proteins. J Biol Chem 250: 4007-4021

OMATA,-T (1995) Structure, function and regulation of the nitrate transport system of the cyanobacterium Synechococcus sp. PCC7942. Plant Cell Physiol. 36: 207-13 
ONO F, FROMMER WB AND VON WIREN N (1998) Transcriptional regulation of putative high-affinity nitrate transporters in tomato. In Swiss-Prot Datenbank

Orsel M, Filleur S, Fraisier V, Daniel-Vedele F (2002) Nitrate transport in plants: which gene and which control? J Exp Bot 53: 825-33

OTTE O, BARZ W (2000) TI: Characterization and oxidative in vitro cross-linking of an extensin-like protein and a proline-rich protein purified from chickpea cell walls. Phytochemistry 53: 1-5

Palmgren MG, Askerlund P, Fredrikson K, Widell S. (1990) Sealed insideout and right-side-out plasma membrane vesicles. Plant Physiol 92: 871880

PARK SM, BONG CB (2002) Class I small heat-shock protein gives thermotolerance in tobacco. Plant Physiol 159: 25-30

PATTON WF (2000) Making blind robots see: The synergy between fluorescent dyes and imaging devices in automated proteomics. Biotechniques 28 (5): 944-957

PATTON WF (2002) Detection technologies in proteome analysis. Journal of Chromatography 771 : 3-31

Perrone-Bizzozero NI, Weiner D, Hauser G, Benowitz LI (1988) Extraction of major acidic $\mathrm{Ca} 2+$ dependent phosphoproteins from synaptic membranes. J Neurosci Res 20: 346-50

Peuke, A. D. AND Kaiser, W. M. (1996). Nitrate or ammonium uptake and Transport, and rapid regulation of nitrate reduction in higher plants. In "Progress in Botany", vol. 57 (H.-D. Behnke, U. Luettge, K. Esser, J. W. Kadereit and R. M., eds.), pp. 93-113. Springer Verlag, Berlin.

PISTORIUS EK, FUNKHOUSER EA AND Voss H (1978) Effect of ammonium and ferricyanide on nitrate utilization by Chlorella vulgaris. Planta 141: 279-282

POA SS, PAULSEN IT UND SAIER MH (1998). Major facilitator superfamily. Microbiology and Molecular Biology Reviews 62: 1-34

PRYDE JG (1986) Triton X114: a detergent that has come in from the cold. TIBS 11: 160-163

PRYDE JG, PHILLIPS JH (1986) Fractionation of membrane proteins by temperature induced phase separation in Triton X114. Biochem J 233: 525-533

Pupillo P, Delgrosso E (1981) A possible plasma membrane particle containing malic enzyme activity. Planta 151: 506-511 
Quesada A, Galvan A AND Fernandez E (1994) Identification of nitrate transporter genes in Chlamydomonas reinhardtii. Plant J 5: 407-419

Quesada A, Hidalgo J and Fernandez E (1998). Three NRT2 genes are differentially regulated in Chlamydomonas reinhardtii. Mol Gen Genet 258: 373-377

Quesada A, Krapp A, Trueman LJ, Daniel-Vedele F, Fernandez E, Forde BG AND CABOCHE M (1997) PCR-identification of a Nicotiana plumbaginifolia cDNA homologous to the high-affinity nitrate transporters of the crnA family. Plant Mol Biol 34: 265-274

QuesAdA A. UND FERnANDEZ E. (1994) Expression of nitrate assiniilation related genes in Chlamydomonas reinhardtii. Plant Mol Biol 24: 185-194

Quesada A, Galvan A, Fernandez E (1994) Identification of nitrate transporter genes in Chlamydomonas reinhardtii. Plant J 5: 407-419

QuesadA A, Gomez I, Fernandez E (1998) Clustering of the nitrite reductase gene and a light-regulated gene with nitrate assimilation loci in Chlamydomonas reinhardtii. Planta 206: 259-65

Quesada A, Hidalgo J, Fernandez E (1998) Three Nrt2 genes are differentially regulated in Chlamydomonas reinhardtii. Mol Gen Genet 258: 373-377

Rabilloud T, Adessi C, Giraudel A, LunARd J (1997): Improvement of the solubilization of proteins in two-dimensional electrophoresis with immobilized $\mathrm{pH}$ gradients. Electrophoresis 18: 307-316

Rentsch D, Lalo M, Rouhara I, Schmelzer E, Delrot S, Frommer WB (1995) NTR1 encodes a high affinity oligopeptide transporter in Arabidopsis. FEBS-Lett 370: 264-8

REUMANN S (2000) The structural properties of plant peroxisomes and their metabolic significance. Biological Chemistry. August, 381: 639-648

Rexach J, Fernandez E, Galvan A (2000) The Chlamydomonas reinhardtii Nar1 gene encodes a chloroplast protein involved in nitrite transport. Plant Cell 12: 1441-1454

Richards B, Karpilow J, Dunn C, ZharkikH L, Maxfield A, Kamb A, Teng DHF (1999) Creation of a stable human reporter cell line suitable for FACSbased, transdominant genetic selection. Somatic Cell and Molecular Genetics 25: 191-205

Richards DP, Stathakis C, Polakowski R, Ahmadzadeh H, Dovichi NJ (1999a) Labeling effects on the isoelectric point of green fluorescent protein. Journal of Chromatography 853: 21-25 
RIGHETtI PG, GIANAZZA E, GelFI C, UND CHIARI M (1987) Isoelectric focusing. In Hames BD und Rickwood D (eds): Gel electrophoresis of proteins. A practical approach. IRL press, Oxford

Ringler P, Borgnia MJ, Stahlberg H, Maloney PC, Agre P, Engel A (1999) Structure of the water channel AqpZ from Escherichia coli revealed by electron crystallography. J Mol Biol. 291: 1181-1190

RODRIGUEZ R, KOBAYASHI M, OMATA T, LARA C (1998) Independence of carbon and nitrogen control in the posttranslational regulation of nitrate transport in the cyanobacterium Synechococcus sp. strain PCC 7942. FEBS Lett 432: $207-12$

Rouguie D, TOURnaire RC, SZPonarski W, Rossignol M, Doumas P (1998) Cloning of the V-ATPase subunit $G$ in plant: Function expression and subcellular localization. FEBS Lett 43: 287-292

SAKAMOTO T, INOUE-SAKAMOTO K AND BRYANT DA (1999) A novel nitrate/nitrite permease in the marine Cyanobacterium synechococcus sp. strain PCC 7002. J Bacteriol 181: 7363-7372

SAMBROOK J, FritSCH EF, MANIATIS T (1989) Molecular cloning. A laboratory manual. Cold Spring Harbour Press, USA

Sanchez NS, Pearce DA, Cardillo TS, Uribe S, Sherman F (2001) Requirements of Cyc2p and the porin, Por1p, for ionic stability and mitochondrial integrity in Saccharomyces cerevisiae. Arch Biochem Biophys 392: 326-332

Santoni V, Doumas P, Rouquie D, mansion M, Rabilloud T, Rossignol M (1999) Large scale characterization of plant plasma membrane proteins. Biochimie 81: 655-661

Santoni V, Kieffer S, Desclaux D, Masson F, Rabilloud T (2000) Membrane proteomics: use of additive main effects with multiplicative interaction model to classify plasma membrane proteins according to their solubility and electrophoretic properties. Electrophoresis 21: 3329-44

Santoni V, Rabilloud T, Doumas P, Rouquie D, Mansion M, Kieffer S, Garin J, ROSSIGNOL M (1999) Towards the recovery of hydrophobic proteins on two-dimensional electrophoresis gels. Electrophoresis 20: 705-11

Sargsyan E, Baryshev M, Szekely L, Sharipo A, Mkrtchian S (2002) Identification of ERp29, an endoplasmic reticulum lumenal protein, as a new member of the thyroglobulin folding complex. J Biol Chem 277: 17009-17015

Satta D, Schapira G, Chafey P, Righetti PG, Wahrmann JP (1984) Solubilization of plasma membranes in anionic, non-ionic and zwitterionic surfactants for iso-dalt analysis: a critical evaluation. Journal of Chromatography 299: 57-72 
Scheible WR., Gonzales FA., Lauerer M., Müller-Röber B., Caboche M., STITT M. (1997) Nitrate acts as a Signal to Induce Organic Acis Metabolism and Repress Starch Metabolism in Tobacco. Plant Cell 9: 783798

Scheible WR, Gonzalez-Fontes A, Morcuende R, Lauerer M, Geiger M, GLAAB J, Gojon A, SCHULZE ED, STITT M (1997) Tobacco mutants with a decreased number of functional nia genes compensate by modifying the diurnal regulation of transcription, post-translational modification and turnover of nitrate reductase. Planta 203: 304-319

SCHENK PW, SNAAR-JAGALSKA BE (1999) Signal perception and transduction: The role of protein kinases. Biochim Biophys Acta 1449: 1-24

SCHMITZ RA, KLOPPROGgE K, GRABBE R (2002) Regulation of nitrogen fixation in Klebsiella pneumoniae and Azotobacter vinelandii: NifL, transducing two environmental signals to the nif transcriptional activator NifA. J Mol Microbiol Biotech 4: 235-242

SCHRATTENHOLZ A (2001) Methoden der Proteomforschung. Spektrum Akademischer Verlag Heidelberg, Berlin

SHAPIRO AL, VINUELA E, MAIZEL JV (1967) Molecular weight estimation of polypeptide chains by electrophoresis in SDS-polyacrylamide gels. Biochem Biophys Res Commun 28: 815-820

SHEN H, LEE YK (1997) Thermotolerance induced by heat shock in Chlorella. Journal of Applied Phycology 9: 471-475

ShImAZAKI Y, OHARA S, MANABE T (1999) Protein spot recognition on the nondenaturing and denaturing two-dimensional electrophoresis patterns using in situ immunosubtraction via Protein $A$ agarose and antibodies. J Biochem Biophys Methods 39(3): 179-84

SKODA B (1997) Contributions to the biochemical taxonomy of the genus Chlorella Beijerinck s.I.-pigment composition. II. Biochemotaxonomical differences in pigment composition of the strains growing under nitrogen deficient nutritional conditions. Archiv für Hydrobiologie Supplement 122: 109-136

SONG B AND WARD BB (2002) Molecular Characterization of Nitrate Transporter and Ammonium Transporter from Marine Eukaryotic Diatoms. In SwissProt Datenbank

Sonoda M, Kitano K, Katoh A, Katoh H, OhKawa H, Ogawa T (1997) Size of cotA and identification of the gene product in Synechocystis sp. strain PCC6803. J Bacteriol 179: 3845-50 
SOPORY SK, MUNSHI M (1998) Protein kinases and phosphatases and their role in cellular signaling in plants. Critical Reviews in Plant Science 17: 245318

Steiner Hy, Song W, Zhang L, Naider F, Becker JM, Stacey g (1994) An Arabidopsis peptide transporter is a member of a new class of membrane transport proteins. Plant Cell 6: 1289-99

STEUDLE E (1997) Water transport across plant tissue: Role of water channels. Biology of the Cell 89: 259-273

STÖHR C (1988) Beitrag zur physiologischen und biochemischen Charakterisierung der Nitrataufnahme von Chlorella saccharophila (2111a) Diplomarbeit. Universität Göttingen

STÖHR C (1993) Reinigung, Charakterisierung und Untersuchungen zur Funktion der plasmamembrangebundenen Nitratreduktase von Chlorella saccharophila. Dissertation. Universität Göttingen

STÖHR C, TISCHNER R AND WARD MR (1993) Characterization of the plasma membrane bound nitrate reductase in Chlorella saccharophila (Kruger) Nadson. Planta 191: 79-85

StÖHR C, Glogau U, MÄTSChKE M, TISChneR R (1995) Evidence for the involvement of plasma-membrane-bound nitrate reductase in signal transduction during blue-light stimulation of nitrate uptake in Chlorella saccharophila. Planta 197: 613-618

STÖHR C, SCHULER F, TISCHNER R (1995a) Glycosyl-phosphatidylinositolanchored proteins exist in the plasma membrane of Chlorella saccharophila (Krueger) Nadson: Plasma-membrane-bound nitrate reductase as an example. Planta 196: 284-287

Stöhr C, Strube F, Marx G, Ullrich WR, Rockel P (2001) A plasma membrane-bound enzyme of tobacco roots catalyses the formation of nitric oxide from nitrite. Planta 212: 835-841

Stratford S, Barnes W, Hohorst DL, Sagert JG, Cotter R, GolubieWski A, SHOWALTER AM, McCoRmick S, BEDINGER P (2001) A leucine-rich repeat region is conserved in pollen extensin-like (Pex) proteins in monocots and dicots. Plant Mol Biol 46: 43-56

Sun W, Bernard C, van-de-Cotte B, Van-Montagu M, Verbruggen N (2001) Plant J 27: 407-415

SZCZECHOWICZ A, HRYNIEWIECKA L, KMITA H (2001) The influence of depletion of voltage dependent anion selective channel on protein import into the yeast Saccharomyces cerevisiae mitochondria. Acta Biochimica Polonica 48: 719-728 
TAKAHASHI M., SUGIURA M, (2001) Isolation of a cDNA coding for nitrite transporter of chloroplast envelope membranes of cucumber. In SwissProt Datenbank

TANAKA T (1998) Rice mRNA for high affinity nitrate transporter. In Swiss-Prot Datenbank

TAte JJ, Persinger J, BARtholomew B (1998) Survey of four different photoreactive moieties for DNA photoaffinity labeling of yeast RNA polymerase III transcription complexes. Nucleic Acids Research 26: 14211426

Ter-Steege MW, Stulen I, Wiersema PK, PaAns AJM, Vaalburg W, Kuiper PJC, CLARKSON DT (1998) Physiologia Plantarum 103 (2): 181-192

TISCHNER R (2000) Nitrate uptake and reduction in higher and lower plants. Plant, Cell and Environment 23: 1005-1024

Tischner R, Koltermann M and Hoffmann G (2001) Sequence and expression studies of the nitrate transporter from Chlorella sorokiniana. In Swiss-Prot Datenbank

TISCHNER R, WALDECK B, GOYAL SS AND RAINS WD (1993). Effect of nitrate pulses on the nitrate-uptake rate, synthesis of messenger RNA coding for nitrate reductase, and nitrate reductase activity in the roots of barley seedlings. Planta 189: 533-537

TISCHNER R, WARD MR, HUFFAKER RC (1989) Evidence for a plasmamembrane-bound nitrate reductase involved in nitrate uptake of Chlorella sorokiniana. Planta 178: 19-24

TOWBIN H, STAEHELIN T, GORDON J (1979) Electrophoretic transfer of proteins from polyacrylamide-gels to nitrocellulose sheets: Procedure and some applications. Proc Natl Acad Sci USA 76: 4350-4354

TRUEMAN LJ, RichaRdson A AND Forde BG(1996) Molecular cloning of higher plant homologues of the high-affinity nitrate transporters of

Chlamydomonas reinhardtii and Aspergillus nidulans. Gene 175: 223-231

TSAy YF, Schroeder JI, Feldmann KA, CraWford NM. (1993) The herbicide sensitivity gene $\mathrm{CHL} 1$ of Arabidopsis encodes a nitrate-inducible nitrate transporter. Cell 72: 705-13

TURCOTTE K, BUREAU T (2002) Phylogenetic analysis reveals Stowaway-like elements may represent a fourth family of the IS630-Tc1-mariner superfamily. Genome 45: 82-90

Tyerman SD, Niemietz CM, Bramley H (2002) Plant aquaporins: Multifunctional water and solute channels with expanding roles. Plant Cell and Environment 25: 173-194 
Unkles Se, HaWker KL, Grieve C, Campbell El, Montague P, Kinghorn JR (1991) crnA encodes a nitrate transporter in Aspergillus nidulans. Proc Nat Acad Sci USA 88: 204-208

UNKLES SE, ZHOU D., SIDDIQI MY, KINGHORN JR AND GLASS AD (2001) Apparent genetic redundancy facilitates ecological plasticity for nitrate transport. EMBO J 20: 6246-6255

VAN-DER-KnaAp E, Song WY, RuAn DL, Sauter M, Ronald PC, Kende H (1999) Expression of a gibberellin-induced leucine-rich repeat receptor-like protein kinase in deepwater rice and its interaction with kinase-associated protein phosphatase. Plant Physiol 120: 559-569

VAVRA J, MANAHAN DT (1999) Protein metabolism in lecithotrophic larvae (Gastropoda: Haliotis rufescens). Biological Bulletin, Woods Hole 196: 177-186

VESTERBERG O (1969) Synthesis and isoelectric fractionation of carrier ampholytes. Acta Chem Scand 15: 325-341

VIDMAR JJ, ZHUO D, SIDDIQI MS, SCHJOERRING JK, TOURAINE B AND GLASS ADM (1999) Regulation of the expression of two new members of the $\mathrm{BCH}$ family of genes, $\mathrm{BCH} 3$ and $\mathrm{BCH} 4$, which encode inducible high affinitynitrate transporters in Hordeum vulgare, with relation to nitrate influx. In Swiss-Prot Datenbank

WANG R, LIU D, CRAWFORD NM (1998) The Arabidopsis CHL1 protein plays a major role in high-affinity nitrate uptake. Proc Natl Acad Sci USA. 95: 15134-15139

Wang RC, Guegler K, LABrie ST, CRAWFord NM (2000) Genomic analysis of a nutrient response in arabidopsis reveals diverse expression patterns and novel metabolic and potential regulatory genes induced by nitrate. Plant Cell 12: 1491-1509

WANG YH, GARVIN DF, KochIAN LV (2001a) Nitrate-induced genes in tomato roots. Array analysis reveals novel genes that may play a role in nitrogen nutrition. Plant Physiol 127: 345-359

WANG ZY, Seto H, FuJIOKA S, YOShIDA S, ChORY J (2001) BRI1 is a critical component of a plasma-membrane receptor for plant steroids. Nature 410: 380-383

WEBER K, OSBORNE M (1969) The reliability of molecular weight determination by dodecyl sulfate polyacrylamide ge electrophoresis. J Biol Chem 224: 4406-4412

WEI W, TWELL D, LINDSEY K (1997) A novel nucleic acid helicase gene identified by promoter trapping in Arabidopsis. Plant J 11: 1307-1314 
Westbrook JA, YAN JX, WAIT R, DunN MJ (2001) A combined radiolabelling and silver staining technique for improved visualisation, localisation, and identification of proteins separated by two-dimensional gel electrophoresis. Proteomics 1: $370-376$

Whitelaw CA, Lyssenko NN, Chen L, Zhou D, MAtToo AK, TuCKer ML (2002) Delayed abscission and shorter internodes correlate with a reduction in the ethylene receptor LeETR1 transcript in transgenic tomato. Plant Physiol 128: $978-987$

Wienkoop S, Schlichting R, UllRich WR, StohR C (2001) Different diurnal cycles of expression of two nitrate reductase transcripts in tobacco roots. Protoplasma 217: 15-19

Wilkens S, DAHLQUist FW, McINTOSH LP, DONALDSON LW, CAPALDI RA (1999) Structural features of the epsilon subunit of the Escherichia coli ATP synthase determined by NMR spectroscopy. Nature Structural Biology 2: 961-967

WISSING J, HEIM S, FLOHE L, BILITEWSKI U, FRANK R (2000) Enrichment of hydrophobic proteins via Triton $\mathrm{X}-114$ phase partitioning and hydroxyapatite column chromatography for mass spectrometry. Electrophoresis 21: 2589-2593

Wössner JP, MolendiJk AJ, VAN-Egmond P, KLIS FM, GoOdenough UW, HARING MA (1994) Domain conservation in several volvocalean cell wall proteins. Plant Mol Biol 26: 947-960

XIAO W, SHEEN J, JAN JC (2000) The role of hexokinase in plant sugar signal transduction and growth and development. Plant Mol Biol 44: 451-461

YAMADA T UND SAKAGUCHI K (1982) Comparative studies on cell walls: Induction of protoplast formation. Arch Microbiol 132: 10-13

Yin LP, HuANg HM, Wen B, BaI YX, LIU XL, HuANG QN, QIU ZS (2000) cDNA Cloning of High Affinity Nitrate Transporter in Common Wheat. In SwissProt Datenbank

Yokoyama T, Kodama N, Aoshima H, IZU H, Matsushita K, Yamada M (2001) Cloning of a cDNA for a constitutive NRT1 transporter from soybean and comparison of gene expression of soybean NRT1 transporters. Biochim Biophys Acta 1518: 79-86

Yoneyama H, NAKAe T (1996) Protein C (OprC) of the outer membrane of Pseudomonas aeruginosa in a copper-regulated channel protein. Microbiology 142: 2137-2144

Zhang S, Buder K, Burkhardt C, Schlott B, Goerlach M, Grosse F (2002) Nuclear DNA helicase II/RNA helicase $A$ binds to filamentous actin. J Biol Chem 277: 843-853 
ZHANG Y, AdAMS B, SUn L, BURBANK DE, VAN-ETTEN JL (2001) Intron conservation in the DNA polymerase gene encoded by chlorella viruses. Virology 285: 313-321

Zhou JJ, Theodoulou FL, Muldin I, Ingemarsson B, Miller A (1998) Cloning and functional characterization of a Brassica napus transporter that is able to transport nitrate and histidine. J Biol Chem 273: 12017-23

Zhou JJ, Trueman LJ, Boorer KJ, Theodoulou FL, Forde BG, Miller AJ (2000) A high affinity fungal nitrate carrier with two transport mechanisms. J Biol Chem 275: 39894-39899 
Ich danke

Herrn Prof. Dr. Rudolf Tischner für die Überlassung des interessanten Themas, freundschaftlich-kritische wie impulsgebende Diskussionen, und das meist doch genau richtige Maß an aufmerksamer Geduld und wohlwollender Ungeduld, um Ideen wie Arbeiten gute Frucht tragen zu lassen.

Herrn Prof. Dr. Diedrich Gradmann für die freundliche Übernahme des Korreferates.

Herrn Brian Forde, PhD. für die Einladung zu einem Forschungsaufenthalt und Herrn Hanmah Zhang, PhD. für die Einweihung in die Geheimnisse der PCR.

Herrn Prof. Dr. R. Kaldenhoff für die freundl. Bereitstellung eines AquaporinAntikörpers

Den Mitarbeitern in der Werkstatt, besonders Herrn Unger, der schnell und versiert Ideen und Sonderwünsche in Kunststoff und Acrylglas erstehen ließ.

Herrn Freter, der immer wieder einmal Kleinigkeiten anzusetzen oder zu übernehmen bereit war und damit wertvolle Dienste leistete.

Meinen nun bereits aus Göttingen entschwundenen Mitgliedern der Arbeitsgruppe, allen voran Julia und Sylke, auch Guido, mit denen mich eine gute gemeinsame Zeit verbindet, in der wir uns mit Kenntnissen und Fertigkeiten hervorragend ergänzten und auch über den Feierabend hinaus eine gute Truppe waren. Auch den gegenwärtigen Mitgliedern der Arbeitsgruppe, namentlich Michael, für wertvolle Anregungen und manch netten Schnack.

Allen Institutsangehörigen für wissenschaftlichen, wie für freundschaftlichen Plausch in der nun schon legendären Sofa-Ecke des Foyers.

Für das Korrekturlesen dieser Arbeit Frau Dr. Tanja Pietrzak und meiner Familie für Auferbauung, Ablenkung und Beschenkung in den kleinen, so wertvollen immateriellen Dingen des Lebens. 
Name:

Geburtsdatum:

Geburtsort:

Staatsangehörigkeit:

1973-1977

1977-1979

1979-1980

1980-1984

1984-1988

Mai 1988

Okt. 1988 - Okt. 1993

Sep. 1995

Sep. 1995 - Mai 1998

April 1996

Mai 1998 - Sep. 1999

März 1999

Okt. 1999 - Dez. 1999

Jan. 2000 - Juli 2001

Sep. 2001 - Feb. 2002
Peter Adolf Kurt Brechlin

13. 12.1966

Hannover

deutsch

Grund- und Hauptschule II Sarstedt Jugenddorf-Christophorusschule Elze/Han

Orientierungsstufe Sarstedt

Schiller-Realschule Sarstedt

Gymnasium Sarstedt, Sarstedt

Allg. Hochschulreife

Studium der Biologie an der G.-A.-Universität Göttingen

Diplom in Biologie

Wissenschaftlicher Mitarbeiter des Albrecht-vonHaller-Institut für Pflanzenwissenschaften der G.A.-Universität Göttingen.

Beginn der Arbeiten zu vorliegender Dissertation

Wissenschaftlicher Mitarbeiter des Zentrums Pharmakologie und Toxikologie des Universitätsklinikums Göttingen.

Forschungsaufenthalt am Department Biochemistry and Physiology des IACR Rothamsted, Harpenden, Herts. UK

Wissenschaftliche Hilfskraft des Albrecht-vonHaller-Institutes für Pflanzenwissenschaften der G.-A.-Universität.

Wissenschaftlicher Mitarbeiter des Zentrums Pharmakologie und Toxikologie des Universitätsklinikums Göttingen.

Projektleiter Blutanalytik bei Fa. NSCI Novel Science International in Göttingen 